Running head: DEVELOPING MENTORING CURRICULUM

\title{
DEVELOPING MENTORING CURRICULUM USING HIGH-QUALITY CURRICULUM AND INSTRUCTION PRINCIPLES: GUIDING FACILITATORS TO NURTURE ADOLESCENT GIRLS' POTENTIAL
}

\author{
A Capstone \\ Presented to \\ The Faculty of the Curry School of Education \\ University of Virginia
}

In Partial Fulfillment

of the Requirements for the Degree

Doctor of Education

by

Marla Read Capper, B.A., M.Ed.

May 2014 
C Copyright by

Marla Read Capper

All Rights Reserved

May 2014 


\title{
EXECUTIVE SUMMARY
}

\author{
Dr. Carol A. Tomlinson, Advisor
}

Kuperminc and Thomason (2013), experts in the field of mentoring have identified a shortage of programmatic resources for group mentoring in the area of curriculum facilitation. They have also identified a need for training and support for mentoring group facilitators. Many facilitators do not have exposure to principles of high-quality curriculum and instruction. This investigation was a pragmatic response to a need identified by Edith, "Winx" Lawrence, Director of The Young Women Leaders Program, a mentoring intervention for at-risk adolescent girls at the University of Virginia that uses a combined one-on-one and group mentoring approach. Qualitative research methods were employed to determine what curricular materials the mentoring group facilitators needed to lead flexibly and thoughtfully, with the goal of bringing out the best in the at-risk, adolescent girls serving as mentees in their groups.

Based on the findings, in addition to the curriculum and instruction literature, materials were created to scaffold group facilitators with their implementation of the mentoring curriculum. The study also examined the usefulness and relevance of the materials created to guide the mentoring group facilitators. Observations, interviews, and both written and verbal feedback were collected throughout the Pre-Pilot, Pilot 1, and Pilot 2 phases of the investigation.

Pre-Pilot findings' suggested that facilitators needed support in the implementation of the curriculum in five specific ways: 1) understanding the intentions of each mentoring lesson and activity, 2) managing the group, 3) creating 
alternatives to activities, 4) determining a common vocabulary, and 5) discovering ways to empower mentors to take on leadership roles in the group. Based on the findings from the Pre-Pilot, in addition to the literature surrounding to two frameworks: The Classroom Assessment Scoring System-Secondary (CLASS-S) (Pianta, Hamre, Mintz, 2012) and Differentiation (Tomlinson, 1999). I created nine High-Quality Curriculum and Instruction Principles that informed the product of my capstone--Facilitators' Implementation Guide (FIG), which was intended to scaffold facilitators' implementation of the mentoring curriculum.

Pilot 1 revealed five findings: 1) Ease of use would be improved if the guide were integrated into the existing 7th Grade Curriculum Handbook (physically into the spiral) and integrated into the facilitator class. The $F I G$ needed to be incorporated into the facilitator class more consistently and facilitators should be expected to read and use the guide for implementation, and even reflect on it as part of class. 2) Most of the content in the guide was relevant and extremely practical, but it could be condensed. The aspects that were too theoretical could be eliminated. 3) Unless the facilitators read the guide they were unclear about the objectives or goals for each Mentoring Meeting and therefore allowing the mentees to determine the direction of the group without knowing what is important to uncover during their time together. 4) Facilitators did not necessarily have information or understanding about how to make the curriculum relevant or engaging for the mentors or mentees. 5) Facilitators incorporated benchmarks with a likert scale to determine their growth and assess how they obtained the objectives each week or periodically. 
Pilot 2 findings suggested that the Facilitators' Implementation Guide (FIG) was relevant and useful. Facilitators responded favorably to using the guide although they expressed that they needed additional training on how to use the FIG properly and efficiently and that sometimes it felt too "academic." They expressed a need for additional support on how to get their mentees more engaged and moving around the room. The Facilitators' Implementation Guide and the Principles of High-Quality Curriculum and Instruction represent a response to Kuperminc and Thomason's (2013) appeal for resources for group mentoring programs and a method to applying well-establish literature from curriculum and instruction to the mentoring field. 


\section{DEDICATION}

To: my husband, John and father, Scott

In loving memory of my mother, Shirley — my first mentor. 


\section{ACKNOWLEDGEMENTS}

First, I acknowledge that without the strength from God, I never would have been able to accomplish this. Some days my faith was all that carried me. He is the one who placed these amazing opportunities and more importantly people in my life.

At the reception after my graduation for my master's degree, the dean of the College of Education at Ohio University, Dean Wells Singleton, approached me to meet my parents. He asked where I planned to complete my Ph.D. in gifted education. It was a question he had been asking me since my third year of my undergraduate work, but for my parents this was the first time they had heard the question. They laughed, thinking it was a joke. Having a Ph.D. from Stanford himself, Dean Singleton held high standards and he expected me to pursue a doctorate or at least treated me like it was possible. He knew I was interested in students with potential and that I was always up for a challenge because he had just watched me spend a year in a rural Appalachian school establishing a gifted program in a place people didn't believe it was a priority. And so the seed was planted... I've often thought of how his belief in me impacted my trajectory and my hope is I have had a similar impact on others. I'd like to thank him and the many others whose belief in me far exceeded my own.

This capstone is the culminating work after comprehensive graduate school journey for which I am tremendously grateful. Many kind, patient friends, family members, and faculty shaped my doctoral experience and whose belief in me made its completion possible. Although writing is a solitary endeavor, completing the doctoral 
degree certainly is a group effort. I could not have done it without their support and expertise.

I am deeply grateful to the Curry faculty who mentored me along the way. I could not have asked for a more impressive, prolific group of woman to mentor me and serve on my committee. Each one of these women has mentored me in a different ways throughout my time at UVA.

Carol, you inspire so many. I feel blessed that we were matched as advisor/advisee. You truly practice what you preach by developing authentic relationships with your students and differentiating to meet their varied needs. You have been supportive and encouraging to me through the years. You model high standards of impeccable work ethic, kindness to others, and you have changed the conversation in education about meeting the needs of students. Thank you for teaching me to embrace my love of curriculum writing. I am so proud to have worked with you and I hope we will continue to collaborate. You have left had an imprint on my thinking and my heart and I will never be the same.

Winx, you model how to live a healthy balance of a successful career with significance and joyful family-life. Thank you for your constant encouragement and support. Your infinite wisdom about mentoring, adolescents, not only made this product better, but also have taught me a great deal through the years. As the "client" of the capstone, you helped me maintain focus on clarity and simplicity—staying true to the goal. YWLP is a special program because of you and I will be forever grateful that you introduced me to it and welcomed me into your world. 
Nancy, thank you for your thoughtful feedback and insight--particularly around the mentoring literature and the methodology. I have learned so much from you with our YWLP work. You are a rigorous scholar and true professional and most importantly with a kind-hearted soul.

Catherine, from the first project I worked on with you, you instilled in me the importance of practicing meticulous methodology. You taught me the importance of reigning in my creativity in the context of observation field notes, but how to break boundaries in thinking and explore creativity through our creativity class together. Throughout my time here at UVA I have always viewed you as a consistent source of support whom I could count on for high standards. This capstone reads better because of your insight as a methodologist and your valuable perspective as a person not involved with YWLP.

Carolyn Callahan, thank you for always asking more of me than I think I can give. Your high expectations of me have opened doors and I am incredibly grateful. Thank you for the professional opportunities and evaluations. Your deep understanding and what you have accomplished for gifted children is inspiring. You were one of the first people I ever learned about in gifted education and it has been humbling to work as your graduate assistant and along side you on projects.

Susan Mintz, thank you for your guidance, quick humor, and the incredible opportunities she provided for me to work with the secondary pre-service teachers. She also was instrumental in the CLASS-Secondary work, which has been extremely influential in my thinking over the last four years with MyTeachingPartner. 
I also appreciate the flexibility and understanding my teammates at CASTL (team led by Joe Allen and Chris Hafen) exhibited throughout the process. Working full-time and completing my doctorate certainly was no easy feat and you all displayed tremendous sensitivity and patience during the process. I'd also like to thank the incredible MyTeachingPartner-Independent coaches at Pace Academy and Norfolk Academy for helping me stay grounded and encouraging me by sending supportive emails and offering "pep talks" throughout my writing process this year. You all were so supportive and offered such valuable advice; many days I wasn't sure who was mentoring whom.

I greatly appreciate the financial assistance for my graduate studies from the National Research Center on the Gifted and Talented (supported by the Javits Foundation), The Young Women Leaders Program, The Women's Center, The Summer \& Saturday Enrichment Programs, Doris Buffet (The Sunshine Lady Foundation Inc.), and the Raven Society.

A special thanks to The Young Women Leaders Program, and all the hardworking women who give their time and energy to such a worthy program for adolescent girls. I will never forget my time at Buford Middle School facilitating the best YWLP group ever. A very special thank you to The Young Women Leaders Program Leadership Team and the facilitators from 2009-2014, particularly Melissa Levy, Jennifer Merritt, Lynn Nichols, Jenna Marshall, Samantha Kirch, Jennifer Leyton-Armakan, Amanda Sovik-Johnston, Janelle Summerville, and Jennie Williams.

I am also thankful for the time I spent at the University of Virginia, Women's Center, and the support it offers the Young Women Leaders Program. Working among 
the strong, competent women there and the important work being conducted made me hopeful for the future for girls and women.

Many friends I have met while in graduate school will be lifelong friends and feel blessed to have met them. Thank you for the love, support, motivation, and taking time for "small celebrations" through the years. A special thank you to some friends who offered extra support in this last year (Susan Albaugh, Sasha Rehm, Andrea Esperat, Michael Salmonwicz, Alexis Andres, Christie Reed, Jennifer Beasley, Jessica Hockett, Kristi Doubet, Eric Carbaugh, Michelle Yoon, Jill Urquhart, Lauren Germain Wormer, John Donnelly, Baxter Kennedy, Sonia Cabell, Hilary Dack, and Sharon Deal). You are wonderful dear friends and impressive colleagues. A particular thank you to Michael Salmonowicz, for your critical eye as my peer editor. You have a gift!

I'd like to thank my family, especially my parents. Dad, you and Mom have always held high standards for me and expected me to succeed. You have given me everything I ever needed to achieve, but most importantly you always have given me infinite love and support.

And saving the best for last, I am deeply grateful to my husband, John. You have sacrificed so much for me to complete this degree. First, by uprooting our lives to follow this dream, second by being so understanding with my long "writing days," and most importantly, by understanding why we have sacrificed living our lives to the fullest. Through all of it, you scarcely complained. You only offered love and support. Now we can return to our life. 
I am deeply grateful for this comprehensive experience. It has taught me how to persevere and fight for something you want in the face of adversity. It has also taught me that although I learned a remarkable amount, I still have a great deal to learn. 
TABLE OF CONTENTS

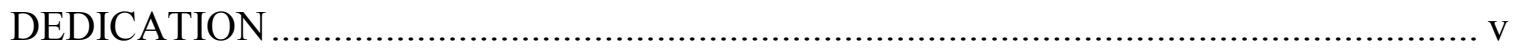

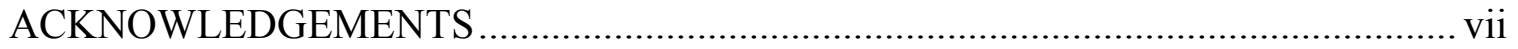

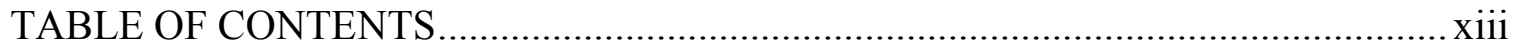

I. INTRODUCTION \& PROBLEM STATEMENT ................................................. 1

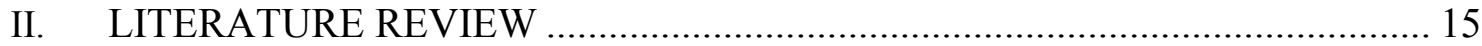

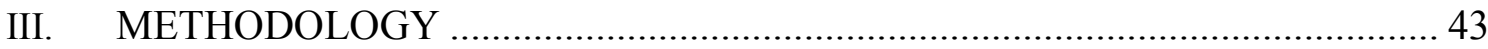

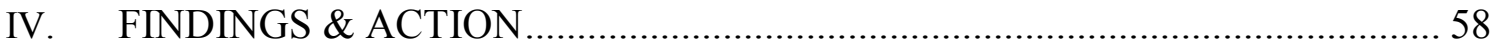

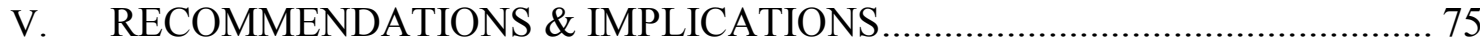

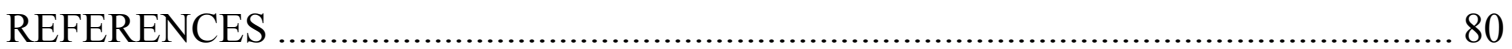

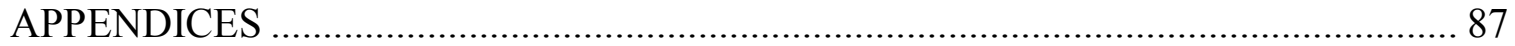




\section{LIST OF TABLES}

TABLE

Page

1. Key YWLP Positions, Meetings \& Materials........................................................ 3

2. Classroom Assessment Scoring System-Secondary ...................................... 17

3. Principles of High-Quality Curriculum \& Instruction ....................................... 23

4. Principle 1 of High-Quality Curriculum and Instruction .................................... 24

5. Principle 2 of High-Quality Curriculum and Instruction ................................... 24

6. Principle 3 of High-Quality Curriculum and Instruction ................................... 25

7. Principle 4 of High-Quality Curriculum and Instruction ................................... 25

8. Principle 5 of High-Quality Curriculum and Instruction .................................. 26

9. Principle 6 of High-Quality Curriculum and Instruction .................................. 26

10. Principle 7 of High-Quality Curriculum and Instruction .................................. 26

11. Principle 8 of High-Quality Curriculum and Instruction .................................. 27

12. Principle 9 of High-Quality Curriculum and Instruction .................................. 27

13. Data Sources, Collection Methods, \& Collection Phases ................................... 48

14. Sample Feedback from Facilitators .......................................................... 70 


\section{LIST OF FIGURES}

FIGURE $\quad$ Page

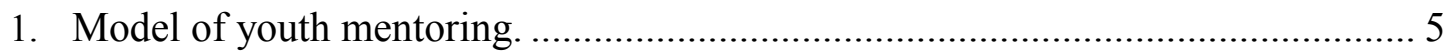

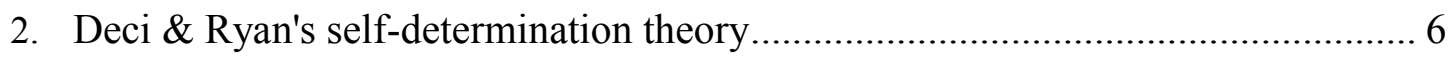

3. Kuperminc's theoretical model of group mentoring. ........................................ 10 


\section{CHAPTER 1}

\section{INTRODUCTION \& PROBLEM STATEMENT}

\section{Addressing a Need for Program Development and Design}

Mentoring has the potential to positively change the lives of young people.

Though mentoring is not a new phenomenon, it has received increased attention and funding in recent years in the United States, particularly under the current administration. First Lady Michelle Obama hosted an event at the White House in 2011 with 20 successful women from a variety of industries, and their mentee matches from D.C. area high schools, which she paired for the event. She spoke to the group in support of mentoring, saying,

What you don't always see is what it took for many of us, many of these women to get to where they are today. You don't always see the thousands of hours that were spent studying, or practicing, or rehearsing, the years spent working for that promotion, the hammers used to break glass ceilings... All of them, every last one of them had someone in their lives who took the time to encourage them and to inspire them. None of us are here on our own. ...And the one thing we ask of you when you're done here... is that you now owe someone else. Your job here is to reach back and pull somebody else up. That's the price of admission tonight. It's never too soon for you all to start mentoring (Obama, 2011). 


\section{Mentoring Program Background}

The mentoring program that is the focus of this capstone, The Young Women Leaders Program (YWLP), founded at the University of Virginia in 1997 by Edith "Winx" Lawrence and Kimberley Roberts, is an after-school, curriculum-based mentoring program that was originally designed to assist middle school girls in the Charlottesville and Albemarle County area reach their potential by empowering them to be leaders of themselves and in their families, schools, and communities. According to the program web site, since its inception over 2,000 young women have participated in YWLP as either a mentor or mentee. In response to enthusiasm from the participants, community, and university, YWLP has grown to serve, not only middle school, but also high school girls. In addition, it has expanded to a total of 14 sister sites, 10 domestic, and 4 international, in Ethiopia, Cameroon, Mozambique, and Peru. While each site has adapted the program slightly to suit its population, its essence and main concepts remains. For the purposes of this capstone I will be discussing the original program at the University of Virginia.

The Young Women Leaders Program was founded on evidenced-based practices suggested by experts in the field of youth mentoring (Rhodes \& Dubois, 2006). It uses a combined approach, providing both one-on-one and group mentoring. YWLP is a complex, multi-component mentoring program with many moving parts and various people contributing to the inner workings to support its operation. See Table 1 for a list of key positions, meetings, and materials defining the various components that comprise the dynamic structure of the program. 
Table 1: Key YWLP Positions, Meetings \& Materials

\begin{tabular}{|c|c|}
\hline YWLP Language & Definition \\
\hline Little sister & Mentee, female adolescent youth \\
\hline Big sister & $\begin{array}{l}\text { Mentor, usually a female undergraduate } \\
\text { student }\end{array}$ \\
\hline Facilitator & $\begin{array}{l}\text { Mentoring group leader, usually a female } \\
\text { graduate student who has experience with } \\
\text { YWLP }\end{array}$ \\
\hline Program Director & Originator and head of the program \\
\hline YWLP Leadership Team & $\begin{array}{l}\text { Compromised of the Program Director, } \\
\text { Assistant Director, Mentoring Coordinator, } \\
\text { Director of Research, Associate Director of } \\
\text { Research }\end{array}$ \\
\hline Research Team & $\begin{array}{l}\text { A team of graduate students led by a Research } \\
\text { Scientist and the Director of Research who } \\
\text { conduct research about the effectiveness of } \\
\text { YWLP }\end{array}$ \\
\hline School Contacts & $\begin{array}{l}\text { School counselors, administrators, or teachers } \\
\text { who collaborate with YWLP-serve as line of } \\
\text { communication between YWLP and the } \\
\text { school, assist with logistics as well as help } \\
\text { identify the at-risk girls who would benefit } \\
\text { from the program }\end{array}$ \\
\hline Mentoring Meeting & $\begin{array}{l}\text { The weekly group mentoring component that } \\
\text { uses a curriculum for developing the } \\
\text { adolescent participants' competencies, } \\
\text { autonomy, and connections between and } \\
\text { among the group members }\end{array}$ \\
\hline Facilitator Class/Meeting & $\begin{array}{l}\text { A three-credit class designed to support the } \\
\text { YWLP group facilitators as leaders of } \\
\text { mentoring groups. Class content focuses on } \\
\text { facilitation skills, small group development, } \\
\text { and other topics relating to group dynamics, } \\
\text { with particular attention to issues related to } \\
\text { promoting leadership among adolescent girls } \\
\text { and college women. (from } 2013 \text { syllabus) }\end{array}$ \\
\hline Big Sister Meeting & $\begin{array}{l}\text { A weekly meeting in small groups led by the } \\
\text { facilitator to communicate the purpose of the } \\
\text { curriculum to all big sisters and to allow for } \\
\text { time to connect and develop leadership }\end{array}$ \\
\hline Service-Learning Class & $\begin{array}{l}\text { A class designed for mentors that occurs over } \\
\text { two semesters that focuses on adolescent } \\
\text { development, issues facing adolescent girls, } \\
\text { and best practices from the mentoring }\end{array}$ \\
\hline
\end{tabular}




\begin{tabular}{|l|l|}
\hline & $\begin{array}{l}\text { literature. It is intended to provide ongoing } \\
\text { relational training and individualized support }\end{array}$ \\
\hline $\begin{array}{l}\text { The Young Women Leaders } \\
\text { Program Mentor Handbook }\end{array}$ & $\begin{array}{l}\text { Synonymous with the } 7^{\text {th }} \text { Grade Curriculum } \\
\text { Handbook }\end{array}$ \\
\hline
\end{tabular}

Organization of the program. Undergraduate women serve as mentors, which are called "big sisters" to their adolescent mentees referred to as "little sisters." YWLP mentors are supported by a structure that provides ongoing training and guidance. See Appendix A for a diagram of the YWLP Structure. Groups are comprised of six to eight big and little sister pairs that meet weekly after school during the academic year for twohour meetings (i.e., Mentoring Meetings). Mentoring Meetings are shaped by a curriculum that is framed by a model of youth mentoring (Rhodes, 2002, 2005) and selfdetermination theory (Deci \& Ryan, 1985, 2000). Rhodes' mentoring model suggests that a mutual trusting mentoring relationship is foundational to promoting adolescent girls' cognitive and social emotional development. See Figure 1 for an illustrated explanation of Rhodes's model of how mentoring can lead to increased positive outcomes through social emotional, cognitive and identity development, in addition to other factors. 


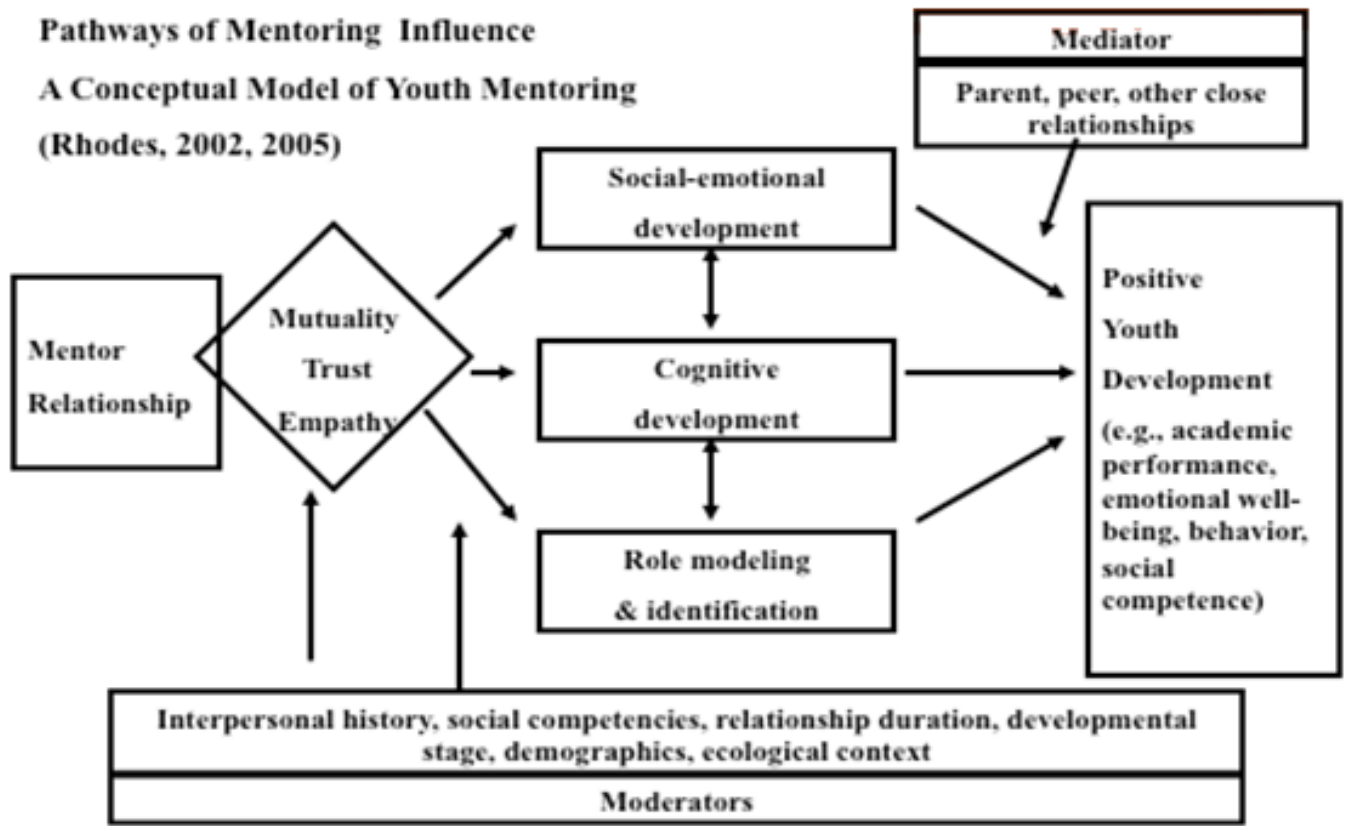

Figure 1. Model of youth mentoring, (Rhodes, 2002, 2005). This model illustrates the pathways of a mentoring relationship. It emphasizes that a trusting mentor-mentee relationship with mutuality and empathy is foundational to positive youth outcomes.

Deci and Ryan $(1985,2000)$ define self-determination theory as a cognitive theory of motivation based on the claim that humans are innately interested in growth. The theory suggests that three needs are fundamental to motivation: 1) autonomy, 2) competence, and 3) connection or relatedness to others. (See Figure 2 below.) 


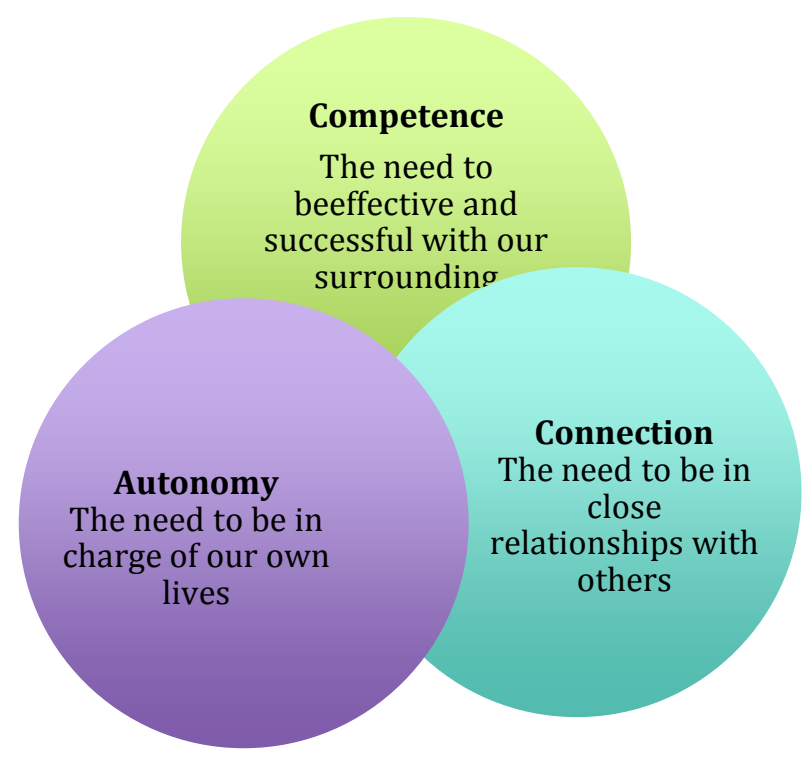

Figure 2. Deci \& Ryan's self-determination theory $(1985,2000)$. The theory is based on the idea that human's possess three basic physiological needs for: competence, connection and autonomy. Self-determination motivation is where all three overlap in the center.

Weekly meetings. YWLP is a curriculum-based mentoring program meaning that it uses a curriculum to structure the weekly Mentoring Meetings. The purpose of the curriculum is to build competence and autonomy through students' supportive connections with their peers and college women in their groups. Mentoring Meetings are facilitated by graduate or undergraduate students who have experience with YWLP; they lead groups through the mentoring curriculum activities that are designed to address important issues that adolescent girls face related to: family, peer, and romantic relationships; healthy decision-making, particularly with regard to peer pressure; peer acceptance; open-mindedness and celebration of others different from themselves; leadership qualities; and academic achievement. 
In addition to the Mentoring Meetings, pairs also meet one-on-one for at least four hours per month to pursue activities that they both enjoy. YWLP pairs are matched thoughtfully to consider interests, personalities, and race (gathered from self-disclosed information on inventories), which is consistent with generally accepted best practice in the field of mentoring (Herrera, Sipe, \& McClanahan, 2000; Rhodes, 2002, 2005). Graduates of seventh grade YWLP may opt to continue in the Alumnae Clubs (eighth grade and high school). These clubs also meet weekly and are designed to help the participants improve specific skills in areas such as technology, civic engagement, and fitness.

Big sisters. Big sisters attend several YWLP meeting throughout the week. Their primary commitment is to attend the Mentoring Meeting with their little sister, but they also meet weekly for the Big Sister Meeting, which is led by their group facilitator. The intention of this meeting is to communicate the goals of the curriculum to big sisters, delegate roles and responsibilities for the Mentoring Meeting, reflect on developments of mentoring relationships and allow time for sisters to connect. Big sisters also enroll in a yearlong service-learning class at the university, which focuses on research and theory pertaining to adolescent development and mentoring, and how the research and theory translates to practice. The class also provides a format for big sisters to reflect on what they are learning and integrate that into their practice as a mentor. Big sisters receive weekly supervision during the semesters they serve as mentors.

Facilitators. In addition to leading the Mentoring Meeting and the Big Sister Meeting, facilitators of the mentoring groups are enrolled in a class a three-credit class that meets weekly. The purpose of the time together each week is to provide guidance 
from YWLP Leadership and also time with fellow facilitators. The class focuses on facilitation skills, small group development, and other topics relating to group dynamics, with particular attention to issues related to promoting leadership among adolescent girls and college women.

I officially began thinking about the issue at the center of this capstone four years ago when this investigation commenced, but in actuality my thoughts about the mentoring curriculum and the facilitators' training was set in motion years earlier when I started my work with YWLP. I have worked with the program in a variety of capacitiesas a researcher on the research team, as a teaching assistant for the service-learning class taken by the university women serving as mentors, as the Mentoring Coordinator on the leadership team, and as a facilitator of one of the mentoring groups. This extensive and multi-dimensional experience with the program has driven me to examine it from multiple angles. Given that my main areas of interest are gifted education and adolescents, particularly adolescent girls, my lens with YWLP has always been to nurture the potential in the at-risk, adolescent girls participating in the program.

\section{Problem}

The prevailing belief (often based on firsthand experiences and anecdotes) is that mentoring is a powerful intervention and can make a difference in a youth's life, but empirical evidence regarding the effectiveness of mentoring is mixed. Three main dimensions characterize mentoring programs: context (locale), structure (mentee-mentor relationship, e.g., one-to-one or group), and goals (task-or skill-directed, or relational/developmental) (Karcher, Kuperminc, Portwood, Sipe and Taylor, 2006). Although the diverse array of mentoring programs available presents a richness that 
makes it possible to better serve the needs of a wide spectrum of communities and circumstances, it muddies the waters when trying to establish best practices and results in conflicting research findings. New developments in mentoring have moved faster than the research and therefore the understanding.

As innovative programs are being developed and the field of mentoring continues to grow, it is essential to establish best practices that suit the emergent program needs. Although Dubois and Rhodes (2006) identified 13 "best practices" (e.g., pre-match training of youth, 1 year commitment, weekly face-to-face contact for 2 hours, community service projects, structure activities and goal setting) as suggestions to be included in mentoring programs, the practices are not always transferable to all contexts or structures (particularly some of the new "fringe" programs), and the inconsistent terminology (e.g., the use of "group mentoring" terminology is inconsistent) clouds the insight related to the ingredients necessary for a thriving mentoring relationship to take place (Karcher, Kuperminc, Portwood, Sipe and Taylor, 2006).

There is a growing interest in group mentoring as an innovative approach for adolescent youth. Kuperminc, an authority in the youth mentoring field, has developed a theoretical model of group mentoring (see Figure 3), which illustrates the theory that youths participating in the group benefit from a combination of mutual support, group cohesion, and connectedness with a mentor. 


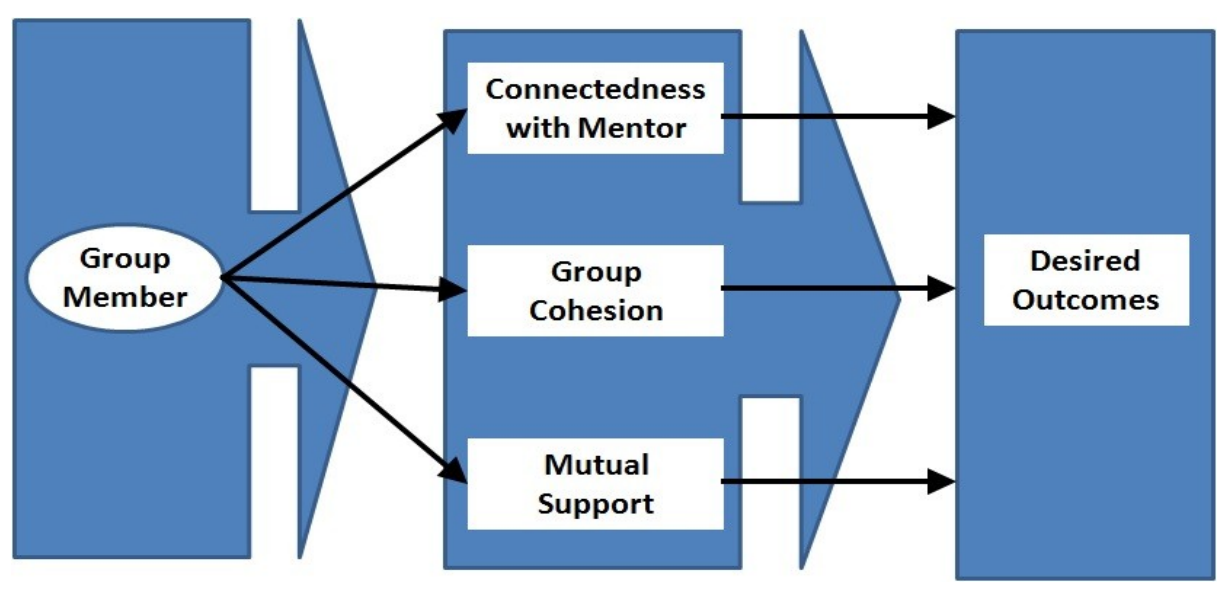

Figure 3. Kuperminc's theoretical model of group mentoring.

The theory of group mentoring is that the group setting provides a context for youth to have interactions with peers in "horizontal" or lateral relationships, as opposed to traditional one-on-one mentoring which is viewed as a hierarchical relationship. Group mentoring promotes socialization with peers and fosters a sense of belonging and group identity with fellow group members. Mentoring encourages a "two-way street" philosophy of mentoring by nurturing a reciprocal perspective of the relationship, furthermore the group context encourages, autonomy, relatedness and self-definition.

Some empirical evidence exists in the group mentoring literature for positive effects on youth outcomes (e.g., school dropouts, academic achievement, academic engagement, and sexual knowledge and attitude), but because so few studies have been conducted, there is a call for more research on this method of intervention. Kuperminc and Thomason (2013) have identified some challenges with the group mentoring intervention related to: 1) mentor-mentee, 2) training - teaching the mentors and facilitators the proper facilitation skills, 3) ongoing supervision and support. There is a dearth of practical resources for programming within this type of intervention. It became 
evident there was a pragmatic need in the mentoring field to develop materials. This study attempted to address that need by formulating practical solutions informed by research and theory to address the programmatic problem.

Problem in context. According to the Charlottesville/Albemarle Commission on Children and Families (CCF), 24\% of urban youth live in poverty in the Charlottesville/Albemarle region (the area the YWLP serves) as compared to $13 \%$ statewide and the rates of teen pregnancy and delinquency rulings in the area are double the state rate. The adolescent girls who participate in YWLP represent a range of socioeconomic, racial, and academic backgrounds, and have been identified by their school counselors or administrators as "at-risk" for delinquency, meaning they possess certain characteristics that place them at-risk for potentially engaging in delinquency behavior in the future. Individual (e.g., school failure, or participation in aggressive behavior) and ecological (e.g., living in high-poverty, high-crime, or negative family situations) factors can place youth "at-risk" for future delinquency (Tolan \& Gorman-Smith, 2002; Tolan, et al., 2008).

According to Lawrence, the Program Director, "Using UVA's expertise, science, and teaching to solve real problems, YWLP's mission is to help young women create a belief in self far greater than anyone's disbelief' (http://ywlp.virginia.edu). The program's focus is to empower adolescent girls through teaching them essential concepts and practical skills about being a leader in the multiple roles in their lives (e.g., student, daughter, friend, sister), making healthy decisions, and proactively planning for their futures. The aim is that this empowerment will increase their chances of a healthy and successful life. 
A combined approach of group and one-on-one mentoring. YWLP is a unique mentoring program because it includes both one-to-one and group mentoring components. According to Sipe (2005), the term "mentor" traditionally means a one-toone relationship between an adult and a youth, but its definition recently has expanded to reflect programming that exists in groups or online. Historically, youth mentoring included a one-to-one relationship between a caring adult and younger person (Dubois \& Karcher, 2005). Although group mentoring is becoming more of a common practice, most group mentoring programs are one or two mentors with multiple youths and, very few studies have focused on this approach. Therefore, a wealth of resources regarding best practices in terms of curricula for and facilitation of group mentoring does not exist. For this reason, I applied current research-based best practices in curriculum and instruction for this investigation and product development.

Facilitators are the bedrock of the group mentoring aspect of the program. The degree to which they are able to effectively deliver the mentoring curriculum largely determines the program's success. Their curriculum implementation must be clear, organized, engaging, relevant, responsive, and flexible in order for the program to prompt the desired outcomes for participants. In initial discussions with the YWLP Director, she recognized that facilitators were delivering the mentoring curriculum inconsistently due to arriving in their leadership positions within YWLP from a variety of academic fields (e.g., psychology, engineering, architecture, education, and economics) and with diverse levels of exposure to basic principles of quality curriculum and instruction.

Through subsequent conferences, she also expressed a concern that most facilitators did not possess a deep understanding of the concepts and principles that serve 
as the foundation for the mentoring curriculum, the rationales supporting the activities and content in the mentoring curriculum, and the connections between various concepts and activities. As a result, some facilitators had difficulty organizing the content of Mentoring Meetings in engaging and relevant ways; responding flexibly to their participants' needs and interests; monitoring participants' understanding of key ideas and skills in the curriculum; and prioritizing which content was most important. This led some facilitators to view the curriculum as a rigid script they must perfunctorily follow, using it as a checklist of activities rather than as a guide to uncover the big ideas intended for the meeting. This approach tended to result in dry meetings that did not respond to the group's dynamics or needs. Other facilitators led their groups in entertaining activities that eluded the main concepts and principles that are designed to drive the activities. Although the latter approach resulted in participants being entertained, it was hollow and anemic, lacking clarity of the true meaning behind the activities, and thus not furthering the true mission of the mentoring program. Once facilitators possess a deeper, more comprehensive understanding of the skills, concepts, and principles within the YWLP mentoring curriculum and are equipped with necessary tools and materials in addition to management and implementation strategies, I believe they will be better prepared to lead confidently, respond flexibly to their groups' needs and interests, and promote more meaningful participation by group members.

Initial data (e.g., formal interviews, and informal discussions with facilitators and big sisters, weekly reflections from big sisters about the assigned class readings and how the readings relate to their mentoring experiences, weekly feedback from facilitators regarding Mentoring Meetings and observations of Mentoring Meetings and classes) 
confirmed the program leadership's concern that facilitators' implementation of the mentoring curriculum was inconsistent. As a result of the YWLP leadership identifying the potential problem, coupled with the initial data collection that substantiated this problem, it was established that there was a need to explore ways to supplement the existing mentoring curriculum, and therefore provide more guidance to, and scaffolding for mentoring group facilitators.

Addressing this problem directly impacts the services provided for middle school girls participating in the program. In order to engage the at-risk, adolescent girls in the program's mentoring curriculum and to cultivate their potential as autonomous, connected, and competent young women, it is necessary for facilitators to be responsive to their needs and interests, while conveying the essential concepts, skills, and principles that are foundational to the mentoring program in engaging and interesting ways. 


\section{CHAPTER 2}

\section{LITERATURE REVIEW}

\section{Applying Educational Research and Theory to Group Mentoring}

Teaching is a highly intricate balancing of many factors. Teachers must consider the students, learning environment, curriculum content and, of course, how the teacher herself relates with her students. Each one of these factors has many complexities, and teachers must carefully consider how these factors interact, how they impact one another and how they influence learning.

Theory and research in the areas of high-quality curriculum and instruction provided insight for the problem and directed the study. Throughout this investigation, and while I was creating the culminating project — a curriculum guide for Young Women Leaders Program facilitators to use during the mentoring meetings as a way to help them with their facilitation (Facilitators' Implementation Guide) - I regularly referenced two instructional frameworks - the CLASS-S (Pianta, Hamre, \& Mintz, 2012) and Tomlinson's (1999) model of differentiation—as well as relevant literature associated with best practices in curriculum and instruction. Both frameworks at their foundation believe that a positive student-teacher relationship is the most important ingredient to a student realizing her potential. Beyond that, both the CLASS-S and differentiation emphasize: a) advocating for students' affective needs, which includes creating a positive learning environment, showing respect toward one another in the learning community and sensitivity to student diversity, and being responsive to students' academic, social 
emotional, and developmental needs; b) organizing content conceptually with clear learning goals and expectations for students; c) pushing for deep understanding with analytical and reflective thinking; d) providing feedback to extend student understanding; e) and utilizing strategies that lead to increased student autonomy engagement such as offering choice (Eccles, Wigfield, \& Schiefele, 1998; Hafen, Allen, Gregory, Mikami, Hamre, Pianta, 2012). For these reasons the CLASS-S and Tomlinson's model of differentiation provided a robust structure for my investigation and final capstone product - the Facilitators' Implementation Guide (FIG). The subsequent sections discuss pertinent literature regarding evidence-based best practices for curriculum and instruction.

\section{High-Quality Instructional Practices}

Do highly effective teachers use a particular set of strategies? Are effective teachers doing something different with their students? The answer is yes. In a three-year investigation funded by the Bill and Melinda Gates Foundation called Measures of Effective Teaching (MET), over 3,000 teachers around the country were studied to better understand teacher effectiveness. The MET Project is a partnership between researchers at eight universities (Dartmouth College, Harvard University, University of Michigan, Rutgers University, University of Virginia, University of Chicago, University of Southern California, Stanford University), educators in seven major school systems (Memphis Public Schools, New York City Schools, Dallas Independent Schools, Denver Public Schools, Pittsburg Public Schools, Charlotte-Mecklenburg Schools, and Hillsborough County Schools) and researchers and professionals at various educational organizations (American Institutes for Research, Cambridge Education, The Danielson 
Group, The Educational Testing Service, Empirical Education, National Board for Professional Teaching Standards, National Math and Science Initiative, New Teacher Center, and RAND) who are interested in improving schools by identifying the instructional strategies that are most effective, and helping teachers develop their craft by using those strategies. Extensive data were collected through multiple measures including classroom observations with instruments designed to measure effective teaching competencies (both subject-specific and cross-discipline), student perception surveys, and student achievement data. Data revealed that effective teachers caused students to perform at a higher level on high-stakes tests (MET, 2013).

High-quality instructional frameworks. One measure involved in the MET study was the Classroom Assessment Scoring System-Secondary (CLASS-S) (Pianta, Hamre, \& Mintz, 2012), which suggests that student-teacher interactions are integral to learning and development for adolescents. The CLASS-S observational tool defines classroom quality through an interactional lens and initially divides observations into three broad domains: Emotional Support, Classroom Organizational Support and Instructional Support. See Appendix B for a more detailed diagram of the CLASS-S framework.

Table 2: Classroom Assessment Scoring System-Secondary (Pianta, Hamre, \& Mintz, 2012)

\begin{tabular}{|l|l|}
\hline Domain & Dimensions \\
\hline Emotional Support & Positive Climate \\
& Teacher Sensitivity \\
& Regard for Adolescent Perspective \\
\hline Classroom Organizational & Behavior Management \\
Support & Productivity \\
& Negative Climate, \\
\hline Instructional Support & Instructional Learning Formats \\
& Analysis and Inquiry \\
\hline
\end{tabular}




\begin{tabular}{|l|l|}
\hline & $\begin{array}{l}\text { Content Understanding } \\
\text { Quality of Feedback } \\
\text { Instructional Dialogue }\end{array}$ \\
\hline Outcome & Engagement \\
\hline
\end{tabular}

A growing body of evidence exists around the important relationship between social emotional factors and student motivation and success (Wentzel, 1993, 1997, 2005; Hafen, Allen, Gregory, Mikami, Hamre, \& Pianta, 2012; Hamre \& Pianta, 2001; Ruzek, Hafen, Allen, Gregory, Mikami, \& Pianta, paper presented at SRA, March, 2014). In recent years, researchers and practitioners alike have come to recognize the importance of teaching the whole child and that in order to reach students effectively one must attend to their social emotional needs first. The Emotional Support domain is a reflection of that belief and is based on the notion that if students feel safe and connected with others at school they will establish a more optimistic academic trajectory (Hamre \& Pianta, 2001). This domain considers the dimensions of Positive Climate (the emotional connections and relationships that teachers have with their students and that peers have with one another), Teacher Sensitivity (teachers' awareness and responsiveness to students' academic and social emotional needs on an individual level), and Regard for Adolescents' Perspectives (teachers' emphasis on students' developmental needs as adolescents such as encouraging peer interactions, allowing for autonomy, fostering responsibility, following students' ideas, nurturing leadership, and promoting flexibility and movement).

Only when emotional support is established in a classroom can a teacher begin to consider how s/he will organize instruction. The CLASS-S Classroom Organizational domain contains the dimensions of Behavior Management (strategies to encourage 
desirable behavior, and to thwart or redirect undesirable behavior) and Productivity (time management, routines, and transitions that maximize learning time), both of which involve how a teacher manages and organizes instruction to make the most of class time and capitalize on every moment by being prepared and productive.

The final domain in the CLASS-S is Instructional Support. This domain contains five dimensions: Instructional Learning Formats (the methods teachers use to effectively engage students with the content through clear learning goals and presentation of the material, active facilitation, and the use of a variety of modalities or strategies), Content Understanding (the depth of the content, in addition to the strategies the teacher uses to conceptually frame and transmit the material), Analysis and Inquiry (higher-level thinking skills and chances for applying what they have learned to a new situation), Quality of Feedback (teacher feedback expands and extends learning, while also encouraging students' understanding), and Instructional Dialogue (teacher uses focused, well thought-out discussions that equally distribute the talk between the teacher and the students). The dimensions in the Instructional Support domain are concentrated on the methods teachers use to deliver content to increase student engagement and push learning. According to the MET Study (2012), when teachers incorporate behaviors from the CLASS-S measure, students achieve at a higher level.

Another study (Allen, Pianta, Gregory, Mikami, \& Lun, 2011) involving the use of the CLASS-S as a framework for a professional development intervention, called MyTeachingPartner, found significant effects when teachers' demonstrated CLASS-S behaviors (in year one of a three-year investigation). This study was accepted without reservation (for the intervention year) into the "What Works" Clearinghouse managed by 
the Institute of Education of Sciences (IES) as one of a limited number of studies that focused on teacher effectiveness for teachers of adolescents. Data analyses of the postintervention year revealed significant effects $(0.22)$ on the intervention students' SOL scores, nearly equivalent to a 9-percentile increase. This is sufficient evidence to substantiate that the dimensions identified in the CLASS-S can be associated with highly effective instruction.

Differentiated instruction. The second framework that informed my investigation and the Facilitators' Implementation Guide was differentiation. Differentiation has received increased attention in the past decade despite the fact that it is not a new idea. Actually, it deservedly bears the label "classic" as its principles resemble the earliest teaching approach of the "one room school house" where a teacher did not have a choice but to address the diverse learner needs due to the wide spectrum of ages and abilities represented in one class (Tomlinson \& Sousa, 2011). Curriculum and instruction are strongly intertwined and differentiation recognizes this deep connection. Tomlinson and Eidson (2003) address this connection when they define differentiation, stating that responsive teaching means considering the four main classroom elements 1) who we teach, 2) what we teach, 3) where we teach, and 4) how we teach. If curriculum is the "what" then differentiating instruction refers to the "how" that drives teachers' unpacking of the lesson so that students of mixed-abilities have equal access to enriching and engaging curricular experiences that provoke growth. The current model of differentiated instruction (Tomlinson, 2011) is guided by five main principles: a) all learning tasks are respectful and equally engaging, b) ongoing formative assessment occurs and then adjustments of the content, process, and product are made based on 
assessment results, c) instruction is responsive to students' individual needs and involves flexible heterogeneous and homogenous groupings to allow for groups based on readiness, interests, and learning profile, d) curriculum is conceptually-focused on big ideas that are essential to the discipline designed to promote deep understanding, e) classes are communities of learners and teachers build community through developing positive, caring teacher-student and peer relationships. Often teachers and administrators are overwhelmed by the various parts that comprise differentiated instruction, but when Tomlinson is asked to define what it is, she will often respond that differentiation is "merely just good teaching." That is not to minimize the hard work that goes into differentiating instruction when it is done well, but at its foundation differentiation is based on straightforward principles of high-quality instruction.

Differentiated instruction has traditionally drawn from research and theory in education, psychology, and social psychology, but also from the emerging science of how people learn, new understandings of what transpires in the brain during adolescent learning (Giedd, 2002, 2012; Sylwester, 2007), and the influence of neuroscience on education (Caine \& Caine, 1994, Jensen, 2008, 2005) has provided a suitable complement for differentiation and practical value in the classroom (Tomlinson \& Sousa, 2011). Brain research validates practices associated with differentiation, such as stressing the importance of creating a positive learning community, which includes trusting student-teacher relationships in order to foster students' academic risk taking. It also bolsters other research that differentiating instruction supports, such as Carol Dweck's $(1999,2006)$ mindsets work, which will be explained in detail a later section.

The premise of differentiated instruction is based on the assumption that 
classrooms are becoming increasingly diverse and students do not all posses the same characteristics; therefore they do not excel or need support in the same areas. This does not change the fact that every student deserves the opportunity to grow and it is the teacher's responsibility to ascertain where students are in their understanding and challenge them. Each student deserves high expectations and has something worth contributing to the class. It is just a matter of tapping into students' potential to uncover their talents, and differentiation facilitates just that. The use of flexible grouping (regularly modifying group membership based on interest, readiness or learning profile) when engaging in a task, is not only motivating and interesting to students because of the variety, but teachers then design assignments in a way that students need one another to succeed. This also enables teachers to observe low-status students making significant contributions to the work of the group and to "assign status" to those students by noting legitimate and genuine contributions. Cohen and colleagues note that this approach has the potential for transformative effects on the social structure of the classroom with regard to access, equitable relations and achievement (Cohen, Lotan, Scarloss, Arellano, 1999).

\section{Principles of High-Quality Curriculum and Instruction}

The subsequent section presents the principles of high-quality curriculum and instruction that I constructed based on the shared characteristics of the two evidencedbased frameworks of CLASS-S and differentiated instruction (see Table 2). In order to further assess the promise of using the principles, a thorough review of the literature is required. Curriculum and instruction experts include a variety of markers to depict highquality curriculum and instruction. Consequently, I cross-referenced what was 
consistently included as the most essential indicators to maximize students' potential with the key tenets of the CLASS-S and differentiation. Subsequently, I constructed nine principles of what constitutes high-quality curriculum and instruction. Table 3 presents the principles in greater detail.

Table 3: Principles of High-Quality Curriculum \& Instruction

\begin{tabular}{|l|}
\hline \multicolumn{1}{|c|}{ Principles of High-Quality Curriculum \& Instruction for Adolescent } \\
\hline Principle 1: Teachers create a safe, positive learning environment, where it is evident that \\
genuine trusting teacher-student and peer relationships are valued as well as student \\
comfort and mutual respect are present. \\
\hline Principle 2: Teachers exhibit an elevated awareness of and responsiveness to students' \\
social emotional needs, recognizing that addressing those needs are foundational to \\
student learning. \\
\hline Principle 3: Teachers encourage students to adopt a growth-mindset and healthy risk- \\
taking during the learning process emphasizing hard work and learning from mistakes. \\
\hline Principle 4: Teachers plan learning activities that capitalize on and address students' \\
developmental needs as adolescents (as a result, increasing motivation and engagement) \\
such as relevance, autonomy, peer interactions, leadership, and flexibility for movement. \\
\hline Principle 5: Teachers employ proactive strategies and routines to encourage productive, \\
pro-social, desirable behavior and redirect undesirable, unproductive behavior. \\
\hline Principle 6: Teachers utilize proactive strategies that promote engagement and attend to \\
student differences such as: actively and enthusiastically facilitating instruction, \\
providing interactive materials, and offering a variety of entry points for a learning task \\
such as a choice of modality, learning profile, or intelligence preference (e.g., Sternberg's \\
[1985] Triarchic Theory of Human Intelligence-analytic, creative, and practical). \\
\hline Principle 7: Teachers organize content conceptually with clear learning goals and an \\
emphasis on meaningful connections such as: with the real world, between new concepts, \\
facts, and skills, or with different perspectives. \\
\hline $\begin{array}{l}\text { Principle 8: Teachers provide meaningful learning tasks that involve rigorous, higher- } \\
\text { level thinking with analytical inquiry, reflection/metacognition and problem solving. }\end{array}$ \\
\hline Principle 9: Teachers assess students' individual levels of understanding consistently and \\
use formative assessment in addition to meaningful feedback for the purpose of \\
increasing student learning.
\end{tabular}


Table 4: Principle 1 of High-Quality Curriculum and Instruction

Principle 1: Teachers create a safe, positive learning environment, where it is evident that genuine trusting teacher-student and peer relationships are valued as well as student comfort and mutual respect are present.

The CLASS-S Framework (Pianta, Hamre, \& Mintz, 2012)

Differentiated Instruction Framework (Tomlinson, 1999, 2001, 2003, 2011)

Positive Climate-

Student-teacher interactions are the foundation for learning and development and teachers begin setting the stage for learning by establishing a positive climate that involves emotional connections among teachers and students, as well as kindness, and respect communicated through both verbal and non-verbal interactions. This is an excerpt from Tomlinson's mentor and a great deal applies to a classroom climate, -"Each kid is like all others and different from all others.

-Kids need to believe they can become something better than they are.

-Kids need to help in living up to their dreams.

-Kids need action joy, and peace" (Tomlinson, 1999, p. 29).

Table 5: Principle 2 of High-Quality Curriculum and Instruction

Principle 2: Teachers exhibit an elevated awareness of and responsiveness to students' social emotional needs, recognizing that addressing those needs are foundational to student learning.

The CLASS-S Framework (Pianta, Hamre, $\quad$ Differentiated Instruction Framework \& Mintz, 2012) (Tomlinson, 1999, 2001, 2003, 2011) "Much of what we are talking about here [the elements of differentiated instruction] loses its power if the classroom environment is defective" (Tomlinson, 1999, p. 26).

Teacher Sensitivity-Highly sensitive teachers exhibit awareness and a timely responsiveness to students' social emotional, and behavioral needs on an individual and class level. This is demonstrated through monitoring, reengaging disengaged students, or recognizing "out of class" feelings that may be impacting learning
Tomlinson (1999) shares the story of The Little Prince and uses the plot as at metaphor for the relationship between a teacher and her student. "The little boy comes to understand that through taming we learn to see the uniqueness in the thing we tame. 'It is only with the heart that one can see rightly. What is essential is invisible to the eye.' ... The teacher remembers to teach whole children...He knows that sometimes emotions come before the French lesson...He understands that a child without self-esteem will learn 
very little. He also knows that genuine accomplishment will produce something more potent than self-esteem: self-efficacy" p. 32.

Table 6: Principle 3 of High-Quality Curriculum and Instruction

Principle 3: Teachers encourage students to adopt a growth-mindset and healthy risktaking during the learning process emphasizing hard work and learning from mistakes.

\section{The CLASS-S Framework (Pianta, Hamre,} \& Mintz, 2012)

Differentiated Instruction Framework (Tomlinson, 2011)

Positive Climate-The teacher communicates positive expectations and statements of belief about what the student can accomplish, "I know you are going to do well on this exam."

Teacher Sensitivity- The teacher demonstrates sensitivity so that students appear comfortable sharing ideas and taking academic risks, responding freely with one another and the teacher.

The mindsets (fixed or malleable) of teachers and students can impact the classroom environment, how students learn and what they believe they can accomplish. There is brain research to suggest that mindset can even impact body chemistry.

Table 7: Principle 4 of High-Quality Curriculum and Instruction

Principle 4: Teachers proactively plan learning activities that capitalize on and address students' developmental needs as adolescents (as a result, increasing motivation and engagement) such as relevance, autonomy, peer interactions, leadership, and flexibility for movement.

The CLASS-S Framework (Pianta, Hamre, \& Mintz, 2012)

Regard for Adolescents' Perspectives-

Teachers who are highly effective place emphasis on their adolescent students' developmental needs for: meaningful peer interactions, connections to current life, support for autonomy, opportunities for flexible class structure and movement, encouragement to share ideas and opinions and chances for leadership.

\section{Differentiated Instruction Framework} (Tomlinson, 1999, 2001, 2003, 2011)

"Flexibility is the hallmark of a differentiated classroom (Tomlinson, p. 48, 1999).

"Students are collaborators in learning" (Tomlinson, p. 48, 1999). 
Table 8: Principle 5 of High-Quality Curriculum and Instruction

Principle 5: Teachers employ proactive strategies and routines to encourage productive, pro-social, desirable behavior and redirect undesirable, unproductive behavior.

The CLASS-S Framework (Pianta, Hamre, $\quad$ Differentiated Instruction Framework \& Mintz, 2012) (Tomlinson, 1999, 2001, 2003, 2011)

Behavior Management-

Teachers who effectively manage their classrooms use methods to encourage desirable behavior and prevent and redirect misbehavior.

Productivity-

Teachers who are particularly productive efficiently organize time in a way that transitions and routines maximize class time. The teacher is prepared, disruptions are minimal and students are aware of what they are supposed to be doing.
"Routines exist not to control students, but to facilitate learning in ways that work best for the various individuals in the class" (Tomlinson \& Sousa p. 12, 2011).

Table 9: Principle 6 of High-Quality Curriculum and Instruction

Principle 6: Teachers utilize proactive strategies that promote engagement and attend to student differences such as: actively and enthusiastically facilitating instruction, providing interactive materials, and offering a variety of entry points for a learning task such as a choice of modality, learning profile, or intelligence preference (e.g., Sternberg's [1977, 1985, 1995] Triarchic Theory of Human Intelligence-analytic, creative, and practical).

The CLASS-S Framework (Pianta, Hamre, \& Mintz, 2012)

Instructional Learning FormatsTeachers who effectively maximize student engagement organize their instruction around clear learning targets, and present the information clearly through the use of interactive materials in addition to a variety of strategies that tap into multiple modalities.

Differentiated Instruction Framework (Tomlinson, 1999, 2001, 2003, 2011) "The teacher understands, appreciates, and builds on students differences" (Tomlinson, p. 48, 1999).

"The teacher adjusts content, process, and product in response to student readiness, interest, and learning profile" (Tomlinson, p. 48, 1999).

Table 10: Principle 7 of High-Quality Curriculum and Instruction

Principle 7: Teachers organize content conceptually with clear learning goals and an emphasis on meaningful connections such as: with the real world, between new concepts, facts, and skills, or with different perspectives.

The CLASS-S Framework (Pianta, Hamre, $\quad$ Differentiated Instruction Framework \& Mintz, 2012) (Tomlinson, 1999, 2001, 2003, 2011) 


\begin{tabular}{|c|c|}
\hline $\begin{array}{l}\text { Content Understanding- } \\
\text { Teachers who display efficiency in the area } \\
\text { of content understanding guide their } \\
\text { students in making connections between } \\
\text { the key concepts and the important } \\
\text { procedures and facts in their academic } \\
\text { discipline. They explicit integrate new } \\
\text { information by assessing students' } \\
\text { background knowledge and clarifying } \\
\text { misconceptions and they make connections } \\
\text { to the real world and to other people's } \\
\text { perspectives in order to deepen students' } \\
\text { understanding of the content. }\end{array}$ & $\begin{array}{l}\text { "The teacher is clear about what matters in } \\
\text { the subject matter" (Tomlinson, p. 48, } \\
\text { 1999). } \\
\text { "You cannot differentiate fog. You must } \\
\text { have a clear idea of what you want the } \\
\text { students to know, understand and do." } \\
\text { From a power point presentation from } \\
\text { Carol Tomlinson during the Summer } \\
\text { Institute of Academic Diversity conference } \\
\text { (held at the University of Virginia, 2009) } \\
\text { regarding the importance of starting with } \\
\text { quality curriculum and clear learning } \\
\text { objectives. }\end{array}$ \\
\hline
\end{tabular}

Table 11: Principle 8 of High-Quality Curriculum and Instruction

Principle 8: Teachers provide meaningful learning tasks that involve rigorous, higherlevel thinking with analytical inquiry, reflection/metacognition, and problem solving.

The CLASS-S Framework (Pianta, Hamre, $\quad$ Differentiated Instruction Framework \& Mintz, 2012) (Tomlinson, 1999, 2001, 2003, 2011)

Analysis \& Inquiry-

Teachers who excel in the dimension of analysis and inquiry demand their students to think at a higher level and provide openended tasks that require students to identify and investigate problems through thorough examination and analysis using the following skills: interpreting data, constructing alternatives, predicting, hypothesizing, brainstorming, developing arguments, providing arguments, being metatcognitive (explaining their thinking, self-evaluating, reflecting, and planning.)

One of the main principles of differentiation is about pushing for deep meaning.

Table 12: Principle 9 of High-Quality Curriculum and Instruction

Principle 9: Teachers assess students' individual levels of understanding consistently and use formative assessment in addition to meaningful feedback for the purpose of increasing student learning.

The CLASS-S Framework (Pianta, Hamre, \& Mintz, 2012)

Quality of Feedback-
Differentiated Instruction Framework (Tomlinson, 1999, 2001, 2003, 2011)

"Teachers use ongoing assessment to inform their instruction... This allows the teachers to match instruction to student 


\begin{tabular}{|l|l|}
\hline $\begin{array}{l}\text { Teachers who offer high-quality feedback } \\
\text { engage in feedback strategies such as: }\end{array}$ & $\begin{array}{l}\text { needs from the onset, including to } \\
\text { attending to gaps in prerequisite }\end{array}$ \\
$\begin{array}{l}\text { feedback loops, scaffolding, building on a } \\
\text { students' response, or offering verbal praise } \\
\text { on a students' persistence to extend or } \\
\text { expand student understanding. }\end{array}$ & $\begin{array}{l}\text { knowledge" Tomlinson \& Sousa p. 12, } \\
\text { "Goals of a differentiated classroom are } \\
\text { maximum growth and individual success" } \\
\text { (Tomlinson, p. 48, 1999. }\end{array}$ \\
\hline
\end{tabular}

Only aspects of the frameworks that were pertinent to the principles were included in the table.

Principle 1: Teachers create a safe, positive learning environment, where it is evident that genuine trusting teacher-student and peer relationships are valued as well as student comfort and mutual respect are present.

Supporting students' social emotional functioning is essential to learning and development. When students do not feel safe, secure, and accepted-it threatens the brain's readiness to learn; therefore teachers who demonstrate an interest in students' lives, get to know them as people not just "receivers of information," and spend time creating a supportive, caring community of learners, communicate a degree of safety and acceptance to their students and place them on a trajectory for academic success (Bransford, Brown, \& Cocking, 2000).

Social norms established in a classroom community impact learning (Bransford, Brown, \& Cocking, 2000) such as how students respond to academic risk-taking or homework completion (Wentzel, 1993). Beyond norms in the classroom, studies have found supportive student-teacher relationships influence other outcomes. Pianta, (1999) found that adolescents (based on self-report) put more effort into their work if they thought that the teacher treated them with respect and cared about them. Wentzel's (1998) findings were similar, linking the perceived support from a teacher (as measured by the student) to academic outcomes (e.g., grades) and in a later study (2003) the 
supportive classroom community motivated students to engage in pro-social behaviors (e.g. sharing, cooperating, and helping one another). Stipek (2006) posits that current pressures of high-stakes testing overshadow secondary classroom environments and consequently student-teacher relationships can suffer. She maintains that teachers have less time for casual conversation regarding personal life outside of school and this limits ways that students and teachers can connect and communicate support and worth. Stipek advocates that secondary schools shift to block scheduling in an effort to increase time spent with students; she also recommends decreasing class sizes so teachers can provide more individualized attention and get acquainted with students more closely. Hamre and Pianta (2001) recommend targeting student-teacher relationships for prevention and intervention programs as a way to increase student achievement.

Principle 2: Teachers exhibit an elevated awareness of and responsiveness to students' social emotional needs, recognizing that addressing those needs are foundational to student learning.

As detailed in the preceding section on Principle 1, it has been well-established that a positive learning environment with trusting, caring student-teacher relationships impacts achievement and one critical factor related to student-teacher relationships is that teachers' display sensitivity toward students' social emotional needs. Doing so acknowledges emotions students are potentially experiencing that may impede the learning process and opens the door for students to perceive their teacher as a source of comfort if necessary. Once the emotions are dealt with it is possible to transition back to learning.

Principle 3: Teachers encourage students to adopt a growth-mindset and healthy 
risk-taking during the learning process emphasizing hard work and learning from mistakes.

Theories regarding intelligence are also identified in the psychology literature as mindsets (Dweck, 1999, 2006). This theoretical framework, divides the mindsets about intelligence into two domains 1) growth--the belief that traits such as intelligence are malleable, 2) fixed--the belief that these traits are unchangeable (Dweck, 1999, 2006). Teachers need to encourage their students to have a growth mindset in order to foster healthy risk-taking and to maximize learning from mistakes and failures. Providing a space for students to make those mistakes in a safe environment in the classroom allows students to feel comfortable taking risks and focusing on real learning instead of "looking smart." Theories regarding intelligence govern individuals' reactions to failures and challenges and provide a motivational framework that associates the role of effort (Dweck, 1999, 2006).

Principle 4: Teachers proactively plan learning activities that capitalize on and address students' developmental needs as adolescents (as a result, increasing motivation and engagement) such as relevance, autonomy, peer interactions, leadership, and flexibility for movement.

Students need to see how the content is relevant to them in order to engage in learning (Csikszentmihalyi, Rathunde, \& Whalen, 1993; Davies, 2000; Steinberg, 2005; Weinstein, 2003). In his exceedingly practical book, Sylwester discusses adolescents' need for relevance and connection. In order to promote engagement curriculum should have practical value and relevance for students' current lives. Some effective curricular strategies that promote engagement include providing opportunities for students to make 
choices, lead in meaningful ways, share responsibility, and explore interests. High-quality curriculum empowers students to actively wrestle with the content and sometimes even real problems related to the content through an authentic experiential application such as: inquiry, problem solving, hypothesis generating and testing, manipulating materials, or professional habits.

When it comes to relevance, one aspect of high-quality curriculum and instruction is related to whether the material being studied matters to the students as they live and function in a world beyond school. The curriculum and instruction needs to tap into what students care about and then connect that to the content in ways that are relevant to students. If students are invested in the materials and have emotional connections to it and see how it matters to them personally, they are more likely to devote time and commitment and thus gather more meaning (Caine \& Caine, 1994). Curriculum and instruction that is relevant requires capitalizing on prior knowledge of the topics and concepts being studied, personal family history, pop culture, personal hobbies, talents, or interests, or even relationships with peers or family. Caine and Caine (1994) state that emotions and meaning are linked; when an individual's emotions are triggered, the brain is activated to make meaningful connections with the content. They also believe that when teachers disregard the emotional aspects of the material, they rob students of significant understanding and sense making. Ultimately, each student needs to make sense of the material individually and feel emotionally connected to the material in order for deep thinking to occur. If teachers are committed to creating lifelong learners, it is necessary to connect the content with their students in relevant ways. Students need to see how the material relates to them and their lives. Once they the relevance is clear 
engagement increases. Engagement is also fostered when students are actively involved with an activity that is related to something about which they care. In other words, if students are actively engaged and on task, they are curious about learning and this mindset promotes lifelong learning (Skinner \& Belmont, 1993).

High-quality curriculum and instruction places students in a position of power over their own learning experiences and is designed within students' zone of proximal development (Vygotsky, 1978) so that students can experience success and grow. They become the "masters of their domains" in school and they are in control of their successes or failures with regard to academic achievement.

Nurturing students' autonomy and control over their own learning impacts their self-efficacy or belief regarding what s/he can accomplish (Bandura, 1977, 1997; Schunk \& Pajares, 2002). Though the constructs can be closely related, self-efficacy is not synonymous with self-esteem, which is the how a person generally feels about him/herself. "It [self-efficacy] is concerned not with skills one has, but with the judgments of what one can do with whatever skills one possesses" (Bandura, 1986, p. 391). Learning experiences and the individuals who are a part of those experiences can shape people's judgments regarding their skills. Schunk and Pajares (2002) recommend helping students create short-term goals that are challenging, but yet realistically attainable so that they experience success. In that same chapter on academic motivation, Schunk and Pajares also advocate for modeling and practicing metacognitive strategies with students by asking them to verbalize their planning of how they will accomplish a task and then to periodically check in on their progress to discuss what they have accomplished. 
Students who possess higher self-efficacy are more engaged learners (Ryan \& Deci, 2000; Bandura, 1997). Teachers are able to increase their students's self- efficacy. The types of experiences students have in school can have a significant impact on their motivation toward accomplishing academic tasks (Stipek, 2002, 2006; Wigfield, Eccles, \& Rodriguez, 1998). Jinks and Morgan (1999) contend that self-efficacy beliefs are the precursors to academic success influencing determination and persistence, which are key components to success. Therefore, if schools are interested in promoting academic competence and thus achievement they must concentrate on increasing students' selfefficacy, not merely self-esteem.

Lorsbach and Jinks (1999) conducted research to support the reciprocal connection between the learning environment and students' self-efficacy beliefs. They found it is possible for teachers to create learning environments that provide opportunities to improve skills and boost confidence and self-efficacy regarding those skills. Increased self-efficacy promotes not only perseverance, but also the courage to persist when faced with a challenging task to think in ways that stretch previous thinking, and to solve problems by using different approaches (Bandura, 1997; Lorsbach, \& Jinks, 1999; Schunk \& Zimmerman, 1997). Lorsbach and Jinks (1999) also found that when individuals have low self-efficacy and doubt their abilities they usually put forth less effort, particularly if the academic task presented is not meaningful to them. When minimal effort is put forth, success is unlikely, confirming feelings of low self-efficacy (Deci \& Ryan, 2000). Therefore, if teachers create meaningful tasks targeted at students' zones of proximal development, students will experience both success, and an increase in self-efficacy. Related to finding that zone of proximal development is Csikszentmihalyi's 
framework of flow theory (1990) stating that when the conditions of challenge, skills, and interest are in balance, students find a "flow" are even more engaged in the learning process. Shernoff, Csikszentmihalyi, Schneider, and Shernoff’s (2003) findings suggest that supporting students sense of autonomy and competence (self-determination theory Deci \& Ryan, 2000) will increase engagement.

Deci and Ryan $(1985,2000)$ define self-determination theory as a cognitive theory of motivation based on the claim that humans are innately interested in growth. The theory suggests that three needs are fundamental to motivation: 1) autonomy, 2) competence, and 3) connection or relatedness to others.

Principle 5: Teachers employ proactive strategies and routines to encourage productive, pro-social, desirable behavior and redirect undesirable, unproductive behavior.

When teachers behave predictability with the use of clear expectations and routines, students are more productive; as a result increased teaching and learning can take place (Cameron, Connor, \& Morrison, 2005). Classrooms operate optimally and are most productive when students are clear about expectations and engaged in meaningful work. When students are suitably challenged they are less likely to participate in off-task behavior as a result of frustration or lack of challenge or rigor.

Cameron and colleagues (2005) found in their investigation that teachers who spend time at the beginning of the year to establish routines and management strategies were able to spend less time on transitions and other management activities throughout the school year because students were aware of what to do. This resulted in a higher level of productivity for the class and learning time was maximized. This study conducted by 
Cameron et al., (2005) is corroborated by the veracity of this statement "Routines exist not to control students, but to facilitate learning in ways that work best for the various individuals in the class" (Tomlinson \& Sousa, 2011, p. 12).

Principle 6: Teachers utilize proactive strategies that promote engagement and attend to student differences such as: actively and enthusiastically facilitating instruction, providing interactive materials, and offering a variety of entry points for a learning task such as a choice of modality, learning profile, or intelligence preference (e.g., Sternberg's [1977, 1985, 1995] Triarchic Theory of Human Intelligence-analytic, creative, and practical).

Students do not all process information and learn the same way. For this reason when a lesson is presented in a manner that attends to a variety of modalities using multiple strategies and manipulatives or interactive materials, more students have increased engagement in the learning process. Sternberg addresses this learner variance in his Triarchic Theory of Intelligence (1985) in which he poses that there are three types of intelligence: creative, practical and analytical. Creative intelligence is associated with generating new ideas. People who possess an elevated creative intelligence are able to make connections between concepts that seem dissimilar to others. Practical intelligence is associated with solving problems. People who are practically intelligent are frequently considered "street smart."

Analytical intelligence is associated with processing information effectively and thinking abstractly. School is set up to support analytical thinkers and most tests measure analytical intelligence. Sternberg believes the key to "successful intelligence" is to balance all three intelligences and know when and how to access all three types of 
thinking. If teachers taught using all three intelligence preferences and made an effort to match learning tasks and instruction with students' intelligence preferences they would notice their students achieving at higher level (Sternberg, 2002; Sternberg, Torff, \& Grigorenko, 1998).

Modifying resources and instructional strategies to match the diverse student needs, increases student learning (Tomlinson, Brighton, Hertberg, Callahan, Moon, Brimijoin, Conover, \& Reynolds, 2003). By designing interactive learning activities that appeal to students' interests, and choice of learning modality, or intelligence preference it increases their motivation to participate in the learning task.

Principle 7: Teachers organize content conceptually with clear learning goals and an emphasis on meaningful connections such as: with the real world, between new concepts, facts, and skills, or with different perspectives.

Effective teachers who utilize the principles of high-quality curriculum recognize the importance of big ideas. Wiggins and McTighe (1998) term these "big ideas" the "heart of a discipline" and condenses them into succinct concepts (Bruner, 1960; Erickson, 1998, 2006, 2008; Hayes-Jacobs 1997; Hayes-Jacobs \& Borland, 1986; Smith, Blakeslee, \& Anderson, 1993; Taba, 1964, 1966) and principles. Wiggins and McTighe and Erickson suggests that because factual knowledge is limitless and it is impossible to teach everything, teachers should emphasize facts that are most important to teach within their discipline, and attach those facts to overarching concepts and principles. Erickson defines concepts as broad macroconcepts or topic-specific concepts, but they are always timeless, abstract, and universal ideas generally expressed in one or two words (e.g., "interdependence" for a macroconcept or "addition" for a topic-specific concept). As 
Erickson explains, "Study that is focused on topics, without a conceptual lens, results in memorization and surface understanding rather than integrated thinking and deep understanding" (1998, p. 168). Using a conceptual framework promotes a deeper understanding of the material, provides a structure to which learners can connect other ideas and facts, forces thinking above the fact-level, de-emphasizes memorization, increases transfer of knowledge and understanding to new learning situations, promotes interdisciplinary links, and fosters the recognition of patterns (Bransford, Brown, \& Cocking, 2000; Erickson, 1998, 2006, 2008).

To correctly capture the essence of a discipline and identify the most significant concepts worth exploring deeply, it is critical for teachers to know their discipline well (Tomlinson \& McTighe, 2006; Wiggins \& McTighe, 1998, 2005). After teachers identify the most important ideas or concepts in the subjects, enduring understandings or principles can develop from them. Wiggins and McTighe (1998) use the term "enduring understandings" to mean "the big ideas that we want students to get inside of and retain after they've forgotten many of the details" (p. 10). As the name implies, such understandings remain with students. Once teachers design curriculum around concepts and enduring understandings, they need to use those to foster collaborative discovery or "uncovering" of understanding and to promote construction of meaning for students (Bransford, Brown, \& Cocking, 2000).

The use of concepts in curriculum design opens the door for many other best practices and invites students to participate. Concepts frame ideas and stress deeper understanding that exceeds mere memorization. The use of concepts, often is accompanied by the utilization of different methods and approaches such as: utilization of 
examples/non-examples, providing explicit instructions for activities, and offering a variety of entry points for lessons or activities or "invitations" to learn (Bransford, Brown, \& Cocking, 2000; Erickson, 1998, 2006, 2008). In sum, high-quality curriculum emphasizes meaningful relationships between significant macroconcepts within a discipline and how those relate to important facts and skills students are learning.

Principle 8: Teacher provide meaningful learning tasks that involve rigorous, higher-level thinking with analytical inquiry, reflection/metacognition, and problem solving.

High-quality curriculum is growth-focused with sophistication increasing as students grow academically. It pushes learning toward the level of expertise on the learning continuum (Tomlinson, 2003) and emphasizes hard work instead of ability. Placing an emphasis on the notion of a learning continuum (novice to expert) promotes the idea of growth and demotes the idea that "knowing" and "understanding" are static. It is critical that teachers believe that all students can grow in their knowledge and understanding and then that they design learning experiences that promote that growth. Focusing on growth for all students utilizes what has been termed by Tomlinson, Kaplan, Renzulli, Purcell, Leppien, and Burns, (2002) as "ascending intellectual demand." defined as "the escalating match between the learner and curriculum" (p. 13). When curriculum and instruction is designed and delivered with ascending intellectual demand, teachers accept the responsibility to meet learners at their present developmental level and ensure their continual development while students come to understand that hard work and growth is expected of all students. 
High-quality curriculum and instruction that operates on the foundation of ascending intellectual demand, emphasizes the important concepts and overarching principles that are key to a discipline. Focusing on meaningful learning of larger ideas as opposed to surface knowledge — often obtained through memorization — promotes deeper understanding that lasts rather than surface knowledge that fades rapidly (Bransford, Brown, \& Cocking, 2000). Possessing a deeper understanding about a concept or skill promotes transferability to future novel contexts, which is one of the paramount goals of education.

Principle 9: Teachers assess students' individual levels of understanding consistently and use formative assessment in addition to meaningful feedback for the purpose of increasing student learning.

Assessment occurs at three main occasions throughout a lesson of study and each possess quite different purposes: at the beginning (pre-assessment) to ascertain baseline data regarding what know already know, understand, and can do (KUD) related to the lesson of study, at the end (summative assessment) to determine whether the students gained the knowledge, understandings and skills identified as important for the lesson of study, and then periodically to gather data pertaining to student growth with the learning objectives/goals (KUD) for the lesson of study (formative assessment). Formative assessment and feedback are important tools for learning (Wentzel, 1997, 2003). Research studies have investigated the power of feedback on academic achievement, and have found that the increased feedback opportunities result in increased learning gains (Bransford, Brown, \& Cocking, 2000; Hattie, 2009; Marzano, Pickering \& Pollock, 2001). 
They key to capitalizing on the power of ongoing assessment is to pre-assess student understanding at the onset of a lesson in order to gain a baseline and then consistently assess growth to determine construction of new knowledge and understanding and any misconceptions that need clarification (Bransford, Brown, \& Cocking, 2000). The step that is often disregarded is using formative assessment data to inform instruction, because it requires the recognition of variance in student understanding and then staring that variance square in the face means teachers must address it by modifying instruction. According to Black and Wiliam (1998), effective formative assessment requires teachers and students to mutually reflect and this maintains students as active participants in the learning process (Black \& Wiliam, 1998; Hattie, 2009; Stiggins, 2006). Consequently, they suggest that when formative assessment is used it not only impacts learning, it also influences student motivation, self-esteem, and self-assessment.

Another tool to push learning and gather useful information about student understanding is by using feedback strategies. Effective feedback, whether it comes by way of a teacher, peers, or even self-attained, extends and deepens student understanding. Wiggins (2012) defines feedback as "goal-referenced; tangible and transparent; actionable; user-friendly (specific and personalized); timely; ongoing; and consistent" (p. 10) and makes a clear distinction between feedback and advice - suggesting that genuine feedback is free of judgment. If used effectively feedback and formative assessment for learning have the power to provide meaningful learning experiences for students and result in significant achievement gains. 


\section{Summary}

The preceding examination of the context, framework, and literature offers support to substantiate using them to steer the investigation and the construction of the principles of high-quality curriculum and instruction. These principles of high-quality curriculum and instruction will assist facilitators to maximize the potential in the adolescent little sisters participating in the mentoring program that is the subject of this investigation. After the initial meeting with the Young Women Leaders Program Director, the following needs emerged for facilitators in order to support a more consistent implementation of the mentoring curriculum across mentoring groups: 1) The main concepts or "take away" messages, of each Mentoring Meeting need to be more clearly communicated; 2) Rationales supporting the activities within the mentoring curriculum should to be articulated; 3) Connections between and among the activities within the mentoring curriculum need to be explained; 4) The "big picture," the program's goals, and how the activities fit in with the program's goals ought to be described.

Providing rationales for the activities and skills in the YWLP curriculum is important because it will present the theory supporting the curriculum (in an accessible manner) while making it more meaningful to the facilitators and mentors, which will nurture potential in the little sisters. The curriculum needs to be articulated in a way that uses elements of high-quality curriculum, explain the reasoning behind the activities, and provide a means for the facilitators to self-evaluate their effectiveness in delivering the curriculum. 
The Young Women Leaders Program operates with the self-determination theory (SDT) as its foundation. SDT is based on the innate human needs to feel competent, connected and autonomous. People have an innate need to experience themselves as capable of making the best use of their talents and abilities, being securely and meaningfully interrelated with others, and having the power to choose, maintain, and regulate their actions (Connell \& Wellborn, 1991). Self-determination theory links the meeting of three basic human need above with motivational and self-regulatory processes that influence overall personal growth and health (Ryan \& Deci, 2000).

This project sought to address a need for the Young Women Leaders Program through an examination of the consistency of the facilitator's implementation of mentoring curriculum. The practical purpose of the investigation was to determine what curricular support facilitators needed to implement the curriculum effectively during the Mentoring Meetings and to lead thoughtfully and flexibly with the goal of nurturing potential in at-risk, adolescent girls. The subsequent chapter outlines the methods and procedures I used throughout my investigation. 


\section{CHAPTER 3 \\ METHODOLOGY \\ Present Study}

An overarching methodological framework comprised of the research design, data structure, and all the decisions regarding the analysis supports the underpinnings of the research process (Patton, 2002). The framework is grounded in a worldview of how truth is perceived and influences every aspect of the investigation therefore prior to the details of the research process being described it is necessary to address the framework (Creswell, 2007).

The paradigm around which all phases of this study were structured, conducted, and reported was pragmatic in nature, meaning "individuals holding this worldview focus on the outcomes of the research—actions, situations, and consequences of inquiry...the important aspect of the research is the problem being studied..." (Creswell, p. 22, 2007). Often pragmatists lean toward the use of multiple measures or mixed methods and do not ascribe to one type of research qualitative or quantitative, but rather are more interested in answering the question or solving the problem (Creswell, 2007). Pragmatists are focused on "...matters of interest in real-world settings in order to solve problems, improve programs, or develop policies" (Patton, p. 136, 2002) and for that reason it is well suited for the action research approach of this capstone. Pragmatists believe that contexts (social, historical, or political) are critical to any investigation and must be considered (Creswell, 2007), providing a richer, panoramic, understanding. 
As a result of the pragmatic lens of this investigation, the goals were twofold, to: 1) provide scaffolding to the YWLP facilitators as they implemented the mentoring curriculum, and; 2) add to the existing body of literature regarding best practices for group mentoring curricula designed for adolescent girls. The focus of the investigation was on understanding the programmatic shortcomings of the Young Women Leaders Program (YWLP) mentoring curriculum in an effort to move the program forward with the probability of improving adolescent participants' outcomes. The study used the markers of high-quality curriculum and instruction according to experts in the field of education, and sought to determine how the presence of those markers altered the implementation of the curriculum and if it better met the needs of the adolescent girls participating in the mentoring program. In this chapter, I provide a detailed description of the method design and procedures I used throughout my investigation.

Due to the practical quality of the capstone format, this research sought to analyze the nature and extent of the client-initiated problem, and determine any discrepancies between current circumstances and the ideal goal with regard to curriculum implementation, while always maintaining focus on what practices best nurture potential for the adolescent girls participating in the mentoring program. The process involved using a variety of methods and procedures to determine optimal ways to tackle the client's identified problem, build a case for program development, and create curricular materials to expand the program's capacity.

The capstone format inherently utilizes many aspects of an action research stance. For instance, it positions the researcher in the role of an active participant (a stakeholder) in the change process (McNiff \& Whitehead, 2011). In this case with the Young Women 
Leaders Program, my goal was to expand the facilitators' understanding of the curriculum's purpose and program's mission as well as best practices with regard to implementation. The capstone process is designed to be an interactive inquiry process that delicately balances solving a client-initiated problem in a collaborative context with data-driven analysis, in an effort to move the organization forward and to bring new knowledge and understanding to help solve the problem. The capstone format is particularly appropriate and useful in this case, bridging the divide that exists between research and theory and practice, more specifically between research on quality curriculum and instruction and a non-profit youth development program mentoring adolescent girls, YWLP.

\section{Revisiting Problem of Practice}

As a result of the YWLP Leadership identifying the programmatic concern regarding the inconsistency with the mentoring curriculum facilitation, coupled with the initial data collection that substantiated this problem of practice, it was evident that there was a need to investigate methods to supplement the existing mentoring curriculum in an effort to provide more direction for mentoring group facilitators. Addressing this problem and providing more scaffolding for facilitators will enhance the implementation of the curriculum with the goal of directly impacting the services provided for the middle school participants. In order to engage these girls in the program's mentoring curriculum and to cultivate their growth as autonomous, connected, and competent young women, it is necessary for facilitators to be responsive to the participants' needs and interests while conveying the program's essential concepts, skills, and principles in ways that are interesting and engaging to the adolescent participants. Those concerns shaped my 
research question, which framed the overall study though three sub-questions emerged as I progressed further into the investigation and directed the Pre-Pilot Phase as well as Pilots 1 and 2:

\section{Capstone Research Question:}

1. What curricular materials do mentoring group facilitators need to lead flexibly and thoughtfully, with the goal of bringing out the best in the at-risk, adolescent girls serving as mentees in their groups?

\section{Pre-Pilot Phase Research Question:}

2. What was contributing to facilitators' inconsistencies with the implementation of the mentoring curriculum?

\section{Pilot 1 Research Question:}

3. In what ways is the newly developed Facilitators' Implementation Guide (FIG) useful and relevant to the implementation of the mentoring curriculum?

\section{Pilot 2 Research Question:}

Pilot 2 was a test of the revised version of Facilitators' Implementation Guide (FIG).

4. How is FIG practical and useful for the facilitation of the mentoring curriculum?

\section{Participants}

This study was focused on a particular youth development program, a mentoring program called the Young Women Leaders Program; therefore, the participant pool was drawn from college students enrolled in the service-learning class and participating as 
mentors or facilitators for the program. When I began in the fall of 2009 the sample was a great deal larger than in later stages of the work as I was determining the context, which is a critical factor when using a pragmatic paradigm (Creswell, 2007), and narrowing the focus of the study. During the Pre-Pilot Phase it included mentors as well as facilitators so that I could gather additional perspectives about the curriculum and the ways it was being implemented and meeting — or not meeting — the needs of adolescent girls in the program.

Sampling. One of the significant distinctions between quantitative and qualitative methods is the philosophy supporting the sampling methods being used (Patton, 2002). Qualitative methods tend to center on relatively small purposeful samples in order to tell a story or investigate something specific, while in quantitative investigations it is important to have a large sample in order to representation the population being studied. I was purposeful in my sampling in an effort to collect authentic responses from mentors and facilitators and their experiences with the mentoring curriculum early on in the investigation and then concerning their use of the Facilitation Implementation Guide (FIG) further along in the study. Participants were selected by means of what Miles and Huberman (1994) term a convenience sample, denoting that facilitator representation was based on volunteerism and interest. For the interviews I initially, I asked for volunteers within the facilitator course and then I asked specific facilitators to deliberately gather particular perspectives (e.g., facilitators who were pre-service teachers and had exposure to best practices in curriculum and instruction, or facilitators who had a lot of experience with YWLP or facilitators were new to the program). While for the verbal and written feedback, I asked facilitators in the class to provide feedback after each week and at the 
end of the semester. They did not receive a grade for the feedback, but instead they received full credit for turning in some feedback. In total, there were 27 facilitators in the sample within the various phases of the investigation. The sample was somewhat diverse with regard to experiences. The facilitators had a wide range of experience working with YWLP, facilitating groups of adolescents, and teaching. They also represented a mix of ages and race and different years of academic progress at the university. Because most facilitators graduate and leave the university, it was necessary for the participant sample to be flexible throughout the process of the project.

\section{Data Sources and Collection Methods}

Data collection for the investigation occurred formally and informally between September, 2009 and December, 2013, and involved observations, interviews, meetings, presentations, email exchanges, artifacts (e.g., journals and reflections) and feedback in response to the curriculum. An extensive amount of data was collected throughout that time and was used to inform the development of the product that eventually resulted in the Facilitation Implementation Guide (FIG). Table 3 includes a chart that illustrates the phases of data collection: Pre-Pilot, Pilot 1, and Pilot 2.

Table 13: Data Sources, Collection Methods, \& Collection Phases

\begin{tabular}{|l|l|l|l|}
\hline Sources & Collection Method & Time/Frequency & Phase \\
\hline Response & Response journals from big sisters & Once a week for ten & Pre-Pilot \\
journals & serving: 1 urban high school, 1 urban & weeks in 2009-2010 & \\
(collected & middle school $\left(7^{\text {th }} \& 8^{\text {th }}\right.$ grade groups), & & \\
weekly) & and 1 suburban middle school $\left(7^{\text {th }} \&\right.$ & & \\
& $8^{\text {th }}$ grade groups). Approximately 45 & & \\
& big sisters, representing 5 groups. & & \\
\hline
\end{tabular}




\begin{tabular}{|c|c|c|c|}
\hline $\begin{array}{l}\text { Final } \\
\text { Reflection } \\
\text { Papers } \\
\text { (collected at } \\
\text { the end of } \\
\text { the semester) }\end{array}$ & $\begin{array}{l}\text { Final Reflection papers from big } \\
\text { sisters serving: } 1 \text { urban high school, } 1 \\
\text { urban middle school }\left(7^{\text {th }} \& 8^{\text {th }} \text { grade }\right. \\
\text { groups }), 1 \text { suburban middle school }\left(7^{\text {th }}\right. \\
\& 8^{\text {th }} \text { grade groups). Approximately } \\
45 \text { big sisters, representing } 5 \text { groups. }\end{array}$ & $\begin{array}{l}\text { Once at the end of } \\
\text { first semester in } \\
2009-2010\end{array}$ & Pre-Pilot \\
\hline $\begin{array}{l}\text { Feedback } \\
\text { (emailed) }\end{array}$ & $\begin{array}{l}\text { Feedback from all } 7^{\text {th }} \text { grade facilitators } \\
\text { regarding the mentoring curriculum: } \\
\text { "What worked with the mentoring } \\
\text { curriculum and what did not?" }\end{array}$ & $\begin{array}{l}\text { Once a week for } 20 \\
\text { weeks in } 2009-2010\end{array}$ & Pre-Pilot \\
\hline Observations & $\begin{array}{l}\text { Observations of weekly facilitator } \\
\text { class/meetings. }\end{array}$ & $\begin{array}{l}\text { One hour, once a } \\
\text { week for } 20 \text { weeks in } \\
2009-2010\end{array}$ & Pre-Pilot \\
\hline Field notes & $\begin{array}{l}\text { Field notes from a new facilitator of } \\
\text { weekly class/meetings. }\end{array}$ & $\begin{array}{l}\text { Once a week for } 20 \\
\text { weeks in } 2009-2010\end{array}$ & Pre-Pilot \\
\hline Interviews & Interviews with facilitators. & $\begin{array}{l}\text { Before I began } \\
\text { writing the } F I G\end{array}$ & Pre-Pilot \\
\hline $\begin{array}{l}\text { Facilitate \& } \\
\text { Reflect }\end{array}$ & $\begin{array}{l}\text { Facilitate Mentoring Meetings at one } \\
\text { urban middle school and work } \\
\text { intimately with curriculum and } \\
\text { big/little sister participants. }\end{array}$ & $\begin{array}{l}\text { Weekly Mentoring } \\
\text { Meetings } 2^{\text {nd }} \\
\text { semester }\end{array}$ & Pre-Pilot \\
\hline $\begin{array}{l}\text { Feedback } \\
\text { from } \\
\text { Facilitators }\end{array}$ & $\begin{array}{l}\text { Written \& verbal feedback from } \\
\text { facilitators regarding the } F I G\end{array}$ & $\begin{array}{l}\text { Weekly during } \\
\text { development and } \\
\text { pilot of the } \\
\text { curriculum guide } \\
(F I G) \text { during Pilot } 1\end{array}$ & Pilot 1 \\
\hline Interviews & Interviews with facilitators. & $\begin{array}{l}\text { After the first } \\
\text { semester of using the } \\
F I G \text { to gather } \\
\text { feedback on usability }\end{array}$ & Pilot 1 \\
\hline $\begin{array}{l}\text { Written \& } \\
\text { Verbal } \\
\text { Feedback }\end{array}$ & $\begin{array}{l}\text { Checking in at facilitator meeting and } \\
\text { class to determine usefulness of the } \\
\text { FIG. }\end{array}$ & $\begin{array}{l}\text { Periodically during } \\
\text { development and } \\
\text { Pilot } 1\end{array}$ & Pilot 1 \\
\hline $\begin{array}{l}\text { Written \& } \\
\text { Oral } \\
\text { Presentations }\end{array}$ & $\begin{array}{l}\text { Co-facilitators presented during the } \\
\text { YWLP facilitator class how they used } \\
\text { the FIG during their group meetings } \\
\text { and its usefulness. }\end{array}$ & $\begin{array}{l}\text { Presentations and } \\
\text { Written } \\
\text { Reflection/Feedback } \\
\text { e-mailed }\end{array}$ & Pilot 2 \\
\hline $\begin{array}{l}\text { Check-in } \\
\text { Meetings }\end{array}$ & $\begin{array}{l}\text { Check-ins with YWLP Director, e- } \\
\text { mails, meetings to be sure that I } \\
\text { understood the concern, and then to be } \\
\text { sure that the product was addressing } \\
\text { the concern. }\end{array}$ & $\begin{array}{l}\text { Throughout the } \\
\text { process }\end{array}$ & $\begin{array}{l}\text { Pre-Pilot, } \\
\text { Pilot } 1, \& \\
\text { Pilot } 2\end{array}$ \\
\hline
\end{tabular}


Formal data sources included: observations of the facilitator meetings and Mentoring Meetings, written reflections from mentors, written and verbal feedback from facilitators, and interviews with facilitators. As time progressed and the project took shape, it became evident which data points were more significant and yielded more valuable information than others.

Pre-pilot data sources. During the Pre-Pilot Phase, data sources included: observations of the facilitator class (with accompanying ethnographic field notes from an additional research team member for triangulation) $(\mathrm{N}=20)$; semi-structured interviews with facilitators $(\mathrm{N}=5)$; an academic year's worth of weekly journal reflections $(\mathrm{N}=900)$ written by mentors $(\mathrm{N}=45)$; and weekly feedback $(\mathrm{N}=180)$ from the facilitators $(\mathrm{N}=9)$ about how the mentoring curriculum worked in their groups, and particularly how it helped their little sisters thrive.

Pilot 1 data sources. During the Pilot 1 Phase data sources included: written feedback from facilitators $(\mathrm{N}=3)$ and semi-structured interviews at the end of the first semester $(\mathrm{N}=2)$.

Pilot 2 data sources. During Pilot 2 facilitators provided structured written feedback $(\mathrm{N}=20)$, which they submitted by email twice — once in December and once in May. Their feedback was in response to how the FIG was useful to their implementation of the mentoring curriculum. Also at the end of the first semester, facilitators provided verbal feedback $(\mathrm{N}=20)$. They presented their ideas about what was working and what was not with the $F I G$ after the first semester.

\section{Pre-Pilot}

The purpose of the Pre-Pilot data collection was to gather information that could 
provide both social and historical contexts, which are essential elements when using a pragmatic framework, (Creswell, 2007) about the problem and answer the following question: "What was contributing to the facilitators' inconsistencies with implementation of the mentoring curriculum?" The Pre-Pilot Phase spanned one academic year, from September 2009 to May 2010.

Journals from mentors. Journal entries $(\mathrm{N}=900)$ were collected from mentors $(\mathrm{N}=45)$ over two academic semesters from September 2009 to May 2010. Mentors were asked to reflect weekly on the assigned readings, mentoring experiences with their little sisters, and how the curriculum went with their particular groups. They reflected on their understanding of the readings and how they applied to them personally as well as to their mentoring work with their little sisters. Journal responses were collected weekly and were approximately two pages in length. See Appendix C for expectations and sample rubric used to assess the journal responses.

At the close of the fall and spring semesters, mentors were asked to write a final reflection paper, similar in content and format to the weekly reflections. Mentors were asked to reflect holistically on the past year and to consider: their relationships with little sisters, what aspects of the mentoring curriculum flourished, what aspects fell short with their groups, and how particular assigned readings were significant to them.

Due to my role as a teaching assistant for the class I had to assume two roles: as researcher and assessor, which meant that I had to read the papers twice. The first reading was for the assessment while using the assignment's rubric and the subsequent reading was for the purpose of analysis. I analyzed all journals and final papers for patterns and themes. The analysis of journals provided greater social and historical context and 
clarifying information about what support facilitators needed to implement the curriculum more effectively for the adolescent girls, in order to create an environment that promoted growth.

Observations. Observational data were collected over two academic semesters from September 2009 to May 2010. Observations $(\mathrm{N}=20)$ of the facilitator class meetings (which facilitators attended in preparation for the Mentoring Meeting) were conducted throughout two semesters. Each observation lasted 90 minutes and took place immediately prior to the university service-learning class designed to provide ongoing training and support for mentors. The content of the observations of the facilitator class focused on: 1) Highlighting key components of the curriculum for the upcoming Mentoring Meetings with the adolescent girls, 2) Answering facilitators' questions about the mentoring curriculum, and 3) Providing practical advice for the facilitators. Throughout the fall semester of 2009, I conducted observations while trying to remain separate from the group. My only participation occurred when questions were directed to me. Otherwise, I sat on the periphery, observing and taking ethnographic field notes. I observed all of the same facilitators interacting for both fall and spring semesters with the exception of one. I replaced that facilitator for the spring semester.

During the spring semester, I conducted observations from a participatory role, since I served as a facilitator and contributed to the meetings as a member. A fellow researcher also took ethnographic field notes during this time in order to triangulate the observations. The field notes provided detailed observations of how the facilitators were interacting with the content in the curriculum each week, including details such as: which concepts and activities needed further explanation, what materials and strategies were 
used to support the facilitators, what adolescent developmental theory was used to deepen participant understanding, which program logistics needed reinforcement, and which group management strategies needed further explanation.

I also kept a journal while serving as a facilitator of one of the mentoring groups. Each week I reflected on: 1) My personal experiences with the implementation of the mentoring curriculum, 2) Issues I faced with big and little sisters, 3) Information or materials that would have been helpful to know/have to make the group function more efficiently 4) Important ideas to consider when trying to encourage the potential in the atrisk little sisters. These notes also informed the final culminating capstone product - the Facilitators' Implementation Guide.

Interviews. I conducted interviews with the facilitators $(\mathrm{N}=5)$ during the Pre-Pilot Phase in a face-to-face format, using a protocol with semi-structured, open-ended questions, which allowed facilitators to elaborate upon their experiences unreservedly. One interview was a joint interview while the others were one-on-one interviews. (See Appendix D for Pre-Pilot Facilitator Interview Protocol.) Interviews were recorded and transcribed within 72 hours for analysis. The facilitator sample represented a mix of graduate and undergraduate students; students at the beginning and end of their degree programs; students who had a great deal of facilitating experience with YWLP; students who had never facilitated with the program before; and students with varying degrees of exposure to group management strategies and best practices related to curriculum and instruction. I used the findings from the interviews to inform the development of the curriculum guide for the facilitators.

\section{Pilot 1}


Interviews. I conducted semi-structured interviews at the close of the first semester $(\mathrm{N}=2)$ during Pilot 1 . I used a protocol for the interviews, but allowed for flexibility to capture the issues facilitators were still facing. (See Appendix E for Pilot 1 Facilitator Interview Protocol.)

Written feedback. During Pilot 1 facilitators provided written feedback $(\mathrm{N}=3)$ concerning what was useful with the guide and what needed to be added.

\section{Pilot 2}

Written feedback. Facilitators submitted written feedback $(\mathrm{N}=20)$ twice throughout the Pilot 2 academic year-once in December and once in May. They received a grade for completing the feedback, but not for the content of the feedback. They reflected as co-facilitators and co-wrote the feedback. Facilitators emailed the feedback to their instructors and the instructors forwarded the feedback to me.

Verbal feedback. Verbal feedback $(\mathrm{N}=20)$ was presented at the end of the first semester of Pilot 2 in November. Significant changes had been made to FIG based on Pilot 1 and the facilitators were asked to reflect on how the guide assisted with their facilitation of the mentoring curriculum. They were also asked to offer suggestions for changes that should be made to improve the guide.

\section{Data Analysis}

Data were analyzed using the pragmatic framework (Creswell, 2007) and action research design (Patton, 2002). There were three main phases of data analysis: 1) organizing the data, 2) data reduction, 3) data representation (Creswell, 2007), but beyond those three main phases there were many cyclical action research steps that were in response to data points (e.g., feedback and observations). 
Data organization. During this phase of data analysis I used Miles and Huberman's analysis strategies (1994). I organized the by data type in color-coded file folders (i.e., field notes, observations, journal responses, and transcribed interviews) Then I used the analytic method of identifying codes, (e.g., "sk" for skills, "con" for concept, “"cur" general curriculum, "mis" misconceptions, "trans” transformative). Once I identified the codes, I compared data types for coding similarities and took notes.

Data reduction. During the data reduction phase, I noted which codes (variables) had the highest frequency and I highlighted the patterns that emerged with different colors. I then grouped the variables I coded into categories based on connections or relationships I found between the variables. I continued this process until I collapsed the categories into sub-categories (e.g., "time," for time pressure, group members were late, ran out of time, busses arrived early, or absenteeism, “con," for take away messages, main concepts, objectives, and agendas, and "supp," for support for mentors and facilitators and misconceptions). I collapsed the categories after I had completed the analysis of the Pre-Pilot data through the data reduction process. I was entering the data representation phase when Pilot 1 began.

Data representation. Throughout the data representation phase of data analysis, I searched for emergent patterns connecting the various data points, instructional frameworks, and the literature. I used the High-Quality Curriculum \& Instruction Principles I constructed to compare patterns that surfaced from facilitators' interviews, observation field notes from the facilitator meetings (mine and the fellow researcher's), journal responses, etc.

\section{Trustworthiness}


One way to examine credibility of the inquiry is through the lens of social construction and constructivist criteria (Patton, 2002). Social constructivists are interested in understanding how one's own experiences and background impacts their research and inquiry (Guba \& Lincoln, 1989). Trustworthiness is related to the researcher's ability to collect, and analyze the data and report the findings in a responsible, commendable manner (Patton, 2002). Certainly my intensive and extensive experience with the Young Women Leaders Program influenced my perspective as I constructed the research design and the final culminating product, but I believe for the richer (Guba and Lincoln, 1989). My various roles with YWLP as facilitator, Mentoring Coordinator, researcher, and teaching assistant promoted a development of genuine trust with participants and client and created what Creswell (2007) terms "prolonged engagement." The roles also provided me opportunities to observe, participate, and lead — enabling me to glean insight regarding the organizational culture. When researchers have extended intimacy and proximity with the subject and/or the phenomenon, valuable data can often be collected (Toma, 2000).

Triangulation. Triangulation was achieved in several ways. The purpose of triangulation is "test for such consistency" (Patton, p. 556, 2002) by using the multiple methods they provide different empirical realities (Patton, 2002). In an effort to increase credibility, data were gathered in a variety of ways and multiple perspectives were represented (i.e., facilitators, mentors, and YWLP leadership team members). Various voices were considered to offer a panoramic view of the facilitators' inconsistency in addition to supporting evidence for themes. Another researcher provided transcriptions of 
her field notes after her observations to offer her viewpoint of what she observed during the facilitator class.

Member checking. I returned to the facilitators and YWLP leadership team with the Facilitators' Implementation Guide so that they could assess the usability and relevance. It was a highly reflexive process as is with action research. During the development phase of the FIG, I was in communication with the facilitators and the YWLP leadership as they were providing feedback on the usability. 


\section{CHAPTER 4}

\section{FINDINGS \& ACTION}

\section{Pragmatic Response to Findings for Program Development}

\section{Pre-Pilot Phase Findings}

Pre-Pilot data analysis revealed five significant findings. The findings suggested that facilitators needed support in the implementation of the curriculum in five specific ways: 1) understanding the intentions of each mentoring lesson and activity, 2) managing the group, 3) creating alternatives to activities, 4) determining a common vocabulary, and 5) discovering ways to empower the big sisters to take on leadership roles in the group.

Intentions of lessons and activities. Facilitators often expressed uncertainty about the intention and objectives of some activities in the curriculum and did not see the explicit connection between the activities and YWLP's greater mission. Through the course of discussions with the facilitators interviewed, it became evident that this lack of clarity was partially responsible for their ambiguity with prioritizing pieces of the curriculum for certain activities. Furthermore, their inability to articulate the intentions undergirding activities in the curriculum left them unclear about which concepts and understandings should be emphasized. They often could not explain the rationale or intention behind the activities in the curriculum. I was able to witness the facilitators' lack of understanding firsthand during the facilitator class as I made my 
observations. Their uncertainty was frequently reflected in their comments or questions while we were discussing the curriculum. The following are some examples:

- "Why is Sister Time important? I don’t even know why we do it."

- "What if we ran out of time and we didn't do Gossip Guard? Does it matter for next week?"

- 'Going over the Leadership Secrets feels too much like school and I don't know how it even connected to last week."

- "What is the point of the interviewing activity? My girls felt very uncomfortable."

- "The girls wanted to go watch the boys' basketball game, so we did that instead last week."

I addressed this by including an "OVERVIEW" section for each Mentoring Meeting. The "OVERVIEW" includes: the concept or big idea that frames the curriculum for the session as well as what participants should know, understand, and be able to do as a result of the session. Another way I addressed facilitators' uncertainty of the purpose of the curriculum's activities was by inserting a section in the FIG that provided justifications for activities so facilitators would be aware of the rationale behind the activities and how they fit with the mission of YWLP. It is important for facilitators to be able to articulate the justifications for activities so they can respond when little sisters ask, "Why are we doing this?" or "Why is this important?" They also need to know what is significant to keep and what can be omitted when they are running short on time. The "JUSTIFICATION" section provides the answers to these questions.

Group management. The second significant discovery uncovered during 
analyses of the facilitator interviews, observations, and journals was that they were unsure of how to manage their groups in several important ways. First, they voiced the need for support around how to organize the Big Sister Meetings. They felt that the big sisters were not completely engaged during meetings and there was a lot to cover during a very short amount of time.

They also communicated that they could have benefitted from strategies on how to set group norms with their big and little sisters and how to manage the many responsibilities that arise on the spot when facilitating a group meeting (allowing students to go to the restroom; accounting for cell phones, water, and snack breaks; going to lockers; pick up time; procedures for taking attendance; and calling home for people who are absent). In addition, they mentioned that it would be helpful to know how to respond to their little sisters' needs in a way that would invite them to engage in activities during mentoring meetings. Facilitators also consistently expressed that the little sisters at times displayed behaviors of disengagement and indifference (such as sidebar conversations, texting, and daydreaming). In an interview, one facilitator expressed a need for ideas regarding how to "follow the group's flow," meaning strategies for how to flexibly follow the energy of the group based on individual members' interests and needs, thus capitalizing on individual members' strengths, promoting talents, allowing for leadership and choice.

I addressed this finding by including sections in the $F I G$ that contain suggestions for ways to: prepare for the Big Sister and Mentoring Meetings, (i.e., TO DO LIST and SUPPLY LISTS), organize the Big Sister and Mentoring Meetings (i.e., AGENDAS), understand what is most important to address when facilitators feel there is too much 
material to cover in the lesson (i.e., TAKE AWAY MESSAGES), engage the sisters based on their needs and interests (i.e., ADAPTATIONS), make the curriculum more relevant by applying it to the girls' lives (i.e., PRACTICAL EXTENSIONS), and implement activities or manage meeting (i.e., TIPS).

Alternatives to activities. The third theme that emerged from data analyses from the Pre-Pilot Phase was that facilitators needed ideas of how they could adjust activities to better meet the needs of their groups when activities were unsuccessful with the groups. They explained that they did not have time to be creative and wished they could have a resource that included alternate ideas of how to implement the curriculum in case the ideas included did not work with their groups.

In an effort to address this need, I included "ADAPTATIONS" for ways to alter the activities if sisters need scaffolding or if the facilitators felt that it would be more successful for their groups with a different approach. Some of the adaptations are ones that the facilitator can plan for ahead of time, but others are ones that may be in the moment adjustments based on how the members of the group are responding to the curriculum. For example, with the M \& M Game, the group members are asked to share information about themselves with the others as a way to get acquainted, but if facilitators anticipate that their sisters might be challenged by this activity and might have difficulty coming up with facts about themselves, there are suggestions in the "ADAPTATION" section that provide modifications (e.g., use candy, such as; red for a fact about school, brown for family, etc., to provide scaffolding for the participants.) This is something the facilitator would most likely foresee and she could plan ahead of time, although could implement in the moment in response to sisters' apprehension. Facilitators 
would benefit from reading over the "ADAPTATIONS" section as they are preparing for the Mentoring Meeting so they are equipped to respond to what best fits their participant's needs.

Another element that I included in FIG that addresses the need that facilitators' expressed was the "FLEX OPTIONS." This feature provides a variety of pathways to arrive at the same big understandings, and goals for the Mentoring Meeting. Many of the suggested options are based on previously reported success from groups. Facilitators can use the "FLEX OPTIONS" as a way to provide the sisters to have some choice and voice in the Mentoring Meeting, which can be quite empowering. The following is an example of a "FLEX OPTION." Facilitators in collaboration with their big and little sisters can choose which activity best suits their group: 1) Stand in a circle alternating big and little sisters. One person starts by hooking pinkies with both of the people next to her, saying the Leadership Secret. Those people hook pinkies with the people next to them, also saying the Leadership Secret. Pass the pinkie hook down the line until everyone gets connected. 2) Have everyone stand in a circle. Have one sister put her hand in the middle and then ripple around the circle, piling hands on top of each other, saying the meeting's Leadership Secret (or some variation of it) as hands are placed on the pile. 3) Create a different way to get the sisters to physically connect and to restate or say the Leadership Secret.

Common vocabulary. The fourth finding that emerged was that big sisters and facilitators were using similar terms but those terms had different meanings to each group. For example, during an interview a facilitator explained that one week she told her big sisters they had a Play Day. Her big sisters thought that meant they had the week off 
with their little sisters when, according to the facilitator, that meant they did not have a Mentoring Meeting at the school but still were supposed to meet with their little sisters. This confusion was a negative experience for the group; the little sisters felt rejected, thinking they were the only group that did not meet that week. This account illustrates how some of the program's terms' lack of clarity can influence outcomes and the need for defining key terminology.

In response, I met with the Program Director and we created a list of terms (including their definitions) that are important for all big and little sisters to know and understand in order to function successfully in their roles. Next, we sent the list to key leaders (including some facilitators) to verify that the list included the necessary YWLP terms and agreed upon definitions. I then incorporated this list of terms at the beginning of the FIG for facilitators' reference.

Empowering big sisters. The fifth theme that surfaced was the important role big sisters played in creating a sense of community among all of the group members. They are a significant influence when establishing the tone. Often facilitators said that if the big sisters did not like an activity, it did not work. Conversely, they said that when they had the support of their mentors, activities soared despite how they looked on paper. One facilitator said that the secret was to delegate important roles to her mentors each week, making them feel empowered and an essential part of the group. From the beginning, facilitators need to learn who their mentors are and what talents they bring to the group so they can access and use them for the betterment of the group. Facilitators must access each big sister's gifts and then validate them to make each person feel like a valuable and cherished member of the community. 
Since facilitators and big sisters are critically essential to the success of this mentoring program for little sisters, I did not address this in merely one section, but rather there are suggested ways to address this concern threaded throughout the guide. For example, in the initial Mentoring Meeting with big sisters I recommend that facilitators ask big sisters to share their stories of how they got involved with YWLP, their expectations of the facilitator, and what they hope to get out of the experience. This sets the stage from the beginning that facilitators believe big sisters' ideas are important and valued. It is also suggested that facilitators ask the big sisters for input in determining how each big sister will contribute most usefully. This sets the expectations that each big sister has gifts and talents that are worth contribution and that everyone is expected to contribute on a high level. To that same end, there is a suggestion in the "TIP" section (the segment that offers guidance for implementation of the activities in the curriculum and others advice with the role as a facilitator) explaining that the facilitator may want to use some sort of object to serve as a "microphone" to signify who has the floor to speak and who should be quietly listening. This will then be passed around to the different speakers. This demonstrates respect and is another way of sending a message of valuing each person's contribution to the group.

Another significant way that $F I G$ offers suggestions for facilitators to build and empower big sisters is by publically remarking on who displayed noteworthy leadership and asking sisters to recognize one another. This practice not only celebrates big sisters' leadership during the meeting and promotes connection by encouraging one another, but it also reinforces the desired behaviors. Another similar practice that happens during the Mentoring Meeting is when sisters take time to honor one another and lift one another up 
in front of the little sisters as well, but this may not be related to something that has happened within the mentoring meeting. As a result of these findings, the Facilitators Implementation Guide includes these elements: objectives (i.e., what group members will know, understand, and do as a result of the session), rationales for activities, strategies for engaging adolescents with the curriculum, and ideas about how to flexibly adapt the curriculum to better meet the needs of individual groups.

\section{Pilot 1}

In order to better understand the context and scope of the programmatic concerns and ways in which the newly developed guide could address those concerns, I launched a pilot (Pilot 1) of the Facilitators' Implementation Guide (FIG) during the 2010-2011 school year. I was interested in whether the guide made a difference with the implementation of the mentoring curriculum (particularly with regard to the Program Director's concern) after I had incorporated the data I gathered during the Pre-Pilot Phase. The question guiding the Pilot 1 study was, "In what ways is the newly developed Facilitators' Implementation Guide useful and relevant to the implementation of the mentoring curriculum?"

Each week I submitted a draft of the relevant section of the curriculum guide to the YWLP leadership team for feedback. After the YWLP leadership vetted the $F I G$, facilitators provided their responses regarding the usefulness and relevance of the curriculum guide while they were using it each week.

Feedback from the facilitators regarding the utility and relevance of the FIG was then used to inform the development of the guide. That process continued throughout the academic year with a more in-depth interview after the first semester to allow for more 
detailed reflection since earlier feedback from facilitators was general and spoke to the overall curriculum guide rather than providing detail for each lesson. For example, representative quotations from the feedback were: Emma initially said, "It's a good product! Also I haven't found any typos and I'm quite a stickler!" Susan initially reported, "I think the FIG is great. In fact--I think it is fantastic!" Due to the lack of substantive feedback it led me to seek a different mode of feedback in the form of a faceto-face interview with facilitators after the first semester.

After the first semester, in a joint interview, facilitators $(\mathrm{N}=2)$ (November, 2010) were asked questions regarding the guide's usefulness, relevance, and how it helped them implement the pre-existing $7^{\text {th }}$ Grade Curriculum Handbook, particularly in the moments when the adolescent girls were interested in something other than the curriculum. Pilot 1 Facilitator Interview Protocol is attached in Appendix F. The interview was semistructured, with follow-up questions emerging naturally from the class of the discussion based on the facilitators responses to the prepared questions (e.g., "Tell me more about what you mean when you say that you use Survey Monkey to assess your group's understanding of the curriculum." "What would this checklist of what your little sisters should know, understand, and be able to do, look like for the milestones?") The interview followed the organic flow of the conversation and allowed the facilitators to discuss what they felt was important with regard to the mentoring curriculum implementation and the usage of FIG. For example, it became evident that Emma and Susan were concerned with the group "getting off track" during the Mentoring Meetings and they shared anecdotes of how they had to skip particular elements of the curriculum (e.g., Gossip Guard) or activities in order to either address an issue that arose (e.g., a conflict between two of the 
little sisters) or account for the unavoidable distractions with which the curriculum activities could not compete (e.g., an African Dance Troop that began performing outside their classroom.) In reference to the latter, Susan admitted, "Sometimes there is just not much you can do about it...."

After analyzing the transcription of the interview with the facilitators along with earlier feedback, five major themes emerged from Pilot 1 regarding the FIG's usability and relevance: 1) Ease of use would be improved if the guide were integrated into the existing 7th Grade Curriculum Handbook (physically into the spiral) and integrated into the facilitator class. The $F I G$ needs to be incorporated into the facilitator class more consistently and facilitators should be expected to read and use the guide for implementation, and even reflect on it as part of class. 2) Most of the content in the guide was relevant and extremely practical, but it could be condensed. The aspects that were too theoretical could be eliminated. 3) Unless the facilitators read the guide they were unclear about the objectives or goals for each Mentoring Meeting and therefore allowing the girls to determine the direction of the group without knowing what is important to uncover during their time together. 4) Facilitators did not necessarily have information or understanding about how to make the curriculum relevant or engaging for the big or little sisters. 5) Facilitators incorporated benchmarks with a likert scale to determine their growth and assess how they obtained the objectives each week or periodically.

Feedback and Response. I communicated these five themes to the YWLP leadership. To address the first, the $F I G$ was integrated into the facilitator class in the fall of 2012 and the professors used it with more intentionality while raising the expectations for the facilitators to read and use it for their particular mentoring groups. In an effort to 
address the second concern, I eliminated entire sections of the theory that seemed too verbose. This process required extensive revisions and additional steps of feedback to the facilitators and YWLP leadership. In the end, the product was significantly shorter and the sections on the theory and research within each lesson were more succinct. I continued to create clear objectives of what the adolescent participants would know, understand, and do as a result of each Mentoring Meeting to address the third concern, but I wrote them in a more simplified way so they were more user-friendly to noneducators. The goal was to invite the facilitators to read them and be prepared to lead their groups, and not stray from what was important to tackle during their time with their groups. I also encouraged the facilitators to communicate objectives to the mentors during the Big Sister Meetings and to the little sisters in the Mentoring Meetings by writing them on the board.

In an effort to attend to the fourth and fifth concerns, I spent more concentrated time on the "TIPS" and "MEASURING STICK" sections. The "TIP" section provided advice regarding the facilitation of activities. The following is an example of "TIPS" included in the FIG for the Human Knot Activity. 1) Guide, if necessary. As the facilitator, it would probably be a good idea for you to stand on the outside and not be a part of the knot. This will allow you to stand on the outside and even on a chair, if necessary, in order give you perspective to offer helpful suggestions if the group needs you. Be sure to withhold from offering suggestions until after the group has shown signs of actual struggle and teamwork. 2) Allow time for struggle. The purpose of this activity is to provide an opportunity for the group to solve a problem together. It is not an easy exercise, especially if your group members are not verbally communicating. This will 
give a practical application of the notion of taking a deep breath and considering options. It also supports collaboration and teamwork. Ending this exercise too soon can result in the group feeling as though they have failed so be sure to provide ample time to work through this exercise, but before the group becomes too frustrated. You will need to read your group and observe their actions to determine what is best. 3) Emphasize the process. The focus of this activity is the process, not the end result of actually untying the knot. This important to keep in mind so that groups do not feel completely unsuccessful if they do not solve the problem. The debriefing/reflection questions provided in the curriculum are important to the emphasis on the process. Be sure to relate what happened during the exercise to the concepts of problem solving and reflection. Try to incorporate the language from mentoring curriculum such as: acknowledging the problem, deep breath, choose another option, etc.

The "MEASURING STICK" section provides formative assessment to track growth. Initially it was intended to measure little sisters' growth based on the program's overall mission and the Mentoring Meeting's goals (KUDs), but then based on feedback and reflection, I made revisions. The revised "MEASURING STICK" contains questions that prompt the big sisters and facilitators to assess their growth as well. The following is an example of one "MEASURING STICK" section included in the FIG.

\section{MEASURING STICK: Assessing Growth * Self-reflection}

- How did you do this week as a facilitator on a scale from 1-5 (5 being best)?

- What were your strengths in this group meeting?

- How would you like to improve?

- What did you do to maximize your little sisters' potential?

- Did you use the best practices from the FIG? 


\section{Reflection on teamwork}

- In what ways did your big sisters support you and help lead the meeting?

- How could the big sisters improve?

- Did your little sisters meet your established outcomes for this Mentoring Meeting?

- Do the Little Sisters in your group know the information presented?

- More details about fellow group members

- A support team is a group of dependable people who can offer support in reaching coals or helping make important decisions

- Did they demonstrate that they understood the established understandings or principles that are the foundation of the meetings' activities?

- A competent leader knows when and how to seek help.

- All leaders need support to achieve their goals.

\section{Pilot 2}

In an effort to further refine $F I G$, I conducted another pilot (Pilot 2) with the facilitators during the 2012-2013 academic school year to determine whether incorporating what I had learned from the Pre-Pilot and Pilot 1 data would make a difference with regard to the facilitation of the curriculum as measured by the facilitators and the program leadership. Now that the professors' expectations for facilitators use of the $F I G$ were raised, they were being intentional about using it in the class, and the FIG was better organized, integrated into the 7th Grade Curriculum Handbook, and userfriendly according to the feedback from the facilitators and program leadership. The focus question for the Pilot 2 study was, "How is the FIG practical and useful for the facilitation of the mentoring curriculum?" After the first semester, the facilitators presented how they used the FIG.

Table 14: Sample Feedback from Facilitators

\begin{tabular}{|c|c|}
\hline Opportunities for Growth & Examples of Positive Responses to FIG \\
\hline Sometimes it is written too much in & It is helpful in the $F I G$ where it lists \\
\hline
\end{tabular}




\begin{tabular}{|c|c|}
\hline "teacher language." & $\begin{array}{l}\text { the concepts because the co-facilitators are } \\
\text { not always on the same page. I remember } \\
\text { one time for "Global Connections" when } \\
\text { my co-facilitator was introducing Zambia. } \\
\text { Her first sentence to the girls was like does } \\
\text { anybody know anything about AIDS or } \\
\text { something like that! I was like great first } \\
\text { dive in! Wow! If we were on the same page } \\
\text { that would have never happened! I feel like } \\
\text { the "Global Connection" thing it is so } \\
\text { important for the co-facilitators to be on the } \\
\text { same page because it's not like either of us } \\
\text { are "Zambia experts" so it's like the blind } \\
\text { leading the blind when the girls ask us } \\
\text { questions. Well, I mean we have as many } \\
\text { stereotypes and preconceived notions that } \\
\text { aren't based in fact as you do so we really } \\
\text { need to be able to prepare. }\end{array}$ \\
\hline $\begin{array}{l}\text { It often feels like there is too much } \\
\text { lecturing and we need to get the little } \\
\text { sisters up and moving around. }\end{array}$ & $\begin{array}{l}\text { Gossip is a huge issue right now in all } \\
\text { girls' friendship circles. There's one little } \\
\text { who's being ostracized so bullying is also a } \\
\text { relevant issue. Both of these topics had } \\
\text { activities this week so that was really } \\
\text { timely and beneficial. }\end{array}$ \\
\hline $\begin{array}{l}\text { It feels like there is a lot for the facilitators } \\
\text { to do to prepare for group. There is a lot of } \\
\text { reading. Is there any way you can } \\
\text { streamline it with the curriculum? Why do } \\
\text { we have to read that too? }\end{array}$ & $\begin{array}{l}\text { Again, we're having trouble with time. We } \\
\text { have to work it out. Even the littles are } \\
\text { commenting that we're not managing the } \\
\text { time well. I think we may need to veer } \\
\text { from the allotted time in the curriculum and } \\
\text { play it a little more by ear. The FIG is } \\
\text { helping us figure out what we have to } \\
\text { cover. }\end{array}$ \\
\hline $\begin{array}{l}\text { How can we communicate this to the big } \\
\text { sisters? Can you make one of these for } \\
\text { them? }\end{array}$ & $\begin{array}{l}\text { This week's FIG was so helpful for us. The } \\
\text { paragraphs about Adolescents' } \\
\text { Developmental Need for Supportive, Close } \\
\text { Connection was so valuable and } \\
\text { interesting. It showed us how important } \\
\text { these big/little relationships are. I also liked } \\
\text { the part about encouraging little sisters to } \\
\text { ask for help. I think that many middle- } \\
\text { school girls do not really know where to } \\
\text { turn sometimes. I also enjoyed reading the } \\
\text { "Self-examination" portion of the Practical } \\
\text { Extensions section. It is important to relate } \\
\text { things to the little sisters so that they stay } \\
\text { interested. This was a very helpful section. }\end{array}$ \\
\hline
\end{tabular}




\begin{tabular}{|c|c|}
\hline $\begin{array}{l}\text { We need more training on how to use the } \\
F I G \text {. }\end{array}$ & $\begin{array}{l}\text { The overall message of the week was to } \\
\text { live above the influence of gossip - being a } \\
\text { gossip guard. Also, we emphasized } \\
\text { recognizing and responding to bullying. I } \\
\text { hope the girls stand up for each other. }\end{array}$ \\
\hline & $\begin{array}{l}\text { When co-facilitators are not on the same } \\
\text { page } F I G \text { help you know what to } \\
\text { emphasize and what not to cut. }\end{array}$ \\
\hline & $\begin{array}{l}\text { Many tips in FIG this week helped us } \\
\text { ensure we had a successful Appreciation } \\
\text { Dinner! }\end{array}$ \\
\hline & $\begin{array}{l}\text { FIG provided excellent solutions to } \\
\text { problems for us for this week! }\end{array}$ \\
\hline & $\begin{array}{l}\text { I learned how important it is to form strong } \\
\text { relationship between the big and the } \\
\text { mother of the little sisters. }\end{array}$ \\
\hline & $\begin{array}{l}\text { I learned how important it is to establish a } \\
\text { warm and welcoming environment. }\end{array}$ \\
\hline & $\begin{array}{l}\text { The } F I G \text { reminded me that if I showed that } \\
\text { I was genuinely excited, the littles and bigs } \\
\text { would surely respond in a similar manner. } \\
\text { The most important thing about the } F I G \\
\text { this week is that as a facilitator, I truly do } \\
\text { set the stage for the rest of the group. }\end{array}$ \\
\hline & $\begin{array}{l}\text { After we completed the puzzle, the littles } \\
\text { (and bigs and facilitators!) felt pure joy and } \\
\text { accomplishment. Allowing everyone to } \\
\text { struggle through the issue (in reference to } \\
\text { "Allow Time for Struggle" from the } F I G \text { ), } \\
\text { rather than simply telling the little the } \\
\text { easiest option enables everyone to feel } \\
\text { pride in knowing they helped solve a } \\
\text { difficult problem. }\end{array}$ \\
\hline & $\begin{array}{l}\text { Through the } F I G \text {, I learned the necessity of } \\
\text { gauging little sister's interest and adjusting } \\
\text { the discussion in appropriate ways. We } \\
\text { spent almost } 30 \text { minutes talking about more } \\
\text { ways we can help the community! Without } \\
\text { adjusting the conversation to the little } \\
\text { sisters' interest, we would have never come } \\
\text { up with such wonderful ideas! In the } \\
\text { future, I will always adjust the flow of the } \\
\text { conversation to match the little sisters' } \\
\text { excitement }\end{array}$ \\
\hline & $\begin{array}{l}F I G \text { really helped me take note of the } \\
\text { similarities and differences of little sisters. }\end{array}$ \\
\hline
\end{tabular}




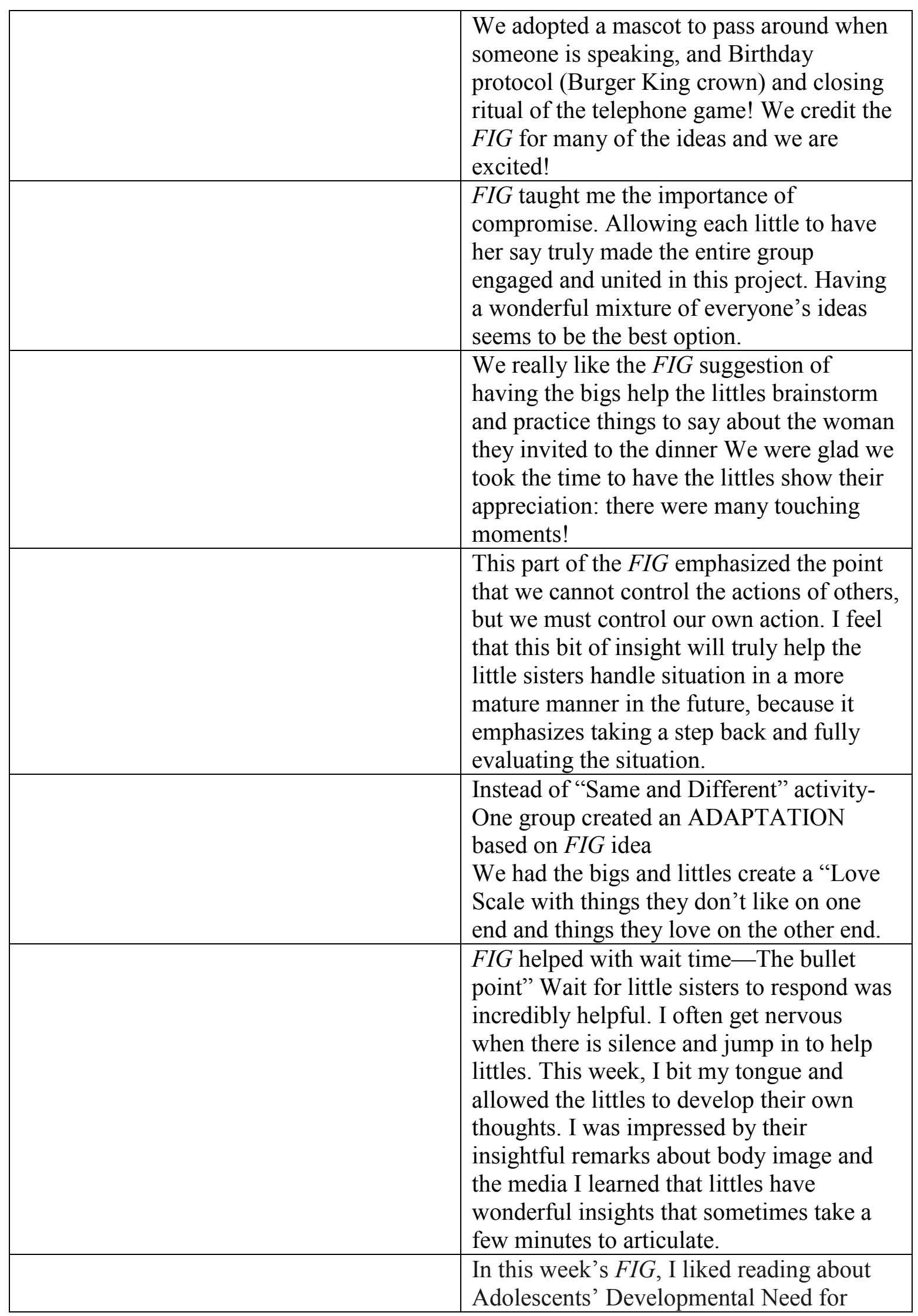




\begin{tabular}{|l|l|}
\hline & $\begin{array}{l}\text { Conformity. I also really appreciated the } \\
\text { tips about Step into the Circle. We really } \\
\text { wanted this activity to run smoothly, so it } \\
\text { was helpful to have some times to be able } \\
\text { to help that along. We also wanted to make } \\
\text { sure it was serious and that everyone knew } \\
\text { they could trust each other. FIG definitely } \\
\text { helped us ensure these things. I also } \\
\text { thought it was important that it told us to } \\
\text { monitor the littles' growth. Sometimes we } \\
\text { just focus on week-to-week growth but we } \\
\text { also need to look at the big picture. I will } \\
\text { definitely be doing this more often. }\end{array}$ \\
\hline $\begin{array}{l}\text { FIG helped us a lot this week, specifically } \\
\text { in helping us think of stress reducing } \\
\text { activities. It also helped us articulate that } \\
\text { stress happens to everyone and that there } \\
\text { are ways of relieving stress. This was } \\
\text { helpful for the bigs and the littles because } \\
\text { we all experience stress in some way. We } \\
\text { used the MEASURING STICK this week } \\
\text { to determine how we did in explaining } \\
\text { stress reduction. I think that everyone } \\
\text { learned a lot and that we helped each other } \\
\text { by sharing our different ways that we } \\
\text { relieve stress. I also think they all took } \\
\text { something away from group and that they } \\
\text { will probably use some of our suggestions } \\
\text { to manage stress. The BIG PICTURE } \\
\text { section was also very helpful because it } \\
\text { helped us tie it into the curriculum and to } \\
\text { the intent of the program. }\end{array}$ \\
\hline
\end{tabular}




\section{CHAPTER 5 \\ RECOMMENDATIONS \& IMPLICATIONS \\ Scaffolding Facilitators \& Maximizing Use of FIG}

\section{Problem of Practice Summary}

Many of university women serving as YWLP facilitators have not been exposed to methods of high-quality instruction, yet it is necessary for them to implement the curriculum using best practices; therefore it is the charge of the YWLP Leadership to train facilitators and offer ongoing support in this area.

In addition to many of the facilitators not being familiar with the principles of high-quality curriculum and instruction, they often keep demanding schedules and are full-time students participating in several other activities. Many are unable to prepare for group facilitation to the extent that is necessary to understand the curriculum content fully in order to maximize the group members' engagement. The lack of understanding results in facilitators emphasizing incorrect areas of the curriculum, communicating misconceptions, or permitting little sisters to merely engage in recreation instead of addressing the intended curriculum related to the identified goals of the program. Finally, many facilitators arrive to their roles with little knowledge and/or understanding of how to manage groups. For those reasons, I was asked to create scaffolding for facilitators to assist them in the implementation of the curriculum. Hence, I created the Facilitators' Implementation Guide. This guide will provide ongoing support in the areas of teaching and learning for facilitators as they implement the curriculum. 


\section{Recommendations for Scaffolding Facilitators}

Train Facilitators on $\boldsymbol{F I G}$. In order to scaffold facilitators' properly they need an introduction to the principles of high-quality curriculum and instruction supporting FIG as well as the two guiding frameworks of differentiation and the CLASS-S. Before the launch of the school year they also need training on how to use FIG effectively so to maximize its use. In the middle of the academic year it would be a good idea to hold another training on the $F I G$ and elements of best practice of facilitation as a "refresher" and for any new facilitators that join.

Integrate $\boldsymbol{F I G}$ more fully. Integrate $F I G$ into the facilitators' class more explicitly. It was very clear that during the Pilot 1 Year before the facilitators were expected to read the $F I G$ or bring it to class, they were not using it as much, but once the YWLP Leadership raised their expectations and began to require them to bring it to class many more facilitators began using it. Once they did and a few of them started having success, and they started talking about it, more facilitators started using it too. Integrating $F I G$ as a requirement and using examples in the class will prove that it is valued and worth the facilitators' time. Also once they begin using it, they will see that it will, in fact, save them time in the end and will enhance the program in the process.

\section{Co-facilitating promotes creativity, but can lead to less consistency. Many}

facilitators are leading in pairs and that can lead to more creativity because of having two people to bounce ideas around, and facilitate in teams of two does increase the collegiality. What was expressed during the interviews, however, was how often the cofacilitating can also lead to the pairs being on "different pages." FIG can help with aligning co-facilitators thinking and getting them on the same page conceptually and 
literally. Because the facilitator guide spells implementation out so practically in addition to explaining the theory it encourages discussion and can re-align thinking if people are misaligned, particularly co-facilitators. I would recommend adding doing some sort of team building with co-facilitators and to match them thoughtfully by strengths and personalities.

Encourage facilitators to practice the elements of FIG such as adapting the curriculum, while maintaining the essential understandings of sessions, getting to know the little sisters in order to better facilitate.

\section{Implications}

I learned a great deal by joining the two frameworks of the CLASS-S and differentiated instruction and then applying those principles two a mentoring context. By marrying the two frameworks the two are strengthened. Their common threads are that they: a) advocate for students' affective needs, b) organize content conceptually with clear learning goals, c) push for deep understanding, d) provide feedback, e) utilize strategies that lead to increased student autonomy engagement such as offering choice

In both the academic and mentoring contexts, engagement is the goal as a way to move through the processes of building competencies, connection, and autonomy. Regardless of whether it is math class or YWLP, students who are engaged or disengaged in a task can exhibit similar behaviors. Therefore, many of the strategies that a teacher would apply in an academic learning environment would also be effective in a mentoring environment. I found as I progressed through the investigation that many of the same principles of curriculum \& instruction were also relevant to a mentoring program setting. 
The Young Women Leaders Program's approach is two-pronged, providing both one-on-one and group mentoring and because of that it is unique. Group mentoring is becoming more prevalent recently as a way to meet the increased demands of mentoring, but the few studies have focused on this type of approach or on the combined approach of one-on-one and group mentoring. Therefore, there was an absence of practical resources concerning curricula for and facilitation of group mentoring and it became clear there was a need for resources to scaffold facilitators with little to no exposure to the teaching profession how to embark upon their facilitation role in a way that set a stage for mentees' to develop competencies and discover potential. This investigation also sought to add to the mentoring literature.

This project sought to address a specific need that was identified by the Young Women Leaders Program through an examination of the consistency of the facilitator's implementation of mentoring curriculum. The practical purpose of the investigation was to determine what curricular support facilitators needed to implement the curriculum effectively during the Mentoring Meetings and to lead thoughtfully and flexibly with the goal of nurturing potential in at-risk, adolescent girls. Although YWLP's combined format is unique, the problem identified is certainly not. It can be transferred to many school-based programs that have university students serving as mentors. The implications of using research and best practices from curriculum and instruction certainly can be transferred to other types of mentoring programs. In the end student engagement is the desired outcome because if a student is not first engaged they cannot learn and they certainly cannot become the best version of themselves as they are mentored.

\section{Future Directions}


I recommend that the Principles of High-Quality Curriculum and Instruction be used to develop the facilitators' skills further. They can be used to frame reflections or discussions either alone or following video or in vivo observations as a method of providing feedback to facilitators. I recommend creating a video library with exemplary behaviors modeling the principles with groups of adolescent girls so facilitators can see concrete evidence of the behaviors in action.

I recommend making FIG available for access to the YWLP sister sites as an additional resource to accompany the $7^{\text {th }}$ Grade $Y W L P$ Curriculum and as a way to increase fidelity to the Young Women Leaders Program goals.

My final recommendation is for YWLP to consider creating a FIG (using the identical high-quality principles of curriculum and instruction as a template) to accompany the $8^{\text {th }}$ Grade Curriculum and scaffold the other facilitators in their implementation. The facilitators implementing the $8^{\text {th }}$ Grade Curriculum arrive with the same lack of experience, knowledge and training and would benefit from having the same support from a similar guide to assist them in their facilitation as well. 


\section{REFERENCES}

Allen, J., Pianta, R., Gregory, A., Mikami, A. Y., \& Lun, J. (2011). An interaction-based approach to enhancing secondary school instruction and student achievement. Science, 333, 1034-1037.

Bandura, A. (1977). Self-efficacy: Toward a unifying theory of behavioral change. Psychological Review, 84, 191-215.

Bandura, A. (1997). Self-efficacy: The exercise of control. New York: W.H. Freeman and Co.

Black, P., \& Wiliam, D. (1998). Inside the black box: Raising standards through classroom assessment. Phi Delta Kappan, 80(2), 139-148.

Bransford, J., Brown, A., \& Cocking, R. (Eds.). (2000). How people learn: Brain, mind, experience, and school (Expanded Edition). Washington, D.C.: National Academy Press.

Bruner, J. S. (1960). The process of education. New York: Vintage.

Caine, G. \& Caine, R. (1994). Making connections: Teaching and the human brain. Menlo Park, CA: Addison-Wesley.

Cameron, C. E., Connor, C. M., \& Morrison, F. J. (2005). Effects of variation in teacher organization on classroom functioning. Journal of School Psychology. 43(1), 6185.

Cohen, E.G. (1998). Making cooperative learning equitable. Educational Leadership, 56, $18-21$.

Cohen, E. G., Lotan, R.A., Scarloss, B.A., \& Arellano, A. R. (1999). Complex instruction: Equity in cooperative learning classrooms. Theory into Practice, 38 , 80-86.

Connell, J. P., \& Wellborn, J. G. (1991). Competence, autonomy, and relatedness: A motivational analysis of self-esteem processes. In M. R. Gunnar \& L. A. Sroufe (Eds.), Self processes in development: Minnesota symposium on child psychology (Vol. 23, pp. 167-216). Hillsdale, NJ: Erlbaum. 
Creswell, J. W. (2007). Qualitative inquiry \& research design: Choosing among five approaches $\left(2^{\text {nd }}\right.$ ed.). Thousand Oaks, CA: Sage.

Csikszentmihalyi, M. (1990). Flow: The psychology of optimal experience. New York: Harper-Perennial.

Csikszentmihalyi, M., Rathunde, K., \& Whalen, W. (1993). Talented teenagers: The roots of success and failure. New York: Cambridge University Press.

Davies, M. (2000). The ideal middle level teacher. In M. Wavering (Ed.), Educating young adolescents: Life in the middle, (pp. 149-169). New York: Garland.

Deci, E. L., \& Ryan, R. M. (1985). Intrinsic motivation and self-determination in human behavior. New York: Plenum Press.

Deci, E. L., \& Ryan, R. M. (2000). The "what" and "why" of goal pursuits: Human needs and the self-determination of behavior. Psychological Inquiry, 11(4), 227-268.

DuBois, D.L., \& Karcher, M.J. (2005). Youth mentoring: Theory, Research, and Practice. In D.L. DuBois \& M.J. Karcher (Eds.), Handbook of youth mentoring (pp. 2-11). Thousand Oaks, CA: Sage.

Dweck C. (1999). Self-Theories: Their role in motivation, personality, and development. Philadelphia: Psychology Press.

Dweck, C. (2006). Mindset: The new psychology of success. New York: Ballantine Books.

Eccles, J. S., Wigfield, A., \& Schiefele, U. (1998). Motivation to succeed. In W. Damon (Series Ed.) \& N. Eisenberg, Handbook of child psychology $\left(5^{\text {th }}\right.$ ed.), Volume III, pp. 1017-1095). New York: Wiley.

Erickson, H. L. (1998). Concept-based curriculum and instruction: Teaching beyond the facts. Thousand Oaks, CA: Corwin Press.

Erickson, H. L. (2006). Concept-based curriculum and instruction for the thinking classroom. Thousand Oaks, CA: Corwin Press.

Erickson, H. L. (2008). Stirring the head, heart, and soul: Redefining curriculum and instruction (3rd ed.). Thousand Oaks, CA: Corwin Press.

Giedd, J. (2002, January 31). Interview transcript from Spinks, S. (Executive Producer). Frontline: Inside the teenage brain [Television broadcast, Program \# 2011]. Alexandria, VA: Public Broadcasting Service. Accessed from http://www.pbs.org 
Giedd, J., MacDonald, S. (2012, September, 20) Inside the Teenage Brain: Talking point with Jay Giedd. http://www.youtube.com/watch?v=2nEBVtPmeCQ.

Guba, E.G., \& Lincoln, Y.S. (1989). Fourth generation evaluation. Newbury Park, CA: Sage.

Hafen, C. A., Allen, J., Gregory, A., Mikami, A. Y., Hamre, B., \& Pianta, R. (2012). The pivotal role of autonomy in secondary school classrooms. Journal of Youth and Adolescence, 41, 245-255.

Hamre, B., \& Pianta, R. (2001). Early teacher-child relationships and the trajectory of children's school outcomes through eighth grade. Child Development, 72(2), 625638 .

Hattie, J., (2009). Visible learning: A synthesis of over 800 meta-analysis relating to achievement. New York: Routledge.

Hayes-Jacobs, H. (1997). Mapping the big picture: Integrating curriculum and assessment K-12. Alexandria, VA: Association for Supervision and Curriculum Development.

Hayes-Jacobs, H., \& Borland, J. H. (1986). The interdisciplinary concept model: Theory and practice. Gifted Child Quarterly, 30, 159-163.

Herrera, C., Sipe, C. L., \& McClanahan, W. S. (2000). Mentoring school-age children: Relationship development in community-based and school-based programs. Philadelphia: Public/Private Ventures. (Published in collaboration with MENTOR/ National Mentoring Partnership, Alexandria, VA).

Jensen, E. (2008). Brain-based learning: The new paradigm of teaching. Thousand Oaks, CA: Corwin Press.

Jensen, E. (2005). Teaching with the brain in mind (2nd ed.). Alexandria, VA: Association for Supervision and Curriculum Development.

Jinks, J., \& Morgan, V. (1996). Students' sense of academic efficacy and achievement in science: A useful new direction for research regarding scientific literacy? Electronic Journal of Science Education, 1(2).

Karcher, M., Kuperminc, G., Portwood, S., Sipe, C., \& Taylor, A. (2006). Mentoring Programs: A framework to inform program development, research, and evaluation. Journal of Community Psychology, 34(6), 709-725. 
Kuperminc, G.P. \& Thomason, J.T. (2013). Group mentoring. In D. L. DuBois \& M J. Karcher (Eds.). Handbook of Youth Mentoring (2nd ed.), pp. 273-290. Thousand Oaks, CA: Sage.

Lawrence, E. \& Levy, M. (2014, January). Designed for Adolescent Girls: Developing Young Women Leaders Through Mentoring. Paper presented at the National Mentoring Summit, Washington, DC.

Lawrence, E., Sovik-Johnston, A., Roberts, K., \& Thorndike, A. (2013). The Young Women Leaders Program Mentor Handbook. Charlottesville, VA: Young Women Leaders Program.

McNiff, J. \& Whitehead, J. (2011). All you need to know about action research. (2nd ed.). Thousand Oaks, CA: Sage.

Marzano, R., Pickering, D., \& Pollock, J. (2001). Classroom instruction that works: Research-based strategies for increasing student achievement. Alexandria, VA: Association for Supervision and Curriculum Development.

Miles, M. B. \& Huberman, A. M. (1994). Qualitative data analysis: an expanded sourcebook $\left(2^{\text {nd }}\right.$ ed.). Thousand Oaks, CA: Sage.

Obama, M. (2011). http://www.whitehouse.gov/the-press-office/2011/03/30/remarksfirst-lady-during-remarkable-women-dc-dinner

Patton, M. Q. (2002). Qualitative research \& evaluation methods ( ${ }^{\text {rd }}$ ed.). Thousand Oaks, CA: Sage.

Pianta, R. (1999). Enhancing relationships between children and teachers. Washington, DC: National Academies Press.

Pianta, R., Hamre, B., Mintz, S., (2012). Classroom Assessment Scoring SystemSecondary (CLASS-S). University of Virginia.

Rhodes, J. E. (2002). Stand by me: The risks and rewards of mentoring today's youth. Cambridge, MA: First Harvard University Press.

Rhodes, J.E. (2005). A model of youth mentoring. In D.L. DuBois \& M.J. Karcher (Eds.), Handbook of youth mentoring (pp. 30-43). Thousand Oaks, CA: Sage.

Ruzek, E., Hafen, C., Allen, J., Gregory, A., Mikami, A. Y., \& Pianta, R. (2014, March). Teacher-student interactions and student motivation and engagement: The mediating roles of autonomy support and peer-relatedness. Paper presented at the meeting of the Society for Research on Adolescents, Austin, TX. 
Schunk, D. H., \& Pajares, F. (2002). The development of academic self-efficacy. In A. Wigfield \& J. Eccles (Eds.). Development of academic motivation (pp. 15-31). San Diego: Academic Press.

Shernoff, D. J., Csikszentmihalyi, M., Schneider, B., \& Shernoff, E. S. (2003). Student engagement in high school classrooms from the perspective of flow theory. School Psychology Quarterly, 18, 158-76.

Sipe, C. (2005). Toward a typology of mentoring. In D. DuBois, \& M. Karcher (Eds.), The SAGE Program on Applied Developmental Science: Handbook of youth mentoring. (pp. 65-81). Thousand Oaks, CA: Sage.

Skinner, E. A., \& Belmont, M. J. (1993). Motivation in the classroom: Reciprocal effects of teacher behavior and student engagement across the school year. Journal of Educational Psychology, 85(4), 571-581.

Smith, E. L., Blakeslee, T. D., \& Anderson, C. W. (1993). Teaching strategies associated with conceptual change learning in science. Journal of Research in Science Teaching, 30(2), pp. 111-126.

Sousa, D., \& Tomlinson, C. (2011). Differentiation and the brain: How neuroscience supports the learner-friendly classroom. Bloomington, IN: Solution Tree Press.

Steinberg, L. (2005). Adolescence ( $7^{\text {th }}$ ed.). Boston: McGraw-Hill.

Sternberg, R. J. (1985). Beyond I.Q.: A triarchic theory of human intelligence. New York: Cambridge University Press.

Sternberg, R. J, Torff, B., \& Grigorenko, E. L. (1998). Teaching triarchically improves school achievement. Journal of Educational Psychology, 90(3), 374-384.

Sternberg, R. J. (2002). Raising the achievement of all students: Teaching for successful intelligence. Educational Psychology Review, 14(4).

Stipek, D. (2002). Motivation to learn: Integrating theory and practice. $\left(4^{\text {th }}\right.$ ed.) Boston: Allyn \& Bacon.

Stipek D. (2006). Relationships matter. Educational leadership, 64(1).

Stiggins, R. (2006). Assessment for learning: A key to motivation and achievement. EDge, 2(2).

Sylwester, R. (2007). The Adolescent brain: Reaching for autonomy. Thousand Oaks, CA: Corwin Press. 
Taba, H. (1962). Curriculum development: theory and practice. New York: Harcourt, Brace, \& World.

Taba, H. (1966). Teaching strategies and cognitive functioning in elementary school children (USOE Cooperative Research Project No. 2404). San Francisco: San Francisco State College.

Tolan P, \& Gorman-Smith D. (2002). What violence prevention research can tell us about developmental psychopathology. Development and Psychopathology, 14, 713729.

Tolan, P., Henry, D., Schoeny, M. \& Bass, A. (2008). Mentoring interventions to affect juvenile delinquency and associated problems. Campbell Systematic Reviews, 16. Available on-line from: http://www.campbellcollaboration.org

Toma, J. D. (2000). How getting close to your subjects makes qualitative data better. Theory into Practice, 39(3), 177-184.

Tomlinson, C. A. (1999). The differentiated classroom: Responding to the needs of all learners. Alexandria, VA: Association for Supervision and Curriculum Development.

Tomlinson, C. A. (2001). How to differentiate instruction in mixed-ability classrooms. Alexandria, VA: Association for Supervision and Curriculum Development.

Tomlinson, C. A., Kaplan, S. N., Renzulli, J. S., Purcell, J., Leppien, J., \& Burns, D. (2002). The parallel curriculum: a design to develop high potential and challenge high-ability learners. Washington, DC: Corwin Press.

Tomlinson, C.A., Brighton, C., Hertberg, H., Callahan, C., Moon, T., Brimijoin, K., Conover, L.A., \& Reynolds, T. (2003). Differentiating instruction in response to student readiness, interest, and learning profile in academically diverse classrooms: A review of literature. Journal for the Education of the Gifted, 27(2/3), 119-145.

Tomlinson. C. A., \& Eidson, C. (2003). Differentiation in practice: A resource guide for differentiating curriculum grades 5-9. Alexandria, VA: Association for Supervision and Curriculum Development.

Tomlinson, C. A., \& McTighe, J. (2006). Integrating differentiated instruction and understanding by design: Connecting content and kids. Alexandria, VA: Association for Supervision and Curriculum Development.

Weinstein, C. (2003). Secondary classroom management: Lessons from research and practice (2nd ed.). Boston: McGraw-Hill. 
Wentzel, K. R. (1993). Social and academic goals at school: Motivation and achievement in early adolescence. Journal of Early Adolescence, 13, 4-20.

Wentzel, K. R. (1997). Student motivation in middle school: The role of perceived caring. Journal of Educational Psychology, 89, 411-419.

Wentzel, K. R. (2003). Motivating students to behave in socially competent ways. Theory Into Practice, 42, 319-326.

Wentzel, K. R. (2005). Peer relationships, motivation, and academic performance at school. In A. Elliot \& C. Dweck (Eds.), Handbook of competence and motivation, (pp. 279-296). New York: Guilford Press.

Wiggins, G., \& McTighe, J. (1998). Understanding by design. Alexandria, VA: Association for Supervision and Curriculum Development.

Wiggins, G., (2012). Seven keys to effective feedback. Educational Leadership, 70(1).

Wigfield, A., Eccles, J. S., \& Rodriguez, D. (1998). The development of children's motivation in school contexts. In. A. Iran-Nejad \& P. D. Pearson (Eds.), Review of research in education (Vol. 23, pp. 73-118). Washington, DC: American Educational Research Association.

Vygotsky, L. (1978). Mind and society: The development of higher mental processes. Cambridge, MA: Harvard University Press. 


\section{APPENDICES}

Appendix A

Young Women Leaders Program Structure

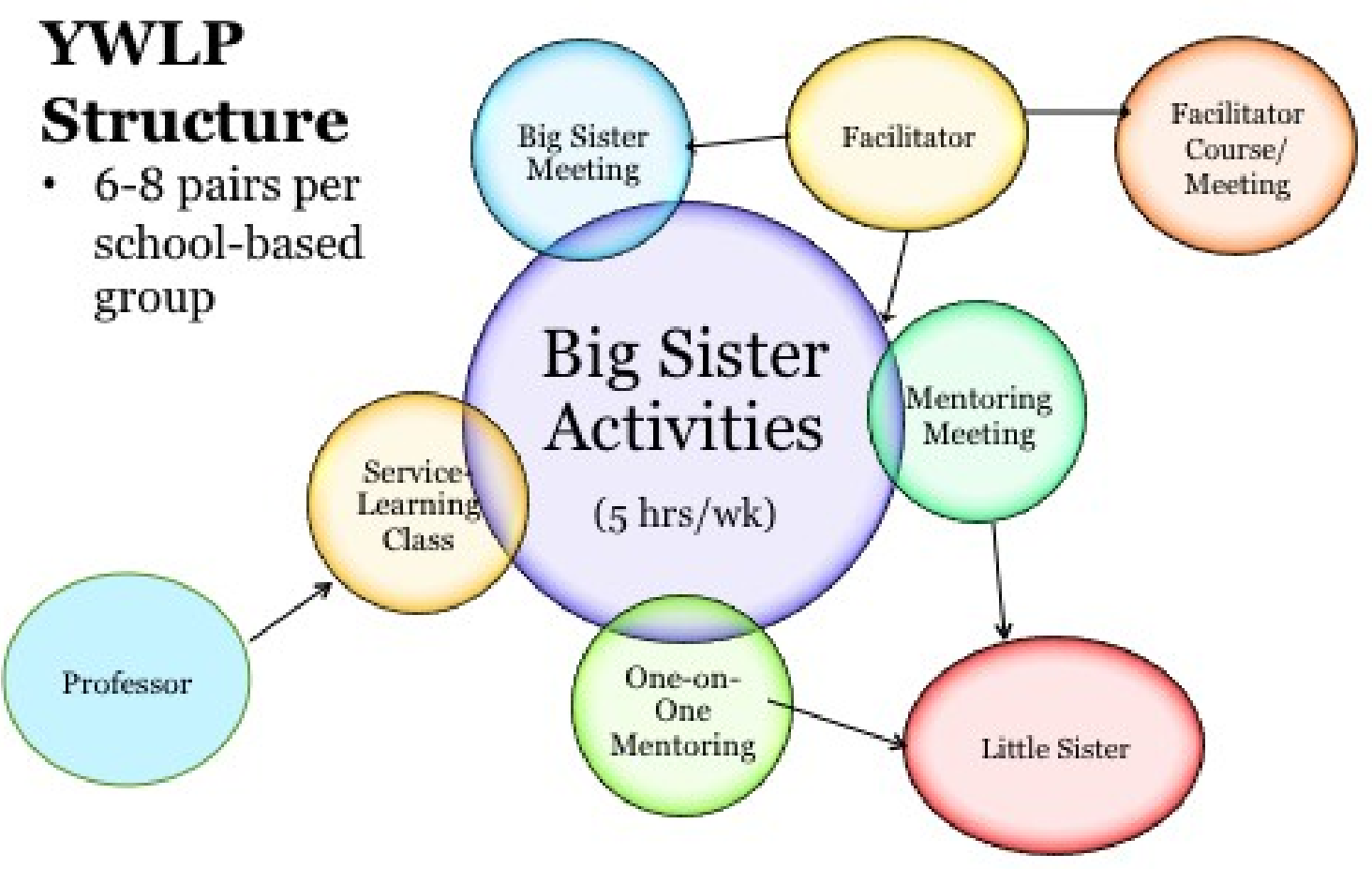

Lawrence, E., \& Levy, M. (January, 2014). Designed for Adolescent Girls: Developing Young Women Leaders Through Mentoring. Paper presented at National Mentoring Summit, Washington, D.C.) 


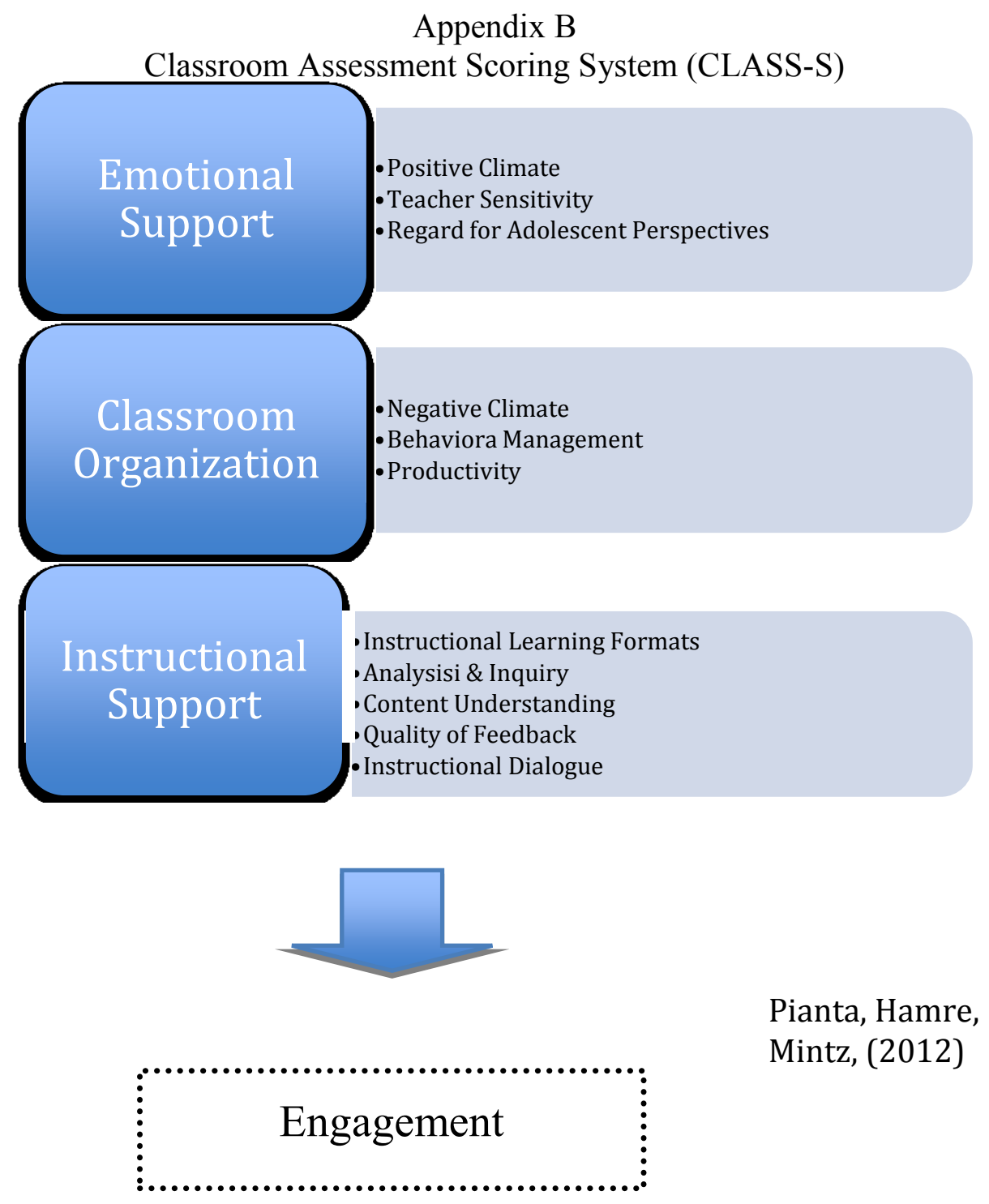


Appendix C

Sample Rubric \& Expectations for Journal Writing Assignment

Service-Learning Class for Mentors and Facilitators: Issues Facing Adolescent Girls

Journal Response Paper Rubric

Journal Response Rubric \# 4: A) Discuss how racial dynamics affect your current YWLP group and/or relationship with your little sister. B) What can you do to address these issues? If you think that race is somehow "absent" from your group, speculate how you might bring these issues into group conversations more overtly.

\begin{tabular}{|c|c|c|c|}
\hline & Novice $=1$ & Average $=2$ & Expert $=3$ \\
\hline $\begin{array}{c}\text { Take away } \\
\text { Messages }\end{array}$ & $\begin{array}{l}\text {-Fails to identify how } \\
\text { racial dynamics affect } \\
\text { her YWLP group. } \\
\text {-Specific details from } \\
\text { reading are not included. }\end{array}$ & $\begin{array}{l}\text {-The ways that racial } \\
\text { dynamics affect her YWLP } \\
\text { group are identified, but only } \\
\text { moderate evidence of } \\
\text { knowledge regarding reading } \\
\text { is evident. } \\
\text {-Some mention of details } \\
\text { from the various readings } \\
\text { and meetings. }\end{array}$ & $\begin{array}{l}\text {-The ways that racial dynamics } \\
\text { affect her YWLP group are } \\
\text { identified and sufficient evidence } \\
\text { of student's engagement with } \\
\text { readings is incorporated } \\
\text { thoughtfully. } \\
\text {-Quotes and specific details from } \\
\text { various readings and group } \\
\text { meetings are included. }\end{array}$ \\
\hline $\begin{array}{l}\text { Understandi } \\
\text { ng (critical } \\
\text { thought) } \\
\text { Regarding } \\
\text { the readings }\end{array}$ & $\begin{array}{l}\text {-Fails to grasp meaning } \\
\text { of readings and the } \\
\text { cultural issues relating to } \\
\text { race. } \\
\text {-Lacks main idea or } \\
\text { suggestions in } \\
\text { addressing these issues. }\end{array}$ & $\begin{array}{l}\text {-Some understanding of } \\
\text { readings and class } \\
\text { discussions, and } \\
\text { demonstrates a recognition } \\
\text { of the important cultural } \\
\text { issues relating to race } \\
\text {-Main idea or suggestions } \\
\text { from readings in helping } \\
\text { your little sister are } \\
\text { identified, but not explained. }\end{array}$ & $\begin{array}{l}\text {-Exceptional understanding of } \\
\text { readings and class discussions, } \\
\text { and demonstrates a masterful } \\
\text { grasp of important cultural issues } \\
\text { relating to race. } \\
\text {-Main idea or suggestions from } \\
\text { the readings in helping your little } \\
\text { sister identified are and } \\
\text { sufficiently explained. }\end{array}$ \\
\hline $\begin{array}{l}\text { Personal } \\
\text { Applicat } \\
\text { ion }\end{array}$ & $\begin{array}{l}\text {-Fails to demonstrate } \\
\text { application of readings } \\
\text { to mentoring little sister. }\end{array}$ & $\begin{array}{l}\text {-Demonstrates surface } \\
\text { application of reading to } \\
\text { mentoring little sister. }\end{array}$ & $\begin{array}{l}\text {-Demonstrates meaningful } \\
\text { application of readings to } \\
\text { mentoring little sister. }\end{array}$ \\
\hline
\end{tabular}




\section{Appendix D \\ Interview Protocol: Pre-Pilot Facilitator Interview}

1. How has your past experiences helped you facilitate a mentoring group?

2. How did you approach your planning for each Mentoring Meeting?

3. How did you determine what (and when it) would fall flat and would work with your group?

4. How did you know what the big idea of each week was?

5. How did you know what was important to keep and what could cut?

6. What support materials would help you run your meetings more smoothly?

7. What else would have helped you successfully execute the curriculum?

8. How can the parallel process be modeled between the facilitator and Big Sister Meetings?

9. How did you know when little sisters understood the content?

10. How could the facilitator meeting be structured better?

11. What are some logistics at the school or within the program that get in the way of running your meetings smoothly?

12. What do you think is important to know about the little sisters in your group?

13. What are some of the norms that you used to set up your mentoring group?

14. What would be a helpful format for this guide?

15. What advice would you offer to a new facilitator to be successful?

16. What do you wish you would have known before you started facilitating a group?

17. Anything else that you think should be included in this guide for facilitators? 
Appendix E

Interview Protocol: Pilot 1 Facilitator Interview

1. How has your past experiences helped you facilitate a mentoring group?

2. How did/do you approach your planning for each Mentoring Meetings?

a. How does planning (as co-facilitators) together help?

b. How does debriefing and reflecting after Mentoring Meetings influence the group?

3. How did you know what the big idea of each week was and how did your big and little sisters know what that was?

4. How did you know what was important and you could cut without sacrificing the main idea for each week?

a. Was this difficult to make this decision in the moment and with a co-facilitator?

5. Specifically what support materials would help you run your Mentoring Meetings more smoothly?

6. How can the parallel process be modeled between the facilitator and Big Sister Meetings?

7. How did you know when the little sisters understood the material from the mentoring curriculum?

a. If you did know this information, what would you do with it?

8. How could the facilitator meeting be structured better to support your use of FIG?

9. In what ways do you need more support in the guide and in the class for how to encourage engagement with big and little sisters?

a. What might that look like?

10. What are some logistics at the school or within the program that make it difficult to run your group meetings smoothly?

11. What do you think is important to know about the little sisters in your group in order to run the activities in the Mentoring Meetings?

12. What are some of the norms that you set up for your mentoring group?

13. What would be a helpful format for this guide?

14. What tips would you give to a new facilitator to be successful?

15. What do you wish you would have known before you started facilitating a group?

16. Is there anything else that you think should be included in this guide for facilitators? 
Appendix F

\section{Young Women Leaders Program}

Facilitators' Implementation Guide

(FIG)

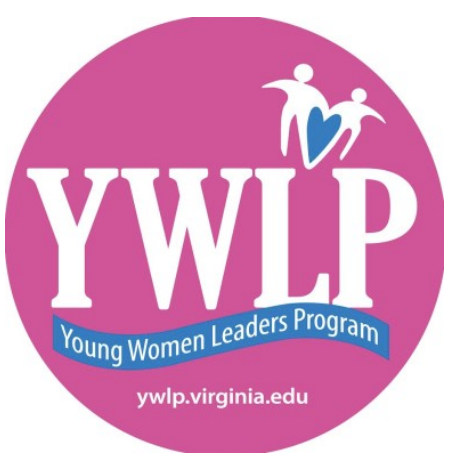




\section{TABLE OF CONTENTS}

Introduction 95

First Semester Topics 98

YWLP Terms 100

WEEK ONE: Getting to Know Each Other. 104

WEEK TWO: Appreciating Others

WEEK THREE: Issues at School

WEEK FOUR: Appreciation Dinner 138

WEEK FIVE: Supporting Our Sisters 147

WEEK SIX: Honoring Differences 161

WEEK SEVEN: Creating a Support Team............................................................ 170

WEEK EIGHT: Keeping Our Cool …………………........................................ 180

WEEK NINE: Valuing Myself: What Gets in the Way? ………………………........ 188

WEEK TEN: How Bright Are My Prospects? ......................................................... 197

WEEK ELEVEN: Getting to Know Each Other Again.................................................. 206

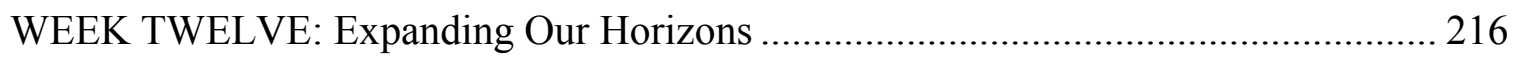

WEEK THIRTEEN: Leading in School and the Community ……………………...... 225

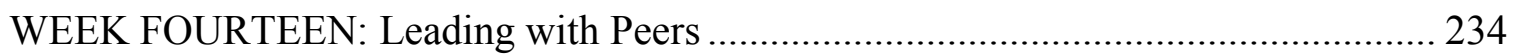




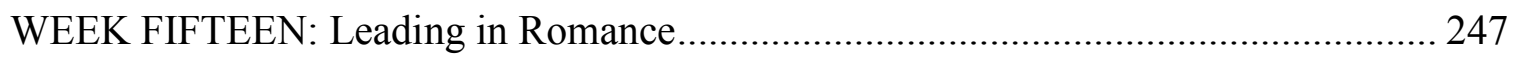

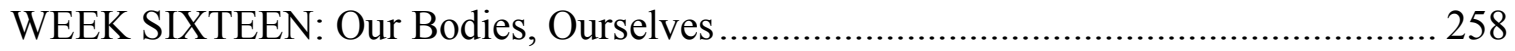

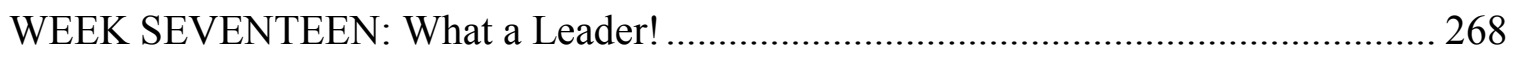

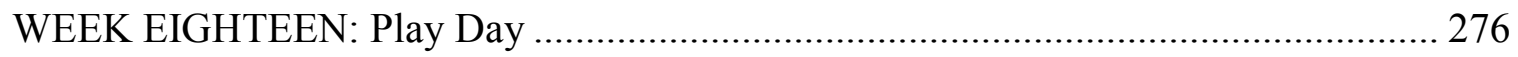

WEEK NINETEEN: Graduation--Leaders Celebrate Success ..................................... 279 


\title{
Young Women Leaders Program
}

\author{
Introduction
}

The purpose of the Facilitators' Implementation Guide (FIG) guide is to provide Young Women Leaders mentoring group facilitators with curricular and other supplemental materials to lead flexibly and thoughtfully, with the goal of bringing out the best in the at-risk, adolescent girls serving as little sisters in their groups. This guide is designed to coincide with the $7^{\text {th }}$ Grade Curriculum Handbook (week-by-week), organizing the content of the Mentoring Meetings and offering suggestions for ways to increase engagement, responsiveness, and relevancy while also prioritizing which content is most important and how to monitor the little sisters' understanding of the key ideas and skills in the curriculum.

When appropriate each week of the $F I G$ will include: 1) an "OVERVIEW" which articulates the desired outcomes, including the conceptual framework for the activities in addition to what the little sisters will know, understand and be able to do as a result of each Mentoring Meetings, 2) "TO DO LISTS" that offer reminders for the Big Sister and Mentoring Meetings, 3) "SUPPLY LISTS" that state the necessary materials for the Big Sister and Mentoring Meetings, 4) "JUSTIFICATIONS," which provide the rationale behind the activities and content; 5) "AGENDAS" which assist in the organization to be sure that the correct information is covered during weekly meetings;

6) "ADAPTATIONS," which are suggestions of strategies that can be used to tailor the existing group activities in the curriculum to make them more engaging and relevant to 
individual groups based on their specific needs and interests; 7) "FLEX OPTIONS," which are choices of alternate activities to introduce, address, or apply concepts and skills in group that are differentiated based on little sisters interests and needs; 8) "PRACTICAL EXTENSIONS," which suggests ways to extend the activities to provide future authentic real world applications; 9) "BIG PICTURES," which provides suggestions of how to connect the concepts; 10) "TIPS," which presents ideas on how to execute the activity based on previous facilitators' experiences; 11) "CURRICULAR COMPANION," which is a section that offers theoretical information and then the practical implications for the implementation for the week's mentoring curriculum. These pieces of information in the FIG articulate and support the existing $7^{\text {th }}$ Grade Curriculum Handbook and are intended to guide and support facilitators and big sisters as they lead their adolescent little sisters toward relational and academic success. 


\section{The FIG Framework}

E ngagement through relevance-

How does this relate to Little Sisters' lives?

M otivation through autonomy

How do Little Sisters have control over their success?

P urpose through clear concepts \& outcomes (KUDS)

What will Little Sisters know, understand and be able to do at the end of each meeting?

O ptimism through believing and expecting success

How can we communicate that we believe in our Little Sisters?

W orth through authentic applications

What authentic, real-world applications do these concepts and skills have for our Little Sisters?

E xcitement through stimulating activities

How can we make YWLP fun?

R esponsiveness through attending to group needs

How can we respond and be sensitive to the academic, social and emotional needs and interests of our little and Big Sisters? 


\section{First Semester Topics}

\section{Week One: Getting to Know Each Other}

After the participants introduce themselves, the group discusses the program's mission and guidelines, as well as issues of commitment and confidentiality. Big and little sisters are then matched and spend time getting to know one another. Leaders connect!

\section{Week Two: Appreciating Others}

This week the group focuses on the importance of appreciating others as a leadership skill. Group members identify women who have been leaders to them and plan ways to honor these women. They also begin to think about what they appreciate about their culture and how they might share that with others through a culture bag, their first leadership project. Leaders appreciate others!

\section{Week Three: Issues at School}

This week the group focuses on increasing pair and group connection by exploring life at school, including talking about things that go well there and where they get stuck. They will look at the skills they already use to solve problems and learn some new ones. They will also practice goal-setting skills as they work on their second leadership project. Leaders solve problems and leaders set goals!

\section{Week Four: Appreciation Dinner}

The group members honor the wonderful women in their lives by preparing and serving them a special meal! Leaders appreciate others!

\section{Week Five: Supporting Our Sisters}

This week the group focuses on the importance of leaders knowing how to ask for help when it is needed and giving help to others when they can. Using goal-setting skills, they will begin to develop and plan their third leadership project, one that focuses on providing service to our local community. Leaders help others!

\section{Week Six: Honoring Differences}

This week the group explores biases toward and stereotyping of others and the impact these assumptions may have on what is "known" about another person. They will also explore what makes a good friend and start to better understand their own strengths/difficulties as a friend. In particular, they will talk about girls gossiping and how to become a Gossip Guard. Leaders respect differences!

\section{Week Seven: Creating a Support Team}

This week the group focuses on the importance of feeling connected to others in our lives by identifying the people who are on our support teams. The group also practices working as a team as they work on their fourth leadership project, designing 
the YWLP t-shirt for this year. Leaders create support teams!

\section{Week Eight: Keeping Our Cool}

The theme of today is the importance of leaders using independent thinking — being autonomous - especially when stressed. The group will focus on common stressors for adolescent girls and strategies for keeping cool in upsetting situations. Leaders keep their cool!

\section{Week Nine: Valuing Myself: Does Anything Interfere?}

This week focuses on images of women, both healthy and unhealthy, in the media. Issues of self-esteem, body image, and cross-cultural awareness are discussed in pairs and in the larger group. Leaders respect themselves!

\section{Week Ten: How Bright Are My Prospects?}

Group members assess what they have learned from each other over the semester, discuss the focus of next semester, and complete their fifth leadership project, the group's Fall Finale presentation. The closing activities make this day special! Leaders celebrate success!

\section{Fall Finale: A Celebration of Young Women Leaders}

All the YWLP groups in the community are invited to celebrate their participation in the program by showcasing what they have learned over the semester. Parents, friends, and school officials are invited to see the show and share in the fun. 


\section{YWLP Terms}

\section{* Little Sister}

The little sisters are the $7^{\text {th }}$ grade girls (mentees) identified as at-risk, but show potential.

\section{* Big Sister}

Big sisters are university students who serve as mentors to adolescent girls.

\section{* Facilitator}

Facilitators are university-affiliated woman who leads Mentoring Meetings.

\section{* YWLP Maxim}

- Competence-

- Connection-

- Autonomy-
"We get things done!"
"We care about each other!"
"We think for ourselves!"

\section{* Confidentiality}

This is critical and foundational to the success of groups. Members can speak freely about the YWLP activities and topics, but all personal information about the other members of the group must not be shared. The group needs to be reminded of this periodically.

\section{* Big Sister Meeting}

Big sisters and facilitators of each group meet weekly. The meeting is lead by the facilitator (often occurs directly before or after university service-learning class) and is designed to provide time and space to discuss important pressing issues as well as the mentoring curriculum.

\section{* Mentoring Meeting}

The weekly Mentoring Meetings held at the school sites. Big and little sisters attend and facilitators lead the implementation of the curriculum with the assistance of the big sisters.

\section{* Play Day}

The YWLP calendar sets time aside for Play Days to provide relaxed time for big and little sisters and their facilitator to participate in fun activities as a group. Play Days are scheduled particularly when the school calendar does not allow for groups to meet consistently in a week and should be scheduled at the very least each week the group does not meet, excluding UVA breaks when university students are away or holidays observed the schools. Plays Days are mandatory. It is the responsibility of the facilitator to initiate the planning of the Play Days, but then the big and little sisters are expected to contribute and assist in the planning. 
- Play Day Ideas: Slumber Parties, cook a dinner together, ice skating, apple picking, hiking, watch a movie, pizza party, stroll on downtown mall, plan a scavenger hunt, attend a play, or a sporting event, etc.

\section{* One-on-One Time}

A significant amount of the bonding between the big and little sisters takes places during their one-on-one time. It is expected that pairs will spend at least 4 hours a month together as a pair doing something they both enjoy. The purpose of one-on-one time is to increase the connection between the pairs. It is the responsibility of the big sister to initiate and gather input from the little sister for the scheduling of the one-onone time.

- Caution: It is not uncommon for little sisters to resist one-on-one time initially and it is expected that big sisters will be persistent in arranging the one-on-one time. For shy big and little sister pairs, it might be helpful to do an activity with another pair to alleviate some of the pressure of being social.

\section{- Leadership Ladder}

The Leadership Ladder is a tool that should be hung on the wall during each of the weekly Mentoring Meetings. It displays the key elements of leadership that will help sisters climb the ladder of success.

\section{* Energizer}

This activity should take place at the beginning of the Mentoring Meetings and should be fast-paced and fun, emphasizing entertainment. It is designed to rejuvenate the little sisters after a long day of school and engage them with the group. The curriculum provides activities for the energizer, but as the facilitators get to know their groups better, they may be better equipped to know what activities would energize their group members.

\section{* Group Check-in}

This activity is designed to provide space for sisters to share what is on their minds. The High/Low Check-in allows sisters to share their thoughts and feelings about what is going on in their personal lives while the Hot Topics provides an opportunity for sisters to share their opinions regarding issues that are important to them. Big and little sisters submit topics about which they care for the Hot Topics. Topics are drawn randomly when the group engages in Hot Topics. If something occurs in the little sisters' lives that is a burning and urgent issue that warrants an immediate discussion (and the little sisters have expressed interest in discussing it) an organic response should take precedence and the group should discuss it. 
- Important reminders: Remind little sisters to not use names when talking about teachers or peers. Also remind big sisters to listen actively and carefully, refraining from any judgment.

\section{* Sister Time}

This is the time reserved within the mentoring group time where the big and little sisters meet as pairs. Sometimes the discussion is dictated and other times it is freestyle. The purpose is to provide weekly time to touch base and connect. Be careful not to steal time away from this activity- it is incredibly valuable.

\section{* YWLP Connects}

This activity should be a ritual that the group decides upon to bring closure to the end of their weekly mentoring group time together.

\section{* Sister-to-Sister}

Time reserved within the mentoring group meetings to connect meaningfully with women across the globe.

\section{* Leadership Project}

A small project that the group accomplishes together that provides an opportunity for the group to practice the leadership skill that they have been developing in YWLP.

\section{* School Legacy Project}

The School Legacy Project is a service learning experience in which the group collaboratively identifies a need at their school and then designs and implements ways to address that need (e.g., planting a tree in the school yard, creating an antibullying campaign, developing a positive self-image mural targeting middle school girls, etc.). The project is intended to "leave their mark" on their school and communicate something important that they have learned from their participation in YWLP.

\section{* Leadership Goal Setting}

These goals are created within the Mentoring Meetings. Big and little sisters check in with one another to keep track of accomplished goals and help with accountability.

\section{* Global Connection Project}

A Global Connections or "sister-to-sister" project is a group service learning experience. It is meant to address a need identified by girls in the local YWLP group's overseas "sister site connection" group. (e.g., collecting books for schools in Cameroon, raising funds for a school scholarship in Cameroon or Mozambique, and raising awareness and funding for medical relief following the Haiti Earthquake). 
The Facilitator Implementation Guide is a curriculum guide designed to provide additional support for the mentoring group facilitators on ways to effectively lead their groups.

\section{* BOOST}

BOOST is a supplemental manual intended to assist big sisters and facilitators support their little sisters in their academic work. It provides advice about Homework Help and tutoring.

\section{* Fall Finale}

Ceremony at the end of the university fall semester to celebrate the groups' connection and display what they have learned through their time together.

\section{* UVA Day}

This is scheduled near the end of the school year and designed to celebrate the year of time together, highlight growth and accomplishments, provide exposure to university life, and offer enrichment by piquing girls interest about potential careers and providing space for fun, positive interactions with other female leaders.

\section{* Certificate of Appreciation}

The Certificate of Appreciation is a way to honor a woman who has been a leader or mentor. Little and big sisters fill them out and YWLP mails them to the chosen women. The little sisters' choices are also invited to the Appreciation Dinner and each little sister stands up and shares with the group how this woman has been a leader for her.

\section{* Appreciation Dinner}

The Appreciation Dinner takes place during the fall and is intended to provide space for little sisters to express their appreciation for a woman (or women) in their lives who have made an impact on them and they would like to honor. The dinner is held (usually after school-during Mentoring Meetings time) at the school site in a space agreed upon by the YWLP School Contact and facilitator. The group works collaboratively as a team to: create the menu, determine how they would like to decorate their space, buy the food and decorations, cook the food, decorate the space, and then clean up and return the space to its original state. YWLP School Contacts, administrators and teachers whose rooms you use weekly are usually invited to the Appreciation Dinner. 


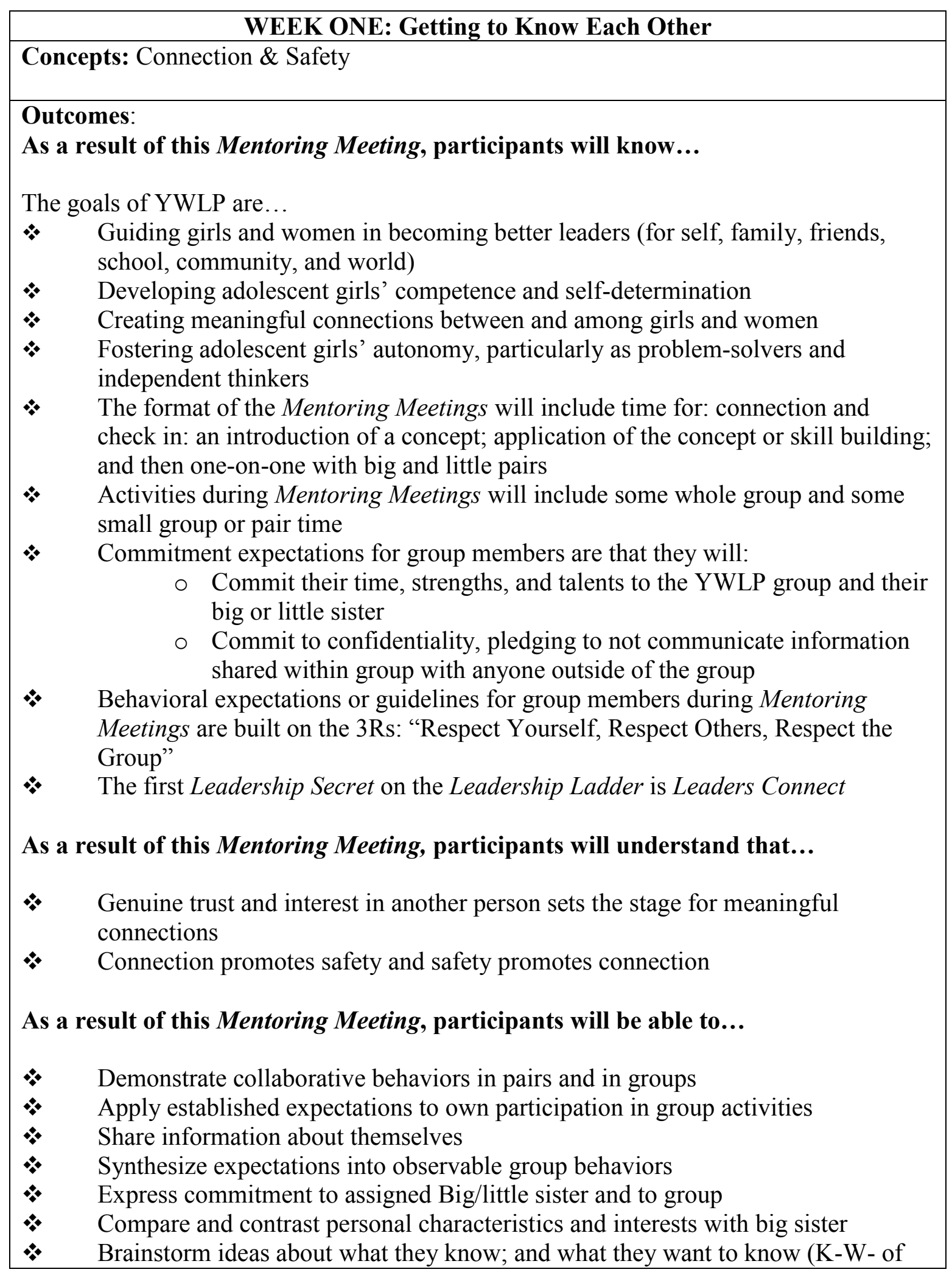




\begin{tabular}{|l}
\hline \multicolumn{1}{|c|}{ K-W-L) } \\
Problem solve about how to gather information from Sister Group
\end{tabular}

\section{SUPPLY LIST: Necessary Supplies for Week One Big Sister Meeting}

$\checkmark$ Index cards for Who's My Big Sister? cards

$\checkmark$ Agenda copied for big sisters (optional)

\section{AGENDA: Big Sister Meeting- Week One}

\section{1) Introductions}

a) Your story

i) Why are you involved with YWLP?

ii) Summary of your involvement

iii) What makes you qualified to lead them in this process?

b) Their stories

i) What inspired your big sisters to get involved with YWLP?

ii) What do they hope to get from the experience?

iii) What expectations do they have for you as the facilitator?

\section{2) Explanation of Big Sister Meetings}

\section{a) Purpose}

i) To provide support for big sisters as they work with adolescent girls

ii) To discuss the outcomes for the week's Mentoring Meeting and collaborate on effective ways to tailor the curriculum to meet the needs of their specific group- keeping in mind all of group members' strengths, limitations, and interests

iii) To determine each big sister's contribution to the week's Mentoring Meeting.

iv) To cultivate big /little relationships

v) To maintain communication between big sisters and YWLP Leadership

b) Schedule

i) Refer to the semester's calendar and clarify dates and times for important events. 
c) Format \& Flow

i) It may be useful to create a brief, skeletal agenda and distribute it to big sisters at the beginning of the meeting. This will help maintain organization and efficiency. Keep in mind that you will most likely have your facilitators' meeting just prior to the Big Sister Meeting so you may have to add information to the agenda, in which case an outline-styled agenda would make most sense.

3) Mission/Goals of YWLP

a) Re-acquaint the big sisters in your group with the goals of the program which are:

i) guiding girls and women in becoming better leaders (for self, family, friends, school, community, and world)

ii) developing adolescent girls' competence and self-determination

iii) creating meaningful connections between and among girls and women

iv) fostering adolescent girls' autonomy, particularly as problem-solvers and independent thinkers

4) Group Guidelines

a) Clarify the function of the facilitator-big sister supportive connection.

i) Facilitators

(1) Facilitators serve as "big sisters" to the big sisters. It is a parallel process.

(2) Illustrate the relationship between the facilitator and the big sisters with an analogy.

(a) Mountain guides who are responsible for leading big sisters along the ups and downs on their journey, providing structure and support.

(b) Pilots who lead the big sisters on an exciting flight that is sometimes turbulent.

ii) Big sisters...

(1) actively participate during the mentoring group meetings.

(2) take initiative in and outside of mentoring group meetings for the betterment of all members.

(3) support their facilitator in leading when necessary.

(4) turn to facilitator for guidance and support.

(5) communicate openly about needs and expectations.

(6) collaborate with facilitator to problem solve.

5) Expectations for Big Sister Meetings

a) Commitment

i) Weekly attendance at mandatory meetings

ii) Physically, emotionally, and mentally present at meetings

iii) Enthusiasm 
iv) Preparedness

b) Confidentiality

i) It is expected that all content discussed in meetings is kept confidential.

ii) Big sisters need to feel safe and trust that what they are discussing at the meetings is not going to be discussed outside of the meeting.

c) Consideration

(1) The 3 Rs-

(a) Respect Yourself (Go slow: Use I-Messages)

(b) Respect Others (Listen to learn: Assume good intentions)

(c) Respect our Group (Sisterhood: Confidentiality)

\section{d) Building a Mentoring Relationships: Mining for What Matters}

Encourage big sisters to step into the little sister's world and search for topics about which little sisters care and want to share

***When interacting with your little sisters, be curious. Ask thoughtful questions and patiently wait for responses. Be sure to avoid drilling your little sister with questions. Explore their responses and listen carefully to what they are saying. It is sometimes just as important to pay attention to what they are not saying (i.e. subtext). It can be challenging to elicit responses that are more than one-word from adolescents, but persist with genuine interest and use their responses to break the ice and as an entry point. Share how you might respond. They will be curious about you.

\section{(1) Daily Life}

(a) Potential questions: What did you do today in school that was interesting? What's going on in your house right now? Do you walk to school take the bus, or does your parent drive you to school? What did you have for lunch? Where's your locker? Do you have classes with friends? How do you stay in touch with friends and family? What do you ordinarily do after school?

(2) Favorite Things

(a) Potential questions: What is your favorite part of the school day other than lunch? Why? What is your favorite music? Why? What is your favorite food? What is your favorite show on television? What is your favorite thing to do when you are not in school?

\section{(3) Family}

(a) Potential questions: Who lives in your house? What is your room like? How many siblings do you have? Do you have relatives who live outside of Charlottesville? If so, where? What are you in charge of at 


\section{home? Do you have any "chores?" \\ (4) YWLP \\ (a) Potential Questions: What do you hope the year will be like with YWLP? Do you have any friends who are in YWLP this year? What have you heard about the program so far that excites you?}

\section{6) Mentoring Group Curriculum}

a) Nuts \& Bolts

i) Provide an overview of YWLP calendar and highlight any major events.

ii) Inform big sisters of the start and end times of the future Big Sister Meetings and the Mentoring Meetings.

iii) Supply directions to the school where the mentoring group meetings will be held. Any logistical information for signing in or parking at the school should be communicated as well.

iv) Stress the purpose and importance of establishing group guidelines and be sure to explicitly convey the message that it is the collaborative responsibility of the big sisters and the facilitator to ensure that the guidelines are followed.

v) Discuss and establish protocol for: room use (setting up and clean up), going to the ladies' room, snack distribution, taking and maintaining attendance, greeting little sisters as they enter, and transportation. Keep in mind that an adult must always accompany little sisters and that big sisters can easily assume some of the abovementioned responsibility.

vi) Provide a summary of the process and purpose of the research being conducted and distribute any research materials, if necessary.

b) Take Away Messages

i) Discuss the outcomes intended for the week's mentoring curriculum. What will little sisters know, understand and be able to do (KUDs) as a result of the Mentoring Meetings?

ii) Emphasize the big understanding(s) or principle(s).

iii) Collaborate on the most effective way to determine whether little sisters: know the information; comprehend the understanding(s); and can perform the skills established in the outcomes (KUDs).

c) Activities

i) Explain that the big sisters are expected to bring their mentoring 7th Grade Curriculum Handbook with them to the meetings and they are required to read the curriculum for the week's mentoring group meeting prior to the big sister meeting.

ii) Outline the flow of the mentoring group meeting. 
iii) Have big sisters prepare the note cards with lists of attributes for the Who's My Big Sister? activity.

iv) Determine if any big sister would like to step up and lead any part of the activities.

v) Assign roles for group members.

\section{TO DO LIST: Key Reminders for Week One Mentoring Meeting}

$\checkmark$ Call parents of each little sister at least one or two days before the program begins to introduce yourself and answer any questions.

$\checkmark$ Be sure that you have permission slips/consent forms submitted for each of the little sisters in your group before you meet.

$\checkmark$ Retrieve your supply box from the Women's Center and elicit help from big sisters to carry materials to the classroom.

$\checkmark$ Call your School Contact and even meet with him/her, if possible. Introduce yourself and establish a line of communication. Support from the YWLP School Contact is invaluable.

$\checkmark \quad$ Locate the room that you will be using for your mentoring group meetings several days before your first meeting and determine what materials are in the room (e.g., chalkboard, dry erase, etc.).

$\checkmark$ Determine the school's protocol with visitors (e.g., sign-in, parking, etc.).

$\checkmark$ Create a sign-up sheet for big and little sisters to write their birthdays.

$\checkmark$ At the beginning of your Mentoring Meetings each week, determine who is in attendance. Determine which little sisters are on your group list, but not in attendance. Send the big sister who is assigned to the missing little sister (or if doable you can) to the office to call the parents to notify them of the absence.

\section{SUPPLY LIST: Necessary Supplies for Week One Mentoring Meeting}

$\checkmark$ Nametags

$\checkmark$ Snacks

$\checkmark$ Who's My Big Sister? cards

$\checkmark$ Chart paper or post-it pad and markers/dry erase marker if you have access to a dry erase board/chalk if you have access to a chalkboard/handouts-- enough copies for each group member

$\checkmark$ M\&Ms or Skittles

$\checkmark$ Blank Venn diagram sheets - enough copies for each pair (Materials section)

$\checkmark$ Confidentiality \& Commitment Contracts - enough for each pair to have two copies

$\checkmark$ Birthday sign-up sheet

$\checkmark$ Leadership Ladder

$\checkmark$ Sister Group Information 
Enthusiasm is infectious! If you relax and sincerely enjoy getting to know the members of your group as individuals, they will most likely reciprocate. This initial Mentoring Meetings is about laying the foundation of trust and connection. Allow time for the members to get to know one another and to laugh. When making plans for how to use the mentoring group time, use the information that you have gathered about the big and little sisters from the inventories and/or various interactions such as: phone conversations, face-to-face exchanges, texts, emails, etc. to tailor your approach to the pre-determined activities in the curriculum to fit your members' interests (e.g., sports, music, reality television, foreign language, etc.). If your approach capitalizes on your group members' strengths and interests, it will hook them into the content and promote engagement.

\section{Celebrate Each Other:}

An essential aspect of any friendship is to take time to celebrate accomplishments (e.g., winning games, achieving high marks on school assignments, etc.) and important milestones (e.g., birthdays, getting jobs, etc.). Group members may hold great variation in their expectations based on their past experiences. It will be helpful if you lead a discussion with your big sisters first and then one including your little sisters that addresses how you will celebrate together. People can be hurt if their expectations are not met and at-risk adolescents are particularly vulnerable to disappointment. Having a discussion about how celebrations will be handled will communicate to group members what they can expect.

***Keep in mind that if you celebrate with cake, ice cream, etc for each individual group member's birthday, it may result in having a celebration each week. This is not ideal for several reasons. First, it will require financial contribution that may be demanding and difficult to sustain. Secondly, repeated festivities will lose their luster and power if they happen too frequently; they become less special.

\section{TIPS: Room Organization}

$>\quad$ You and your big sisters need to arrive at least 10-15 minutes prior to when the mentoring group meeting is scheduled to begin. You need to set up the room by organizing the furniture and materials, in addition, you are encouraged to write the KUDs (in general), the concept, and the flow of the meeting (agenda) on the board or chart paper.

You and your big sisters need to decide if you would like to sit at desks/tables, sit 
on the floor, etc. Regardless, you will most likely need to rearrange the furniture. (Keep in mind that you will need to put the room exactly as you found it once the meeting has ended.) To maximize the use of your time, organize all of the necessary supplies for the meeting's activities and have them ready for use.

It may be a good idea to ask a couple of big sisters to be in charge of materials and snacks.

Your classroom may have supplies and a dry erase board in it, but do not rely on the school to have anything. Also, any copying should be done at the Women's Center, not at the school.

\section{TIPS: YWLP Introduction}

$>\quad$ Once it is time to start the mentoring group meeting, gather everyone in a circle and begin by first welcoming them and introducing yourself. Sit within the circle and make room for everyone to be in the circle to the same degree.

$>\quad$ You may want to use some sort of stuffed animal or object (e.g., ball, rock, YWLP key chain) to serve as a mascot and "microphone" to signify who has the floor to speak and who should be quietly listening. This then will be passed to the various speakers.

$>\quad$ Be sure that everyone is either sitting or standing and that everyone is on the same level (i.e., Do not allow some students to sit on desks, while others sit at desks and still others on the floor. This creates an unspoken hierarchy.)

\section{FLEX OPTIONS: YWLP Introduction}

\section{*Who's My Big/Little Sister?}

Choose One:

- Hand out the Who's My Big Sister? cards and have everyone in the group stand up. Little sisters ask the big sisters questions until each can find her new big sister.

- Play a matching game with questions and answers and have sisters mingle to find the correct match or their "other half."

- Invent your own way to introduce the big/little pairs that is engaging and gets them moving around the room.

\section{* Energizer:}

* M\&M Game: Call the group back into the circle, big and little pairs should sit next to each other, and pass around a bag of M\&Ms. Encourage each person to take as many as she wants, but to leave enough for everyone to have some. After everyone has taken several, let them know that for each one they took they must 
tell the group one fact about themselves.

- ADAPTATION: If you sense that your group will have a hard time with this, assign categories (for example red $=$ a school fact or yellow $=$ a family fact).

- ADAPTATION: If you have big or little sisters who have chocolate allergies, you could use Skittles instead of M\&Ms.

Two Truths \& a Lie: Call the group back into the circle; big and little pairs should sit next to one another. Give everyone an index card and ask them to write two truths and a lie. Then collect all of the cards and as the facilitator you read them aloud and have the other group members try about guess you it might be based on first impressions.

- ADAPTATION: If the group members seem comfortable, you may redistribute the cards randomly and have people read them.

\section{TIPS: YWLP Group Guidelines}

$>\quad$ Discuss with your big sisters at the Big Sister Meeting about who should come to the Mentoring Meetings with ideas of potential group guidelines and expectations.

$>\quad$ It is your job as the facilitator to do just that, facilitate the discussion. Try to lead the group to address the important guidelines that would make an effective and safe group, but allow your group members to come up with it as much as possible. Big sisters can be "plants" and offer leading suggestions.

Use the "3Rs" as a starting place, but be specific and even role-play a concept if you think the group would enjoy that. Have big sisters prepared to possibly act out examples and non-examples of behaviors that abide by the guidelines.

$>\quad$ Write the guidelines on large paper that can be displayed at the weekly Mentoring Meetings as a reminder. When participants are not honoring the guidelines set by the group, you can direct their attention to this poster.

\section{JUSTIFICATION:}

Establishing the group guidelines, as a group, is critical because it encourages the participants to feel ownership of the group. It cultivates autonomy and provides a venue for the girls and women to exercise their voices. It also determines 
expectations and begins to create group norms based on what your particular group members think is important.

\section{TIPS: Confidentiality and Commitment Contract}

$>\quad$ Discuss the contract and confidentiality as a group and answer any questions that may arise. Present the need for confidentiality in a serious manner because it is of vital importance for group members to feel safe when sharing their thoughts and emotions. Stress our need for their commitment to YWLP and how they were identified as an emerging leader, specifically chosen to be a part of the program.

$>\quad$ Ask the pairs to verbally commit to meeting regularly for the year. Discuss any possible conflicts such as: orchestra, babysitting, basketball, dance class, tutoring etc. and how they may circumvent those potential conflicts.

Define "confidentiality" for the group. "Confidentiality" means you can talk about the YWLP activities and topics but not personal information about the other members of the group. Give examples and stress the importance of this as it offers a safe place for participants.

Explicitly explain the limits of confidentiality: "The one exception to our group confidentiality is that if I learn that one of you is either in danger or a danger to someone else, it's my job to make sure you are safe. If I feel afraid for you, I'll talk to you and help you talk to someone who could help with the situation."

\section{TIPS: Leadership Secret - Leaders Connect}

$>\quad$ Introduce the Leadership Secret: Leaders Connect. Explicitly point out the main concept of the meeting and principles/understandings of: 1) Genuine trust and interest in another person sets the stage for meaningful connection; 2) Connection promotes safety and safety promotes connection.

$>\quad$ Use the image of a ladder as an analogy of climbing toward success and how building connections is the foundation for the rest of the year. Hang the ladder up in the room each week and take it down at the end of each Mentoring Meetings.

\section{TIPS: Sister Time}

Comfort Zone: Pairs need to find a spot in the room where they can have some 


\begin{tabular}{|c|c|}
\hline & $\begin{array}{l}\text { degree of privacy. If the weather permits, encourage pairs to go outside and } \\
\text { provide a firm time for them to return. Since you are taking their pictures, } \\
\text { encourage them to stay nearby. }\end{array}$ \\
\hline$>$ & $\begin{array}{l}\text { Circulate with the Birthday Sign-Up Sheet: While big and little sisters are } \\
\text { meeting in their pairs and getting to know one another, walk around the room } \\
\text { with the Birthday sign-up sheet. The initial conversation between the big and little } \\
\text { sisters can be awkward for some pairs, particularly if they are shy. Walking } \\
\text { around with the Birthday sign-up sheet will provide a natural purpose for your } \\
\text { circulating and also allow you to comfortably intervene if necessary. }\end{array}$ \\
\hline$>$ & $\begin{array}{l}\text { Revive Dying Conversations: While the big and little sister pairs are completing } \\
\text { the Interest Venn diagrams, walk around the room and observe the pairs. If pairs } \\
\text { seem to be having an awkward time or if they are particularly quiet, approach } \\
\text { them and try to revive their conversation. Use information that you know about } \\
\text { them or just infuse enthusiasm into their exchange. Encourage pairs to examine } \\
\text { their similarities or differences on the Venn diagram and hypothesize why they } \\
\text { are paired together. }\end{array}$ \\
\hline & $\begin{array}{l}\text { FICATION: } \\
\text { Sister Time is critical in developing a connection between the big and little sisters } \\
\text { so do not cut back on the allotted time for the pairs. It is helpful if you provide } \\
\text { structure while also allowing flexibility so that they can connect with each other. } \\
\text { In the final interviews, little sisters often acknowledge that Sister Time is their } \\
\text { favorite part of the mentoring group meetings where they feel the safest and most } \\
\text { connected. }\end{array}$ \\
\hline & Sister-to-Sister Segment \\
\hline$>$ & $\begin{array}{l}\text { Goal: Once you are back in the circle, share YWLP's goal of supporting } \\
\text { leadership in girls and women, not only in this group, but also around the globe. It } \\
\text { would be helpful to take time to tell the sisters where the other YWLP sites are } \\
\text { and to use a map or globe to show where to other YWLP groups are as well as } \\
\text { their Sister Group introduced in the next section. This is not provided- but } \\
\text { perhaps you could get a picture on-line or use the school's globe. The library } \\
\text { usually has one. }\end{array}$ \\
\hline$>$ & $\begin{array}{l}\text { Introductions: Introduce your Sister Group for the year. Share something about } \\
\text { your Sister Group (pictures, slide show, etc). When leading the group in } \\
\text { brainstorming what they would like to know about these girls and women, it }\end{array}$ \\
\hline
\end{tabular}


would be helpful for them to also consider how they can go about gathering this information. Using a K-W-L (WHAT YOU KNOW, WHAT YOU WANT TO KNOW, and WHAT YOU HAVE LEARNED) format will allow girls to harness their prior knowledge about your Sister Group's country in addition to allowing you to address any obvious misconceptions that they may have regarding the country or people from that country. Only the K and W sections will be completed at this point. You would save this sheet and add to it as the group learns more information about their Sister Group. Hanging it in the room so that everyone can contribute and see it would add to the sense of group. If you so choose, you can use the K-W-L sheet (attached) in individual handouts or write on a large piece of paper, dry erase board, etc.

\section{MEASURING STICK: Assessing Growth}

Assessing for understanding is not explicitly written into the mentoring curriculum, but it is necessary to determine where sisters are in their thinking in order to set goals for growth.

\section{- Self-reflection}

- How will you assess your effectiveness as a facilitator and measure your growth from meeting to meeting?

- How will you determine whether you met your established outcomes (KUDs) for this mentoring group meeting?

- What did you do this week during the meeting or outside of the meeting to nurture the little or big sisters' potential?

- Do the Little Sisters in your group know the information presented?

- Goals of YWLP

- The format of the Mentoring Meetings

- The commitment expectations for group members

- Behavioral expectations or guidelines for group members during Mentoring Meetings are built on the 3Rs: "Respect Yourself, Respect Others, Respect the Group."

- The first Leadership Secret on the Leadership Ladder is Leaders Connect

- Do the Little Sisters in your group understand the big ideas or principles shaping the Mentoring Meeting?

- Genuine trust and interest in another person sets the stage for meaningful connections.

○ Connection promotes safety and safety promotes connection. 
- Are the Little Sisters able to apply facts and principles in meaningful ways? Can they...

- Demonstrate collaborative behaviors in pairs and in groups

- Apply established expectations to own participation in group activities

- Share information about themselves

- Synthesize expectations into observable group behaviors

- Express commitment to assigned big/little sister and to group

- Compare and contrast personal characteristics/interests with assigned big sister

- Brainstorm ideas about what they know; and what they want to know (K\&WTK)

- Problem solve about how to gather information from Sister Group

\section{JUSTIFICATION:}

It is important to assess whether you effectively communicated the facts and principles undergirding the Mentoring Meeting's activities. It is equally important to determine on an individual basis whether little sisters gained this understandings and knowledge. Having this data provides information for you as the facilitator to know what you may need to touch on again in future meetings; what misconceptions you may have to address; how you can extend individual little sister's thinking; and finally, how you can push the thinking of the group as a whole.

\section{FLEX OPTIONS: YWLP Connects- Closing Ritual}

\section{Choose One:}

* Stand in a circle alternating big and little sisters. One person starts by hooking pinkies with both of the people next to her, saying the Leadership Secret. Those people hook pinkies with the people next to them, also saying the Leadership Secret. Pass the pinkie hook down the line until everyone gets connected.

* Have everyone stand in a circle. Have one sister put her hand in the middle and then ripple around the circle, piling hands on top of each other, saying the meeting's Leadership Secret (or some variation of it) as hands are placed on the pile.

* Create a different way to get the sisters to physically connect and to restate or say the Leadership Secret.

\section{JUSTIFICATION:}

Next week the group will decide how they would like to provide closure for the meetings each week. It is a good idea to do something fun and maybe even a little quirky that officially ends the meeting. Maintaining an official ending to the mentoring group meeting will encourage people to stay until the final ritual and discourage people from trickling out of the gathering and disturbing the flow and dynamic of the group. 


\section{PRACTICAL EXTENSION: Relating the Activities to Real Life}

* This mentoring group meeting is focused on the concepts of connection and safety. To extend these ideas to real life, provide time for the sisters to share how they would most prefer to communicate with the fellow members of the group. Talk about their access, responsiveness, and comfort levels with various modes of communication.

- "What's cool, what's creepy?" Be sure that each little and big sister has the chance to voice what they are fine with and what would make them feel uncomfortable in terms of communicating and connecting with one another. This should be an informal discussion and may even happen at the end after people are feeling more comfortable with one another.

- Make a contact list for your group with each member's preferred mode of communication. In the next week type it up and either email it or copy it for each participant.

\section{JUSTIFICATION:}

This allows sisters to voice their expectations and create some boundaries and also connect the sisters in the group, establishing an expectation that group members will communicate throughout the week. 


\section{WEEK TWO: Appreciating Others}

\section{Outcomes:}

As a result of this Mentoring Meeting, participants will know...

- $\quad$ Fellow group members' names

- $\quad H i g h / L o w s$ activity is an opening ritual that provides structure for checking in with people to find how people are doing

- $\quad$ Details about their sister

As a result of this Mentoring Meeting, participants will understand that...

- $\quad$ Expressing appreciation toward another person can be a powerful leadership strategy that promotes connection

- $\quad$ Providing affirmation and recognition of others create connections between people and encourages desired behaviors

As a result of this Mentoring Meeting, participants will be able to...

- $\quad$ Recognize and express appreciation for another sister in the group who displays qualities of a leader

- $\quad$ Reflect on women who have made a difference in their lives

- Demonstrate collaborative behaviors in pairs and in groups

- $\quad$ Apply established expectations to own participation in group activities

- Discuss the relationship between the concepts of appreciation to the idea of connecting with others

- $\quad$ Compare and contrast appreciated qualities

- $\quad$ Problem solve about how to gather information from Sister Group

\section{TO DO LIST: Key Reminders For Week Two Big Sister Meeting}

$\checkmark$ This is a critical time to create the norms and culture of your group. Take time to publically and privately commend big sister's who display leadership or participate actively.

$\checkmark$ Directly AFTER the Big Sister Meeting, text or email any big sisters who displayed any desired behaviors that promoted engagement. Thanking them individually will encourage them to continue those behaviors.

$\checkmark$ Duplicate the phone/email list of all of the big sisters so that you can distribute it at the meeting to determine accuracy. 
Appreciation Dinner invitations and envelopes (approx. 3 per little sister)

$\checkmark$ Agenda copied for big sisters (optional)

AGENDA: Big Sister Meeting-Week Two

1) Building Big Sister Connections

a. High/Lows (individual \& pair check-in)

b. Announcements

c. Reports from group leadership roles/jobs (e.g., photographer, attendance, Sisterto-Sister, etc.)

d. Determine which big and little sisters have birthdays this week. Talk as a group about how you would like to celebrate birthdays throughout the year. It is important to celebrate with equal enthusiasm. Some groups may want to acknowledge or celebrate monthly to avoid overkill with celebration.

\section{2) Reflection}

a. In small groups, pairs, or as a whole group reflect on the successes and challenges of the Mentoring Meeting from the prior week.

$i$. What would you change?

ii. What did you (as a team) do well?

iii. What interesting thing happened?

$i v$. Who stood out as a leader? (big and little sisters)

\section{3) Building Mentoring Relationships}

a. Reinforce positive behaviors in little sisters (or provide other information from the facilitator class)

b. Express genuine appreciation for each other and discuss the contributions from little sisters that were appreciated

c. Determine to whom big sisters will give their Certificates of Appreciation and why?

\section{4) Mentoring Group Curriculum}

a. Nuts \& Bolts

i. Problem solve about room, parking, transportation, communication, etc.

ii. Problem solve potential little sisters' responses to curriculum

iii. Research component- survey completion

\section{b. Take Away Messages}

i. Conduct an open conversation about the take away messages.

* Expressing appreciation toward another person can be a powerful leadership strategy that promotes connection. 
* Providing affirmation and recognition of others create connections between people and encourages desired behaviors.

\section{5) Appreciation for Big Sisters}

a. Who displayed noteworthy leadership this past week?

\section{TO DO LIST: Key Reminders for Week Two Mentoring Meeting}

$\checkmark$ Call parents of little sisters who you were unable to talk with last week.

$\checkmark$ Decide where you are going to store your supply box. Some facilitators just keep it in their car.

$\checkmark$ Establish contact with your YWLP School Contact if you were unable to before.

$\checkmark$ Check in with the office to be sure that they make an after-school announcement. It may be a good idea to write up an announcement and have them read it in the mornings as well. Each school is different with their protocol. Just contact the school office personnel and they should be able to provide proper guidance.

$\checkmark$ Your room may be locked, so arrive early enough to find a custodian to let you into your room, if necessary.

$\checkmark$ At the beginning of your meeting each week, determine who is in attendance. Determine which little sisters are on your list, but not in attendance. Send the big sister who is assigned to the missing little sister (or if doable, you can) to the office to call the parents to notify them of the absence.

\section{SUPPLY LIST: Necessary Supplies for Week Two Mentoring Meeting}

$\checkmark$ Nametags

$\checkmark$ Snacks

$\checkmark$ Ball of yarn

$\checkmark$ Mascot or item to serve as microphone to indicate who has the floor to speak.

$\checkmark$ Hot Topic box

$\checkmark$ Hot Topic paper slips

$\checkmark$ Writing utensils (pens, or pencils, and markers)

$\checkmark$ Leadership Ladder

$\checkmark$ Signs made for group

$\checkmark$ Certificates of Appreciation (3 per group member)

$\checkmark$ Chart paper and markers/dry erase markers

$\checkmark$ Same and Different categories

$\checkmark$ Invitations \& envelopes for Appreciation Dinner invitations (about 3 per little sister)

$\checkmark$ Sister Group information 


\begin{tabular}{l} 
CURRICULAR COMPANION \\
Supplemental Ideas for Implementing Mentoring Group Curriculum \\
-Creating a Positive Atmosphere that Nurturing Connections Through \\
Appreciation \\
\hline $\begin{array}{l}\text { Last week, you initiated the process of creating a safe and positive climate that sets the } \\
\text { stage for meaningful connections between the members of your group. This task calls for } \\
\text { on-going consideration. Refer to Week One's section Setting the Stage for Connections } \\
\text { for guidance on what practices you and your big sisters can carry out to continue } \\
\text { cultivating connections in your group. The information below also provides some } \\
\text { suggestions for how to nurture connections through the lens of this week's concept, } \\
\text { appreciation. Your group members are still getting to know one another, but expressing } \\
\text { appreciation for others early on will set a tone that celebrates one another and draws your } \\
\text { group members closer together. } \\
\text { Shape Purpose } \\
\text { What do I bring to the table? Help your big sisters discover their strengths, which will } \\
\text { model how they can assist their little sisters in the discovery of their innate strengths. } \\
\text { Everyone wants to feel as though they "bring something to the table." Reflect } \\
\text { thoughtfully about what each of your members has to offer and then create opportunities } \\
\text { for them to either inductively or deductively discover those strengths and talents. Once } \\
\text { they have determined "what they bring to the table" they can begin to develop those } \\
\text { strengths, establish an identity in the group, and finally they can then contribute to the } \\
\text { group in positive ways. } \\
\text { Hunt for Affirmation } \\
\text { People have an inherent need for affirmation and acceptance; your sisters are certainly no } \\
\text { exception. Big and little sisters alike desire affirmation and this can initially come from } \\
\text { you, but modeling the practice of offering affirmation for fellow sisters and then } \\
\text { transferring this power on to other group members will empower the group and cultivate } \\
\text { connection. }\end{array}$ \\
\hline
\end{tabular}




\section{Value Each Sister's Contribution}

Just as a symphony that is made up of wide variety of instruments, so is your group. The cymbals are just as important to the final product of the musical piece as the bassoon. Each instrument adds to the overall beauty of the musical piece. This is true of each of your group members. Though some sisters may be more vocal than others, it is necessary to communicate to all of them that each person has a valuable contribution to the group. Honor each sister's strengths and nurture the development of those strengths.

\section{Celebrate Sparkling Moments}

Small celebrations are what make life fun! Take time to celebrate one another's successes inside and outside of the group. Honoring efforts that take place within the group can be formal or informal; regardless it can be a powerful practice because it provides recognition and support for sisters' successes outside of group and reinforces desired behaviors within the group context.

\section{Seal it with Sincerity}

When expressing appreciation for one another, emphasize the importance of being genuine; otherwise the expression will become hollow. This may require some thoughtful preparation on your part as you search for meaningful praise and appreciation for each sister.

\section{FLEX OPTIONS: Energizer}

\section{Choose One:}

* Community Web: With everyone standing in a circle, hold the end of a ball of yarn and toss it to someone in the circle while saying your name. This person holds a section of the yarn and then tosses the ball to someone else while saying her own name. If there's time, do it again with the "tosser" saying the name of the sister she throws it to.

* High-Speed Name Ball: With everyone standing in a circle, each girl says her 
name. Then, as the facilitator, throw the ball to any sister and say her name. Tell her to do the same to someone else. Do this until everyone has received the ball. To avoid pressure, it can be done slowly and people can shout out and help one another with the names at first. Repeat this process, by throwing it to the same person as last time. Feel free to go slowly and repeat the circle a couple of times-until it seems as though people are generally comfortable with names. Then try to go faster and use a timer. You can have the researcher present at your group do the timing or take yourself out of the group and do the timing. Ideally, you would participate in this activity if possible. This can be repeated at the beginning of the Mentoring Meeting for several weeks to see if the group can get faster and more accurate. It also helps with names. It is a way of helping with group bonding.

* Name Game: Move the Body, Move the Brain: Ask sisters to stand in a circle and introduce themselves again. When they introduce themselves they need to say: "My name is .... and I like to..... A gesture needs to accompany that description. Then the next person says her own introduction and then repeats the sister before her, including the gesture. (Because different parts of the brain are being activated, gestures help people remember names.) This repeats around the circle. Since this is only the second meeting, people should jump in "save" one another if it seems like sisters are drawing a blank on names. We do NOT want anyone to feel uncomfortable.

* Invent: Create your own way of getting group members up and moving around while working on memorizing one another's names.

\section{JUSTIFICATION:}

The purpose of this activity is to get people moving around and working on name recognition. This should be a fun activity and if you sense that it is stressful for some group members, then be sure to step in and offer assistance. Communicate this to your big sisters as well. Adding the element of timing the activity may or may not be an appropriate strategy for your group at this point. You will have to know your group members and read their body language as you are doing the activity. Timing can be an effective element to add as the year progresses as it can be extremely motivating.

\section{TIPS: High/Lows}

$>\quad$ Time Boundaries: Establish the expectation that everyone is sharing one high and one low (no more, no less) and if necessary set a timer for each response to keep the activity moving. If not careful, high/ lows can exceed the allocated time. Having the mascot or "microphone" object can be helpful in this case. 
Time Well-Spent: The high/low activity is valuable and creates connections between group members by providing information helpful in understanding one another. There is a tendency to eliminate this activity or reduce the time spent on this activity. Only you will know whether that is a good idea as the year progresses, but certainly at this point when the group is getting acquainted, it is important to take the time to share personal thoughts, emotions, and details.

\section{JUSTIFICATION:}

It is important to provide time for big and little sisters to share what they are feeling and thinking. Knowing this information can:

1) Alert big sisters and you to what support is necessary to provide;

2) Provide insight related to demonstrated behaviors;

3) Offer reasons to celebrate;

4) Provide insight to personal information that can be useful in developing relationships

5) Provide information that can be used to tailor the curriculum. As a facilitator, make a mental note of details shared during this time and keep a log so that you can refer to this information. Depending on your memory abilities, you may want to start a notebook or keep index cards to organize the information you gather from the sisters in your group. It would not be a good idea to take notes during the meeting, but you can write down the information directly after the meeting.

\section{TIPS: Sister Time}

$>\quad$ Supporting the Pairs: Since the goal of this activity is to provide a structured way for big and little sister pairs to relate to each other and find out how they are alike and different, it is important to...

Allow sufficient time for Sister Time discussion and to not rush group members through this activity

Circulate around the room to jump in and "save" pairs that are not generating ideas or are too shy to share

Provide privacy for pairs so that they can intimately share information about themselves that they may not include when they share with the rest of the group.

\section{TIPS: Leadership Secret- Leaders Appreciate Others}

Do As I Do: Sometimes giving and receiving praise can be difficult for women. Set the tone in your group from an early stage that public and private recognition of others' contributions should be a common practice. Once others see you modeling it, they will begin to, not only, display the desired behaviors, but also they will begin to look for ways to positively reinforce others. The practice of giving and receiving acknowledgement can be quite empowering and can create powerful connections with the sisters in the group. 


\begin{tabular}{|c|c|}
\hline$>$ & $\begin{array}{l}\text { Identify Specific Traits: Present the notion of appreciating others as a common } \\
\text { practice for leaders. Present it as looking for qualities in girls and women that you } \\
\text { admire. Having discussions about the specific actions or qualities will personalize } \\
\text { the effort and provide the sisters with the time to reflect on why they appreciate the } \\
\text { person. }\end{array}$ \\
\hline$>$ & $\begin{array}{l}\text { Let's Do This Together: Everyone should create Certificates of Appreciation--- } \\
\text { even you! It is critical to the success of the activity that the little sisters see their } \\
\text { big sisters going through the reflective process and taking time to appreciate }\end{array}$ \\
\hline \multicolumn{2}{|c|}{ TIPS: Sister-to-Sister Segment } \\
\hline$>$ & $\begin{array}{l}\text { Make it Real: Thinking about girls and women who may live in areas that the big } \\
\text { and little sister may have never visited is asking them to think abstractly and may } \\
\text { be an obstacle for meaningful connection or engagement. Provide a map that you } \\
\text { can revisit and tangible items from the materials that they are sending will help } \\
\text { make it more concrete. Any visuals or tangible objects that can represent the } \\
\text { women or girls in your Sister Group will facilitate in making the abstract concept } \\
\text { of the Sister Group more concrete. Watch the news or perhaps some stories } \\
\text { related to the place where your Sister Group lives could also add to the } \\
\text { experience. }\end{array}$ \\
\hline$>$ & $\begin{array}{l}\text { How Does This Relate to Me? The purpose of having a Sister Group is to } \\
\text { provide an opportunity for the sisters in your group to connect with girls and } \\
\text { women who are different from them. This reinforces the concept of connection, } \\
\text { but also the concepts of appreciation or understanding through efforts to extend } \\
\text { and challenge your group's thinking about girls and women in other contexts. } \\
\text { This idea is wonderful, but big and little sisters will not gain as much from the } \\
\text { experience if they do not see how it affects them. It is important to always relate } \\
\text { everything you talk about with regard to your Sister Group back to the sisters in } \\
\text { your group. In order for this activity to be relevant and meaningful to the little } \\
\text { sisters, you, as the facilitator, must make explicit connections between the sisters } \\
\text { in your group and your Sister Group. }\end{array}$ \\
\hline \multicolumn{2}{|r|}{ MEASURING STICK: Assessing Growth } \\
\hline \multirow[t]{3}{*}{$*$} & Self-reflection \\
\hline & $\begin{array}{l}\text { - How will you assess your effectiveness as a facilitator and measure your } \\
\text { growth from meeting to meeting? }\end{array}$ \\
\hline & $\begin{array}{l}\text { - How will you determine whether you met your established outcomes for } \\
\text { this Mentoring Meeting? }\end{array}$ \\
\hline \multirow[t]{3}{*}{$*$} & Do the Little Sisters in your group know the information presented? \\
\hline & - $\quad$ Fellow group members' names \\
\hline & - $\quad H i g h / L o w s$ activity is an opening ritual that provides structure for \\
\hline
\end{tabular}




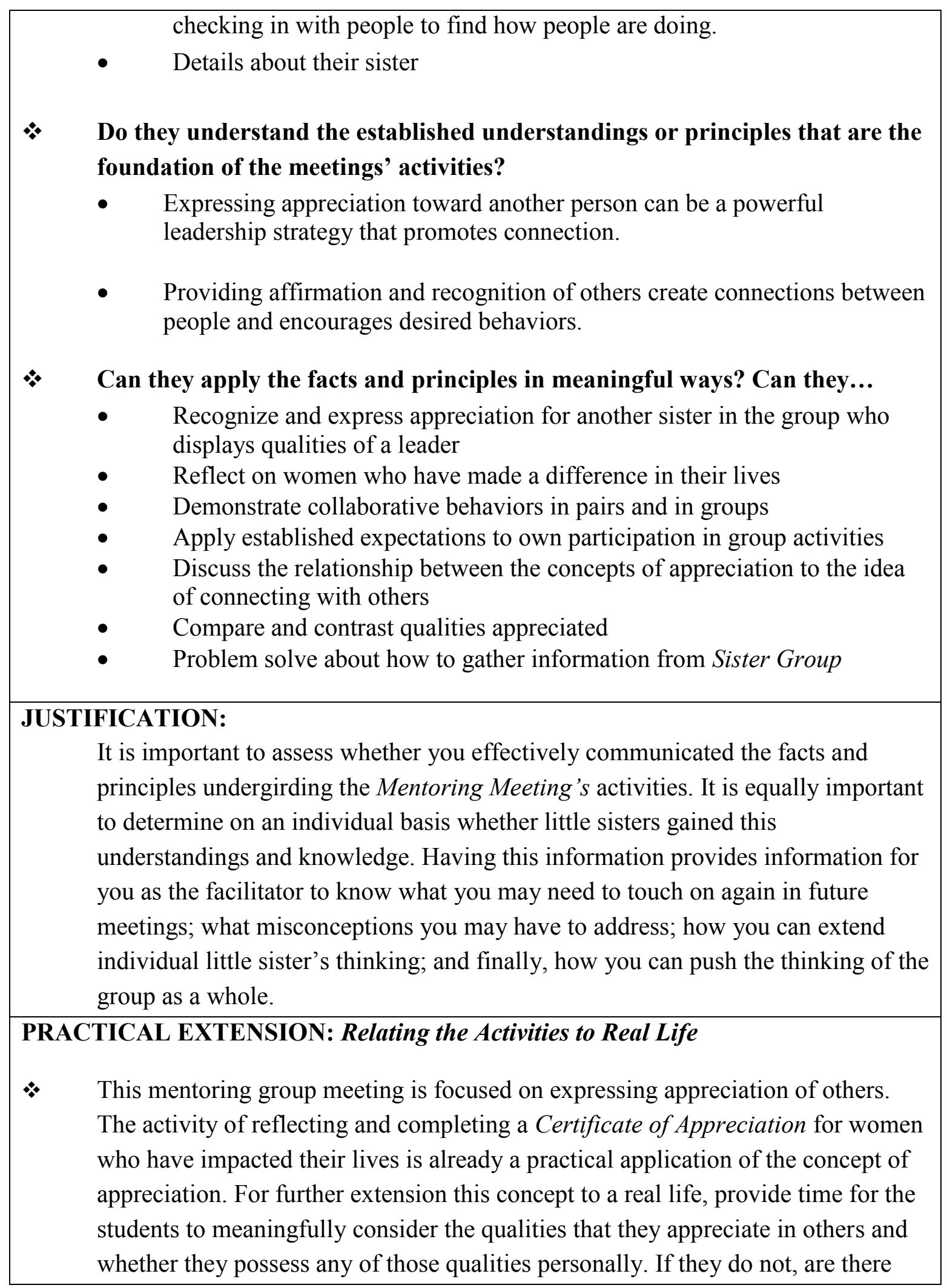


ways that they could adopt some of them?

JUSTIFICATION:

This allows big and little sisters the time to reflect and internalize the characteristics and actions they admire and appreciate.

THE BIG PICTURE: Uniting the Concepts within the Curriculum

- How does the discussion of expressing appreciation for others relate to the previous meeting that focused on connection and safety?

- Group members need to feel safe in order to share freely how they appreciate one another. As the facilitator, you must continue to establish and re-establish safety and security fro your group members. This is the basic need that must be met before anything else positive can occur.

O Once group members begin to feel connected to one another they will be more comfortable expressing how they appreciate one another and in turn once group members begin recognizing what they appreciate in one another and vocalizing it, it will increase their feelings of connection.

- Explicitly creating the connections between the concepts each Mentoring Meetings will deepen sisters' understanding of the concepts and will increase the chances that they will be able to transfer the skills and knowledge to new situations. 


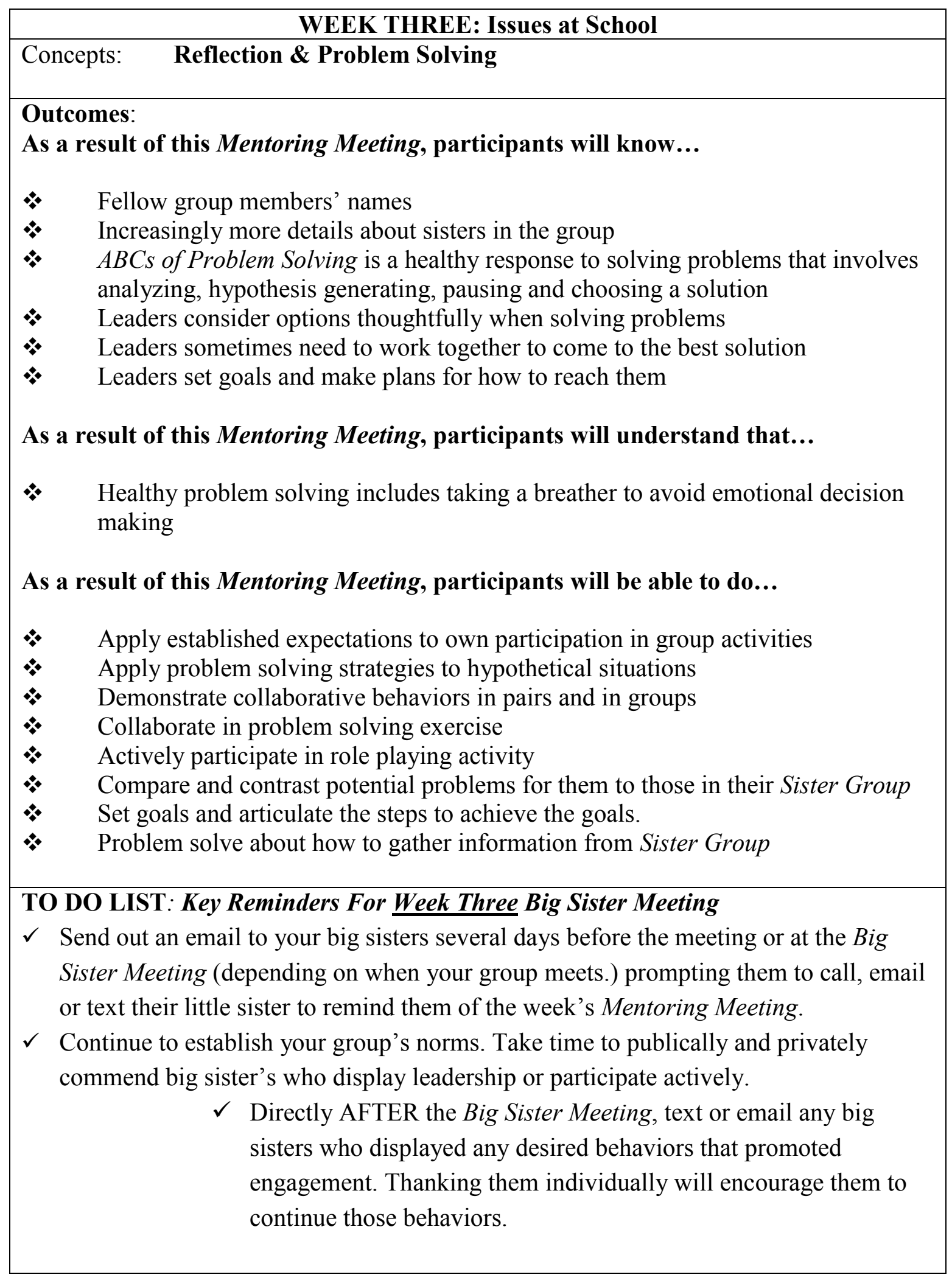


SUPPLY LIST: Necessary Supplies for Week Three Big Sister Meeting

$\checkmark$ Agenda copied for big sisters (optional)

\section{AGENDA: Big Sister Meeting-Week Three}

1) Building Big Sister Connections

a. High/Lows (individual \& pair check-in)

b. Announcements

c. Reports from Group Leadership Roles/Jobs (e.g., photographer, attendance, Sister-to-Sister, etc.)

d. Determine which big and little sisters have birthdays this week and how you are going to celebrate them.

2) Reflection

a. In small groups, pairs, or as a whole group reflect on the successes and challenges of the Mentoring Meeting from the prior week.

i. What would you change?

ii. What did you (as a team) do well?

iii. What interesting thing happened?

$i v$. Who stood out as a leader? (big and little sisters)

\section{3) Building Mentoring Relationships}

a. Walk through the process of $A B C s$ of Problem Solving with a real issue that a big sister/facilitator is willing to share.

b. Discuss what to expect as a day in the life the little sisters. What might be some of the difficulties they face? What are some possible ways we could respond?

c. How can we show that our interest in their daily lives?

4) Mentoring Group Curriculum

a. Nuts \& Bolts

i. Problem-solve about room, parking, transportation, communication, materials, etc.

ii. Discuss Appreciation Dinner details (invitation, food, space, etc.)

iii. Certificate of Appreciation delivery

1. Who can deliver these to the office or hand deliver to teachers?

iv. Problem solve about little sisters' potential responses to the curriculum

v. Issues or patterns of behavior?

$v i$. If time, practice Human Knot or at least be sure sister are aware of procedures.

vii. Ideas for end fun for the mentoring group meeting?

b. Take Away Message

* Healthy problem solving includes taking a breather and reflection to avoid 
emotional decision-making.

\section{TO DO LIST: Key Reminders for Week Three Mentoring Meeting}

$\checkmark$ Check in with the office to be sure that they make an after-school announcement. It may be a good idea to write up an announcement and have them read it in the mornings as well. Each school is different with their protocol. Contact the school office personnel and they should be able to provide proper guidance.

$\checkmark$ Classrooms are sometimes locked; allow time in case you need to find a custodian to unlock your room.

$\checkmark \quad$ At the beginning of your meeting each week, determine who is in attendance. Determine which little sisters are on your list, but not in attendance. Send the big sister who is assigned to the missing little sister (or if doable, you can) to the office to call the parents to notify them of the absence.

$\checkmark \quad$ If you have not already done so, determine how you are going to create and deliver the Appreciation Dinner invitations.

$\checkmark$ Be in touch with YWLP School Contact about details (i.e. space) for Appreciation Dinner.

$\checkmark$ Also get a tentative head count based on communication with parents, big sisters or little sisters about who is potentially attending the Appreciation Dinner.

\section{SUPPLY LIST: Necessary Supplies for Week Three Mentoring Meeting}

$\checkmark$ Connection ball

$\checkmark$ Snacks

$\checkmark$ Mascot or "microphone"

$\checkmark$ Any posters or charts your group has created

$\checkmark$ Hot Topics box

$\checkmark$ Hot Topics paper slips

$\checkmark \quad$ Writing utensils (pens \& pencils)

$\checkmark$ Leadership Ladder

$\checkmark$ Sister Group information

$\checkmark$ Large Post-It pad or chart paper

$\checkmark$ Supplies for Appreciation Dinner decorations 


\section{CURRICULAR COMPANION}

\section{Supplemental Ideas for Implementing Mentoring Group Curriculum}

〜Developing Competence Through Solving Authentic Problems

Why an emphasis on reflection and problem-solving skills?

\section{Hardship Shows No Favoritism}

All people deal with adversity; it is an unavoidable fact of life. When people are armed with strategies of ways to deal with the adversity that will inevitably face them, they are more likely to respond in healthy and competent ways.

\section{It's Human Nature}

Humans are both problem-solvers and problem-generators. When problems arise, it is human nature to try and solve them, but some sisters in your group may not possess the skills and strategies necessary to solve the problems in beneficial ways. Adolescents, in particular, have the desire to react quickly and often their decisions are based on emotions. Some efforts to resolve issues that arise may actually do the opposite and provoke more problems. This is why it is important to equip the little sisters with the required decision-making skills to tackle the tough challenges of adolescence and beyond.

\section{Critical Competency for Success}

Not only are problem-solving skills useful for big and little sisters when they face adversity in personal life, but problem-solving is considered one of the most important competencies for the $21^{\text {st }}$ Century classrooms and workplace.

\section{Weigh Your Options}

Competent, capable leaders take time to consider their options when making important decisions, but this is not necessarily an innate behavior. Little sisters need practice slowing down and taking time to reflect on the link between actions and consequences when making decisions. The formal term for "thinking about thinking" or "reflecting on thought processes" is called metacognition. Metacognitive practices have been shown to increase the degree to which students can transfer skills and knowledge to new situations in the future which is a desired goal driving the YWLP curriculum. 


\section{TIPS: Energizer}

$>\quad$ Conserve Energy: Participants usually are quite engaged by the connection ball activity, but you should be careful not to overuse it. Use it when the group needs some energy infused. If your group already has a lot of energy, you decide to continue with the High-Speed Name Ball activity to see if you can beat your last week's time.

Quickly Unstick: There are some responses on the Connection Ball that are simpler to answer than others, so if a participant gets stuck, simply ask her to pick another question that is close to her finger.

\section{FLEX OPTIONS: Group Check-in}

\section{Choose One:}

* The curriculum advises that you decide whether you are going to use the High/Lows or the Hot Topics box for the group check-in procedure. You should this decision based upon what your group members need and you certainly can adjust and use the other strategy for checking in when it seems necessary. It should be noted that BOTH exercises are valuable and should be used for the facilitator and big sisters to gather information about the little sisters in particular, but about anyone in the group. This information can then be used to adjust and tailor that meeting or future ones.

- High/Lows serve the purpose of checking in with sisters with regard to how they are feeling in general. Some groups find this time to be extremely precious because it provides a structure to gather insight regarding what's going on inside the minds and hearts of the members.

- Hot Topics Box provides time to discuss issues that group members are facing at the time of the discussion. It sets up a forum for hearing and sharing perspectives.

\section{TIPS: Sister Time}

Assess Comfort Levels: Provide some time for big sisters to discuss the potential topics that could arise during the School Tours. Be sure that big sisters feel comfortable and accompany those who do not or team up pairs to create a foursome.

Safety: Remember that a big sister/facilitator must ALWAYS accompany little sisters at all times.

D Time: Provide a time limit for the activity that allows for casual discussions and time for connection. Make sure that each pair has a watch so that they can return 
on time and maximize productivity with the remaining time in the Mentoring Meetings.

\section{TIPS: Leadership Secret- Leaders Solve Problems}

Climb the Ladder: Each of the rungs of the ladder is connected to the ones before it, but the connections may not be explicit. As the facilitator, it is your job to explicitly link the Leadership Secrets together each week. Spend some time talking about the one from the prior week and have the little sisters connect them together.

\section{JUSTIFICATION:}

Connecting the Leadership Secrets (concepts) from the Leadership Ladder will increase the likelihood of transferability to other contexts as well as increase retention due to the organization of the ideas around big ideas.

* Consider Grouping Options: You may want to do this as a whole group, or as Think-Pair-Share. Think-Pair-Share is an exercise that provides participants to think alone first, develop a thought, and then share it in a pair.

\section{JUSTIFICATION:}

This promotes participation by providing multiple venues for sharing. It also builds participants" confidence to share with the entire group, because they have had a "dry run" and maybe even received affirmation for their idea when they shared it with their partner. (This can be done in a square-4 participants- instead of a pair, too.

\section{TIPS: Human Knot Activity}

Guide, if Necessary: As the facilitator, it would probably be a good idea for you to stand on the outside and not be a part of the knot. This will allow you to stand on the outside and even on a chair, if necessary, in order give you perspective to offer helpful suggestions if the group needs you. Be sure to withhold from offering suggestions until after the group has shown signs of actual struggle and teamwork.

Allow Time for Struggle: The purpose of this activity is to provide an opportunity for the group to solve a problem together. It is not an easy exercise, especially if your group members are not verbally communicating. This will give a practical application of the notion of taking a deep breath and considering options. It also supports collaboration and teamwork. Ending this exercise too soon can result in the group feeling as though they have failed so be sure to provide ample time to work through this exercise, but before the group becomes too frustrated. You will need to read your group and observe their actions to determine what is best. 
Emphasize the Process: The focus of this activity is the process, not the end result of actually untying the knot. This important to keep in mind so that groups do not feel completely unsuccessful if they do not solve the problem. The debriefing/reflection questions provided in the curriculum are important to the emphasis on the process. Be sure to relate what happened during the exercise to the concepts of problem solving and reflection. Try to incorporate the language from mentoring curriculum such as: acknowledging the problem, deep breath, choose another option, etc.

\section{JUSTIFICATION:}

This activity is an important, kinesthetic way to apply the concepts of problem solving and reflection. Spend time being explicit about this application and how the skills can be transferred to everyday life. Us the analogy of the knot to represent the struggles or situations in which we find ourselves entangled.

\section{FLEX OPTIONS: Leaders Solve Problems}

Choose One: For both of these activities, keep in mind that there is NOT one best way to approach a problem. Be sure to reiterate the concepts of reflection and taking a breath to avoid emotional decision-making.

* Role Play: Divide into groups of four, pick a typical problem that happens at school or something from the Hot Topics Box, and practice using the ABCs of Problem Solving. Examples:

○ You are being picked on by a teacher

○ Your sister, roommate, or friend keeps borrowing your clothes without asking.

- You want new shoes but don't have any money.

* Analyze This: Divide into small groups (either pairs or quads) and have one of the sisters provide a recent problem with which she has been faced. Analyze the problem from the standpoint of the ABCs of Problem Solving. How did she exhibit the stages? How did she not? What might do differently? If time allows, choose another current problem with which one of the sisters is struggling and analyze the process again.

\section{JUSTIFICATION:}

The activities above provide an opportunity to apply the problem solving strategies and skills introduced during the meeting. It is critical that the application utilizes authentic, real-world issues with which little and/or big sisters are faced. 


\section{MEASURING STICK: Assessing Growth}

\section{Self-reflection}

- How will you assess your effectiveness as a facilitator and measure your growth from meeting to meeting?

- How will you determine whether you met your established outcomes (KUDs) for this mentoring group meeting?

\section{- Do the Little Sisters in your group know...}

- Fellow group members' names

- Increasingly more details about sisters in the group

- ABCs of Problem Solving is a healthy response to solving problems that involves analyzing, hypothesis generating, pausing and choosing a solution

- Leaders consider options thoughtfully when solving problems

- Leaders sometimes need to work together to come to the best solution

- Leaders set goals and make plans for how to reach them

* Do they understand the established understandings or principles that are the foundation of the meetings' activities?

- Healthy problem solving includes taking a breather to avoid emotional decisionmaking.

* Can they apply the facts and principles in meaningful ways? Can they...

- Apply established expectations to own participation in group activities

- Apply problem solving strategies to hypothetical situations

- Demonstrate collaborative behaviors in pairs and in groups

- Collaborate in problem solving exercise

- Actively participate in role playing activity

- Compare and contrast potential problems for them to those in their Sister Group

- Set goals and articulate the steps to achieve the goals

- Problem solve about how to gather information from Sister Group

\section{JUSTIFICATION:}

It is important to assess whether you effectively communicated the facts, skills, and principles undergirding the Mentoring Meeting's activities. It is equally important to determine on an individual basis whether little sisters gained this understandings and knowledge. Having this data provides information for you, as the facilitator, to know what you may need address again in future meetings; what misconceptions you may have to clarify; how you can extend individual sister's thinking; and finally, how you can push the thinking of the group as a whole. 


\section{PRACTICAL EXTENSION: Relating the Activities to Real Life}

- Use it or Lose it: $A B C s$ of Problem Solving provides a practical extension that is authentic. The exercise provides time during the meeting for the sisters to work collaboratively and models the process of healthy problem solving. Encourage the big and little sisters to use this skill sin the next week. Ask the big sisters to check in with their little sisters about using the $A B C s$ of Problem Solving strategy throughout the week.

\section{JUSTIFICATION:}

If a skill is not used right away, it will be lost. Stress the importance of incorporating these skills and regardless of whether you delineate the actual names of each step, be sure to emphasize the use the process.

\section{THE BIG PICTURE: Uniting the Concepts within the Curriculum}

Safety $\longrightarrow$ Connection $\longrightarrow$ Appreciation
Problem-Solving Reflection

- Reflect: How do these concepts relate to one another? Take some time either as a whole group, or in pairs to discuss the connection between the concepts that shape each of the weeks. This is related to the Leadership Ladder discussion above so you may not need to facilitate this discussion again. Check in with little sisters in some way (e.g., a whole group or pair discussion or even an exit card) to discover their understanding with the big picture and how we are creating connections between the ideas each week. 


\section{Concept: Appreciation}

WEEK FOUR: Appreciation Dinner

Outcomes:

As a result of this Mentoring Meeting, participants will know...

- $\quad$ More details about their sisters

- Little sisters' guests and why they invited them to the Appreciation Dinner

As a result of this Mentoring Meeting, participants will understand that...

- $\quad$ Expressing appreciation toward another person can be a powerful leadership strategy that promotes connection.

As a result of this Mentoring Meeting, participants will be able to...

- Work as a team to prepare for the Appreciation Dinner

- $\quad$ Complete a certificate of appreciation for the invited guests

- Welcome invited guests

- Introduce their guests they have invited to the Appreciation Dinner to the rest of the group

- Publicly express to the rest of the group what they appreciate about their guests

- $\quad$ Perform the group's YWLP Connects ritual to the guests

- Demonstrate collaborative behaviors in pairs and in groups

\section{TO DO LIST: Key Reminders For Week Four Big Sister Meeting}

$\checkmark$ Continue to take time to publically and privately commend big sisters who display leadership or participate actively.

$\checkmark$ Continue to text or email any big sisters who displayed any desired behaviors that promoted engagement. Thanking them individually will encourage them to continue those behaviors.

$\checkmark$ Finalize plans for the Appreciation Dinner. You will probably need to determine many details before this point (such as securing room through the YWLP School Contact and shopping for supplies for the dinner), but depending on what day your group meets, you may have some time this week to make final plans.

$\checkmark$ Relay pertinent information that is discussed during the facilitator class.

SUPPLY LIST: Necessary Supplies for Week Four Big Sister Meeting

$\checkmark$ Agenda copied for big sisters (optional)

$\checkmark$ Chart of responsibilities for Appreciation Dinner or some other way to keep track of responsibilities. If you have the chart completed from the last mentoring group 
meeting, then consider duplicating it for each member of the group to serve as a reminder.

AGENDA: Big Sister Meeting-Week Four

1) Building Big Sister Connections

a) High/Lows (individual \& pair check-in)

b. Announcements

c. Reports from group leadership roles/jobs (e.g., photographer, attendance, Sisterto-Sister, etc.)

d. Determine which big and little sisters have birthdays this week and how you are going to celebrate them.

2) Reflection

a) In small groups, pairs, or as a whole group reflect on the successes and challenges of the Mentoring Meeting from the prior week.

$i$. What would you change?

ii. What did you (as a team) do well?

iii. What interesting thing happened?

$i v$. Who stood out as a leader? (big and little sisters)

3) Building Mentoring Relationships

a) The Appreciation Dinner has two layers of appreciation. Of course, the little sisters are inviting women they appreciate and for whom they are thankful, but there is another layer of appreciation. Appreciation also means to understand. Discuss how big sisters can use the time during the Appreciation Dinner to develop appreciation and understanding for the little sisters.

b) Discuss the importance of meeting the women whom the little sisters appreciate and admire? (See Curricular Companion section below.)

$i$. What information could be gathered from the invited guests that would help in getting to know and understand the little sisters better?

1. Brainstorm potential questions to ask the guests.

ii. How can big sisters meet the women who little sisters have invited to the Appreciation Dinner (i.e. identified as significant influences in their lives), but are unable to attend?

1. Why does this matter?

2. How could (meeting or not meeting the invited guests) impact the big/little sister relationship?

4) Mentoring Group Curriculum

a) Nuts \& Bolts

i. $\quad$ Brainstorm little sisters' potential behaviors during the preparation for the Appreciation Dinner and the actual event.

1. How might some little sisters need extra support? 
2. How might it impact little sisters if they do not have someone at the Appreciation Dinner?

ii. Finalize Plans for the Appreciation Dinner

1. Who?

a) Have all of the invitations been delivered?

b) Who has indicated that they are coming to the dinner?

2. When?

a) Are the guests, YWLP School Contact(s), teachers whose room is being used, big sisters, parents, etc. aware of the time and place of the Appreciation Dinner? This should be communicated at least two weeks prior to the event.

b) Is it going to be during regular group time?

c) If not, when? Why?

3. What are you serving for dinner?

a) Who is going shopping for food and decorations?

$i$. Check in with the YWLP Leadership Team to determine the budget allotment and how you will be reimbursed.

b) Have you considered any food allergies, intolerances, or aversions?

c) Have you considered whether the menu is simple to make--allowing for the number of people who will be contributing, the space, the supplies, the time, and clean up?

4. Where?

a) Have you secured the use of the teacher's room through the YWLP School Contact?

b) Everyone should participate in cleaning up after the dinner--so be sure to make adjustments in transportation if necessary.

5. Make sure that every pair has at least one job. Which pairs are...

a) greeting?

b) cooking?

c) serving?

d) putting up decorations, making place cards, name tags, signs, etc.?

e) teaching the guests the closing ritual?

f) writing the thank you cards to the teachers whose rooms you used?

g) cleaning up afterward and returning classroom to its original state?

\section{b) Take Away Message for Little Sisters}

i. Expressing appreciation toward another person can be a powerful leadership strategy that promotes connection.

c) Additional Take Away Message for Big Sisters \& Facilitators

i. Getting to know important women in little sisters lives can provide insight about the little sister.

5) Appreciation for Big Sisters

a) Who displayed noteworthy leadership this past week? 


\section{TO DO LIST: Key Reminders For Week Four Mentoring Meeting}

$\checkmark$ Check in with the office to be sure that they make an after-school announcement. It may be a good idea to write up an announcement and have them read it in the mornings as well. Each school is different with their protocol. Just contact the school office personnel and they should be able to provide proper guidance.

$\checkmark$ Contact your YWLP School Contact to finalize plans for the Appreciation Dinner (e.g., your room, materials, etc.)

$\checkmark$ You will probably want to invite your School Contact (s) to the Appreciation Dinner so that the group can get to know her/them.

$\checkmark$ The room you will be using may be locked, so arrive early enough to find a custodian to let you into your room, if necessary.

$\checkmark$ Take note of how the room is set up, because you will need to return the room to its original condition.

$\checkmark$ You may need to get more help from big sisters to unload supplies for the dinner.

$\checkmark$ At the beginning of your meeting each week, determine who is in attendance. Determine which little sisters are on your list, but not in attendance. Send the big sister who is assigned to the missing little sister (or if doable, you can) to the office to call the parents to notify them of the absence.

\section{SUPPLY LIST: Necessary Supplies for Week Four Mentoring Group Meeting}

$\checkmark \quad$ Nametags \&/or place cards - enough for all of the Appreciation Dinner guests as well.

$\checkmark$ Mascot or item to serve as microphone to indicate who has the floor to speak.

$\checkmark$ Cooking supplies - all ingredients, including spices as well as pots and utensils (The school may or may not have pots, pans, utensils, etc. Be sure to check on this beforehand)

$\checkmark$ Decorations - including tape, signs, markers, or anything else such as balloons, streamers, etc.

$\checkmark$ Certificates of Appreciation

$\checkmark$ A Thank you card (pre-made or "homemade") 


\section{CURRICULAR COMPANION}

\section{Supplemental Ideas for Implementing Mentoring Group Curriculum}

The Value of Connecting with Significant Women in Little Sisters' Lives $\sim$ Nurturing Connections With Important Female Influences

\section{Solving the Puzzle}

Understanding little sisters is critical in creating a meaningful connection with them. In the beginning stages of the relationship, big sisters \& facilitators need to gather as many details as possible about their little sisters in an effort to accurately understand them. Every bit of information represents another "piece of the puzzle" and the more pieces big sisters \& facilitators assemble, the better understanding they can gain about their little sisters. This provides a broader, more comprehensive perspective and as a result a more effective mentoring relationship. Meeting the important people in little sisters' lives and watching how they interact, provides more pieces to the puzzle. Big sisters and facilitators should use the time at the Appreciation Dinner to gather details (puzzle pieces) in an effort to broaden and deepen their understanding (and their appreciation) of the little sisters.

\section{Build a Strong Foundation}

In order to build a robust foundation for the mentoring relationship, big sisters must obviously demonstrate sincere interest and warmth for their little sisters. Once little sisters are clear about the big sisters' honest intentions, they will begin to trust them and the relationship can begin to grow. Until that basic foundation is achieved, the relationship will not progress.

As the relationship between the big and little sisters begins to grow, big sisters need to spend time getting to know the little sisters' mothers or other important women (perhaps"othermothers") in their lives. This cannot be overemphasized! It is necessary for big sisters to spend quality time getting to know the women who are significant influences in little sisters' lives. This, not only provides insight into the little sisters, but it also builds feelings of trust, empathy, and mutuality, all of which are critical components of a strong foundation upon which the big/little sister relationship can be developed. Once little sisters witness their big sisters taking the time to enter their worlds and show genuine interest in getting to know people they admire and appreciate, it can strengthen the mentoring connection. 


\section{Gatekeeper}

It is essential to have the little sisters' mothers' support. In many ways, mothers are still the "gatekeepers" to their daughters' lives. Often times, little sisters rely on their mothers for transportation, communication, support, direction, and permission. If little sisters' mothers feel threatened or usurped, feelings of distrust will grow which can damage the mentoring relationship. Once the trust is lost, it is difficult to regain it. This is exactly why it is particularly important for big sisters to initially communicate with a nonjudgmental, cooperative tone that is focused on what is best for little sisters.

\section{Mesmerize the Mothers}

Charming or winning over little sisters' mothers can sometimes be a tricky feat. When mothers have close relationships with their daughters, they may feel threatened by big sisters' presence. They may perceive big sisters' attempts to connect with their daughters as an intrusion. When mothers are not close with their daughters, they may view big sisters as outsiders trying to take control. In both cases, these perceptions could manifest in behaviors that are fueled by jealousy or resentment, both of which have the potential to undermine the mentoring relationship.

** It is important for big sisters to revisit these ideas and consider the potential feelings mothers could be experiencing. When obstacles arise, it is important to remember that it may not have anything to do with individual big sisters, but rather more to do with the relationship between the mothers and their daughters. The mere presence of an "outsider" trying to create a meaningful connection may dredge up suppressed thoughts and emotions that were formed long before big sisters entered the scene. Pausing for thoughtful reflection may provide big sisters with helpful insight (healthy intentions) and explain confusing, frustrating or even hurtful behaviors.

\section{Long-Term Influence}

Developing strong bonds with little sisters' parents can make a significant difference for little sisters in the long run. Experts in the field of mentoring universally recommend involving mentees' parents in the mentoring process. If the mentoring relationship remains transparent, and lines of communication are open, parents are less likely to feel threatened and more likely to nurture the connection. Mentoring literature has found that this parental support, in turn, has the potential for long-term positive effects on family 
dynamics.

In many cases, mothers are the dominant parental figure. Getting mothers to endorse and support the mentoring relationships can have a powerful, enduring impact on little sisters. Once little sisters' mothers are brought on board, and they begin to actively promote the mentoring relationship, the chances that little sisters will form healthy relationships with adults beyond the nuclear family in the future increases. Healthy development, including the ability to create beneficial relationships is one of the goals of YWLP. 


\section{TIPS: High/Lows}

$>\quad$ Time Boundary: Time is of particular importance during the mentoring group meeting since a great deal needs to be squeezed into one meeting. Explain the time predicament to the group, while still providing a safe platform for sisters to thoughtfully check in and express their thoughts and emotions.

- Remember that sisters will have some time to catch up while they are preparing for the Appreciation Dinner. You may even remind everyone of that beforehand in an effort to expedite this portion of group.

\section{TIPS: Preparing Little Sisters}

$>\quad$ Each little sister will have an opportunity to stand up and introduce their guest, give them the Certificate of Appreciation, and say what it is that they admire about them. Use some time either before you begin preparing or during the preparation time (depending on how much time is needed to prepare the meal) to help the little sisters determine exactly what they are going to say. This can be done in pairs and big sisters should encourage their little sisters to be descriptive and specific. Big sister can offer direction as needed. The intention is that little sisters feel prepared and comfortable (as comfortable as possible) speaking in front of the group and honoring their guests.

- This exercise is powerful because it honors the guests, deepens the connection between the guest and the little sisters, and provides little sisters with a venue to practice public speaking- a necessary skill to be an effective leader.

\section{TIPS: Preparing Space \& Food-Decorating \& Cooking}

$>\quad$ Organize the supplies before the little sisters arrive.

$>\quad$ Capitalize on sisters' strengths and interests.

- Determine sisters' responsibilities at the Big Sister Meeting based on people's strengths and interests.

- Consider whether the little sister may work best in an active or passive role.

- Assign the most sensible pairs to the jobs involving the oven and stove, if the meal preparation requires it.

- Assign the most creative people to the decorating task.

Keep the big \& little sisters pairs together and consider what pairs may work well together based on the information gathered thus far.

- Consider

- Group "status" level (popularity)

- Energy level or disposition

- Ability to cooperate

- Previous connections

- You may want to create homogeneous groups (similar) or heterogeneous 
(dissimilar). Based on the criteria above, heterogeneous groupings may provide a stretch for the group that could be challenging, but in the end result in growth.

\section{TIPS: Appreciation Dinner}

$>\quad$ Watch Time: Use your preparation time wisely, because you do not want to still be cooking, decorating, setting up, etc. as the guests arrive.

$>\quad$ Warm Welcome: Greet the guests at the door with friendly smiles and firm handshakes. It is your job, as the facilitator, to make the guests feel welcome and to set a warm, inviting tone for the event. It is also your job to emphasize the importance of this to the big sisters.

$>\quad$ Assigned Seating: You may decide to have formal assigned seating in which case you will need to create nameplates. This could be a good idea if you want to encourage particular people to interact, cultivating specific supportive relationships.

Serve Guests: You may want to have little sisters serve their guests.

- Trays (possibly from the cafeteria) may be good idea to assist with serving the food.

$>\quad$ Express Admiration: The most important part of the Appreciation Dinner is the time that the little sisters publically express what they admire about their invited guests. Be sure to give them time to practice saying what they are going to say about their guests and big sisters should provide constructive feedback to help them in their preparation.

\section{TIPS: Clean Up}

$>$ Be Prepared: If you do not have time to clean the dishes before the guests arrive, at least soak them while you are eating so that they will be easier to clean later. Teamwork: Everyone should help with this!

$>\quad$ Delegate Labor: Provide clear direction and responsibilities for each pair, but present it as a collaborative effort so that if some pairs have easier jobs and finish early, they will step in and help others.

Respect for the School: The classroom needs to look exactly how it did when you arrived - actually even better. Remember that you are YWLP ambassadors. Represent YWLP positively! 


\begin{tabular}{|c|c|}
\hline & WEEK FIVE: Supporting Our Sisters \\
\hline & epts: $\quad$ Support, Mutuality, \& Competence \\
\hline & $\begin{array}{l}\text { mes: } \\
\text { esult of this Mentoring Meeting, participants will know... }\end{array}$ \\
\hline$\%$ & More details about fellow group members \\
\hline 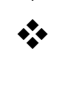 & $\begin{array}{l}\text { The leaning call and response loop is "Support Team Ready?" "Support Team } \\
\text { Ready!" "I'm leaning." }\end{array}$ \\
\hline 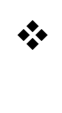 & $\begin{array}{l}\text { The leaning call and response loop must be stated before a sister leans into the } \\
\text { group }\end{array}$ \\
\hline & esult of this Mentoring Meeting, participants will understand that... \\
\hline * & $\begin{array}{l}\text { Healthy friendships include times when friends lean on each other and times when } \\
\text { friends are supported by one another. }\end{array}$ \\
\hline 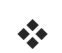 & A competent leader knows when to ask for help. \\
\hline * & $\begin{array}{l}\text { When people give generously to others without expecting anything in return, they } \\
\text { often benefit, too. }\end{array}$ \\
\hline$*$ & $\begin{array}{l}\text { In order to build a strong connection between two people, there must be mutual } \\
\text { feelings of trust, appreciation, and support. }\end{array}$ \\
\hline & esult of this Mentoring Meeting, participants will be able to... \\
\hline$*$ & Demonstrate collaborative behaviors in pairs and in groups \\
\hline$\%$ & Apply established expectations to own participation in group activities \\
\hline & $\begin{array}{l}\text { Discuss the relationship between the concepts of appreciation and connection to } \\
\text { the ideas support, mutuality and competence }\end{array}$ \\
\hline$\%$ & Demonstrate earnest engagement when participating in group activities \\
\hline$\%$ & Use leaning call and response loop \\
\hline$\%$ & Share personal ideas and emotions regarding the Appreciation Dinner \\
\hline * & Express gratitude for another pair \\
\hline 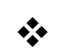 & Share academic progress \\
\hline$*$ & Make plans to ask for help with school work, if necessary \\
\hline & $\begin{array}{l}\text { Connect Leadership Secret (Leaders Help Others) to previous weeks' Leadership } \\
\text { Secrets (Leaders Connect; Leaders Appreciate Others; Leaders Solve Problems, } \\
\& \text { Leaders Set Goals) }\end{array}$ \\
\hline$\%$ & Discuss how they have supported \&/or been supported by others \\
\hline & Reflect on experiences when they have supported \&/or been supported by another \\
\hline & Cooperatively plan ways to help others \\
\hline
\end{tabular}


Continue to encourage big sisters who display leadership or participate actively during group.

$\checkmark$ Directly AFTER the Big Sister Meeting, text or email any big sisters who displayed any desired behaviors that promoted engagement. Thanking them individually will encourage them to continue those behaviors.

Make copies of the agenda for the Big Sister Meeting. (optional)

$\checkmark$ Send an email to big sisters to remind them to contact their little sisters' guests thanking them for attending the Appreciation Dinner.

$\checkmark$ Deliver the thank you note for the teacher whose room you used. You may have already done this.

$\checkmark$ Depending on your group dynamic, you may want to provide a venue for big sisters to share with you how they are feeling in written form at the end of the Big Sister Meeting. Some big sisters may not feel comfortable expressing their thoughts and emotions publically at this point, but it is useful for you to know how they are feeling about their relationship with their little sisters and their involvement in the program. This will provide information that you, as the facilitator, can use to inform your decisions regarding necessary guidance and support. It is also a helpful to gather information about your effectiveness as a facilitator.

\section{$\checkmark$ Potential Questions:}

1. How is your relationship with your little sister progressing?

2. What is your favorite part of YWLP so far?

3. What obstacles do you see impeding the relationship with your little sister at this point?

4. How can your facilitator support you more?

5. What could YWLP Leadership be doing to support you more?

6. What changes do you think should be made (either by you or someone elseplease specify) to either the big sister meeting time, Mentoring Meetings, individual time \& Play Dates?

7. How would you like to provide more support to your fellow sisters and facilitator?

8. What else would you like to tell your Facilitator?

\section{SUPPLY LIST: Necessary Supplies for Week Five Big Sister Meeting}

$\checkmark$ Agenda copied for big sisters (optional)

$\checkmark$ A copy of BOOST 
Information about Who's Hungry?activity

AGENDA: Big Sister Meeting-Week Five

1) Building Big Sister Connections

a. High/Lows (individual \& pair check-in)

b. Announcements

c. Reports from Group Leadership Roles/Jobs (e.g., photographer, attendance, Sister-to-Sister, etc.)

d. Determine which big and little sisters have birthdays this week and how you are going to celebrate them.

\section{2) Reflection}

a. In small groups, pairs, or as a whole group reflect on the successes and challenges of the mentoring group meeting from the prior week.

i. What would you change about the Appreciation Dinner?

ii. What would you change about how you worked as a team for the Appreciation Dinner?

iii. What did you (as a team) do well?

$i v$. What interesting thing happened?

v. Who stood out as a leader? (big and little sisters)

\section{3) Strengthening Mentoring Relationships}

a. Discuss in small group, pairs or as a whole group, where everyone is with her little sister. A mentoring relationship has stages (Introduction, Building, Growing, Maturing, Transitioning). Keep in mind that relationships can fluctuate and go backward before they go forward, or even remain static for some time.

b. What can big sisters do to support little sisters in the various domains: academics, social \& familial relationships, emotional health?

\section{4) Mentoring Group Curriculum}

\section{a. Nuts \& Bolts}

i. Problem-solve potential little sisters' responses to the curriculum this week.

1. Who needs extra support?

ii. How can the big sisters and facilitators ensure that the Leaning Towers activity is executed safely?

iii. How can you as a group use BOOST most effectively? (Be sure that everyone brings either electronic or hard copies of BOOST to the Big Sister Meeting so that you can look at it for specific ideas.

iv. How can the big sisters and facilitator communicate sensitivity for the Who's Hungry? Discussion?

v. What is necessary for the Who's Hungry? activity to go smoothly? 
$i$. Conduct an open discussion about how the following principles resonate with members.

* A competent leader knows when to ask for help.

* When people give generously to others without expecting anything in return, they often benefit, too.

* In order to build a strong connection between two people, there must be mutual feelings of trust, appreciation, and support.

* Healthy friendships include times when friends lean on each other and times when friends are supported by one another.

5) Appreciation for Big Sisters

a. Who displayed noteworthy leadership this past week? Be specific with the behaviors and how they impact the group (or pair) interactions and dynamic. For example, "Camille always greets everyone in group with a smile and a personal question about their lives. This really makes people feel welcome and more willing to share thoughts and feelings with each other. This really brings the group together."

\section{TO DO LIST: Key Reminders For Week Five Mentoring Meeting}

$\checkmark$ Check in with the office to be sure that they make an after-school announcement.

$\checkmark$ Your room may be locked, so arrive early enough so that you can find a custodian to let you into your room, if necessary.

$\checkmark$ At the beginning of your meeting each week, determine who is in attendance. Determine which little sisters are on your list, but not in attendance. Send the big sister who is assigned to the missing little sister (or if doable, you can) to the office to call the parents to notify them of the absence.

\section{SUPPLY LIST: Necessary Supplies for Week Five Mentoring Meeting}

$\checkmark$ Nametags

$\checkmark$ Snacks

$\checkmark$ Mascot or item to serve as microphone to indicate who has the floor to speak.

$\checkmark$ Hot Topic box

$\checkmark$ Hot Topic paper slips

$\checkmark$ Writing utensils (pens, or pencils, and markers)

$\checkmark$ Leadership Ladder

$\checkmark$ Signs made for group

$\checkmark$ Who's Hungry? information

$\checkmark$ Music (appropriate for adolescents- rated G) $\odot$ \& way to project it (e.g., speakers hooked to ipod)

$\checkmark \quad 3$ Bowls

$\checkmark$ Candy, popcorn, or food that can be easily divided

$\checkmark$ Sister Group information 


\title{
CURRICULAR COMPANION
}

\author{
Supplemental Ideas for Implementing Mentoring Group Curriculum
}

\section{Promoting Competence \& Connection through Helping Others \& Maintaining Supportive, Trusting Relationships}

"If you light a lamp for somebody, it will also brighten your path." -Buddhist saying

\section{Adolescents' Developmental Need for Supportive, Close Connection}

Little sisters are in a phase of developmental where they are maturing both cognitively and emotionally. This means that they can think more abstractly, but they also experience heightened emotions and this can complicate their relationships, which are of the upmost importance to them. They are often preoccupied by acceptance and rejection and sometimes even define themselves (and redefine) by their ever-changing barometer of social status. It is a developmental need for our little sisters to share close bonds with others and big sisters are in the ideal position to meet this need.

That being said, this need may manifest in different ways for little sisters. Some may reveal their desire to have a close bond with their big sisters, while others may have a history of disappointing relationships that may make them a bit reluctant to show their desire to fulfill that developmental need. The fact to remember is that regardless of whether the little sisters disclose this developmental need for an intimate connection, it does exist. Some big sisters just may need to prove their trustworthiness, reliability, and loyalty first before little sisters are willing to expose their interest to connect.

\section{Supporting Little Sisters}

Adolescents are more in need of support and guidance rather than directives telling them what to do and how to do it. It is part of development for adolescents to make mistakes and then to learn from them. Part of being an effective big sister is to catch your little sister when she falls- because she will. Falling is a part of life and certainly a part of adolescence. Everyone falls at some point, but if little sisters know that they have a supportive friend there to catch them when they take healthy risks and fall, they will be more likely to jump back up and try again.

According to Bowlby (1991), a child development psychologist, people perform their best when they securely believe that they have trusted supporters close by who will help them if necessary. With this thought in mind, if little sisters are confident that their big sisters care about them unconditionally and will support them, they will be more likely to take healthy risks, and put forth effort toward something that may be challenging. 


\section{Promote Mutuality: Pairs Sharing Feelings}

Effective relationships between two people require that the each person feels connected, understood, liked and respected. In addition, there needs to be a mutual feeling of trust. Without those ingredients the benefits of mentoring are unlikely. This means that big sisters need to make concerted efforts to communicate feelings of caring and respect in addition to develop mutual understanding and trust. This may be more difficult for some big sisters than for others depending on their little sisters, but all big sisters need to make this their mission. You, as the facilitator, need to make it your mission to oversee and "facilitate" the development of the big/little sister relationships in your group. This will mean different things to different facilitators, depending on the individuals in your group, but remember that you are there to support all of the pairs in your group. It is your responsibility to help big sisters make their little sisters feel understood, like, respect and connected.

The design of YWLP is purposeful and it has a group component for a specific reason. The relationships between the big and little sisters are paramount, but the other sisters in the group are important to the little sisters, too. There have been groups in the past where the assigned pairs did not connect securely, but the little sisters have connected with others in the group. This can have healthy benefits as well so do not underplay the importance of the group dynamic. Little sisters will hopefully gain feelings of being understood, liked, respected and connected from other sisters in the group in addition to their big sister. Cultivating those feelings within all of the members will add to the overall closeness and health of the entire group.

\section{Show Empathy}

Big sisters will not always give the perfect advice for every situation that arises with their little sisters and this is not expected. Big sisters need to support their little sisters and provide a non-judgmental ear. Big sisters, most likely, have not had the same life experiences as the little sisters and will not be able to personally relate to everything the little sisters say, but if they listen with "not only eyes and ears, but also hearts and minds" their healthy intentions will be communicated and the pair will bond. Actions that are fueled by love and come from a non-judgmental place are better received and have a stronger impact. Big sisters should listen and care, not offer patronizing advice.

\section{Feelings of Competence}

Psychologist, Erik Erikson, has stated that "giving loving care" to others and contributing to society as necessary for healthy development, corroborating YWLP's efforts to include philanthropic endeavors. When people begin to think outside themselves and focus on others, they begin to feel better about themselves and consider themselves as competent individuals with something valuable to offer. A great deal of research exists to support 
the notion of providing service-learning opportunities for adolescents. YWLP is a multilayered service-learning model that provides various opportunities for members (big sisters, little sister \& facilitators) to give and receive. On the macro-level YWLP is centered on developing big and little sisters' competence, connection and autonomy, all of which are impacted by supporting and offering help to others.

\section{Encourage Little Sisters to Ask for Help}

Knowing strengths and limits is an important part of developing as a leader. It actually takes confidence to seek assistance. Asking for help should not be confused with helplessness, or giving up, instead it requires a person to express active interest in tapping into another person's expertise. It is not simply asking another person to do the work for her. There is a great distinction between asking for help and asking someone to do something for you. For example, collaborating with another who has a different skill set or asking a teacher for further explanation are healthy ways of asking for help.

Little sisters need to know that asking for help when it is needed is a sign of strength, not weakness. It is a skill of being resourceful. Big sisters need to model specific behaviors of how to ask others for help. There are research findings to support the notion that having a mentor and possessing feelings of security can lead to significant changes in mentees attitudes toward helping others and asking for help. This can have a significant impact on little sisters' academic achievement!

\section{Give the Gift of Laughter}

It sounds incredibly simple, but big and little sisters need to have fun and laugh together! Infuse fun and laughter into the mentoring group meetings. When big sisters take time to connect socially and genuinely enjoy each their little sisters' company they have greatest impact. The greatest benefits for little sisters results from a relationship where the big sister is highly supportive, but also provides moderate levels of opportunities for structured activities. This includes having fun during both social and academic activities. Big sisters need to try to create fun memories with their little sisters, whatever they do. Whether they go, whether it be strolling the downtown mall, getting ice cream, going hiking, or even working on homework, pairs should focus on enjoying their time together. 


\section{TIPS: Leaning Towers Energizer}

$>\quad$ Symbolic of Relationships: Leaning Towers is a powerful activity. It is tangible representation of a relationship- the notion that friends support one another and are supported by one another. The debrief afterward provides the framework to discuss these ideas in the literal sense with regard to the activity, but then the elements (i.e. trust, leaning, supporting, communicating, etc.) can be connected to basic elements in friendships.

Stress seriousness: This activity requires the participants to be focused and serious because it involves having confidence that your fellow sisters will be there for you. When someone agrees to participate, they are trusting that their sisters will support them and if sisters do not, it can be a serious breach of trust. Also, the "leaners" and "supporters" need to be explicitly instructed on what their responsibilities are and how to perform correctly.

$>\quad$ Know Sisters' Limits: There will not be enough time for everyone to be a "leaner" in this activity and in most cases, not every sister will be interested in being a "leaner" at this point. It does involve a level of risk-taking that not every sister will be ready to take. When deciding which sisters will be the "leaners" consider size and readiness level. It may be wise to start with a small sister who seems ready for the challenge- meaning that this is not a sizeable risk for her or stretching her outside of her comfort zone to a great degree. Then as the "supporters" become more competent with the skills needed for their position, you can have other sisters as "leaners."

\section{JUSTIFICATION:}

The purpose of this activity is to give sisters the opportunity to bond through communicating, trusting, and supporting one another. It introduces the idea of mutuality and the needs for communication and interdependence in a healthy relationship. It is meant to be a serious activity, yet most people in report that they enjoyed it. Groups often continue the activity and allow all sisters who would like to experience being the "leaner try it."

\section{TIPS: Group Check-in}

High/Lows: It would be useful to do High/Lows this week so that the group can reflect on the Appreciation Dinner. This time can be used to discuss the leadership exhibited during the planning of the event as well as during the actual dinner. The discussion should focus on how the group worked well as a team, in addition to how some individuals or pairs contributed as leaders. Keep in mind that sometimes leaders lead quietly behind the scenes before the actual event and they are just as important as the vocal leader who leads during the event. Be sure to recognize both types of leadership. 
Hot Topics Box: Discussing topics that are important to little sisters is a valuable use of time. It often gets overlooked due to time constraints, but little sisters often report in their end-of-year survey that they enjoy this activity and value the time to express their ideas about topics that are relevant to their current lives. Be sure to find time to have these discussions.

\section{TIPS: Sister Time}

$>\quad$ Supporting the Little Sisters' Academic Achievement: The goal of Sister Time this week is to provide a structured way for big and little sister pairs to discuss progress in school.

$>\quad$ Hesitant Little Sisters: Depending on little sisters' school performance, they may be reluctant to open up to their big sisters about their progress in school right away. Allow sufficient time for sisters to have a genuine discussion and to get beyond the statements, "School is fine." Also, be sure that you circulate around the room so that you can support sisters who need it, but also allow for privacy in case little sisters do not want to share their academic progress with anyone except their big sister.

Hesitant Big Sisters: This is a topic that will need to be revisited regularly throughout the relationship. Big sisters may not be too eager to discuss academic progress with their little sisters because it may be an uncomfortable topic for little sisters. It is important that big sisters dig deeper and ask questions beyond, "How's school?"

$>\quad$ Guide Gently: Big sisters need to be prepared to provide specific guidance and listen closely without judgment. Use BOOST! Depending on the situation, it may be useful for big sisters to share any struggles (maybe even from middle school) or successes that they have had in school and strategies that have worked for them.

$>\quad$ Connect with Teacher(s): As a follow up for the conversation, it may be useful for big sisters to connect with little sisters' teachers. This must be done with the permission of the little sister and should be approached as if the big sister is joining the "team" supporting the little sisters' academic achievement.

\section{TIPS: Leaders Help Others}

Times of Plenty \& Scarcity: For the "Who's Hungry?" activity, it is critical to present the idea of hunger being the leadership issue for the semester in a way that is non-judgmental, communicating that people experience times of up and downtimes of abundance and times of shortage. A person's circumstance needs to be separated from them as a person. This is a critically important notion to consider for everyone, not only, because some of the little sisters may currently not have a 
lot of resources in their lives and may feel uncomfortable by our focus on providing for the hungry, but also because non one is "above" unfortunate circumstances. People's life conditions can change quickly and drastically (i.e. natural disasters -like Katrina \& Irene, fires, tornadoes; job loss due to plummeting job market, etc.) so it is important to realize that no one is exempt from the possibility of experiencing a time of shortage. This is a particularly timely lesson to learn due to the recent (last several years) events and current economic climate in the United States.

Emphasize the "Human Family": In a family, the members take care of each other. In the first activity, the concept of supporting and taking care of others is a responsibility of being part of the "human family." Because the little sisters are adolescents, they relate best to ideas when they are introduced in a way that starts with them. Developmentally, they are still egocentric and if you are ever going to reach their minds or hearts, you need to start by connecting with them personally first. That being said, you might want to have the sisters give examples of how they help members of their biological family. Then progress outward, discussing how they could help members of their extended family, friends, school community, world, etc. This can be done is small groups or as a whole group. Keep in mind that if you have discussions in small groups, it increases the chances of participation of each sister. In other words, more sisters are able to share their ideas. With a whole group discussion, you, as the facilitator have more influence of the direction of the conversation, so you need to consider your group members' comfort levels and leadership skills.

$>\quad$ Read \& Monitor Your Sisters in the Moment: Throughout both "Who's Hungry?" activities pay close attention to sisters' body language and facial expressions, not only to, detect levels of comfort, but also squelch any disrespectful or dismissive behaviors. For example, in the debriefing segment at the end of Activity 1, there is a question that asks the sisters to consider where their families would be with regard to levels of resources. Consider how some of your sisters may respond to this and how you, as the facilitator, and the big sisters can sensitively discuss this and offer support.

- $\quad$ ADAPTATION: To provide another modality that offers supplemental visuals for both activities in "Who's Hungry?" you may want to provide photos of potential people from the countries that might be members of the various levels, sitting on the floor, sitting on three- and- a-half chairs, or spread out over six chairs-In other words, what countries might be represented on each level? Show this on a map. Where is your Sister Group? Providing a picture of a person puts a face on the number and this can be a powerful addition to the exercise.

\section{MEASURING STICK: Assessing Growth}




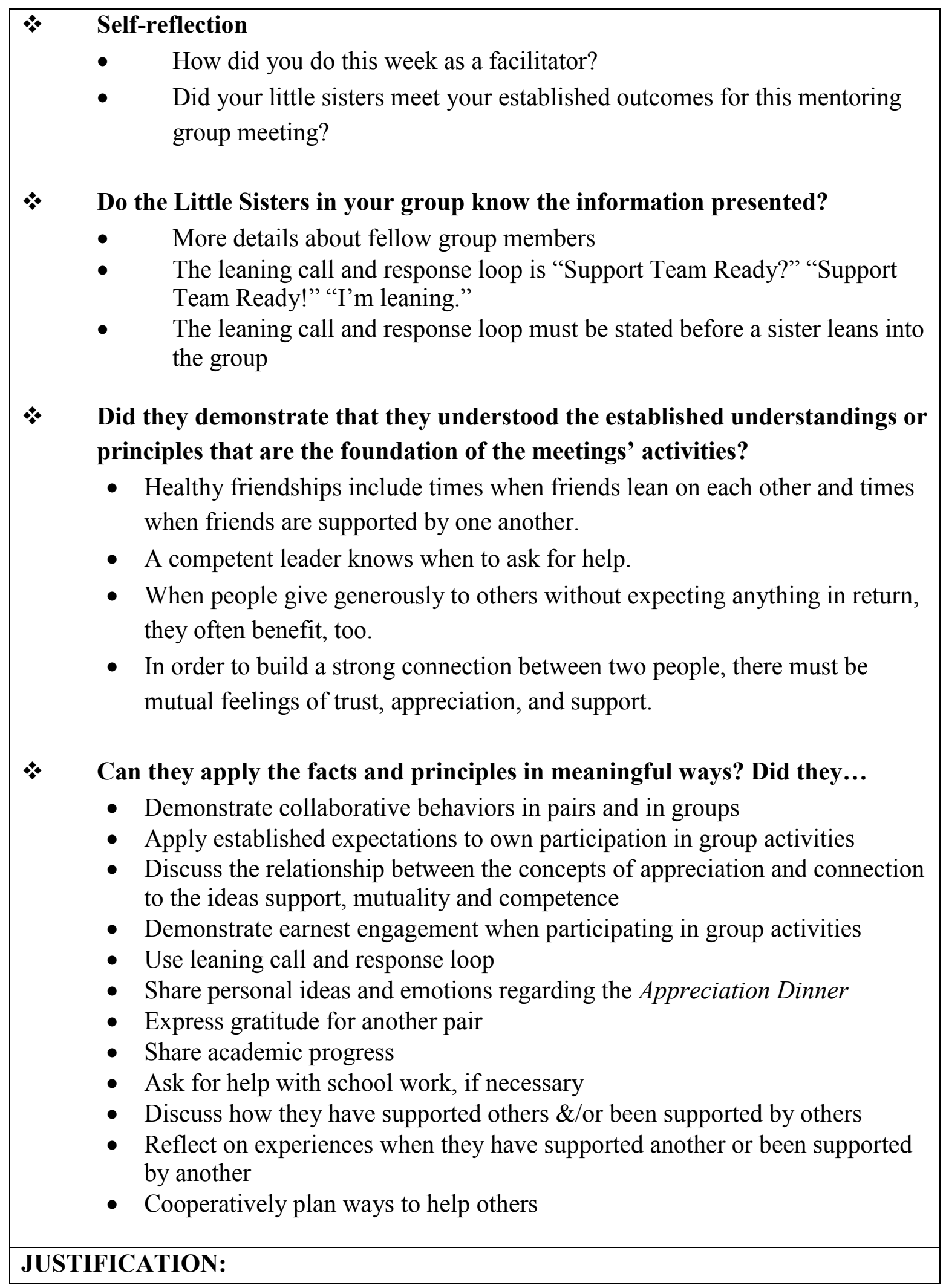




\begin{tabular}{|c|c|}
\hline & $\begin{array}{l}\text { It is important to find some way to assess whether you effectively communicated } \\
\text { the facts and principles undergirding the Mentoring Meeting's activities. It is } \\
\text { equally important to determine (on an individual basis) whether little sisters } \\
\text { gained this understandings and knowledge. This can be done through a formal or } \\
\text { informal conversation, a comment that is made, a behavior displayed, a written } \\
\text { "exit card" with questions related to the outcomes (KUDs). } \\
\text { Mix up how you have the little sisters express what they know, understand } \\
\text { and can do. They will get bored when you overuse a strategy. } \\
\text { It is important that you keep track of little sisters' growth in some way- } \\
\text { whether it is done formally or informally. You can share this responsibility } \\
\text { with big sisters- perhaps a notebook could be passed around the group, } \\
\text { tracking the little sisters' changes. Documenting the growth is important } \\
\text { because it sometimes happens so quickly that it is difficult to remember } \\
\text { what the little sister used to be like or so slowly and even slightly that } \\
\text { changes are noticed. This will provide information to share with parents } \\
\text { and for the events at the end of the year. }\end{array}$ \\
\hline \multicolumn{2}{|r|}{ PRACTICAL EXTENSIONS: Relating the Activities to Real Life } \\
\hline$*$ & $\begin{array}{l}\text { Leadership Project III: One natural extension that is already built into the } \\
\text { curriculum is the Leadership Project III. Ask them to notice places in town that } \\
\text { are collecting for the Food Bank, advertisements for the Food Bank, etc. }\end{array}$ \\
\hline 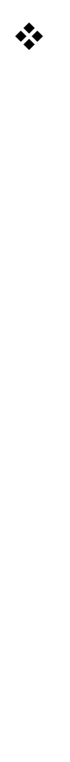 & $\begin{array}{l}\text { Widening their Circle of Influence: This mentoring group meeting is focused on } \\
\text { the concepts of support and caring for one another. More specifically, supporting } \\
\text { one another within the YWLP group and developing relationships within the } \\
\text { group that are interdependent. The Mentoring Meetings time is spent examining } \\
\text { different levels of help, helping themselves, helping friends and biological family, } \\
\text { and helping others in the human family. Relating the "Who's Hungry?" activity to } \\
\text { real life may require some little sisters to stretch their thinking more than others- } \\
\text { depending on their current life circumstance and level of resources. Ask little } \\
\text { sisters to spend the next week examining how they make a difference in others' } \\
\text { lives. Challenge them to think of whom they can connect with outside of their } \\
\text { immediate circle of friends and family. Then next week, repeat the question of } \\
\text { what gets in the way of doing kind gestures for others. Then you could also ask } \\
\text { them think about how they felt when they were kind to someone else? }\end{array}$ \\
\hline$\%$ & Self-Examination: Another way to extend this lesson beyond the mentoring \\
\hline
\end{tabular}




group meeting, it to ask them to consider how they (and their biological family)
use the resources given to them. They can chart it for the week if they are really
interested! You might have a discussion about how their consumption and
consumerism impacts the rest of the human family. Also a discussion of
relativism would be appropriate during the next week. What seems like limited
resources to one person in one country may seem like abundance to another in a
different country. This really encourages them to think outside of themselves.
JUSTIFICATION for Leadership Project II
The purpose of this activity is to provide an opportunity for big and little sisters to
help others in need in a meaningful way. As a bi-product, it brings the group
together because they are working together on a project that matters.
THE BIG PICTURE: Uniting the Concepts within the Curriculum
How does the discussion of supporting others relate to the previous meeting that
focused on appreciation? How does the discussion of supporting other relate to the
previous weeks of connection and safety? For the illustration below consider the arrows
going both ways. Examine the interconnections between all of the concepts.
Oxplicitly creating the connections between the concepts each Mentoring
Meetings will deepen sisters' understanding of the concepts and will increase the
chances that they will be able to transfer the skills and knowledge to new
situations.




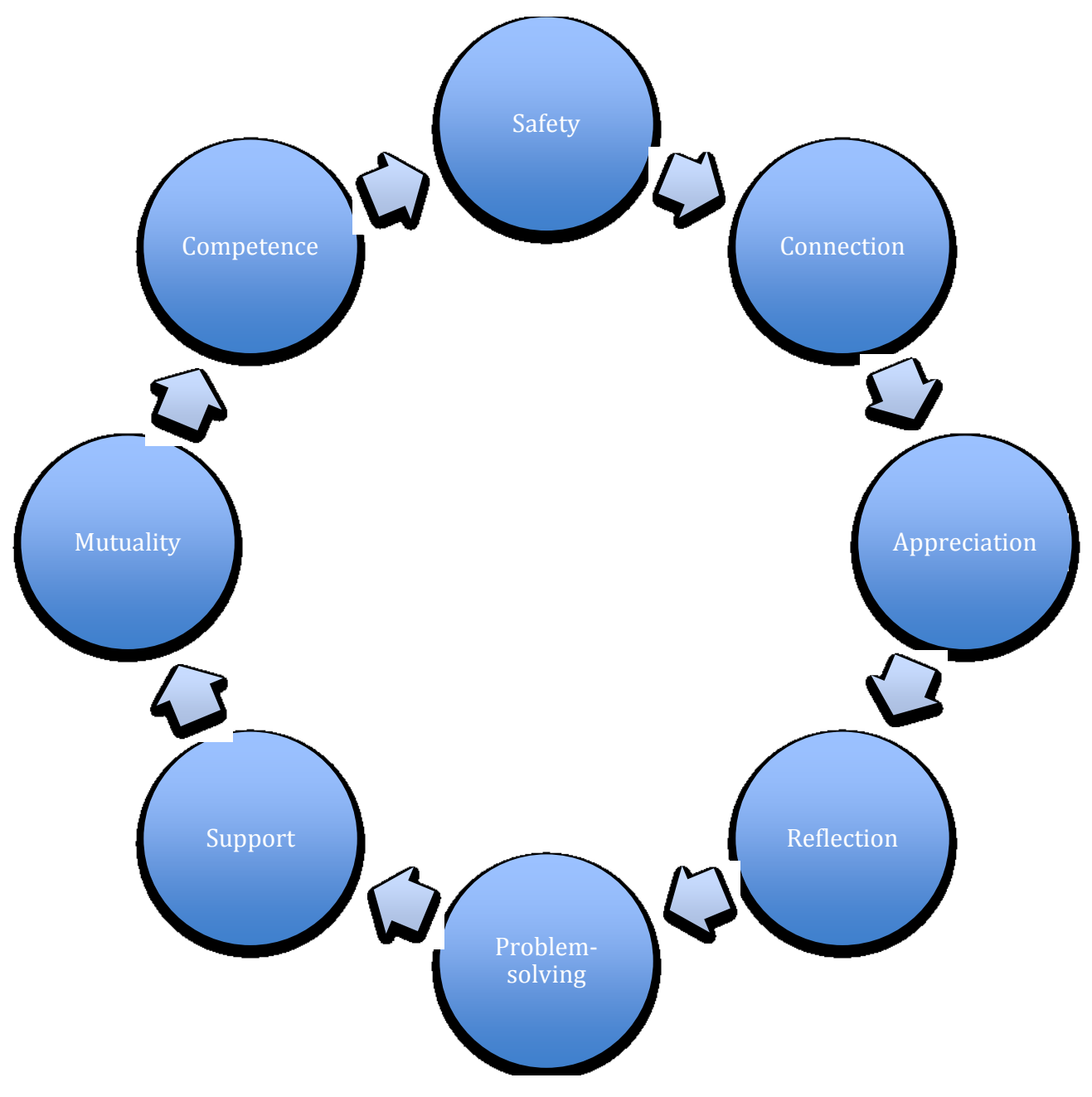




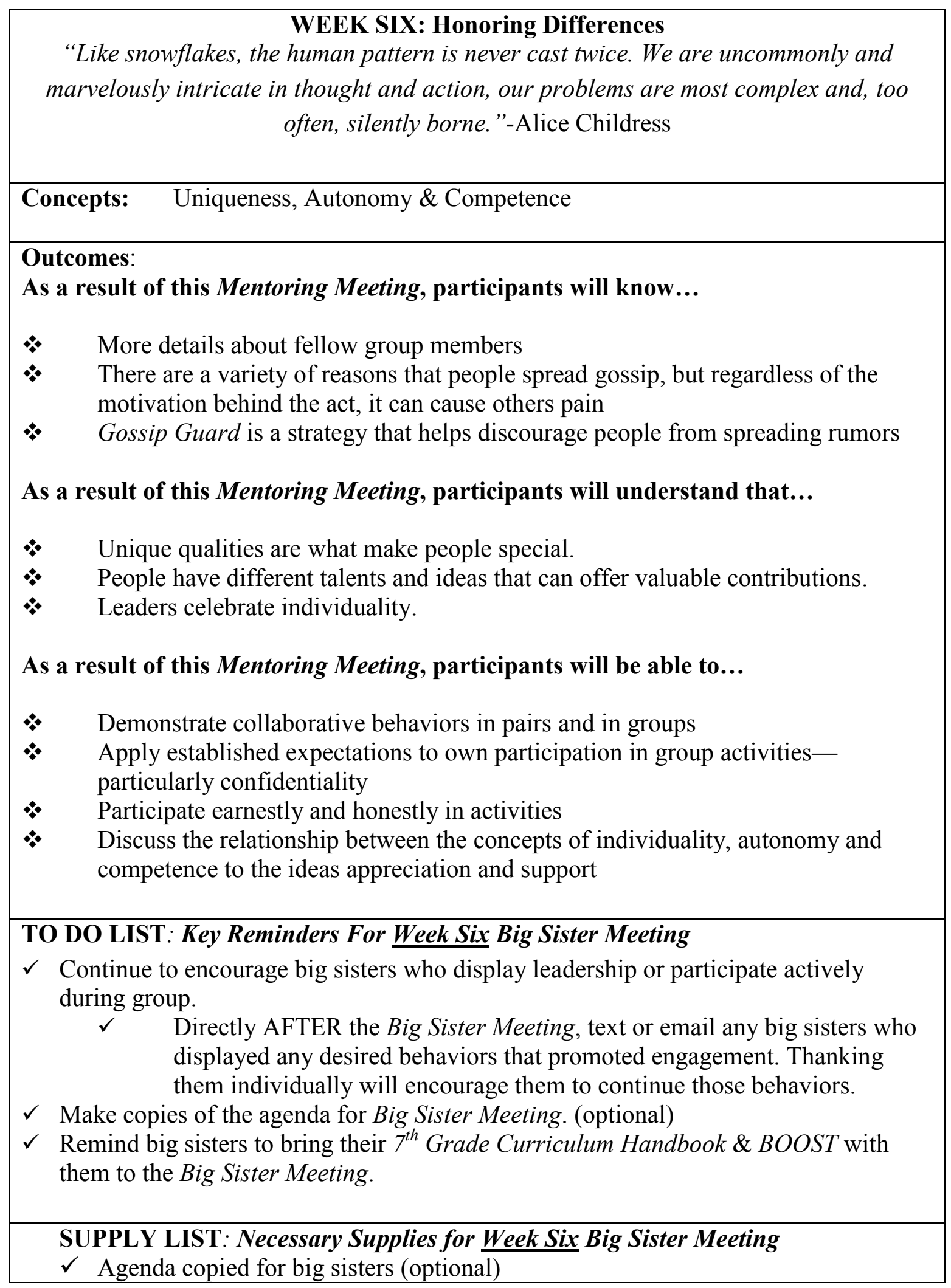




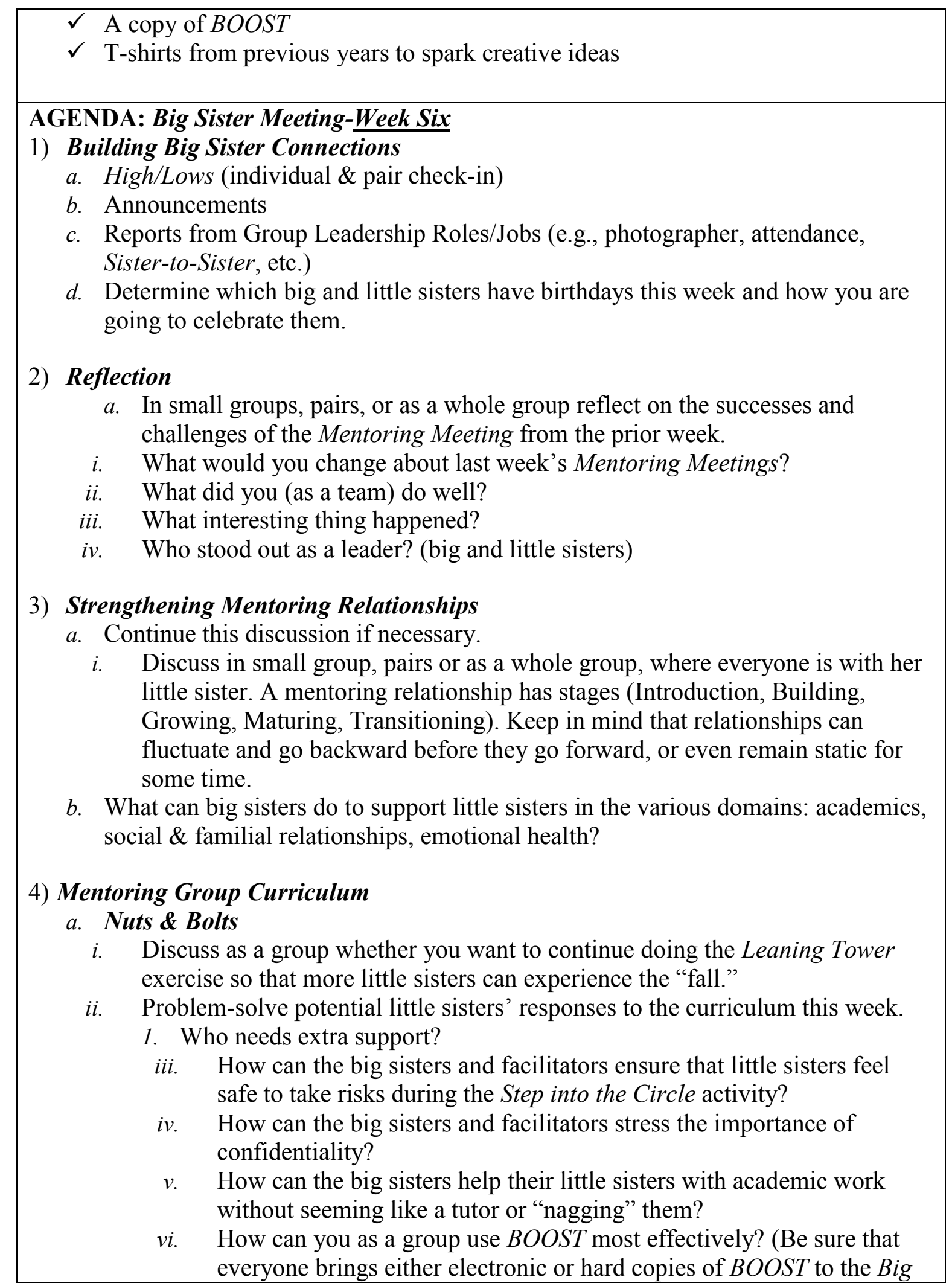


b. Take Away Messages

Sister Meeting so that you can look at it together for specific ideas.

Conduct an open discussion about what the following principles mean to big sisters.

i) Individuals' unique qualities are what make them special.

ii) People have different talents and ideas that can contribute valuably.

iii) Leaders celebrate individuality.

\section{5) Appreciation for Big Sisters}

a. Who displayed noteworthy leadership this past week? Be specific with the behaviors and how they impact the group (or pair) interactions and dynamic. For example, "Camille always greets everyone in group with a smile and a personal question about their lives. This really makes people feel welcome and more willing to share thoughts and feelings with each other. This really brings the group together."

\section{TO DO LIST: Key Reminders For Week Six Mentoring Meeting}

$\checkmark$ Check in with the office to be sure that they make an after-school announcement.

$\checkmark$ Your room may be locked, so arrive early enough to find a custodian to let you into your room, if necessary.

$\checkmark$ At the beginning of your meeting each week, determine who is in attendance. Determine which little sisters are on your list, but not in attendance. Send the big sister who is assigned to the missing little sister (or if doable, you can) to the office to call the parents to notify them of the absence.

$\checkmark$ Arrange the furniture (with the help of your big sisters) in a way that will allow for the Step into the Circle activity.

\section{SUPPLY LIST: Necessary Supplies for Week Six Mentoring Meeting}

$\checkmark$ Nametags

$\checkmark$ Snacks

$\checkmark$ Mascot or item to serve as microphone to indicate who has the floor to speak.

$\checkmark$ Hot topic box

$\checkmark$ Hot topic paper slips

$\checkmark$ Writing utensils (pens, or pencils, and markers)

$\checkmark$ Leadership Ladder

$\checkmark$ Signs made for group

$\checkmark$ Step into the Circle prompts

$\checkmark$ Sister Group information

$\checkmark$ YWLP t-shirts from previous years to show examples 


\section{CURRICULAR COMPANION}

\section{Supplemental Ideas for Implementing Mentoring Group Curriculum}

\section{Promoting Competence \& Connection through Valuing Differences}

"Remember always that you have not only the right to be an individual; you have an obligation to be one. You cannot make any useful contribution in life unless you do this." Eleanor Roosevelt

\section{Adolescents' Developmental Need for Conformity}

According to Steinberg (2005) when it comes to every day decisions like trends in music, clothing, hair, etc. adolescent are more likely to trust and conform to their peers' opinions. Conformity to peers is higher during early and middle adolescence- peaking at age 14 so it is important to remember that little sisters' behaviors, appearance, and ideas are often heavily influenced by their peers

\section{Encourage Little Sisters to Embrace their Individuality}

Developmentally, little sisters are in a stage where they do not want to stick out from the pack in any way_-good or bad. This makes it challenging for mentors, teachers, or parents to encourage early adolescent little sisters to follow their passions and talents. It is critical that the positive influences (potentially teachers, parents, big sisters, etc.) in little sisters' lives send a clear message that not only is individuality celebrated, but it is everyone's obligation to discover her own individual strengths and talents and then work to advance those talents. This sends the message that every individual has a meaningful contribution that is valuable.

\section{Supporting Sisters' Differences}

Since little sisters are still developing their interests and skills sets, sometimes their strengths and talents are not obvious to them. As big sisters learn more about their little sisters, they can provide valuable insight and encourage their little sisters to pursue interests and activities that will assist in developing related skills.

\section{Feelings of Autonomy}

Adolescents are living in this "in between" world where they are in the process of developing into emotionally autonomous individuals from parents, but are not a fully autonomous yet (Steinberg \& Silverberg, 1986). So this means that little sisters may be in a situation where they are becoming more emotionally autonomous from their parents before they are developmentally ready for this degree of independence. This is exactly where big sisters can step in and provide support for the little sisters. 


\section{FLEX OPTIONS: Energizer}

\section{Choose One:}

Leaning Towers: Repeat from last week is the group expresses interest and if not all of the sisters were able to be "leaners."

$>\quad$ Train Wreck: The group sits in a circle and one of the sisters stands in the middle of the circle. She makes a statement (e.g., "I am wearing earrings" or "I like hip hop."). Everyone who is wearing earrings scrambles to find a new chair. The person left in the middle makes the new statement.

\section{TIPS: Group Check-in}

$>\quad$ It may be a good idea to switch to the other group check-in strategy that you have not been using, just to provide some variety.

High/Lows: Read your group members. If it seems like the sisters could use some time to talk a bit more, you may want to do this is smaller groups-perhaps groups of three or four (depending on attendance) so that each sister has more time to share what is on her mind. Since academic achievement was the topic of Sister Time last week and the discussion will be continued this week, it might be a good idea to emphasize school success during High/Lows.

$>\quad H o t$ Topics Box: Discussing topics that are important to little sisters is a valuable use of time. It often gets overlooked due to time constraints, but little sisters often report in their end-of-year survey that they enjoy this activity and value the time to express their ideas about topics that are relevant to their current lives. Be sure to find time to have these discussions.

T-Shirt Design: Introduce the idea of the YWLP t-shirt. Share some of the examples that big sisters and you have from previous years. Be sure to present this as an opportunity to be creative, contribute to YWLP and leave your mark. Encourage big and little sisters to start thinking about ideas for the t-shirt design.

\section{TIPS: Sister Time}

$>\quad$ Supporting the Little Sisters' Academic Achievement: The goal of Sister Time this week is to provide a follow up form last week where the big and little sister pairs discussed academic progress.

$>\quad$ Hesitant Little Sisters (revisited): Continue the conversation...

Depending on little sisters' school performance, they may be reluctant to open up to their big sisters about their progress in school right away. Allow sufficient time 
for sisters to have a genuine discussion and to get beyond the statements, "School is fine." Also, be sure that you circulate around the room so that you can support sisters who need it, but also allow for privacy in case little sisters do not want to share their academic progress with anyone except their big sister.

Hesitant Big Sisters (revisited): Continue the conversation...

This is a topic that will need to be revisited regularly throughout the relationship. Big sisters may not be too eager to discuss academic progress with their little sisters because it may be an uncomfortable topic for little sisters. It is important that big sisters dig deeper and ask questions beyond, "How's school?"

> Guide Gently (revisited): Continue the conversation...

Big sisters need to be prepared to provide specific guidance and listen closely without judgment. Use BOOST! Depending on the situation, it may be useful for big sisters to share any struggles (maybe even from middle school) or successes that they have had in school and strategies that have worked for them.

Connect with Teachers (revisited): Continue the conversation...

As a follow up for the conversation, it may be useful for big sisters to connect with little sisters' teachers. This must be done with the permission of the little sister and should be approached as if the big sister is joining the "team" supporting the little sisters' academic achievement.

\section{TIPS: Step into the Circle}

Nurture levels of comfort. When you start the activity, it is a good idea to start with statements that are less intimate and require less risk-taking to share (e.g., If you have an older sibling, etc.). This will provide practice stepping into the circle and will increase sisters' comfort levels.

Individuals' unique qualities are what make them special. The purpose of the Step into the Circle activity is to celebrate and respect how people are special and unique. It is important to take a few moments to explain the principles supporting the activity before the group engages in Step into the Circle. Otherwise, it may seem just like a game without a purpose.

Adolescents are developmentally wired to conform. As a result it is important to remember that they want to blend in and conform to their peers. This activity asks them to do the opposite. It provides the little \& big sisters the space to take risks and share whom they truly are - if they are willing to reveal themselves.

$>\quad$ Trust is essential. If the sisters in the group do not trust one another, the Step into the Circle activity will not work. In fact, if the group members do not trust one 
another, one should not attempt this activity as it may do more harm than good.

$>\quad$ Take note of commonalities between the sisters. As you are facilitating the activity, it would be a good idea to make notes of things that big and little sisters have in common. You can use the information for later groupings. You can capitalize on that information and harness the emotions felt to draw sisters together to support one another.

Read \& monitor your sisters. Be sure to study your sisters and be alert to the non-verbal signs that may represent discomfort or anxiety. If the majority of the group is expressing discomfort, you may want to do an abbreviated version and wait until your group has bonded more. If just one or two sisters seem as though they are not ready to take the risk to be vulnerable with the group and share a bit of themselves, then provide an opportunity for the sister to gracefully exit.

Give sisters who are not ready for the activity a way to still participate, but a role that does not involve sharing- e.g., reader of the prompts.

Reflection is key. Taking the time to reflect on this activity is a key element. The purpose of the activity and particularly the discussion is to get the little sisters to think about how they are similar and dissimilar with their fellow sisters and that both are completely acceptable. This activity is meant to provide a space for sisters to learn a bit about other sisters AND about themselves.

\section{JUSTIFICATION for Step into the Circle}

If this activity is done once the group has bonded and feels safe with one another, it can have great rewards. Historically, big and little sisters have expressed that they enjoy this activity. It serves as a space to honor the unique experiences and qualities of each of the sisters while also uniting some sisters through common experiences.

\section{MEASURING STICK: Assessing Growth}

\section{Self-reflection}

○ How did you do this week as a facilitator?

- Did your little sisters meet your established outcomes for this mentoring group meeting?

\section{- Do the Little Sisters in your group know the information presented?}

- More details about fellow group members

- There are a variety of reasons that people spread gossip, but regardless of the motivation behind the act, it can cause others pain 


\begin{tabular}{l} 
- Gossip Guard is a strategy that helps discourage people from spreading \\
rumors. \\
Did they demonstrate that they understood the established understandings or \\
principles that are the foundation of the meetings' activities? \\
- Individuals' unique qualities are what make them special. \\
- People have different talents and ideas that can contribute valuably. \\
- Leaders celebrate individuality. \\
- Dan they apply the facts and principles in meaningful ways? Did they... \\
- Apply established expectations to own participation in group activities- \\
- particularly confidentiality. \\
- Discuss the relationship between the concepts of individual, autonomy and \\
competence to the ideas appreciation and support. \\
Healthy risk-taking. One way to extend this lesson beyond the Mentoring Meeting, is \\
to ask them to consider how they "step into the circle" in their daily lives. When do \\
JUSTIFICATION: \\
It is important to find some way to assess whether you effectively communicated \\
the facts and principles undergirding the Mentoring Meeting's activities. It is \\
equally important to determine (on an individual basis) whether little sisters \\
gained this understandings and knowledge. This can be done through a formal or \\
informal conversation, a comment that is made, a behavior displayed, a written \\
exit card with questions related to the outcomes (KUDs). \\
Mix up how you have the little sisters express what they know, understand and \\
can do. They will get bored when you overuse a strategy. \\
is is important that you keep track of little sisters' growth in some way- whether it \\
perhaps a notebook could be passed around the group, tracking the little sisters' \\
changes. Documenting the growth is important because it sometimes happens so \\
quickly that it is difficult to remember what the little sister used to be like or so \\
slowly and even slightly that changes are noticed. This will provide information \\
to share with parents and for the events at the end of the year. \\
\hline PRACTICAL EXTENSIONS: Relating the Activities to Real Life \\
-
\end{tabular}


they feel they need to take risks and stand up for what they believe in? What prevents them from doing so?

* Celebrate being unique. What are some small changes that big and little sisters can do to express that they are proud of their individuality? How can sisters show support for their sisters' uniqueness?

\section{THE BIG PICTURE: Uniting the Concepts within the Curriculum}

○ How does the discussion of honoring differences relate to the previous meeting that focused on supporting others? How about the previous weeks of connection and safety?

- Explicitly creating the connections between the concepts each Mentoring Meetings will deepen sisters' understanding of the concepts and will increase the chances that they will be able to transfer the skills and knowledge to new situations.

- For the visual learners, consider asking the sister to create an illustration that makes connections between some or all of the concepts. Or for the verbal processors, they can participate in a discussion that connects the concepts. 


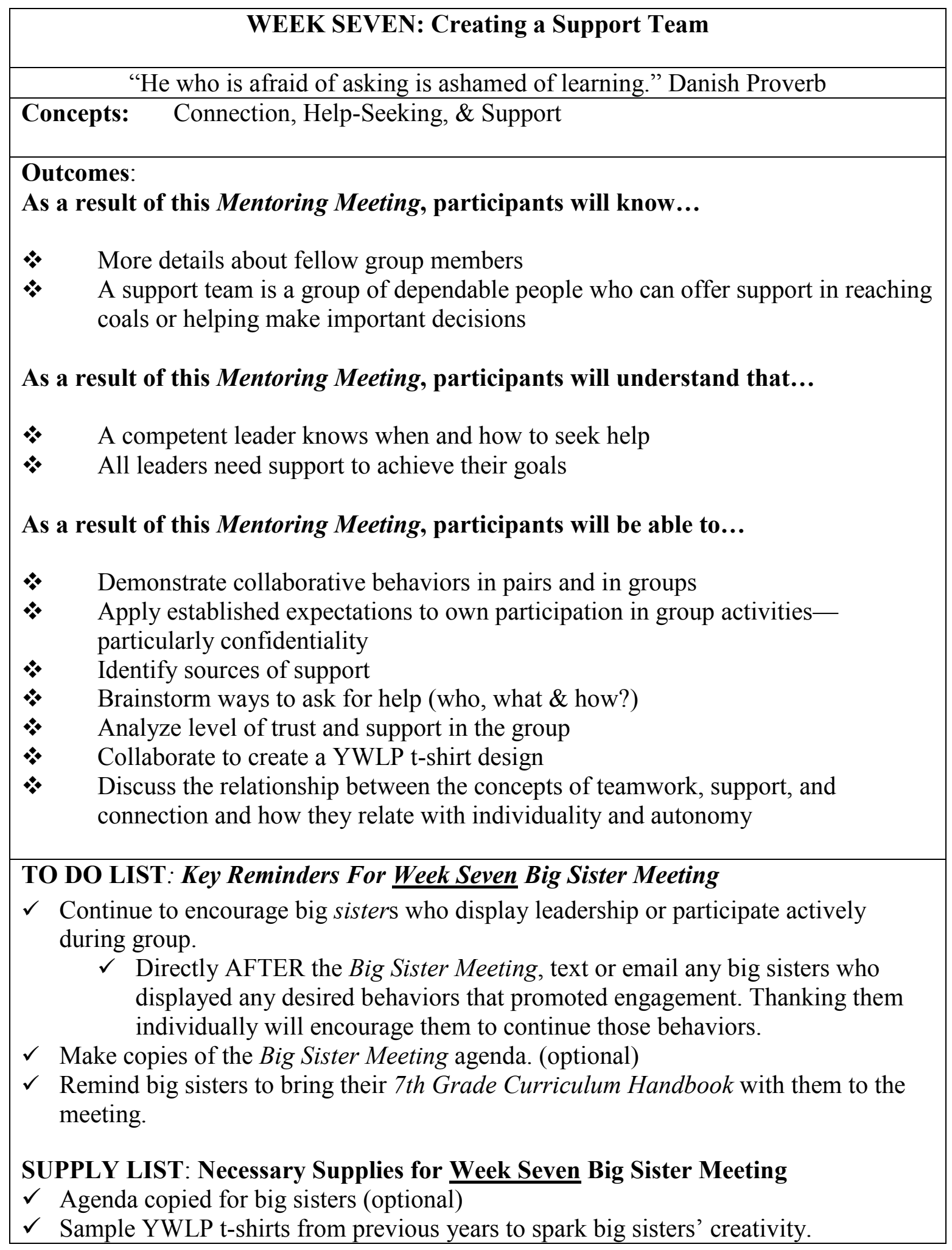




\section{AGENDA: Big Sister Meeting-Week Seven}

1) Building Big Sister Connections

a. High/Lows (individual \& pair check-in)

b. Announcements

c. Reports from Group Leadership Roles/Jobs (e.g., photographer, attendance, Sister-to-Sister, etc.)

d. Determine which big and little sisters have birthdays this week and how you are going to celebrate them.

\section{2) Reflection}

a. In small groups, pairs, or as a whole group reflect on the successes and challenges of the Mentoring Meeting from the prior week.

i. What would you change about last week's Mentoring Meetings?

ii. What did you (as a team) do well?

iii. What interesting thing happened?

iv. Who stood out as a leader? (big and little sisters)

\section{3) Strengthening Mentoring Relationships}

a. Continue this discussion if necessary.

$i$. Discuss in small group, pairs or as a whole group, where everyone is with her little sister. A mentoring relationship has stages (Introduction, Building, Growing, Maturing, Transitioning). Keep in mind that relationships can fluctuate and go backward before they go forward, or even remain static for some time.

b. What can big sisters do to support little sisters in the various domains: academics, social \& familial relationships, emotional health?

\section{4) Mentoring Group Curriculum}

\section{a. Nuts \& Bolts}

i. Discuss as a group how you want to frame the energizer and what categories (i.e., TV shows, food, cars, video games, music, etc.) you would like to use.

ii. Problem-solve potential little sisters' responses to the curriculum this week.

1. Who needs extra support?

2. What if the little sisters do not have any ideas for the t-shirt designs?

3. What type of grouping should the group use for the t-shirt creation/collaboration?

a. What would make most sense?

$b$. Who works well together?

c. Who does not usually work together?

d. Big/little pairs?

e. Should two sets of pairs work together?

iii. How can the big sisters and facilitators ensure that little sisters feel successful and supported when identifying their support team 
members?

1. What should big sisters and facilitators do if little sisters are unable to easily identify supportive people in their lives?

$i v$. How can the big sisters and facilitators stress the importance of asking for help when you need it?

\section{b. Take Away Messages}

Conduct an open discussion about what the following principles mean to the big sisters.

i) A competent leader knows when and how to seek help.

ii) Leaders know when to ask for support to achieve their goals.

\section{5) Appreciation for Big Sisters}

a. Who displayed noteworthy leadership this past week? Be specific with the behaviors and how they impact the group (or pair) interactions and dynamic. For example, "Camille always greets everyone in group with a smile and a personal question about their lives. This really makes people feel welcome and more willing to share thoughts and feelings with each other. This really brings the group together."

\section{TO DO LIST: Key Reminders For Week Seven Mentoring Meeting}

$\checkmark$ Check in with the office to be sure that they make an after-school announcement.

$\checkmark$ Your room may be locked, so arrive early enough to find a custodian to let you into your room, if necessary.

$\checkmark \quad$ At the beginning of your meeting each week, determine who is in attendance. Determine which little sisters are on your list, but not in attendance. Send the big sister who is assigned to the missing little sister (or if doable, you can) to the office to call the parents to notify them of the absence.

$\checkmark$ Be sure that you have space (floor or large tabletops) if you would like to use large sheets of paper for the t-shirt design work.

\section{SUPPLY LIST: Necessary Supplies for Week Seven Mentoring Meeting}

$\checkmark$ Nametags

$\checkmark$ Snacks

$\checkmark$ Mascot or item to serve as microphone to indicate who has the floor to speak.

$\checkmark$ Hot Topic box

$\checkmark$ Hot Topic paper slips

$\checkmark$ Writing utensils (pens, or pencils, and markers)

$\checkmark$ Using the Support Team sheet (in materials section)

$\checkmark$ Paper (and other art utensils if necessary) for the t-shirt designs

$\checkmark$ Leadership Ladder

$\checkmark$ Signs made for group (Group Guidelines, etc.) 


\begin{tabular}{|c|}
\hline CURRICULAR COMPANION \\
\hline Supplemental Ideas for Implementing Mentoring Group Curriculum \\
\hline Promoting Connection \& Competence through Seeking Help and Offering Support \\
\hline $\begin{array}{l}\text { "None of us has gotten where we are solely by pulling ourselves up from our own } \\
\text { bootstraps. We got here because somebody bent down and helped us." }\end{array}$ \\
\hline --Thurgood Marshall \\
\hline Encourage Little Sisters to Seek Help When Needed \\
\hline $\begin{array}{l}\text { There is no shame in knowing your resources and using them- in fact, that is a talent. } \\
\text { Knowing when to ask for help is an important skill to develop. Leaders possess an } \\
\text { awareness of their skill set and have an understanding of the limitations of their abilities } \\
\text { and where they may need some assistance in successfully completing a task. As big } \\
\text { sisters and women who most likely have an influence over our little sisters, it is your role } \\
\text { to assist them in self assessing their skills and abilities and send a clear message that once } \\
\text { we have put forth our best effort, and we still have questions or need assistance in } \\
\text { completing the task, it is smart to ask for help. }\end{array}$ \\
\hline Knowing Whom to Ask for Assistance \\
\hline $\begin{array}{l}\text { Just as a shop owner takes inventory of what s/he has on the shelve at the store, it is a } \\
\text { good idea for people to take a moment to reflect on their friends, or even their support } \\
\text { team and determine what skills and abilities they can offer. "What are their strengths?" } \\
\text { You can write this information in your journal or in a place that you can refer to later. } \\
\text { Then when you need to turn to someone for help, you have a list of people that might be } \\
\text { of assistance. (i.e., Notice how your friends perform on their spelling tests, algebra } \\
\text { exams, solving computer issues, etc.). }\end{array}$ \\
\hline Feelings of Connection through Offering Support \\
\hline $\begin{array}{l}\text { Helping others is good for the soul. When you help someone else, you begin to focus } \\
\text { outwardly on someone else's concerns and issues and less on the challenges that life is } \\
\text { throwing your way. Those who have a made a difference in your life may not even know } \\
\text { how they have impacted you, but you are forever changed and connected. The same goes } \\
\text { for those you help. }\end{array}$ \\
\hline
\end{tabular}




\section{FLEX OPTIONS: Energizer}

Choose One:

Leaning Towers: Repeat from last week if the group expresses interest and if not all of the sisters were able to be "leaners."

Categories: The group stands in a circle and one person stands in the middle. That person picks a category (e.g., television show, food, music, amusement park ride, etc.). She goes around the circle, giving each player 5 seconds to name something that fits that category. Be sure that she counts silently to not create stress. If the group makes it around the circle, the facilitator chooses another sister to stand in the middle. If a sister cannot think of something to fit the category, then she is out and she sits on the floor in the circle. Repeat the process until there is only person standing or until time allows.

- ADAPTATION: For groups that are shier or less confident, demonstrate with the big sisters to show the little sisters how the activity works. You may also want to adjust the 5 -second time limit if you notice that your sisters are struggling.

- ADAPTATION: If you have little sisters in your group whom you think my feel uncomfortable with the pressure of being on the spot incorporate a "lifeline" strategy to keep more sisters involved with the activity and to make it fun. Remember that the purpose of energizers is to draw into group.

- Steppin' Together: This exercise will get the group to cooperate. Teach group a three-count stomp pattern and do it together. (For example: stomp...stomp...clap...stomp...stomp...clap.... 1...2... 3...etc.) Then teach the group a four-count stomp. Then depending on the group's ability, teach a five-count stomp. Divide the group in half and assign the three, four or five- count stomp pattern to each group. Then have both groups perform simultaneously. If there is time and based on the group's success, you can have sisters create their own stomp patterns to teach to the rest of the group.

\section{TIPS: Group Check-in}

It may be a good idea to switch to the other group check-in strategy that you have not been using, just to provide some variety.

High/Lows: Read your group members. If it seems like the sisters could use some time to talk a bit more, you may want to do this is smaller groups-perhaps groups of three or four (depending on attendance) so that each sister has more time to share what is on her mind.

Hot Topics Box: It is a valuable use of time to discuss topics that are important to 
little sisters. Make time to have these discussions.

\section{TIP: Sister Time}

D Homework Help: The goal of Sister Time this week is to touch base with the events of the week and to check in about homework assignments/school progress. It might be helpful to actually take a quick look at the little sisters' backpacks, binders, or lockers to determine if they need assistance with organization.

\section{TIPS: Leaders Create Support Teams}

$>\quad$ Accomplished people have many people to thank. Emphasize the message that all successful people lean on those who have blazed the trail before them. It is considered savvy and resourceful to "stand on the shoulders of giants" and build on other's previous efforts and not reinvent the wheel. This applies to the idea that we need to guide our little sisters in the pursuit of determining their strengths and areas that are not quite as strong and teach them the skills to ask for help when necessary.

Read \& monitor your sisters. This exercise may be challenging for some little sisters and they may not feel as though they have a lot of supportive people in their lives. Read your little sisters and start with school resources like counselors or teachers first if it seems as though they do not have a lot of supportive relationships outside of school.

$>\quad$ Determine where the diagram will be displayed. Help your little sisters visualize where they will hang their sign. Also share where you are planning to hang your sign. It might be a private place like in your room or the back of a cabinet door or closet or public like the refrigerator. Discuss the advantages of the various spots. This will increase the likelihood that they will actually hang it up. Check back in with little sisters in a few weeks to see if they have actually hung it up and whether they have consulted any of the people on their Support Team.

\section{JUSTIFICATION:}

This is a useful exercise for everyone! It is helpful to have a concrete list of dependable people in our lives with their specific skills for easy reference when we are in a jam or need some extra assistance completing a task.

\section{TIPS: Leadership Project IV: YWLP T-Shirt Design}

$>$ Brainstorm Ideas: You may decide to do this in pairs, small groups, or larger groups, depending on the energy and creativity of your group members. Respond to them, but be prepared with pre-made groupings in case you decide to go that 
way because groupings do matter. Think about big and little sisters' strengths with regard to creativity and interpersonal skills of collaboration, and leadership.

Listen to Feedback: When the t-shirt ideas are shared, frame the discussion in a way that is non-judgmental, but rather supportive and collaborative. Have sisters highlight what they like about the designs and what works first and list those positive elements on the board so that you can then refer to them as the ideas are shared and you are moving toward the final product.

Negotiate Differences \& Compromise: Be sensitive in this discussion and be sure that all sisters have the opportunity to share their ideas. Capitalize on the various elements that people like. If necessary, vote anonymously so that you can move the group along in the decision-making process, but spare sisters' feelings. Try to incorporate something from each idea presented. This will empower everyone and make her feel as though they are a part of the group's design.

$>\quad$ Develop Final Product: This can be a painstaking process if you do not streamline it. As you are developing the ideas for the final product, be sure to note all of the aspects from the various ideas presented and even give verbal credit to the people who had the ideas so that they feel validated. You may need to divide the process into the various elements (e.g., color of shirt, color of print, design, pocket, front, back, etc.) in order to expedite the development. Make a concerted effort to come to a conclusion before the group ends.

\section{MEASURING STICK: Assessing Growth}

\section{* Self-reflection}

- How did you do this week as a facilitator on a scale from 1-5 (5 being best)?

- What were your strengths in this group meeting?

- In what ways did you foster potential in your little sisters?

- What would you like to improve?

* Reflection on teamwork

- In what ways did your big sisters support you and help lead the meeting?

- How could the big sisters improve?

- $\quad$ Did your little sisters meet your established outcomes for this Mentoring Meeting?

* Do the Little Sisters in your group know the information presented?

- $\quad$ More details about fellow group members

- $\quad$ A support team is a group of dependable people who can offer support in 


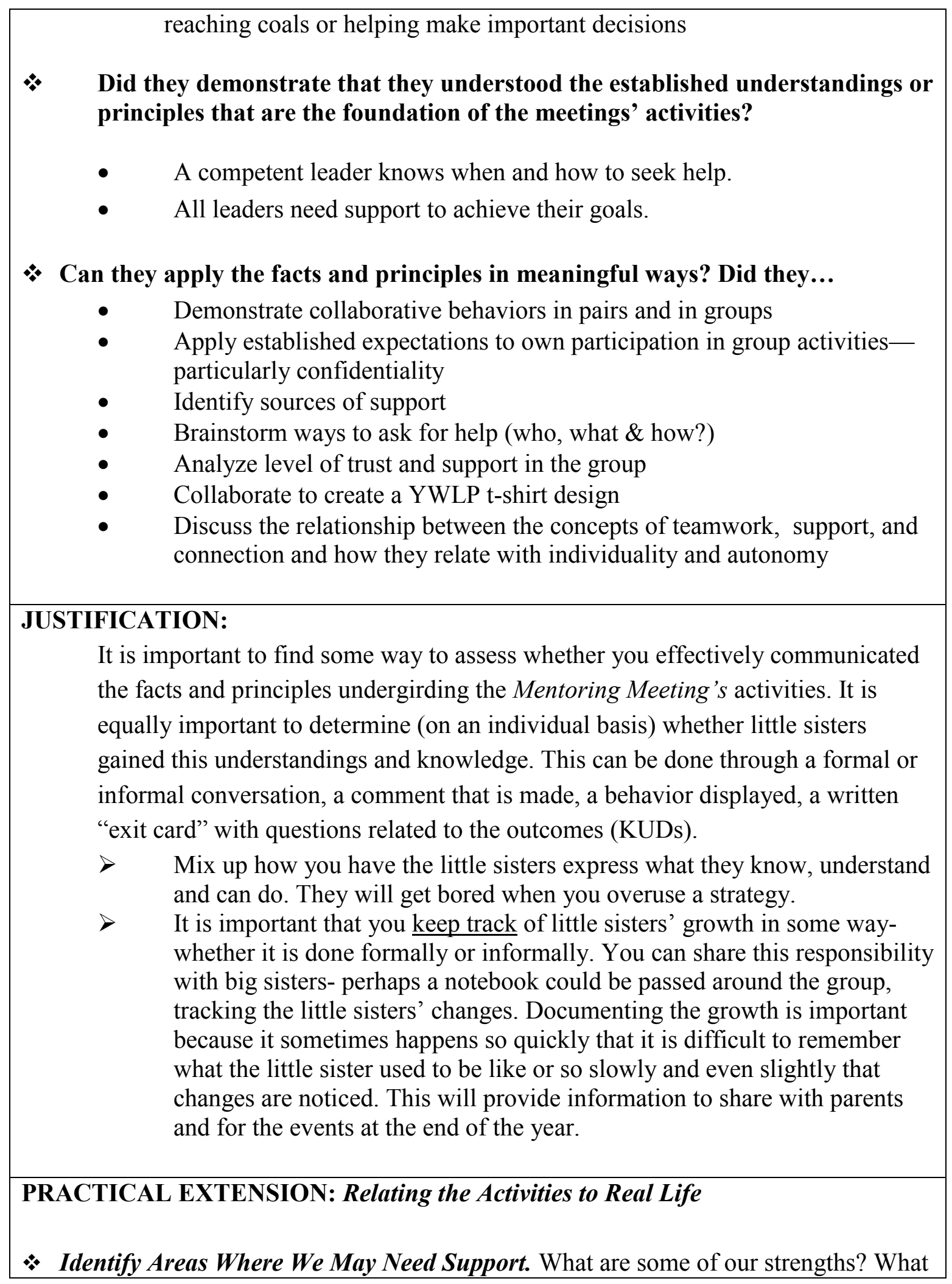


are some of our areas of improvement? What goals do we have and what skills and resources do we need to attain those goals?

* Utilizing the Support Team. Take some time to think about what each person on our support team has to offer, meaning what talents and gifts do they possess? What are some ways that each person can serve as a resource?

THE BIG PICTURE: Uniting the Concepts within the Curriculum

- How does the discussion of seeking help relate to the previous meeting that focused on honoring differences? How about the previous weeks' concepts?

- Explicitly creating the connections between the concepts each Mentoring Meetings will deepen sisters' understanding of the concepts and will increase the chances that they will be able to transfer the skills and knowledge to new situations.

- For the visual learners, consider asking the sister to create an illustration that makes connections between some or all of the concepts. Or for the verbal processors, they can participate in a discussion that connects the concepts. 


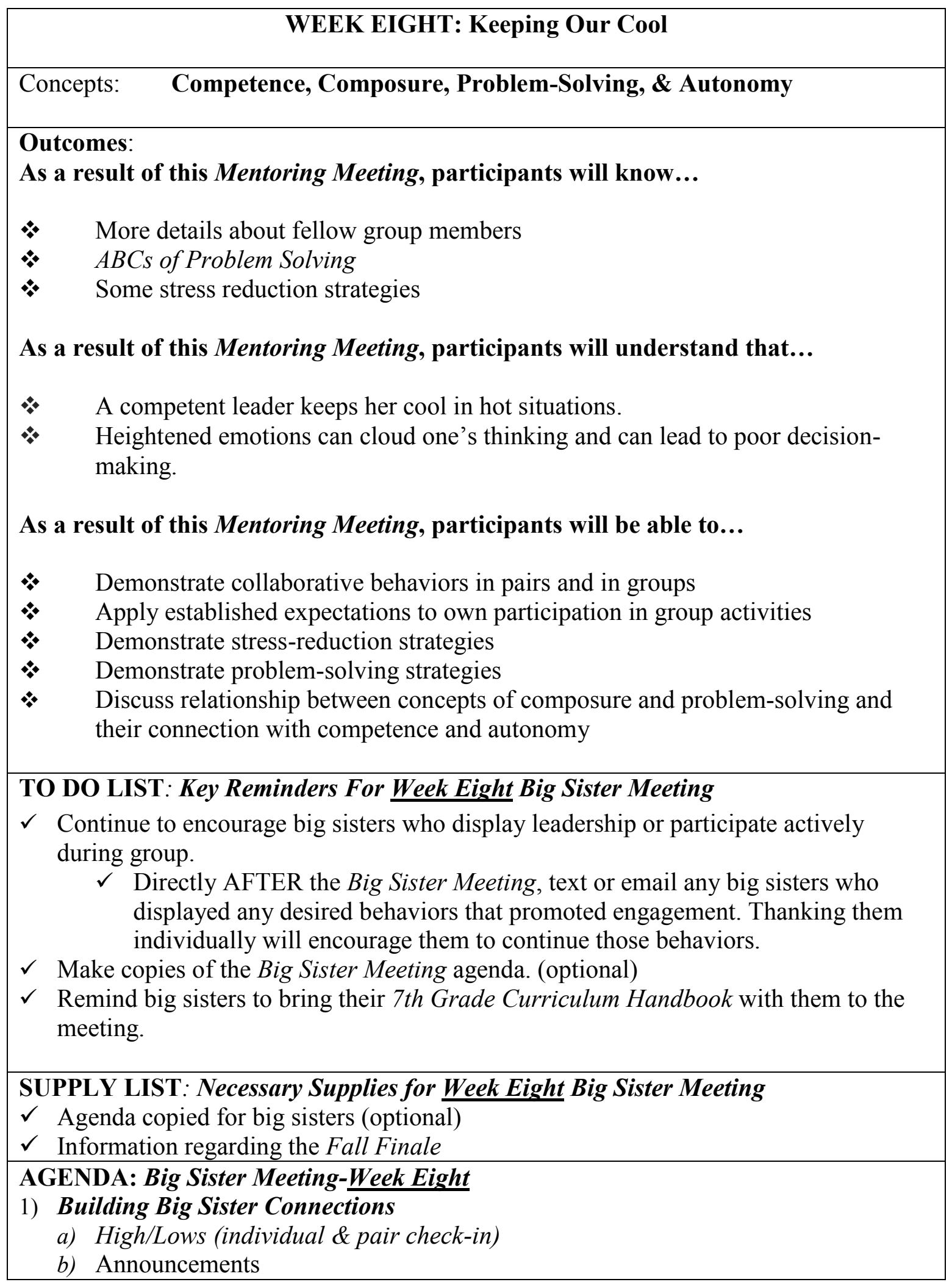


c) Reports from Group Leadership Roles/Jobs (e.g., photographer, attendance, Sister-to-Sister, etc.)

d) Determine which big and little sisters have birthdays this week and how you are going to celebrate them.

2) Reflection

a) In small groups, pairs, or as a whole group reflect on the successes and challenges of the Mentoring Meeting from the prior week.

i. What would you change about last week's Mentoring Meetings?

ii. What did you (as a team) do well?

iii. What interesting thing happened?

iv. Who stood out as a leader? (big and little sisters)

\section{3) Strengthening Mentoring Relationships}

a) This should be an on-going discussion that involves reflection, assessment, and re-assessment as relationships of this nature evolve and continually change shape.

$i$. Discuss in small group, pairs or as a whole group, where everyone is with her little sister. A mentoring relationship has stages (Introduction, Building, Growing, Maturing, Transitioning). Keep in mind that relationships can fluctuate and go backward before they go forward, or even remain static for some time.

ii. What can big sisters do to support little sisters in the various domains: academics, social \& familial relationships, emotional health?

\section{4) Mentoring Group Curriculum}

\section{a) Nuts \& Bolts}

$i$. Discuss as a group what you would like to do for the energizer. Yoga?

Stretching? What would your sisters enjoy the most?

ii. Problem-solve potential little sisters' responses to the curriculum this week.

i. Who needs extra support?

ii. What if the little sisters do not want to participate in the energizer? How can you present the exercise with enthusiasm that will make them want to participate?

iii. What if the little sisters do not remember the Leadership Secrets? How can big sisters support their little Sisters by providing hints or scaffolding?

$i v$. How can big sisters and facilitators organize the discussion about the Fall Finale presentation in a time- efficient manner?

v. How can big sisters check in with their little sisters about their progress in school without appearing judgmental? How can big sisters encourage their little sisters to open up to them about how they are doing and in what areas they need help?

iii. How will the big sisters and facilitators organize the Stress Reduction Stations?

i. What strategies should you introduce? 


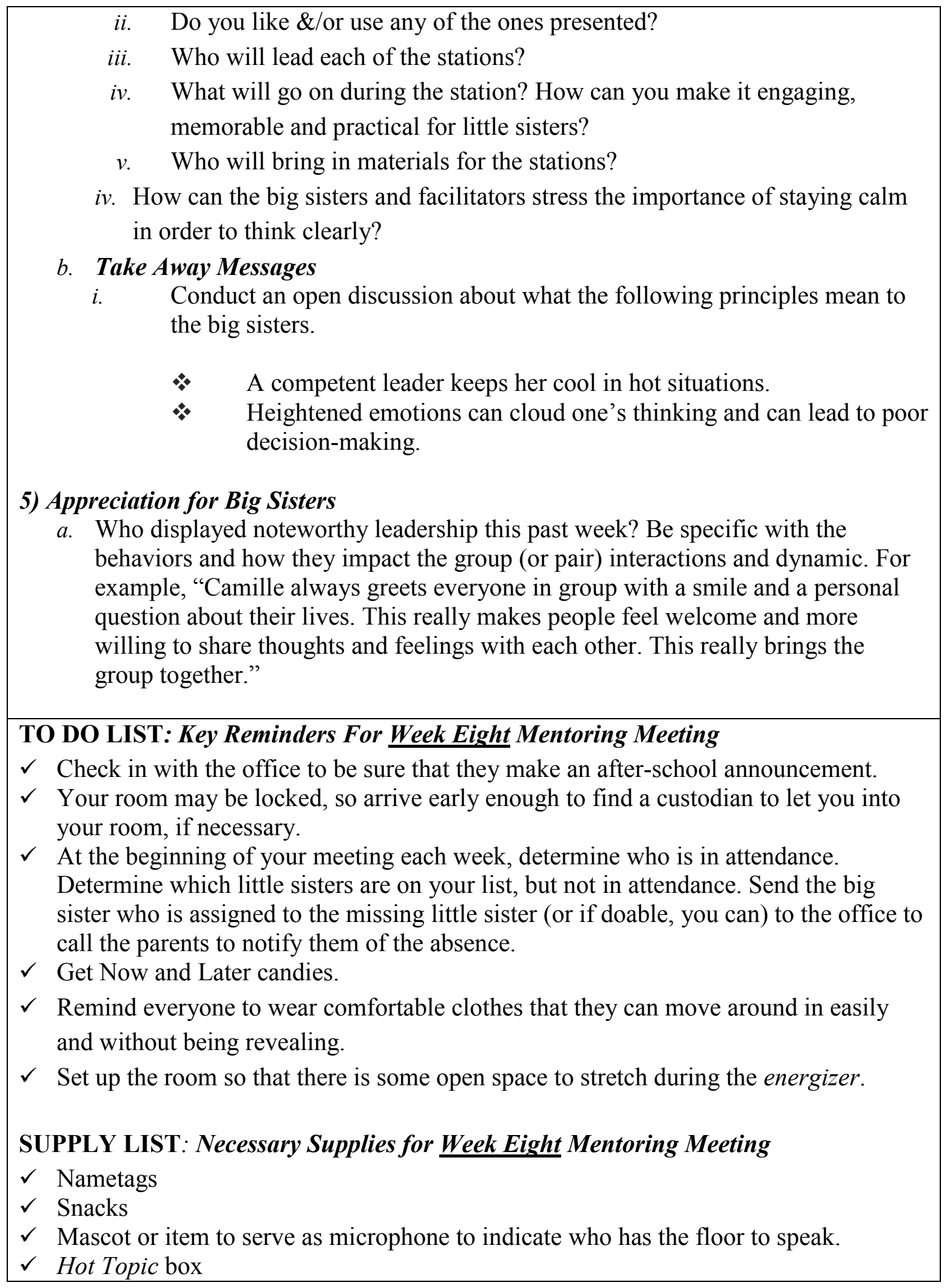


\begin{tabular}{|ll}
\hline$\checkmark$ & Hot Topic paper slips \\
$\checkmark$ & Writing utensils (pens, or pencils, and markers) \\
$\checkmark$ & Leadership Ladder \\
$\checkmark$ & Signs made for group (Group Guidelines, etc.) \\
$\checkmark$ & Now and Later candies \\
$\checkmark$ & Materials for Stress Reduction Stations (e.g., pillow, music, workout equipment, \\
& paper to scrunch, etc.)
\end{tabular} CURRICULAR COMPANION

Supplemental Ideas for Implementing Mentoring Group Curriculum

Promoting Competence through by Avoiding Emotional Decision-Making

"The sign of intelligent people is their ability to control emotions by the application of reason." - Marya Mannes

\section{Self-Control and Taking Charge}

When a person remains poised in the face of a high-pressure or uncomfortable circumstance, it exhibits that she has self-control. Successful leaders take charge of their lives by controlling their emotions, thoughts, and how they deal with problems. They have an air of confidence and know how to manage their emotions to ensure they make decisions that are thoughtful and driven by reason and logic. They avoid making snap decisions based on careless, knee-jerk reactions. Once a person realizes she cannot control others or the adverse, stressful situations that life presents, but she does have control of herself and how she reacts to those situations, it reduces her stress level, empowers her, and fosters a healthy approach to life.

\section{Manage Stress the Use of Stress Reduction Strategies}

Stress can be managed. Identifying sources of stress is a helpful starting point, but some times that can be a bit abstract for adolescents and so they may need guidance. Potential triggers of stress may be related to: friendships, relationships with family members, academic achievement, romantic relationships, and responsibilities at home. Once they recognize the stress triggers, big sisters can help little sisters devise a game plan of healthy management.

Stress can be lowered through a variety of techniques. It varies by individuals and a technique that works for one may not work for another. In fact, something that reduces stress for one person might even serve as a trigger for another. It is important to consider all of the senses and what makes a person go to a "happy place." Reflecting (perhaps verbally with a partner) on what spaces, places, and activities can assist individuals in decreasing feelings of anxiety. 


\section{TIPS: Energizer}

$>\quad$ Stress Reducer: Remember that the intent of this activity is to reduce stress so keep in mind that you do not want to make your sister participate in something that is going to cause stress or make them feel uncomfortable. Decide as a group what activity would be appropriate for your group based on your observations of your little sisters from previous weeks and what you know about them. It would make sense to have one or two people leading the group in the breathing, yoga, etc. It would be ideal if a big/little pair stepped forward and took the initiative, but if you, as the facilitator, know that some of your sisters have experience with these exercises, you may ask them to lead. This could serve as a valuable way for several sisters to contribute, which would result in empowering them.

\section{TIPS: Group Check-in}

$>\quad$ Read your group to determine which check-in strategy is most suitable based on recent events of which you are aware, the energy the sisters are displaying, etc.

$>\quad$ High/Lows: Decide whether your group needs some whole- group or small-group bonding and then create the groupings based on that.

Hot Topics Box: It is a valuable use of time to discuss topics that are important to little sisters. Make time to have these discussions.

Fall Finale: Be sure to remind everyone of the Fall Finale and get sisters to start thinking about potential ideas for the performance aspect. If you bring this up over some time, you will allow sisters to have more time to consider possibilities and creativity.

\section{TIP: Sister Time}

DHomework Help: The goal of Sister Time this week is to touch base with the events of the week and to continue the conversation about homework assignments/school progress. It might be helpful to actually take a quick look at the little sisters' backpacks, binders or lockers to determine if they need assistance with organization.

\section{TIPS: Leadership Secret-Leaders Keep Their Cool I}

$>\quad$ Stress happens. Stress is unhealthy and can lead to other mental and physical complications. Send a clear message that life can be stressful at times for everyone, no matter who you are. Emphasize to the sisters in your group that the pressures of life cannot be avoided, so it is important to learn how to control and 
manage our responses to these pressures so that we can react in healthy ways and reduce our stress levels. We have more control over our stress levels than we might think we do.

Keep a close eye on the time. As the facilitator, be sure to keep your eye on the time and use a timer on your phone or watch to keep track of the time spent at each station. Determine how you are going to signal the sisters to change stations. It may seem silly, but you may even decide to practice switching stations to increase efficiency.

Internalize the stress reduction techniques. Take time to reflect after the sisters have all visited each of the stations. Each person is different and different stress reduction strategies work for different people so it important to allow time for everyone to process and consider which strategies might work best for them individually.

\section{JUSTIFICATION:}

At some point in time, life becomes stressful for everyone. Learning healthy ways to manage stress and to remain levelheaded in the face of tense situations is a valuable tool.

\section{TIPS: Leadership Secret- Leaders Keep Their Cool II}

$>\quad$ Make it personal, but not too personal. Use personal examples that the sisters have experienced, but be sure to lay clear ground rules that no names should be used. Monitor sisters' emotional levels and if they become too emotional that they cry or become excessively angry, splinter the groups off and have little sisters share one-on-one with their big sisters. Also beware of ganging up on one person, whether it is an individual who is present or not, but especially if it is about another little sister in the group.

$>\quad$ Highlight the use of logic and problem solving line of thinking. Focus the conversation on how they feel and how they are going to respond. Remind them that they cannot control what others do, but they can control their own actions. Look as objectively as possible at the circumstances and emphasize that it is a problem that needs to be solved in a reasonable, not emotional, manner.

\section{MEASURING STICK: Assessing Growth}

* Self-reflection

- How did you do this week as a facilitator on a scale from 1-5 (5 being best)? 


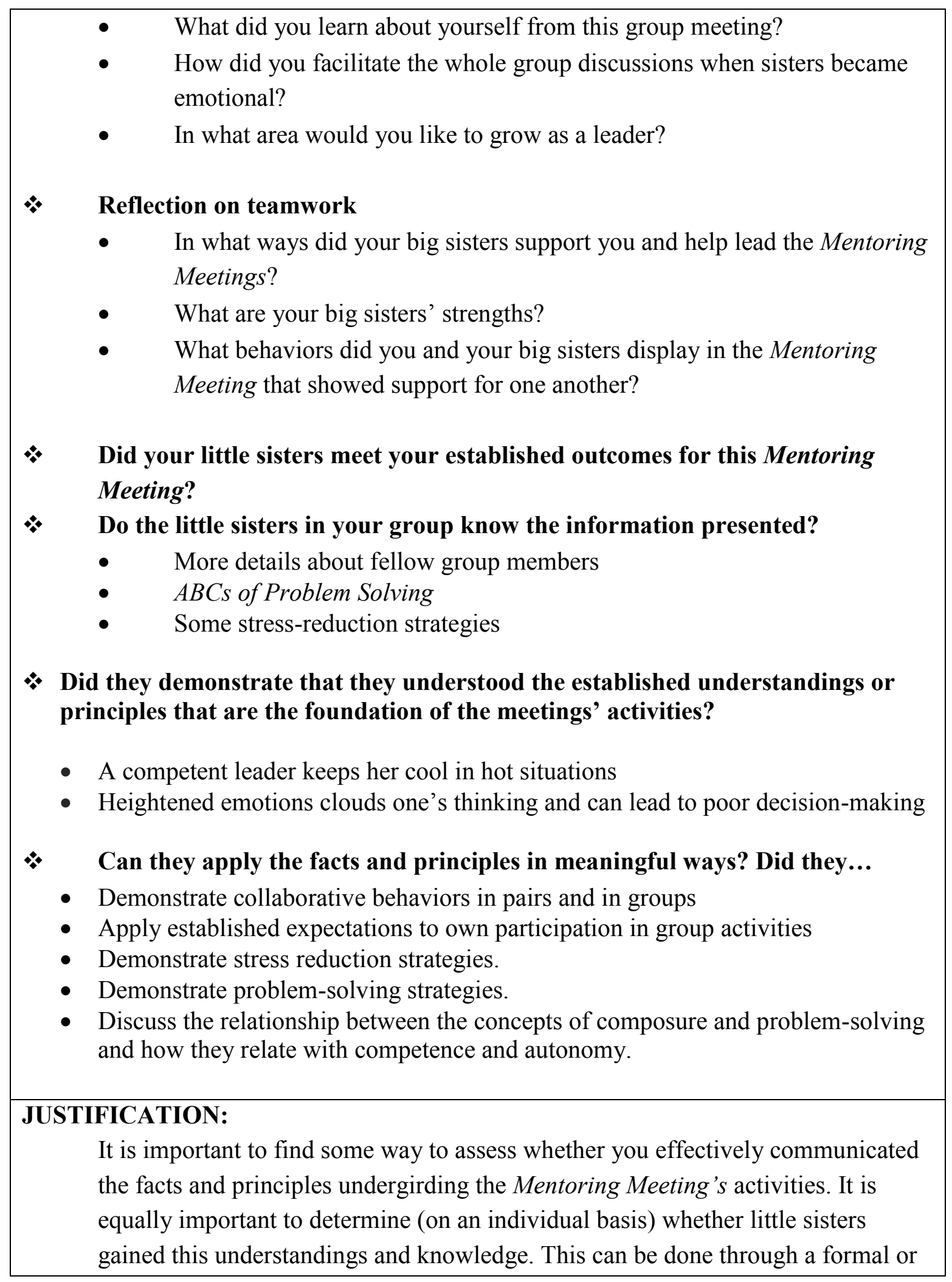




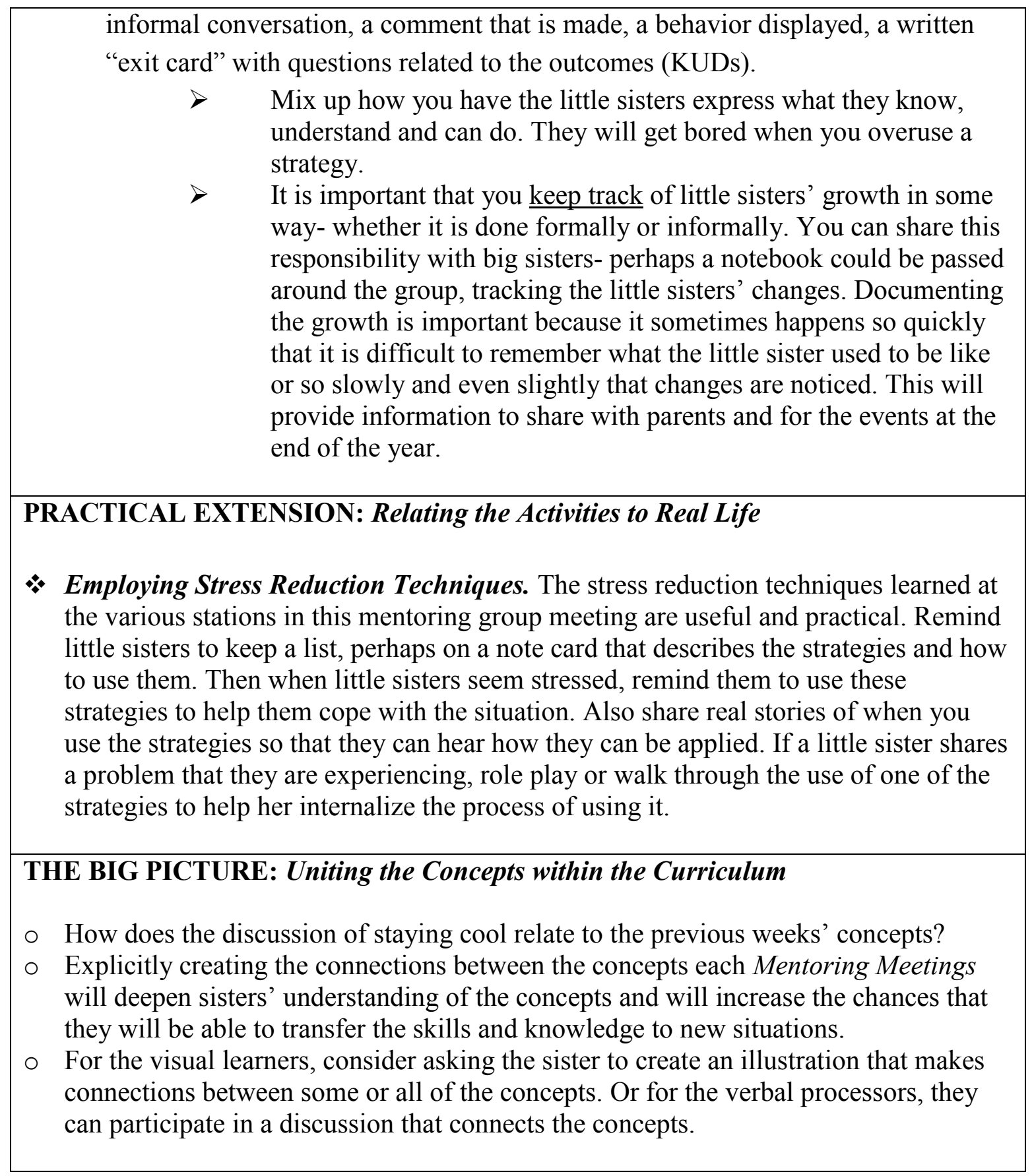




\begin{tabular}{|c|c|}
\hline & WEEK NINE: Valuing Myself: What Gets in the Way? \\
\hline & "Nobody can make you feel inferior without your consent. Eleanor Roosevelt \\
\hline & Respect, Self-Worth, \& Messages \\
\hline & $\begin{array}{l}\text { comes: } \\
\text { result of this Mentoring Meeting, participants will know... }\end{array}$ \\
\hline & More details about fellow group members \\
\hline & Society, school, family and friends can affect the way a person feels about herself \\
\hline & Messages about girls/women are communicated through the media \\
\hline & We communicate messages about ourselves through social media \\
\hline & result of this Mentoring Meeting, participants will understand that... \\
\hline 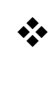 & $\begin{array}{l}\text { Leaders recognize their self-worth and behave in ways that communicate respect } \\
\text { for themselves and others. }\end{array}$ \\
\hline & $\begin{array}{l}\text { The messages communicated through the media can shape how girls and women } \\
\text { view themselves and others. }\end{array}$ \\
\hline & result of this Mentoring Meeting, participants will be able to... \\
\hline 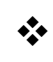 & Collaborate in pairs and in groups to reach a common goal \\
\hline & Apply established expectations to own participation in group activities \\
\hline & $\begin{array}{l}\text { Compare and contrast issues of self-perception and self- esteem with which they } \\
\text { are faced as Americans girls/women with those of girls/women in other countries. }\end{array}$ \\
\hline$*$ & Analyze messages communicated by the media and ourselves \\
\hline & $\begin{array}{l}\text { Discuss the relationship between the concepts of self-worth, respect, and } \\
\text { messages and how they relate with connection (with self and others) and } \\
\text { autonomy }\end{array}$ \\
\hline & DO LIST: Key Reminders For Week Nine Big Sister Meeting \\
\hline & $\begin{array}{l}\text { Continue to encourage big sisters who display leadership or participate actively } \\
\text { during group. } \\
\checkmark \text { Directly AFTER the Big Sister Meeting, text or email any big sisters who } \\
\text { displayed any desired behaviors that promoted engagement. Thanking them } \\
\text { individually will encourage them to continue those behaviors. }\end{array}$ \\
\hline & Make copies of the Big Sister Meeting agenda. (optional) \\
\hline & $\begin{array}{l}\text { Remind big sisters to bring their } 7^{\text {th }} \text { Grade Curriculum Handbook with them to the } \\
\text { meeting. }\end{array}$ \\
\hline
\end{tabular}




\section{SUPPLY LIST: Necessary Supplies for Week Nine Big Sister Meeting}

$\checkmark$ Agenda copied for big sisters (optional)

$\checkmark$ Videos to potentially use to discuss the role and presentation of women. Ask big sisters to bring links of videos to potentially use

$\checkmark$ Laptop to watch the videos together (optional)

\section{AGENDA: Big Sister Meeting-Week Nine}

1) Building Big Sister Connections

a. High/Lows (individual \& pair check-in)

b. Announcements

c. Reports from Group Leadership Roles/Jobs (e.g., photographer, attendance, Sister-to-Sister, etc.)

d. Determine which big and little sisters have birthdays this week and how you are going to celebrate them.

\section{2) Reflection}

a. In small groups, pairs, or as a whole group reflect on the successes and challenges of the Mentoring Meeting from the prior week.

ii. What would you change about last week's Mentoring Meetings?

iii. What did you (as a team) do well?

iv. What interesting thing happened?

$v$. Who stood out as a leader? (big and little sisters)

\section{3) Strengthening Mentoring Relationships}

a. Continue this discussion if necessary.

$i$. Discuss in small group, pairs or as a whole group, where everyone is with her little sister. A mentoring relationship has stages (Introduction, Building, Growing, Maturing, Transitioning). Keep in mind that relationships can fluctuate and go backward before they go forward, or even remain static for some time.

ii. What can big sisters do to support little sisters in the various domains: academics, social \& familial relationships, emotional health?

\section{4) Mentoring Group Curriculum}

a) Nuts \& Bolts

ii. Discuss as a group which energizers you like the best and which were the most successful. It might be a good idea to narrow down some choices for the little sisters in case they do not remember the energizers. Make sure to allow other ideas if they do by chance remember ones that they particularly liked.

iii. Problem-solve potential little sisters' responses to the curriculum this week.

1. What if the little sisters do not have any ideas about energizers?

a) How would you like to present the energizer?

2. What if the little sisters do not want to open up about their progress in 
school or their homework?

a) What are some ways that we could get them to open up and make them feel safe?

3. What type of grouping should the group use for the Leaders Respect Themselves activities as well as the Fall Finale collaboration?

a) Who works well together and who does not usually work together?

b) Big/little pairs?

c) Should two sets of pairs work together?

\section{5) Take Away Messages}

a) Conduct an open discussion about what the following principles mean to the big sisters.

- Leaders recognize their self-worth and behave in ways that communicate respect for herself and others.

- The messages communicated through the media can shape how girls and women view themselves.

\section{6) Appreciation for Big Sisters}

a) Who displayed noteworthy leadership this past week? Be specific with the behaviors and how they impact the group (or pair) interactions and dynamic. For example, "Camille always greets everyone in group with a smile and a personal question about their lives. This really makes people feel welcome and more willing to share thoughts and feelings with each other. This really brings the group together."

\section{TO DO LIST: Key Reminders For Week Nine Mentoring Meeting}

$\checkmark$ Check in with the office to be sure that they make an after-school announcement.

$\checkmark$ Your room may be locked, so arrive early enough to find a custodian to let you into your room, if necessary.

$\checkmark \quad$ At the beginning of your meeting each week, determine who is in attendance. Determine which little sisters are on your list, but not in attendance. Send the big sister who is assigned to the missing little sister (or if doable, you can) to the office to call the parents to notify them of the absence.

$\checkmark \quad$ Make sure that you and all of our big sisters bring 7th Grade Curriculum Handbook so that you can refer to the questions to pose during the Media Myths activity.

$\checkmark$ Confirm that you have Internet connection or that your music videos are saved on a thumb drive, cd, etc.

\section{SUPPLY LIST: Necessary Supplies for Week Nine Mentoring Meeting}

$\checkmark$ Nametags, if necessary

$\checkmark$ Snacks

$\checkmark$ Mascot or item to serve as microphone to indicate who has the floor to speak. 
$\checkmark$ Hot Topic box \& paper slips

$\checkmark$ Writing utensils (pens, or pencils, and markers)

$\checkmark$ Leadership Ladder

$\checkmark$ Signs made for group (Group Guidelines, etc.)

$\checkmark$ Magazines (enough for each little sister to have her own)

$\checkmark$ Questions (listed in 7th Grade Curriculum Handbook) to pose during the Media Myths activity

$\checkmark$ Music videos (If you plan to show videos online, be sure you have internet access or save videos to a thumb drive or $\mathrm{cd}$ ) 


\begin{tabular}{l} 
CURRICULAR COMPANION \\
Supplemental Ideas for Implementing Mentoring Group Curriculum \\
Promoting Competence Through Recognizing Messages We \& Others \\
Communicate \\
About Ourselves as Girls \& Women \\
"It took me a long time not to judge myself through someone else's eyes." \\
-Sally Field \\
\hline $\begin{array}{l}\text { Be Mindful of Messages We Send About Ourselves } \\
\text { Every action we make sends a message about who we are and how we perceive } \\
\text { ourselves. From the way we dress, the manner in which we talk, the way we treat others, } \\
\text { to even how we solve problems and apply ourselves in the face of a challenge. It is an } \\
\text { important lesson for little sisters to learn this idea and to encourage them to reflect on } \\
\text { how their actions communicate who they are. Some times there is a disconnect between } \\
\text { who a person is and the way they portray themselves. Reflecting on that disconnect can } \\
\text { help a person analyze if they need to adjust their behaviors or their self-perception. Since } \\
\text { little sisters are at an age where they are rather malleable and seeking to define their } \\
\text { identity, big sisters are in the unique role of guiding little sisters in this process, while } \\
\text { maintaining non-judgmental support. } \\
\text { The instantaneous sending of messages literally and figuratively on social media sites can } \\
\text { be a challenge for anyone to manage, but particularly for adolescents who are still in the } \\
\text { process of determining who they are. Big sisters should discuss the challenges of using } \\
\text { social media. Taking a closer look at the messages they are personally communicating } \\
\text { about themselves through the images, comments, etc. on Facebook, Twitter and other } \\
\text { social media would be a helpful exercise. }\end{array}$
\end{tabular}




\section{TIPS: Energizer}

$>\quad$ Wild Card: Come to the mentoring group meeting prepared. At the Big Sister Meeting, brainstorm energizers that little sisters enjoyed and seemed to bring out the best in the group. Then when you offer the choice to the little sisters, it will save time and you can offer a few ideas of ones that were successful. Stay open to other suggestions from little sisters and follow the momentum and desires of the group.

\section{TIPS: Group Check-in}

$>\quad$ It may be a good idea to switch to the other group check-in strategy that you have not been using, just to provide some variety.

$>\quad$ High/Lows: Read your group members. If it seems like the sisters could use some time to talk a bit more, you may want to do this is smaller groups-perhaps groups of three or four (depending on attendance) so that each sister has more time to share what is on her mind.

$>\quad$ Hot Topics Box: It is a valuable use of time to discuss topics that are important to little sisters. Make time to have these discussions.

\section{TIP: Sister Time}

Homework Help: The goal of Sister Time this week is to touch base with the events of the week and to continue the conversation about homework assignments/school progress. It might be helpful to actually take a quick look at the little sisters' backpacks, binders or lockers to determine if they need assistance with organization.

\section{TIPS: Leaders Respect Themselves}

$>\quad$ Prompt analysis and independent thinking. Use the questions to encourage little sisters to genuinely think about the messages being communicated. Structure the groups so that there is accountability, meaning that little sisters have a job for which they are responsible. This will increase their engagement.

Optimize grouping to foster discussion. Organize groups so that little sisters feel comfortable sharing their ideas. Be mindful of not putting overly domineering sisters with introverted ones.

Wait for Little Sisters to respond. Do not be afraid of silence. Use extended wait times after posing a question. Do not "bail out" the little sisters as jumping in and "saving" them will communicate a lower expectation for their ability to think 
and consider the question and as a result will decrease participation.

\section{JUSTIFICATION:}

Taking some time to analyze and discuss the ways in which girls and women are portrayed in the media today is a useful exercise. It can assist sisters in considering how they portray themselves and whether it contradicts or coincides with the media. It is a powerful, concrete way to open some girls' eyes and will change the way some little sisters see themselves and other girls and women.

\section{TIPS: Leadership Project V: Fall Finale Presentation}

$>$ Brainstorm Ideas: Optimistically, you are beyond the brainstorming stage, but you may need more time to narrow down your ideas. If so, continue the brainstorming process in pairs, small groups, or larger groups, whatever will be the most productive. Circulate and listen to the groups' ideas. Think about ways that you can incorporate the various ideas so that people feel as though they have contributed and are validated and empowered.

$>\quad$ Presentation: Share ideas of previous years, but push your group to be creative and try to think of a new way to present. Based on your observations, it might be a good idea to delegate a pair to be the leaders. You might also want to divide the presentation into various aspects and have groups make decisions on that, such as lyrics, movements, flow, etc.

Film it: It is a good idea to film your presentation and even watch it if time allows. Then the little and big sisters can see what they look like and can make adjustments before the Fall Finale if need be. It also is a concrete way for the Sister Group to get to now the group.

\section{MEASURING STICK: Assessing Growth}

\section{* Self-reflection}

- How did you do this week as a facilitator on a scale from 1-5 (5 being best)?

- What were your strengths in this group meeting?

- How have you progressed in the area that you identified as an area in which you would like to grow?

\section{Reflection on teamwork}

- In what ways did your big sisters support you and help lead the Mentoring Meeting?

- How did you and your group work together? 
* Do the little sisters in your group know the information presented?

- More details about fellow group members

- Society, school, family and friends can affect the way a person feels about herself

- Messages about girls/women are communicated through the media

- We communicate messages about ourselves through social media

Did they demonstrate that they understood the established understandings or principles that are the foundation of the meetings' activities?

- Leaders recognize their self-worth and behave in ways that communicate respect for themselves and others

$\circ$ The messages communicated through the media can shape how girls and women view themselves and others

* Can they apply the facts and principles in meaningful ways? Did they...

- Apply established expectations to own participation in group activities

- Collaborate in pairs and in groups to reach a common goal

- Apply established expectations to own participation in group activities

- Compare and contrast issues of self-perception and self-esteem with which they are faced as Americans girls/women with those of girls/women in other countries

- Analyze messages communicated by the media and ourselves

- Discuss the relationship between the concepts of self-worth, respect, and messages and how they relate with connection (with self and others) and autonomy

\section{JUSTIFICATION:}

It is important to find some way to assess whether you effectively communicated the facts and principles undergirding the Mentoring Meeting's activities. It is equally important to determine (on an individual basis) whether little sisters gained this understandings and knowledge. This can be done through a formal or informal conversation, a comment that is made, a behavior displayed, or a written exit card with questions related to the outcomes (KUDs).

\section{PRACTICAL EXTENSION: Relating the Activities to Real Life}

* Stand up and take action. Write to a company to express your disapproval of the messages they are sending out about girls and women. This might be a small business owner who carries a product that expresses a negative depiction of girls or women or it might mean that you write to an actual company that makes a product. Change can happen as a result of your letter, phone calls, petitions, etc.

\section{THE BIG PICTURE: Uniting the Concepts within the Curriculum}



* How does the discussion of self-worth and respect relate to the concept of connection? How about the previous weeks' concepts?
* Explicitly creating the connections between the concepts each Mentoring Meetings will deepen sisters' understanding of the concepts and will increase the chances that they will be able to transfer the skills and knowledge to new situations.
- For the visual learners, consider asking the sister to create an illustration that makes connections between some or all of the concepts. Or for the verbal processors, they can participate in a discussion that connects the concepts.




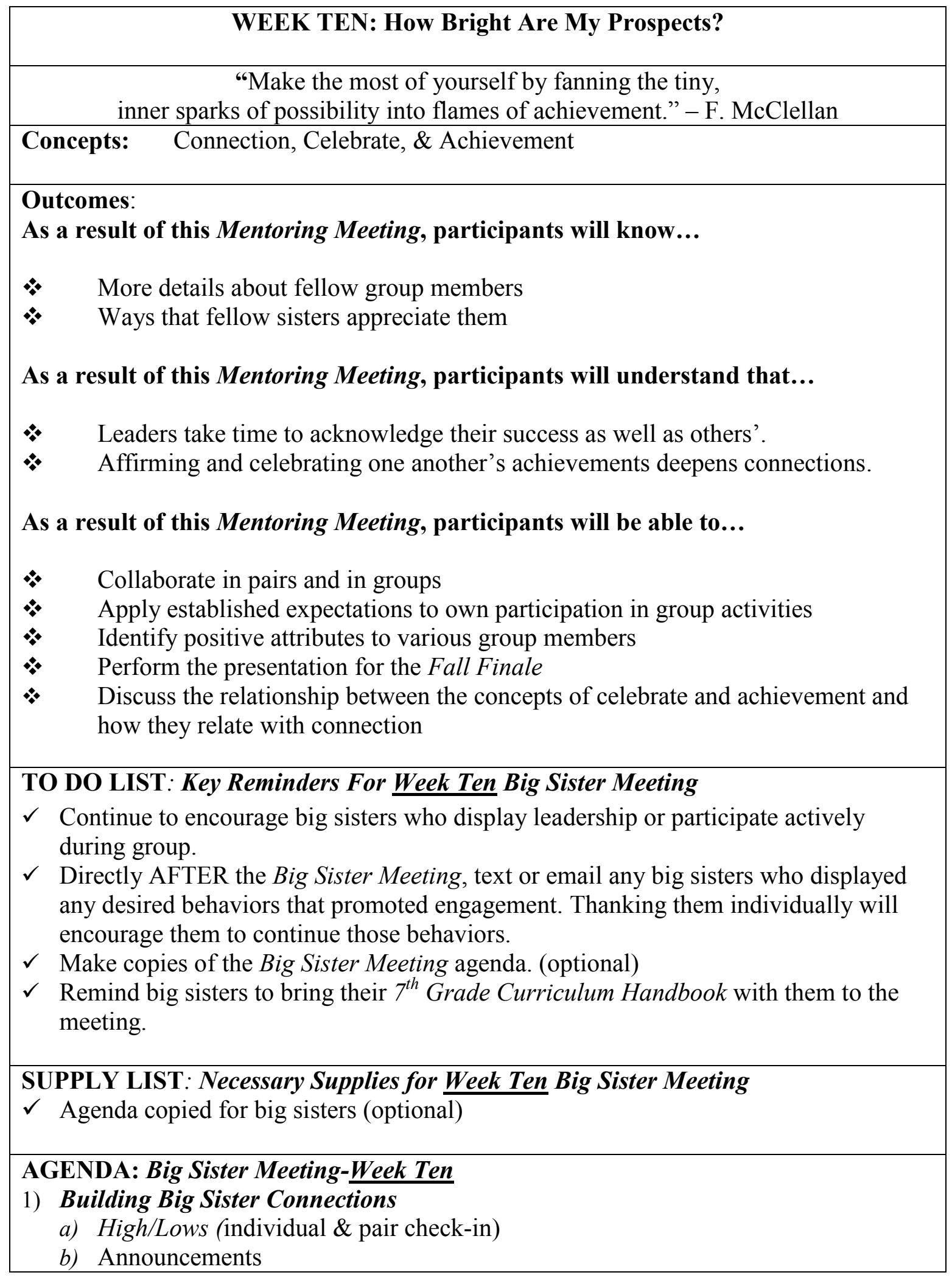


c) Reports from Group Leadership Roles/Jobs (e.g., photographer, attendance, Sister-to-Sister, etc.)

d) Determine which big and little sisters have birthdays this week and how you are going to celebrate them.

2) Reflection

a) In small groups, pairs, or as a whole group reflect on the successes and challenges of last weeks' Mentoring Meeting.

i. What would you change about last week's Mentoring Meetings?

ii. What did you (as a team) do well?

iii. What interesting thing happened?

$i v$. Who stood out as a leader? (big and little sisters)

3) Strengthening Mentoring Relationships

a) Continue this discussion if necessary.

$i$. Discuss in small group, pairs or as a whole group, where everyone is with her little sister. A mentoring relationship has stages (Introduction, Building, Growing, Maturing, Transitioning). Keep in mind that relationships can fluctuate and go backward before they go forward, or even remain static for some time.

ii. What can big sisters do to support little sisters in the various domains: academics, social \& familial relationships, emotional health?

4) Mentoring Group Curriculum

a) Nuts \& Bolts

i. Discuss as a group, which big/little sister pair would like to lead the energizer this week.

ii. Problem-solve potential little sisters' responses to the curriculum this week.

1) Who needs extra support?

2) What if the little sisters do not have any ideas about what to say to affirm another sister?

iii. How would you like to structure the meeting to maximize time for the Fall Finale presentation?

b) Take Away Messages

$i$. Conduct an open discussion about what the following principles mean to the big sisters.

1) Leaders take time to acknowledge their success as well as others'.

2) Affirming and celebrating one another's achievements deepens connections.

\section{5) Appreciation for Big Sisters}

a) Who displayed noteworthy leadership this past week? Be specific with the behaviors and how they impact the group (or pair) interactions and dynamic. For example, "Camille always greets everyone in group with a smile and a personal question about their lives. This really makes people feel welcome and more 
willing to share thoughts and feelings with each other. This really brings the group together."

\section{TO DO LIST: Key Reminders For Week Ten Mentoring Meeting}

$\checkmark$ Check in with the office to be sure that they make an after-school announcement.

$\checkmark$ Your room may be locked, so arrive early enough to find a custodian to let you into your room, if necessary.

$\checkmark$ At the beginning of your meeting each week, determine who is in attendance. Determine which little sisters are on your list, but not in attendance. Send the big sister who is assigned to the missing little sister (or if doable, you can) to the office to call the parents to notify them of the absence.

$\checkmark$ Arrange the classroom so that there is space to practice for the Fall Finale.

\section{SUPPLY LIST: Necessary Supplies for Week Ten Mentoring Meeting}

$\checkmark$ Nametags

$\checkmark$ Snacks

$\checkmark$ Mascot or item to serve as microphone to indicate who has the floor to speak.

$\checkmark$ Hot Topic box \& Hot Topic paper slips

$\checkmark$ Writing utensils (pens, or pencils, paper -for affirmations- and markers)

$\checkmark$ Leadership Ladder

$\checkmark$ Signs made for group (Group Guidelines, etc.)

$\checkmark$ List for permanent addresses so that the group can stay in touch over the holidays. 


\section{CURRICULAR COMPANION}

\section{Supplemental Ideas for Implementing Mentoring Group Curriculum}

\section{Promoting Connection by Celebrating Achievements}

\section{Celebrate the Small Stuff}

It is important to take time to celebrate little successes. Every day we have some sort of victory whether it is small or large if we just take the time to notice those victories or accomplishments. It might be that we finally got to the gym after procrastinating for weeks, or we did something nice for a friend, or even got a good grade on a vocabulary test after studying. If we focus on the things that we do well every day, it increases our feelings of competence and improves our confidence, too! These feelings of confidence and competence compel us to try harder can often lead to more success. It is a good addiction. In other words, success leads to more success!

\section{TIPS: Energizer}

$>\quad$ Pair(s)Leading the Way: Facilitate a discussion about which pairs would like to exercise their leadership skills and the lead the group in the energizer. Before the meeting think about whom you think would be suitable for this position. Then offer it up to the big sisters. You might even consider sending out an email before the Big Sister Meeting so that the big sisters have time to contact their little sisters and ask them if they would like to lead the activity for the meeting. Be sure to be available and up to speed on the energizer so that you can assist if the pairs need you.

$>$ ADAPTATION: You may decide to divide the group into two smaller groups so that more than one big/little sister pair can lead an energizer.

\section{TIPS: Group Check-in}

$>\quad$ Variety: It may be a good idea to switch to the other group check-in strategy that you have not been using, just to provide some variety.

$>\quad$ High/Lows: Read your group members. If it seems like the sisters could use some time to talk a bit more, you may want to do this is smaller groups-perhaps groups of three or four (depending on attendance) so that each sister has more time to share what is on her mind.

$>\quad$ Hot Topics Box: It is a valuable use of time to discuss topics that are important to little sisters. Make time to have these discussions. 
Connecting by Being Honest: The goal of Sister Time this week is to touch base with how the week has gone and to communicate the realistic expectation for communication over the holidays. It is better for big sisters to be honest about how frequently or infrequently they will be in touch. Big sisters should explain their situations (e.g. hectic working schedule, traveling, etc.) so that little sisters understand the circumstances and they will not be disappointed. Unfortunately, this time period is one that can damage relationships if both parties are not honest about their situations and expectations. The little sisters are still determining whether the big sisters are actually people they can depend on and whether they should fully invest in them. This will better prepare little sisters for the time apart. Be sure to swap phone numbers, etc. so that you can be in touch. This information may be the same as always, but for some people it will change due to staying at a different place over the holiday break. Also, as a group, you will plan to send letters to the little sisters homes so be sure to get current addresses.

\section{TIP: Leaders Celebrate Success}

$>\quad$ Specific is terrific. Encourage the little and big sisters to write something that is specific and genuine. This is not always possible since sisters may not know each other very well do to absences from the group or lack of interaction during group or even during school day. Avoid saying things like "Susan is nice." Instead describe a time when she showed kindness. Also, if possible, avoid superficial comments about people's appearance. If little sisters need help with this, big sisters should prompt their thinking. It might be a good idea to write this in different areas of the room so that pairs can talk if necessary without hurting others' feelings.

\section{JUSTIFICATION:}

This is an excellent way to bring the group members closer together as well as a way to increase sisters' self confidence and self-worth.

\section{TIPS: Leadership Project V: Fall Finale Presentation}

$>\quad$ Practice, Practice, Practice: It is critical that your group feels prepared and confident for their presentation. Previous Fall Finales have proven that even the most prepared and confident groups get a little shy and awkward during the Fall Finale presentation. Make sure that you designate some big sisters to step in case this happens.

Organize and Manage Your Time: Plan with your big sisters the best way to organize your time during the Mentoring Meetings. Make sure that you allow sufficient time to practice. Use the strengths of your sisters to make this run 
smoothly.

\section{MEASURING STICK: Assessing Growth}

\section{* Self-reflection}

- How did you do this week and this semester as a facilitator on a scale from 1-5 (5 being best)?

- How have you grown as a facilitator this semester?

- What goals do you have for yourself as a facilitator for next semester?

\section{* $\quad$ Reflection on teamwork}

- What skills could your big sisters improve that would help the group meetings run more smoothly?

- What could your big sisters do to help increase the connection of the group members?

Do the Little Sisters in your group know the information presented?

- More details about fellow group members

- Ways that fellow sisters appreciate them

\section{Did they demonstrate that they understood the established understandings or} principles that are the foundation of the meetings' activities?

- Leaders take time to acknowledge their success as well as others'.

- Affirming and celebrating one another's achievements deepens connections.

\section{* Can they apply the facts and principles in meaningful ways? Did they...}

- Collaborate in pairs and in groups

- Apply established expectations to own participation in group activities

- Identify positive attributes to various group members

- Perform the presentation for the Fall Finale

- Discuss the relationship between the concepts of celebrate and achievement and how they relate with connection

\section{JUSTIFICATION:}

It is important to find some way to assess whether you effectively communicated the facts and principles undergirding the Mentoring Meeting's activities. It is equally important to determine (on an individual basis) whether little sisters gained this understandings and knowledge. This can be done through a formal or 


\begin{tabular}{|l|}
\hline informal conversation, a comment that is made, a behavior displayed, a written \\
"exit card" with questions related to the outcomes (KUDs). \\
Mix up how you have the little sisters express what they know, understand and \\
can do. They will get bored when you overuse a strategy. \\
Reflect on little sisters' growth for the semester. Discuss little sisters' progress \\
with their big sisters.
\end{tabular}




\section{Second Semester}

\section{Week Eleven: Getting to Know Each Other Again}

This week the group catches up with each other after the winter break, reviews what they liked and did not like about the first semester, and brainstorms ways to change for this semester. They also begin planning their leadership projects for the semester, one of which is setting leadership goals. Leaders set goals!

\section{Week Twelve: Expanding Our Horizons}

Group members recognize and build upon their successes as a leader and practice interviewing another member of the group they don't know very well. They also work on developing their relationship leadership goals for the semester. Leaders set goals, celebrate success, and connect!

\section{Week Thirteen: Leading in School and the Community}

This week group members decide on their academic leadership goal for the semester and learn some strategies for bringing out the best in adults. They also continue planning their leadership projects for the school and the community. Leaders set goals, connect, and appreciate others!

\section{Week Fourteen: Leading with Peers}

This week introduces some strategies adolescents can use for keeping their cool and respecting themselves when faced with drama situations. They also continue planning their leadership projects. Leaders keep their cool and respect themselves!

\section{Week Fifteen: Leading in Romance}

The group focuses on some tough decisions that middle school girls face, decisions concerning sexuality, dating relationships, and dealing with peers and pressure. They learn some facts that can help them make important decisions thoughtfully and strategies for thinking like a leader. Leaders respect themselves and solve problems!

\section{Week Sixteen: Our Bodies, Ourselves}

The group members consider the ways the media and society influence how girls and women treat their bodies and some ways they can individually and collectively protect themselves from these pressures. They learn how to give each other creative compliments and acknowledge the ways they have supported one another on their leadership projects. Leaders respect differences and themselves and leaders create support teams and help others!

\section{Week Seventeen: What a Leader!}

This week the group focuses on the numerous ways each participant has developed as a leader in YWLP this year. They also finish up their leadership projects. Leaders set goals and celebrate success! 


\section{Week Eighteen: Play Day!}

The group catches up on the curriculum, plays games, creates a presentation for $Y W L P$ Graduation, and has fun! Leaders create support teams!

\section{Week Nineteen: YWLP Graduation}

On this special day, big/little pairs, families, and school officials gather to celebrate YWLP successes throughout the year and participate in the YWLP Graduation Ceremony. Big sisters and facilitators say something special about each little sister and the group members make a presentation on all the Leadership Projects they completed this year. Leaders celebrate success! 


\section{WEEK ELEVEN: Getting to Know Each Other Again}

Concepts: Re-establishing Community \& Reconnection

\section{Outcomes:}

As a result of this Mentoring Meeting, participants will know...

* More details about fellow group members

* Steps to goal setting are: 1) Decide on a GOAL, 2) Develop the necessary STEPS to achieve it (specific is terrific); 3) Create a TIMELINE for the steps; and 4)

Decide who can SUPPORT achieving the goal

* YWLP terms

As a result of this Mentoring Meeting, participants will understand...

* After spending time apart, it is important for friends to reconnect and rebuild trust in order to move their relationship forward.

As a result of this Mentoring Meeting, participants will be able to...

* Demonstrate collaborative behaviors in pairs and groups

* Apply established expectations to own participation in group activitiesparticularly confidentiality

* Participate earnestly and honestly in activities

* Re-establish norms and expectations

* Set meaningful and specific goals

* Reconnect with one another

* Discuss the relationship between some of the concepts

\section{TO DO LIST: Key Reminders For Week Eleven Big Sister Meeting}

$\checkmark \quad$ Continue to encourage big sister's who display leadership or participate actively during group.

$\checkmark \quad$ Directly AFTER the Big Sister Meeting, text or email any big sisters who displayed any desired behaviors that promoted engagement. Thanking them individually will encourage them to continue those behaviors.

$\checkmark \quad$ Make copies of the Big Sister Meeting agenda. (optional)

$\checkmark \quad$ Remind big sisters to bring their $7^{\text {th }}$ Grade Curriculum Handbook with them to the Big Sister Meeting.

SUPPLY LIST: Necessary Supplies for Week Eleven Big Sister Meeting

$\checkmark \quad$ Agenda copied for big sisters (optional)

AGENDA: Agenda for Week Eleven Big Sister Meeting 


\section{1) Building Big Sister Connections}

a) High/Lows (individual \& pair check-in)

b) Announcements

c) Reports from Group Leadership Roles/Jobs (e.g. photographer, attendance, Sister-to-Sister, etc.)

2) Reflection

a) In small groups, pairs, or as a whole group reflect on the successes and challenges of how the group functioned the last semester.

$i$ What would you change about how the group functions?

ii. What norms would you like to nurture as a group? First discuss with big sisters and then discuss with little sisters at the Mentoring Meetings.

iii. What adjustments should be made to improve how the group works together?

$i v$. How can the structure of the meetings or one-one one time be altered to increase the support offered to the little sisters?

v. Which little sisters can be given a leadership role?

vi. Which little sisters need more support?

3) Strengthening Mentoring Relationships

a) Discuss the following in small groups or pairs. Consider writing the questions on index cards, handouts, or chart paper so the big sisters have something to reference.

$i$ What are the strengths and weaknesses of the mentoring relationships?

ii. What obstacles are impeding your relationship? (e.g. difficulty getting in touch to establish meeting times, demanding workloads, shyness, language barrier, phone disconnection, etc.)

iii. How can the bonds be strengthened?

b) Have big sisters who have experienced some success with their little sisters share some strategies.

c) As the facilitator, listen to your group and see if there is a pattern. For example, if you notice that many of your sisters are discussing the difficulties with setting and maintaining boundaries then perhaps it merits a whole group discussion. Brainstorm solutions as a group. Seek out YWLP leadership for 


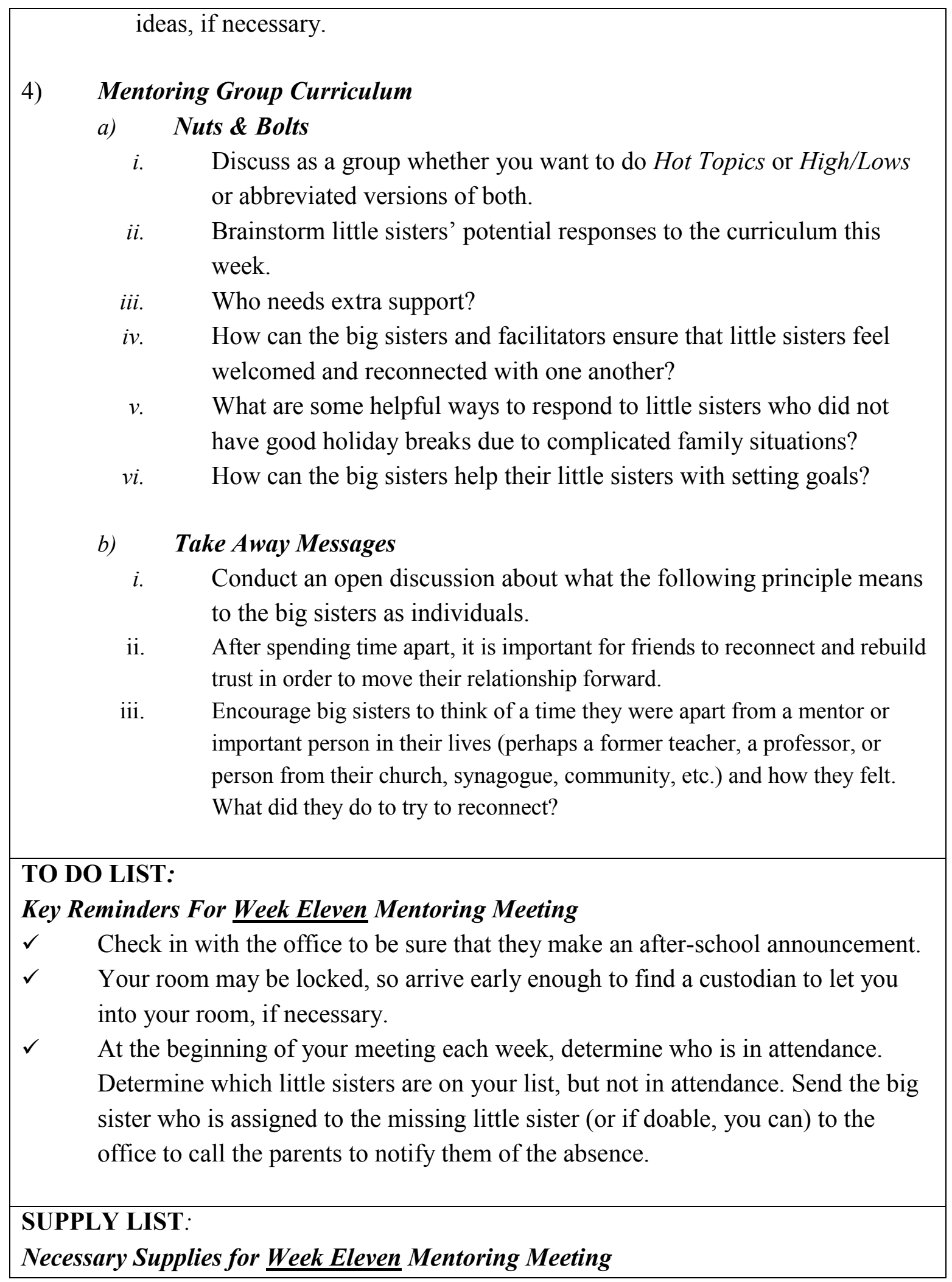




\begin{tabular}{|ll|}
\hline$\checkmark$ & Nametags \\
$\checkmark$ & Snacks \\
$\checkmark$ & Mascot or item to serve as microphone to indicate who has the floor to speak. \\
$\checkmark$ & Hot Topic box \\
$\checkmark$ & Hot Topic paper slips \\
$\checkmark$ & Writing utensils (pens, or pencils, and markers) \\
$\checkmark$ & Sheets of paper \\
$\checkmark$ & Leadership Ladder \\
$\checkmark$ & Signs made for group \\
$\checkmark$ & Sister Group information \\
$\checkmark$ & Materials to play Taboo (paper, buzzer, YWLP terms, timer) \\
$\checkmark$ & YWLP Feedback forms \\
$\checkmark$ & Materials to make the pink SELF accountability/goal bracelets \\
&
\end{tabular}




\section{CURRICULAR COMPANION}

\section{Supplemental Ideas for Implementing Mentoring Group Curriculum}

\section{Nurturing Reconnection and Reestablishing Community}

\section{Address the Sisters' Feelings about the Holidays}

The holiday can be a positive or negative experience for a variety of reasons. For some sisters, the holiday may have been filled with love, joy, and quality time with family and friends, but others may have experienced disappointment, loneliness, rejection, etc. As you prepare for this week's mentoring group meeting, keep this in mind and that the holiday season is often a time for heighten emotions. Some sisters may have heavy hearts and minds and they may want to discuss their feelings while others may display behaviors of indifference. Monitor your group members closely, particularly as they enter the meeting space when time is less structured. If you observe that members might need extended time during Sister Time or Group Check-in, adjust the schedule accordingly. If group members are preoccupied with their feelings, they will most be unable to set them aside in order to participate in the planned activities in a meaningful way.

\section{Restore Feelings of Trust Between Sisters}

As the facilitator, you should make the assumption that most of the mentoring pairs probably have not have a great deal of communication over the holiday break. This means that it will be particularly important to re-establish the trust between the pairs and as a group. For adolescents, the few weeks away will most likely feel more significant as time feels different at that age. A lot has probably happened in many of the little sisters' lives. Take some time at the beginning of the meeting to discuss norms and expectations, including the expectation of every member maintaining confidentially.

\section{Revisit Group Norms}

After the holiday break and the break in ritual and practice of having the Mentoring Meetings, it is important to decide first (as the facilitator and leader of the group) which norms and expectations you would like to maintain. This is also the time to add new ones if you so desire. Once you have determined the norms that are important and beneficial to the group, then at the big sisters meeting consult the big sisters in your group. Once you have discussed which norms you would like to maintain, ask the little sisters the same question and communicate which norms and expectations you and the big sisters find to be important. Lead the little sisters in the discussion so that they feel empowered that they were a part of the decision.

Nurture Little Sisters' Reconnection 
Disruptions, inconsistencies, or time apart may cause mentees to withdraw for protection. As the facilitator, it is your responsibility to monitor how pairs are reconnecting. You can do this during the entire meeting, but Sister Time will be critical. It may be necessary for you to step in and casually cultivate the conversation if you see some pairs struggling.

Also, because this is an important meeting for pairs to reconnect, if a big or little sister is absent, it may be necessary for you to pair with one of them-especially if it an little sisterbut really for either.

If for some reason a big sister is not in attendance, be extremely deliberate about making the little sister feel cared for and included! This is considered a fragile time and it can be harmful to the little sister if she feels rejected by her big sister (even if the big sister has a valid reason for her absence. The little sister may not have the ability to understand that and they may previous feelings of rejection that this absence may compound.) If little sisters have connected with their big sisters and value their relationship, they may feel an even more profound distress if their big sister is absent or if they merely perceive their reconnection to be disappointing.

\section{Nurture Big Sisters' Reconnection}

One of the most common times for big sisters to abandon the program is at the start of the new semester. Due of the break in communication, some big sisters may feel less connected to their little sisters and fellow big sisters and so it is the facilitators' role to rekindle feelings of connection between the fellow big sisters and with their little sisters. This might be an appropriate time to plan a "Big Sister Event" such as a dinner out, movie night, etc.

Though big sisters are not young adolescents, it is possible that they will experience feelings of rejection, too. For example, if their little sisters do not attend the meeting, some of the big sisters may interpret this absence as a lack of interest (which may or may not be accurate) and they may disengage from the program. It is your job, as the facilitator, to make all sisters feel connected to the group and to YWLP.

\section{Reestablish Sense of Community in the Group}

Have fun together be flexible. Make time to laugh together because the positive climate that you, as the facilitator, re-establish during this meeting, sets the tone for the rest of the school year. Emphasize to the big sisters that it is important for them to deliberately and emphatically communicate how much they enjoy being a part of the mentoring group. It is not uncommon for little sisters to drop out of the program at this time because they feel disconnected or they sense that their big sisters are unenthusiastic. If a little sister perceives that her mentoring relationship is not going well, she may perceive intentional rejection. Encourage big sisters to voice to their little sisters and to the rest of the group how much they missed their fellow sisters and YWLP. 


\section{TIPS:}

\section{Welcome \& Energizer}

$>\quad$ Reconnect: Regardless of which activity you and your group chooses to do, use the time to reconnect with one another as individuals and as a group. Also use the time to reacquaint the members of the group to YWLP and its purpose.

$>\quad$ Revisit Program's Purpose: Consider taking a very brief a moment to have a few big sisters (determine ahead of time) and invite little sisters to share also what they missed about YWLP and what they gain from their involvement. This will, not only, help remind everyone of what they get out of their participation in YWLP, and why they should continue their involvement, but it will also provide a warm welcome where people feel happy to be at the meeting.

$>\quad$ Stress norms: Even before you participate in the energizer, lead the group in a discussion about expectations and norms. Infuse levity by using a positive and inviting tone. Candy, snacks, music, etc. can all help achieve this. If necessary you can always revisit these later in the meeting, but it is important to establish expectations before you engage in any group activities. You want all of your sisters to feel safe participating and clear of what is required of them.

Minimize Discomfort: Always provide a safety net. Some sisters may not remember their fellow sisters very well. This is not as uncommon as you think as not everyone is as invested in the group as you are. Consider how you and your big sisters can respectfully "rescue" little sisters (or even big sisters) who may not remember one another. Doing so, will save sisters from feeling embarrassed and rejected. Some sisters may not recall a lot of the YWLP terms from last semester. Be sure that big sisters have a "cheat sheet" or their 7th Grade Curriculum Handbooks to help them if necessary. If people feel awkward or "in the dark," it may cause them to immediately disengage.

\section{JUSTIFICATION:}

The purpose of these activities is for everyone to feel welcome and for sisters to have the opportunity to reconnect with one another and the program.

\section{TIPS: Group Check-in}

$>$ High/Lows: Because this is the first group meeting after the holiday, sisters may have a lot to say and some of it may be rather personal. It might make sense to do this segment of the meeting in small groups where members will feel more comfortable and will have more time to "have the floor."

Hot Topics Box: little sister may have topics that are important to them right after 
the holidays. Monitor the small groups during the High/Lows and if it seems as though many little sisters seem to still need to talk, you can decide about whether to extend the High/Lows time. If you notice that groups are talking about similar topics and are not sounding like their needs are being met, you may decide as the facilitator to fold the discussions into one large discussion.

$>\quad$ Sister Group: Take a few moments to discuss which holidays your Sister Group celebrates and how your celebrations may be similar and different.

\section{TIPS: Sister Time}

$>\quad$ Cultivating Connection: See Curriculum Companion section for insight on how to facilitate connections between sisters in light of the time everyone has spent apart.

$>\quad$ Supporting the Little Sisters' Academic Achievement: The goal of Sister Time this week is to provide a follow up form last week where the big and little sister pairs discussed academic progress.

$>\quad$ Completing the YWLP Feedback Form: These forms provide valuable information, so be sure to emphasize the seriousness of it to the group. Also stress that this is a time to voice their ideas and concerns in a safe way. This is an opportunity for sisters to offer constructive feedback that directly impacts YWLP.

\section{TIPS: Leaders Set Goals}

$>\quad$ Take time to review. Before the sisters begin to set goals for themselves, it is a good idea to review the steps of how to set goals. You might want to do this as a whole group in case there aren't many sisters who remember the process. Be sure to have a visual accompany this-whether it be a handout, on the board or the old poster with the information.

$>\quad$ Building and braiding. This time is intended for sisters to create a goal, build a plan of attack to reach the goal and braid an accountability bracelet. For most people, the act of braiding the bracelet will make it more comfortable to have the discussion. Monitor this though to be sure the braiding does not distract that sisters and they miss the intent of the activity, which is to discuss some goals about self.

\section{MEASURING STICK: Assessing Growth}

* Self- reflection

- How did you do this week as a facilitator?

- Did your little sisters meet your established outcomes for this mentoring 


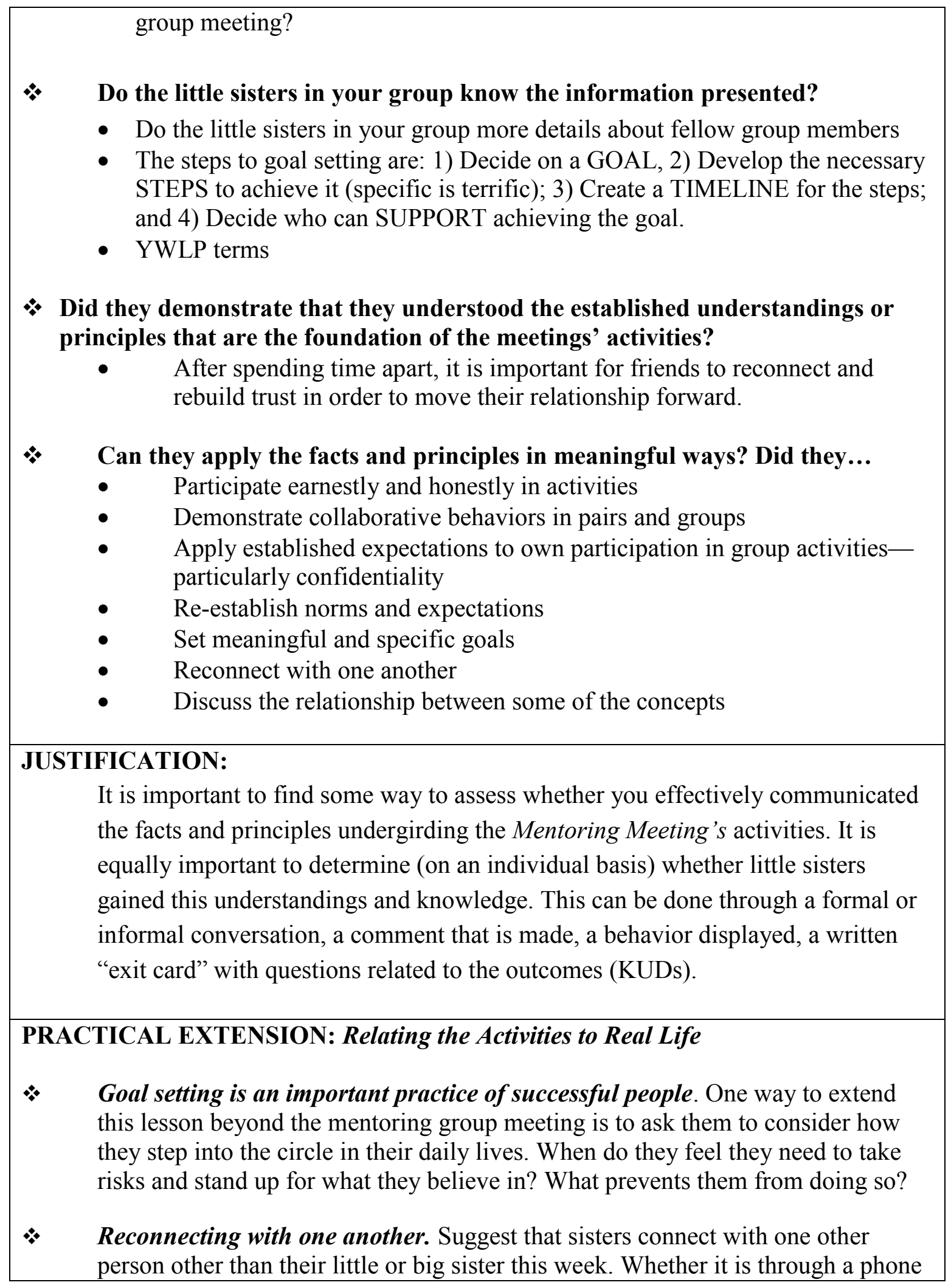


call, note, email, text, etc. You may want to pre-determine this and maybe even assign them secretly in case not everyone follows through with the task. Email big sisters (and little sisters if you have their email addresses) to remind them to do this. Ask big sisters to let you know once they have contacted someone so that you can step in and contact little sisters if nobody else does. This connection with a person other than assigned big or little sisters will encourage the sense of community.

\section{THE BIG PICTURE:}

Uniting the Concepts within the Curriculum

What are some of the concepts or big ideas from last semester?

$\circ \quad$ How does the discussion of re-establishing a community and reconnecting relate to other concepts from last semester?

- Explicitly creating the connections between the concepts each Mentoring Meetings will deepen sisters' understanding of the concepts and will increase the chances that they will be able to transfer the skills and knowledge to new situations.

- For the visual learners, consider asking the sister to create an illustration that makes connections between some or all of the concepts. Or for the verbal processors, they can participate in a discussion that connects the concepts. 


\begin{tabular}{|c|c|}
\hline & WEEK TWELVE: Expanding Our Horizons \\
\hline & Competence, Success, \& Stretching Yourself \\
\hline & $\begin{array}{l}\text { mes: } \\
\text { esult of this Mentoring Meeting, participants will know... }\end{array}$ \\
\hline 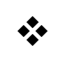 & Fellow group members' names on demand \\
\hline & Appropriate behavior for an interview \\
\hline & Steps for setting goals \\
\hline & esult of this Mentoring Meeting, participants will understand... \\
\hline$*$ & $\begin{array}{l}\text { Growth and improvement come from attempting to do what you previously could } \\
\text { not. }\end{array}$ \\
\hline$\star$ & Successful leaders stretch themselves beyond prior limits. \\
\hline & esult of this Mentoring Meeting, participants will be able to... \\
\hline 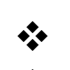 & Demonstrate collaborative behaviors in pairs and groups \\
\hline & $\begin{array}{l}\text { Apply established expectations to own participation in group activities- } \\
\text { particularly confidentiality }\end{array}$ \\
\hline & Participate earnestly and honestly in activities \\
\hline & Articulate personal accomplishments \\
\hline & Set and share goals \\
\hline & Connect the concepts \\
\hline & O LIST: Key Reminders For Week Twelve Big Sister Meeting \\
\hline & $\begin{array}{l}\text { Continue to encourage Big Sister's who display leadership or participate actively } \\
\text { during group. }\end{array}$ \\
\hline$\checkmark$ & Make copies of the agenda for the Big Sister Meeting. (optional) \\
\hline & $\begin{array}{l}\text { Remind big sisters to bring their } 7^{\text {th }} \text { Grade Curriculum Handbook with them to } \\
\text { the Big Sister Meeting. }\end{array}$ \\
\hline & LY LIST: Necessary Supplies for Week Twelve Big Sister Meeting \\
\hline & Agenda copied for big sisters (optional) \\
\hline & 7th Grade Curriculum Handbook \\
\hline & $\begin{array}{l}\text { NDA: Agenda for Week Twelve Big Sister Meeting } \\
\text { illding Big Sister Connections }\end{array}$ \\
\hline & a. $\quad$ High/Lows (individual \& pair check-in) \\
\hline & Announcements \\
\hline
\end{tabular}




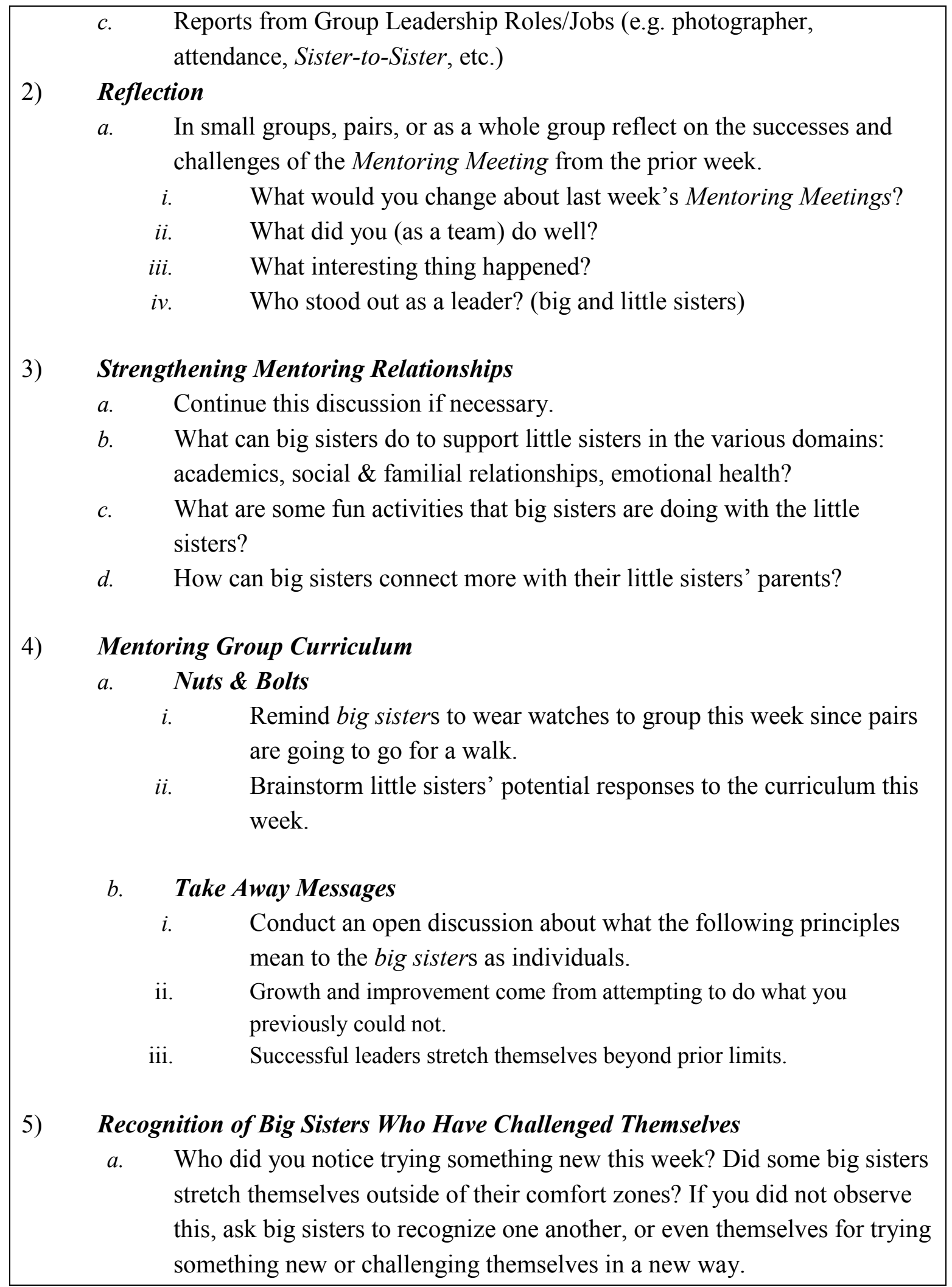




\title{
TO DO LIST:
}

\section{Key Reminders For Week Twelve Mentoring Meeting}

$\checkmark \quad$ Check in with the office to be sure that they make an after-school announcement.

$\checkmark \quad$ Also check with the School Contact to determine if there are any places that are restricted for the Sister Time walk.

$\checkmark \quad$ Your room may be locked, so arrive early enough to find a custodian to let you into your room, if necessary.

$\checkmark \quad$ At the beginning of your meeting each week, determine who is in attendance. Determine which little sisters are on your list, but not in attendance. Send the big sister who is assigned to the missing little sister (or if doable, you can) to the office to call the parents to notify them of the absence.

\author{
SUPPLY LIST: Necessary Supplies for Week Twelve Mentoring Meeting \\ $\checkmark \quad$ Nametags \\ $\checkmark \quad$ Snacks \\ $\checkmark \quad$ Mascot or item to serve as microphone to indicate who has the floor to speak. \\ $\checkmark \quad$ Hot Topic box \\ $\checkmark \quad$ Hot Topic paper slips \\ $\checkmark \quad$ Writing utensils (pens, or pencils, and markers) \\ $\checkmark \quad$ Leadership Ladder \\ $\checkmark \quad$ Signs made for group \\ $\checkmark \quad$ Blue YWLP Goal Sheets \& blue stickies \\ $\checkmark \quad$ Ball for name game \\ $\checkmark \quad$ Star stickies for Star Time \\ $\checkmark \quad$ Sister Group information \\ $\checkmark \quad$ Big sisters need to remember to wear watches \\ $\checkmark \quad$ Materials to make the blue RELATIONSHIP accountability/goal bracelets
}




\section{CURRICULAR COMPANION}

\section{Supplemental Ideas for Implementing Mentoring Group Curriculum}

\section{Building Competencies for Success}

"A person can grow only as much as her horizon allows." John Powell

\section{Adolescents' Developmental Need for Responsibility}

Adolescents crave to make a meaningful contribution and to be heard. They want people to depend on them and are empowered by opportunities where they are able to make significant decisions and are responsible. When making goals, it is helpful to have support from people who are responsible for helping us-accountability partners. An accountability partner is a person who coaches another by helping her keep a commitment or reach a goal. The big and little sister pairs are accountability partners and they can help one another reach the goals that they have set.

\section{Developing Competencies}

Because adolescents are still forming their identities, they are impressionable. They are sensitive and internalize what others say about their talents and weaknesses. They use that information as they evolve and questioning who they are. Mentors have the ideal opportunity to make a significant impression and help mentees open their eyes to the wide array of possibilities. They also can help their mentees identify their strengths and encourage them to pursue activities that would build those strengths. Use Star Time as a time to highlight strengths and "successes" that are meaningful to your sisters. If you, as the facilitator, can connect the "success" to a goal or point out how the "success" exhibits growth for a sister who has tried something new or broadened her horizon that would make the activity more meaningful.

\section{Encouraging Little Sisters to Embrace their Accomplishments}

It can be awkward for people to share their successes; that is particularly true for women and girls. Model how one can humbly share their accomplishments in a way that is not bragging, but instead celebratory. Celebrate liberally for others, too! Exhibit genuine happiness for others' accomplishments and encourage big and little sisters to do the same.

Teach sisters to celebrate while being humble. For example, if a little sister is pleased with her performance on an exam that others did poorly on, teach her to be mindful and considerate of others while still being proud of her achievement.

\section{Celebrating Sisters' Accomplishments}


Build each other up! You are a support network for one another. Model for other sisters how to point out and celebrate friends' accomplishments. Be genuine in your efforts, but do it often! It is important for everyone to hear someone else recognize their achievements and a public statement is even more powerful.

\section{TIPS: Energizer}

$>\quad$ Stress collaboration \& competition: This activity requires the participants to work together. Sisters need to be prepared to catch the ball and say the name of the sister to whom they are throwing the ball. There is an element of collaboration and teamwork. In addition, having the group be competitive with itself is a good lesson to emphasize. Sisters should think about how the concepts of teamwork and self-competition apply to their own lives. This mindset will help them avoid the rut of always comparing themselves to others. Personal best = team's best!

Know Sisters' Limits: Some sister may be stressed out by this activity, so depending on your group--you may want to take it slow. You may also want to have the sisters throwing to the same sister until they get to know that one name very well under pressure and then switch it up once they seem to feel more comfortable. The stress of the game may make some sisters forget names that they absolutely know, so be aware of that. You do not want anyone to feel embarrassed and withdraw from the activity all together. Going around the circle and saying your names a few times before you start the activity is probably a good idea, too.

\section{JUSTIFICATION:}

The purpose of this activity is to give sisters the opportunity to reinforce one another's names in a fun way. The activity provides a chance to work together as a team toward a common goal. It also can be quite motivating if the group wants to repeat the activity and work together to attempt to beat their previous time.

\section{TIPS: Check-in}

$>\quad$ Variety: It may be a good idea to switch to the other group check-in strategy that you have not been using, just to provide some variety.

$>\quad$ Star Time: You might find it helpful to give the sisters an example of an appropriate success to share on the stars. Providing an example may generate some ideas. Also, give the pairs some time to talk about what they might write on the stars in case the little sisters need some encouragement.

$>\quad$ Leadership Project: The School Legacy Project \& Sister-to-Sister Project teams need to be organized with what they are going to report. It might make sense to 
have a pair or two stand on front of the group to report to everyone. The planning and organizing the "report" may require that the sisters address this outside of group, or you may want to encourage them to debrief about this as soon as the sisters arrive and before group starts.

\section{TIPS: Sister Time}

Set Limits: Because pairs are going for a walk during Sister Time today (weather permitting), be sure that each pair has a watch. Communicate clearly your expectations such as when they should return, where they should and should not roam, etc. Allow yourself an extra five minutes (i.e. Hypothetically, tell them 10 minutes but you really are allowing for 15.), because it will take everyone time to settle back into the room. You have the big sisters' phone numbers from your list, confirm who has texting and consider texting them a five minute warning to serve as a time cue for their return. If you are not careful, the adventure of letting them go for a walk could consume a large amount of the group time.

Cultivating the Connections Between the Pairs: Once big and little sister pairs are emotionally connected they have a greater influence on one another. The goal of Sister Time this week is to give the pairs a bit more privacy in order to increase their emotional connection. This can be accomplished by allowing them to walk around the school grounds.

\section{TIPS: Leaders Set Goals}

$>\quad$ Prime the Pump: little sisters may need guidance and direction on setting their goals. What they need to improve may not be as obvious to them as it is to others on the outside. Challenge big sisters to really listen to what their little sisters are saying in casual conversation. See if they can detect any clues that would be helpful with goal setting. For example, if a little sister is sharing how she had to stay up extremely late working on an assignment for school, a good goal might be to break the assignments into smaller pieces and to start earlier. Another example would be if a little sister is sharing in casual conversation that she was arguing with her brother, a big sister could guide her toward making a goal about her relationship with her brother.

\section{TIPS: Leaders Connect}

$>\quad$ Perfect Match: Think about whom you are going to pair up for this activity beforehand! You may even want to involve big sisters at the meeting to determine who would work well together based on personalities, social capital, friendships, who is usually on task, confidence levels, etc. It is best to pair people who are not friends, but avoid pairings between people who have known strained 
relationships. One of the wonderful by-products of YWLP is that it provides an opportunity for girls to interact with others whom they would never otherwise interact.

Cheerleaders on the Side: This activity is awkward for some little sisters, especially when they interview another little sister whom they do not know. When the big and little sisters are working in pairs going over the Interview Prep Sheet, ask the big sisters to take it seriously and coach their little sisters so that they can shine in the next step of the activity. Then once the little sisters are interviewing each other, instruct big sisters to intervene when necessary, but to make encouraging statements from the sidelines. Big sisters will know some the information that will be asked so if necessary, they can quietly offer support. As you are going around the room and monitoring the groups, watch out for big sisters (intentionally or unintentionally) "ganging up" on little sisters and making them feel uncomfortable. Watch the little sisters reactions (body language and facial expressions) in order to determine if the statements are making them uncomfortable and awkward.

\section{MEASURING STICK: Assessing Understanding}

\section{* Self Reflection}

- How did you do this week as a facilitator?

- $\quad$ Did you use the best practices suggested in the FIG?

* Did your little sisters meet your established outcomes for this Mentoring Meeting?

- $\quad$ Do the little sisters in your group know the information presented?

- $\quad$ Fellow group members' names on demand

- Appropriate behavior for an interview

- $\quad$ Steps for setting goals

- Did they demonstrate that they understood the established understandings or principles that are the foundation of the meetings' activities?

* Growth and improvement come from attempting to do what you previously could not.

* Successful leaders stretch themselves beyond prior limits.

- $\quad$ Can they apply the facts and principles in meaningful ways? Did they...

- $\quad$ Demonstrate collaborative behaviors in pairs and groups

- Apply established expectations to own participation in group activitiesparticularly confidentiality 


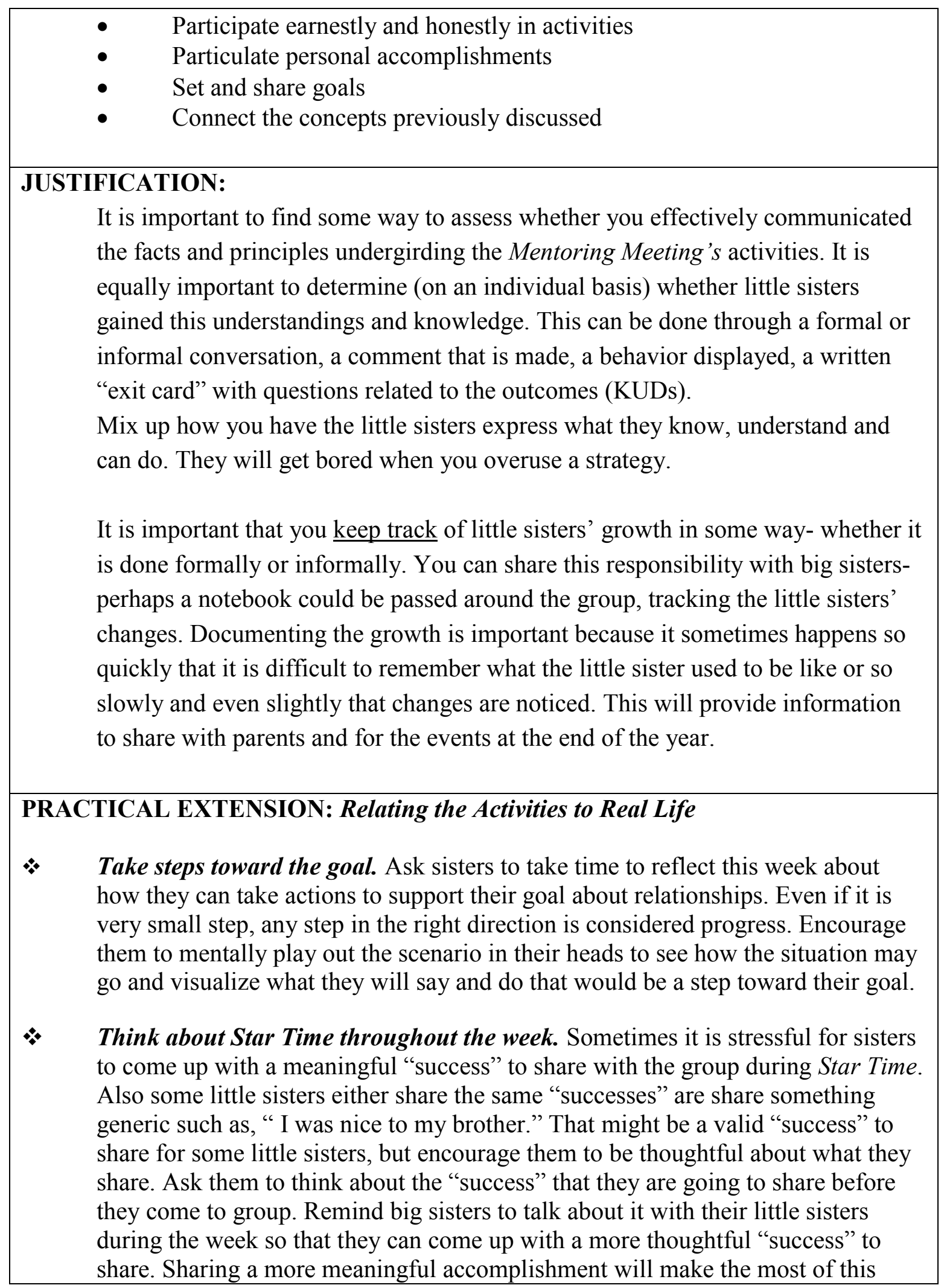


portion of the Mentoring Meetings and will really allow sisters to shine!

\section{THE BIG PICTURE: Uniting the Concepts within the Curriculum}

- How does the discussion of expanding your horizons relate to the previous meeting that focused on connection/reconnection?

- Explicitly creating the connections between the concepts each Mentoring Meetings will deepen sisters' understanding of the concepts and will increase the chances that they will be able to transfer the skills and knowledge to new situations.

- For the visual learners, consider asking the sister to create an illustration that makes connections between some or all of the concepts. Or for the verbal processors, they can participate in a discussion that connects the concepts. 


\begin{tabular}{|c|c|}
\hline \multicolumn{2}{|r|}{ WEEK THIRTEEN: Leading in School and the Community } \\
\hline \multicolumn{2}{|c|}{ Concepts: $\quad$ Connection \& Appreciation } \\
\hline \multicolumn{2}{|c|}{$\begin{array}{l}\text { Outcomes: } \\
\text { As a result of this Mentoring Meeting, participants will know... }\end{array}$} \\
\hline 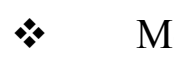 & Kore details about fellow group members \\
\hline $\begin{array}{l}\text { Le } \\
\text { pa }\end{array}$ & $\begin{array}{l}\text { eadership High Fives: 1) eye-to-eye 2) miles of smiles 3) shake it 4) Ps \& Ts 5) } \\
\text { ay it forward }\end{array}$ \\
\hline $\begin{array}{l}\text { St } \\
\text { pr }\end{array}$ & $\begin{array}{l}\text { teps of group planning 1) brainstorm ideas, decide \& create rough draft 3) } \\
\text { resent 4) make changes 5) execute plan }\end{array}$ \\
\hline \multicolumn{2}{|c|}{ As a result of this Mentoring Meeting, participants will understand that... } \\
\hline $\begin{array}{l}\mathrm{Cc} \\
\mathrm{w}:\end{array}$ & $\begin{array}{l}\text { Oonnecting with others sets the stage to make a meaningful difference and one } \\
\text { vay to do that is to take time to express appreciation of others. }\end{array}$ \\
\hline \multicolumn{2}{|c|}{ As a result of this Mentoring Meeting, participants will be able to... } \\
\hline$\%$ & emonstrate collaborative behaviors in pairs and groups \\
\hline $\begin{array}{l}\mathrm{A}_{1} \\
\mathrm{pa}\end{array}$ & $\begin{array}{l}\text { pply established expectations to own participation in group activities- } \\
\text { articularly confidentiality }\end{array}$ \\
\hline & articipate earnestly and honestly in activities \\
\hline & reate an academic goal \\
\hline & reate accountability bracelet \\
\hline & xpress appreciation in written form \\
\hline & roblem solve and plan as a group \\
\hline & onnect the concepts previously discussed \\
\hline \multicolumn{2}{|c|}{ TO DO LIST: Key Reminders For $\underline{\text { Week Thirteen Big Sister Meeting }}$} \\
\hline $\begin{array}{l}\mathrm{Cc} \\
\mathrm{du}\end{array}$ & $\begin{array}{l}\text { Oontinue to encourage big sister's who display leadership or participate actively } \\
\text { uring group. }\end{array}$ \\
\hline$\checkmark$ & Make copies of the Big Sister Meeting agenda. (optional) \\
\hline$\checkmark$ & emind big sisters to bring their $7^{\text {th }}$ Grade Curriculum Handbook with them. \\
\hline $\begin{array}{l}\mathrm{Y} \\
\mathrm{Le}\end{array}$ & $\begin{array}{l}\text { ou might need to communicate throughout the week regarding the School } \\
\text { egacy Proiect and/ or the Sister-to-Sister Proiect. }\end{array}$ \\
\hline \multicolumn{2}{|c|}{ SUPPLY LIST: Necessary Supplies for Week Thirteen Big Sister Meeting } \\
\hline$\checkmark \quad A \xi$ & genda copied for big sisters (optional) \\
\hline
\end{tabular}




\section{AGENDA: Agenda for Week Thirteen Big Sister Meeting \\ 1) Building Big Sister Connections \\ a) High/Lows (individual \& pair check-in) \\ b) Announcements \\ c) Reports from Group Leadership Roles/Jobs (e.g. photographer, attendance, Sister-to-Sister, etc.)}

\section{2) Reflection}

a) In small groups, pairs, or as a whole group reflect on the successes and challenges of the Mentoring Meeting from the prior week.

$i$. What would you change about last week's Mentoring Meeting?

ii. What did you (as a team) do well?

iii. What interesting thing happened?

iv. Who stood out as a leader? (big and little sisters)

3) Strengthening Mentoring Relationships

a) Continue this discussion, if necessary.

$i$. Discuss in small group, pairs or as a whole group, where everyone is with her little sister. A mentoring relationship has stages

(Introduction, Building, Growing, Maturing, Transitioning). Keep in mind that relationships can fluctuate and go backward before they go forward, or even remain static for some time. Have the big sisters put a label on the development of their relationships.

i. What can big sisters do to support little sisters with their academic progress?

ii. What are some fun activities that big sisters are doing with the little sisters?

iii. How can big sisters connect more with their little sisters' parents or other important people in little sisters' lives?

4) Mentoring Group Curriculum

a) Nuts \& Bolts

$i$. Brainstorm little sisters' potential responses to the curriculum this week.

$i$. Who has mentioned that they have a difficult time in school either socially or academically?

ii. Who has mentioned or demonstrated academic excellence or high social capital (popularity)? 


\begin{tabular}{|c|}
\hline $\begin{array}{c}\text { iii. } \quad \text { How will you show sensitivity to those students? } \\
\text { iv. } \quad \text { How will ensure that your group does not become a competitive } \\
\text { place where some people feel less valued than others? }\end{array}$ \\
ii. $\quad$ How will you facilitate the role-playing exercise for the Leadership \\
high Fives so that sisters have fun, but also learn something? \\
iii. $\quad$ How can you make the most of your time to work on the School \\
$\quad$ Legacy Project and/or the Sister-to-Sister Project?
\end{tabular}




\begin{tabular}{|ll|}
\hline$\checkmark$ & Hot Topic box \\
$\checkmark$ & Hot Topic paper slips \\
$\checkmark$ & Writing utensils (pens, or pencils, and markers) \\
$\checkmark$ & Leadership Ladder \\
$\checkmark$ & Signs made for group \\
$\checkmark$ & White YWLP Goal Sheets \& white stickies \\
$\checkmark$ & Materials to make the accountability bracelets \\
$\checkmark$ & Star stickies for Star Time \\
$\checkmark$ & Certificates of Appreciation \\
$\checkmark$ & School Legacy Project materials \\
$\checkmark$ & Sister Group information \\
\end{tabular}




\section{CURRICULAR COMPANION}

\section{Supplemental Ideas for Implementing Mentoring Group Curriculum}

\section{Building Competencies for Leading in School and the Community}

\section{The Importance of Eye Contact}

Eye contact is a critical form of non-verbal communication. It can open and close the line of communication just by the type of look delivered. Increased eye contact is associated with credibility, confidence, and assertiveness. Avoiding eye contact and excessive blinking are often interpreted as submissiveness, untrustworthiness, and lacking confidence. When attempting to make a connection with another person, it is critical that you make eye contact (not stare), but communicate genuine interest with your eyes.

\section{The Significance of Smiling}

Not only is smiling good for one's health because it relieves stress and feels good, but it also makes everybody seem more attractive; meaning that people gravitate toward happy people and smiling is a sign of happiness. Smiling can actually change a person's mood and it is contagious! Leaders smile because it is a powerful tool. When people wear a smile it makes them appear more confidant, appealing, and approachable.

\section{Handshakes Say a lot About a Person}

When in a formal professional setting, greet the person with a handshake. For example, for our little sisters it may not be appropriate for them to greet their teachers daily with a handshake; however it would be appropriate for a job interview or when meeting an adult for the first time or after not seeing him/her for a while. Handshakes are important. Little sisters need to know the proper way to shake hands because the way one is executed can say a lot about a person. The proper handshake should be firm, with an energy that communicates confidence and authenticity. The "dead fish" handshake communicates weakness and should be avoided at all costs.

\section{Possessing an Attitude of Gratitude}

All people need to feel appreciated and valued. In order to nurture fulfilling relationships with the people in your life, be intentional about expressing appreciation, affirmation, and encouragement. Once people start to focus on the positive things around them instead of the negative it changes their entire outlook on life. Pass it on! When a person takes the time to focus on the positive in the people around her and then she takes the time to 
communicate her appreciation and gratitude, it can make a huge difference on the relationships.

\section{TIPS: Energizer}

$>\quad$ Emphasize Friendliness: People gravitate toward friendly, happy, people; they are charismatic. Forging a connection is the goal. Eye contact, smiles, handshakes and kind words all facilitate emotional connections. These behaviors can help establish a positive first impression as well as help maintain positive perceptions. These "connection" behaviors are advantageous in every area of life and can certainly help gain respect from adults.

$>\quad$ Always Include People: If your group chooses the Eye Contact activity, be sure to continue to include people even after they have been disqualified for not making eye contact with someone. Those who have been "kicked out" really are not kicked out at all, but instead emphasize that now they take on a different role-you could make them judges or the counter, etc. If people feel excluded they will be disruptive and might sabotage the activity.

$>\quad$ Set the Stage for Friendly Competition: If you choose to do the Don't Laugh activity, before you even start, have sisters guess, which pairs might be the best at this task and which ones might have the hardest time not laughing. This sets the bar and makes some pairs rise to the expectation while for others it creates a challenge to prove people wrong.

\section{JUSTIFICATION:}

The purpose of this activity is to give little sisters some practice with eye contact. Both activities reward the ability to make eye contact even when it might be uncomfortable.

\section{TIPS: Group Check-in}

$>\quad$ Star Time or High/Lows: Try to make this fun by having different sisters lead the group in a way to applaud. Encourage people write things on their stars that are related to the goals they have created. Also it is helpful to link the accomplishments on the stars to the Leadership Ladder.

$>\quad H o t$ Topics: If you choose to do this activity instead of the High/Lows, make sure that you still find time for Star Time. Also be sure to set a timer or a limit on the discussion if you discuss Hot Topics. Find an organized way to let a variety of sisters contribute. It might be a good idea to use the "mascot" or microphone that you use for High/Lows.

\section{TIPS: Sister Time/Homework Help}


Goal Setting: Sisters have been creating goals so encourage big and little sisters to share their progress on the previous set goals. As they are completing the bracelets, the sisters need to create their last goal, which is on academics. Encourage big sisters to use the information that they have been gathering about their little sisters' academic achievement to guide them as they make this goal. Goals should reflect a high expectation, but also a realistic one.

Guide Gently (revisited): Big sisters need to be prepared to provide specific guidance and listen closely without judgment. Use BOOST! Depending on the situation, it may be useful for big sisters to share any struggles (maybe even from middle school) or successes that they have had in school and strategies that have worked for them.

\section{TIPS: Leaders Connect and Appreciate Others}

$>\quad$ Stress the Relevance: Why do these behaviors matter? Making eye contact, smiling, shaking hands, etc. can seem silly and even a bit awkward to adolescents and they may not see their importance. Emphasize the impact of these behaviors for current and future interactions.

$>\quad$ Compare \& Contrast: Ask big sisters to share examples of when they did not practice these and the possible implications. When doing the skits, you could even have the actors do it the incorrect way first and then redo it the correct way and then discuss how the behaviors could possibly change the outcome.

\section{MEASURING STICK: Assessing Growth}

\section{* Self-reflection \& Group reflection}

- How did you do this week as a facilitator?

- How are you keeping track of little sisters' growth with regard to the identified objectives? Growth in other ways?

- $\quad$ Did any big sisters lead by example and exhibit how they lead in the schools or community?

* Did your little sisters meet your established outcomes for this Mentoring Meeting?

* Do the little sisters in your group know the information presented?

- $\quad$ More details about fellow group members

- $\quad$ Leadership High Fives: 1) eye-to-eye 2) miles of smiles 3) shake it 4) Ps \& Ts 5) pay it forward 


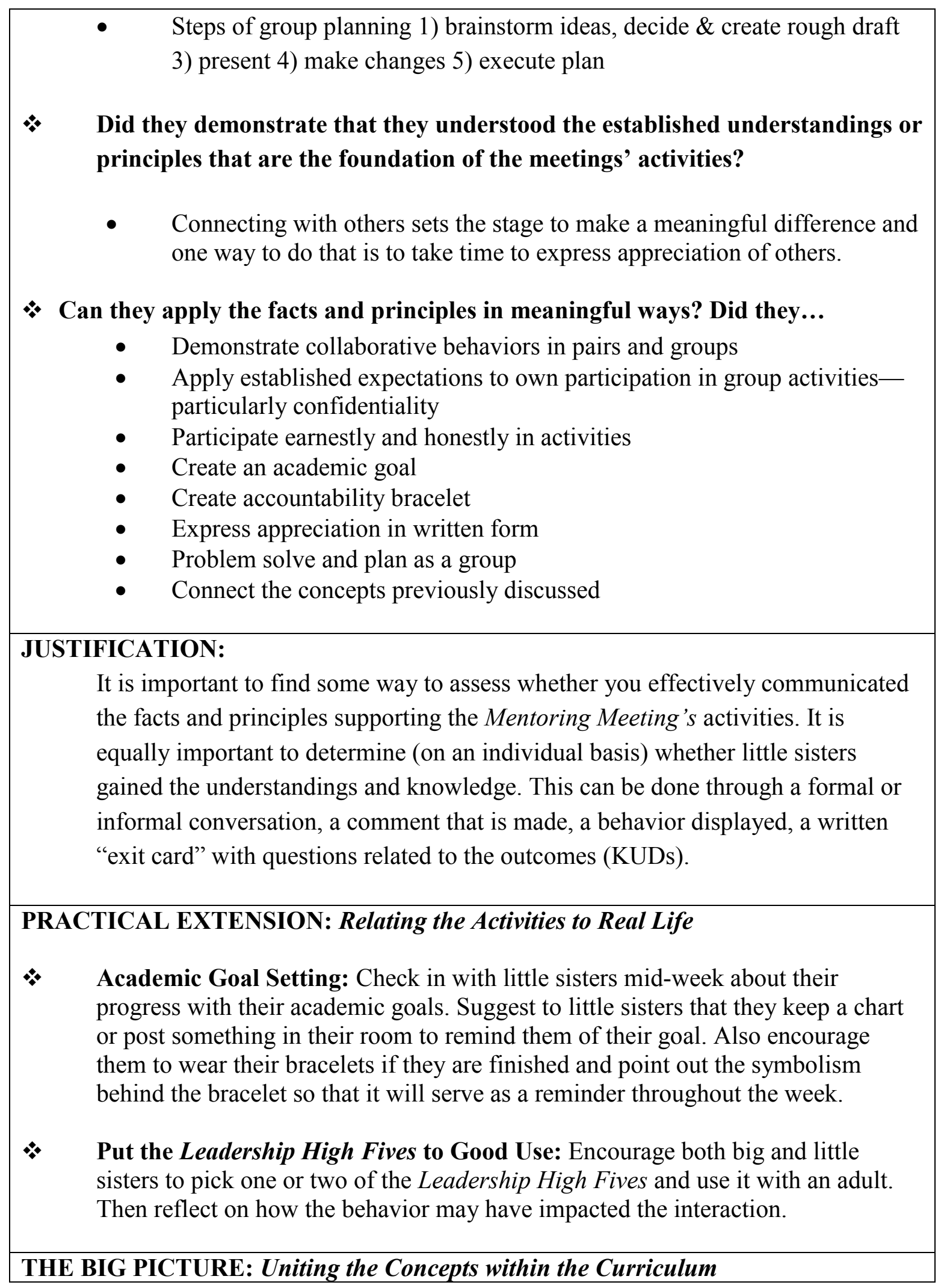


- How does the discussion of leading in school relate to the concepts from previous meetings?

- Explicitly creating the connections between the concepts each Mentoring Meetings will deepen sisters' understanding of the concepts and will increase the chances that they will be able to transfer the skills and knowledge to new situations.

- For the visual learners, consider asking the sister to create an illustration that makes connections between some or all of the concepts. Or for the verbal processors, they can participate in a discussion that connects the concepts. 


\begin{tabular}{|c|c|}
\hline & WEEK FOURTEEN: Leading with Peers \\
\hline & pts: $\quad$ Composure \& Voice \\
\hline & $\begin{array}{l}\text { mes: } \\
\text { esult of this Mentoring Meeting, participants will know... }\end{array}$ \\
\hline 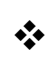 & More details about fellow group members \\
\hline & Coping strategies to remain "cool" in dramatic situations (e.g. bullying) \\
\hline & esult of this Mentoring Meeting, participants will understand that... \\
\hline 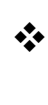 & $\begin{array}{l}\text { Successful leaders lead by example and use their voices to defend what is right, } \\
\text { including victims of bullying and teasing. }\end{array}$ \\
\hline$*$ & Leaders can influence their peers by keeping their cool and standing up for others. \\
\hline & esult of this Mentoring Meeting, participants will be able to... \\
\hline$*$ & Demonstrate collaborative behaviors in pairs and in groups \\
\hline$\%$ & $\begin{array}{l}\text { Apply established expectations to own participation in group activities- } \\
\text { particularly confidentiality }\end{array}$ \\
\hline$\%$ & Participate earnestly and honestly in activities \\
\hline$*$ & $\begin{array}{l}\text { Demonstrate proficiency with the identified leadership skills for connecting with } \\
\text { adults }\end{array}$ \\
\hline$*$ & Apply healthy strategies in role play situations related to relationship drama \\
\hline & Connect the concepts previously discussed \\
\hline & O LIST: Key Reminders For $\underline{\text { Week Fourteen Big Sister Meeting }}$ \\
\hline$\checkmark$ & $\begin{array}{l}\text { Continue to encourage big sister's who display leadership or participate actively } \\
\text { during group. }\end{array}$ \\
\hline$\checkmark$ & Make copies of the Big Sister Meeting agenda. (optional) \\
\hline$\checkmark$ & $\begin{array}{l}\text { Remind big sisters to bring their } 7^{\text {th }} \text { Grade Curriculum Handbook with them to } \\
\text { the Big Sister Meeting. }\end{array}$ \\
\hline$\checkmark$ & You might need to communicate throughout the week regarding the School \\
\hline & Legacy Project and/ or the Sister-to-Sister Project. \\
\hline & LY LIST: Necessary Supplies for Week Fourteen Big Sister Meeting \\
\hline & Agenda copied for big sisters (optional) \\
\hline & NDA: Agenda for Week Fourteen Big Sister Meeting \\
\hline & Building Big Sister Connections \\
\hline
\end{tabular}


a) High/Lows (individual \& pair check-in)

b) Announcements

c) Reports from Group Leadership Roles/Jobs (e.g. photographer, attendance, Sister-to-Sister, etc.)

2) Reflection

a) In small groups, pairs, or as a whole group reflect on the successes and challenges of the Mentoring Meeting from the prior week.

$i$. What would you change about last week's Mentoring Meetings?

ii. What did you (as a team) do well?

iii. What interesting thing happened?

iv. Who stood out as a leader? (big and little sisters)

3) Strengthening Mentoring Relationships

a) Continue this discussion, if necessary.

i. Discuss in small group, pairs or as a whole group, where everyone is with her little sister. A mentoring relationship has stages (Introduction, Building, Growing, Maturing, Transitioning). Keep in mind that relationships can fluctuate and go backward before they go forward, or even remain static for some time. Have the big sisters put a label on the development of their relationships.

ii. What can big sisters do to support little sisters in the various domains: academics, social \& familial relationships, emotional health?

iii. What are some fun activities that big sisters are doing with the little sisters?

iv. How can big sisters connect more with their little sisters' parents or other important people in little sisters' lives?

4) Mentoring Group Curriculum

a) Nuts \& Bolts

$i$. Brainstorm little sisters' potential responses to the curriculum this week.

ii. Who has mentioned that they have either been the victim of bullying or bullied someone else before?

iii. How will you show sensitivity to those students in addressing their needs?

$i v$. The topic of bullying can conjure up negative feelings. Are you prepared to address issues that may arise between or among girls in the mentoring group? 


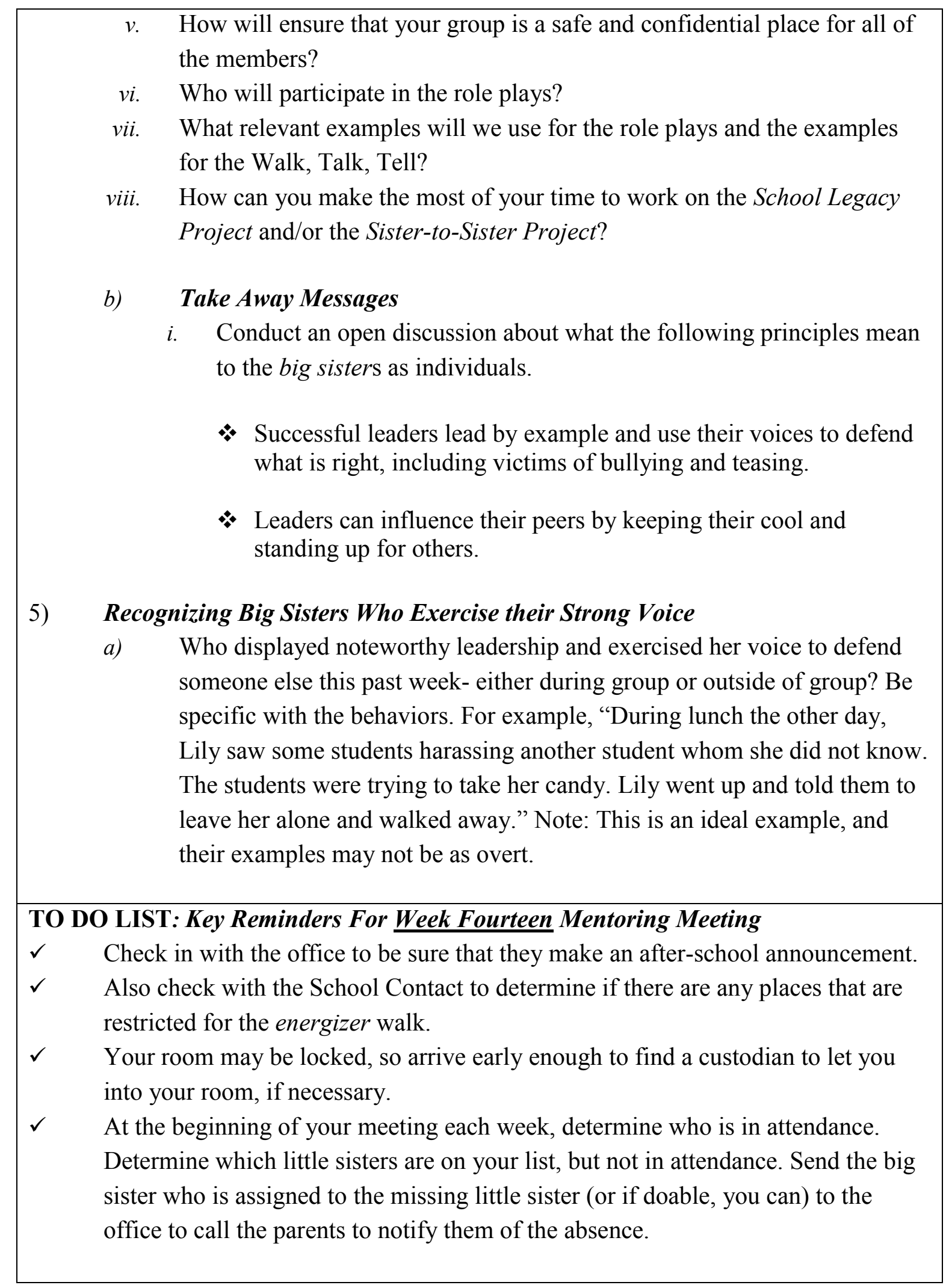




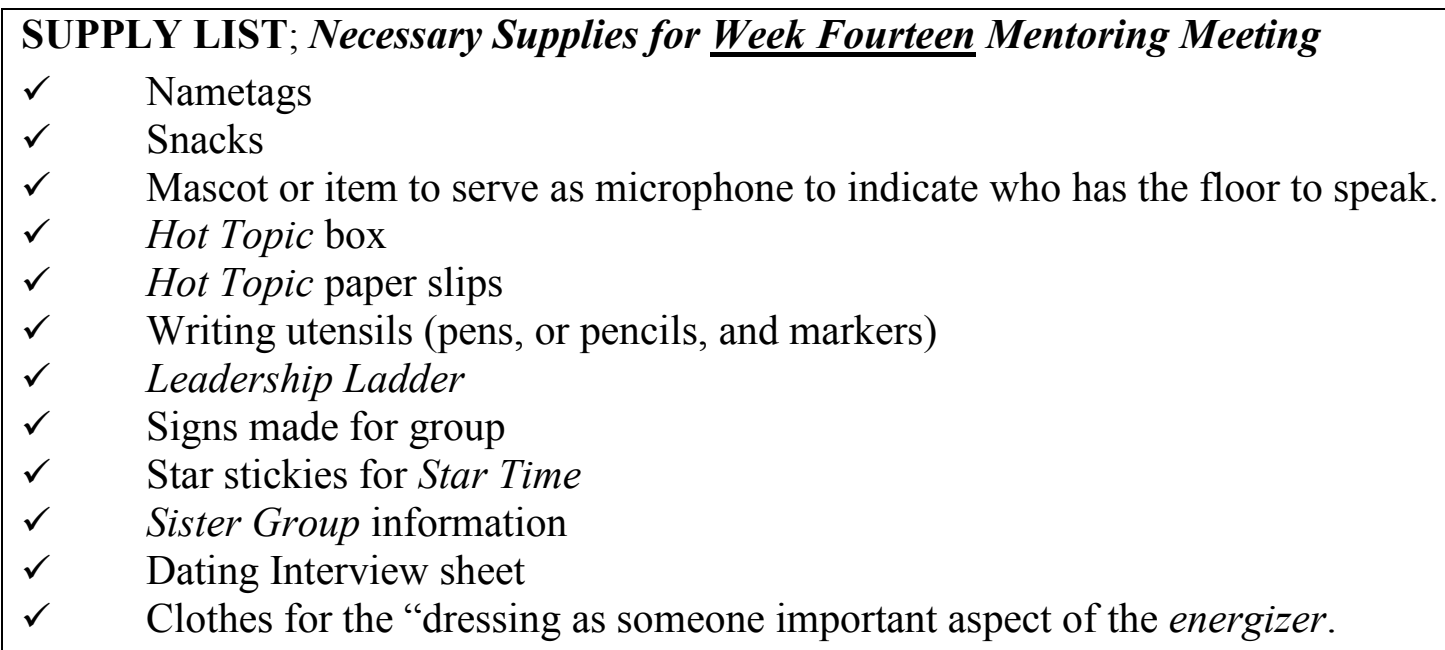




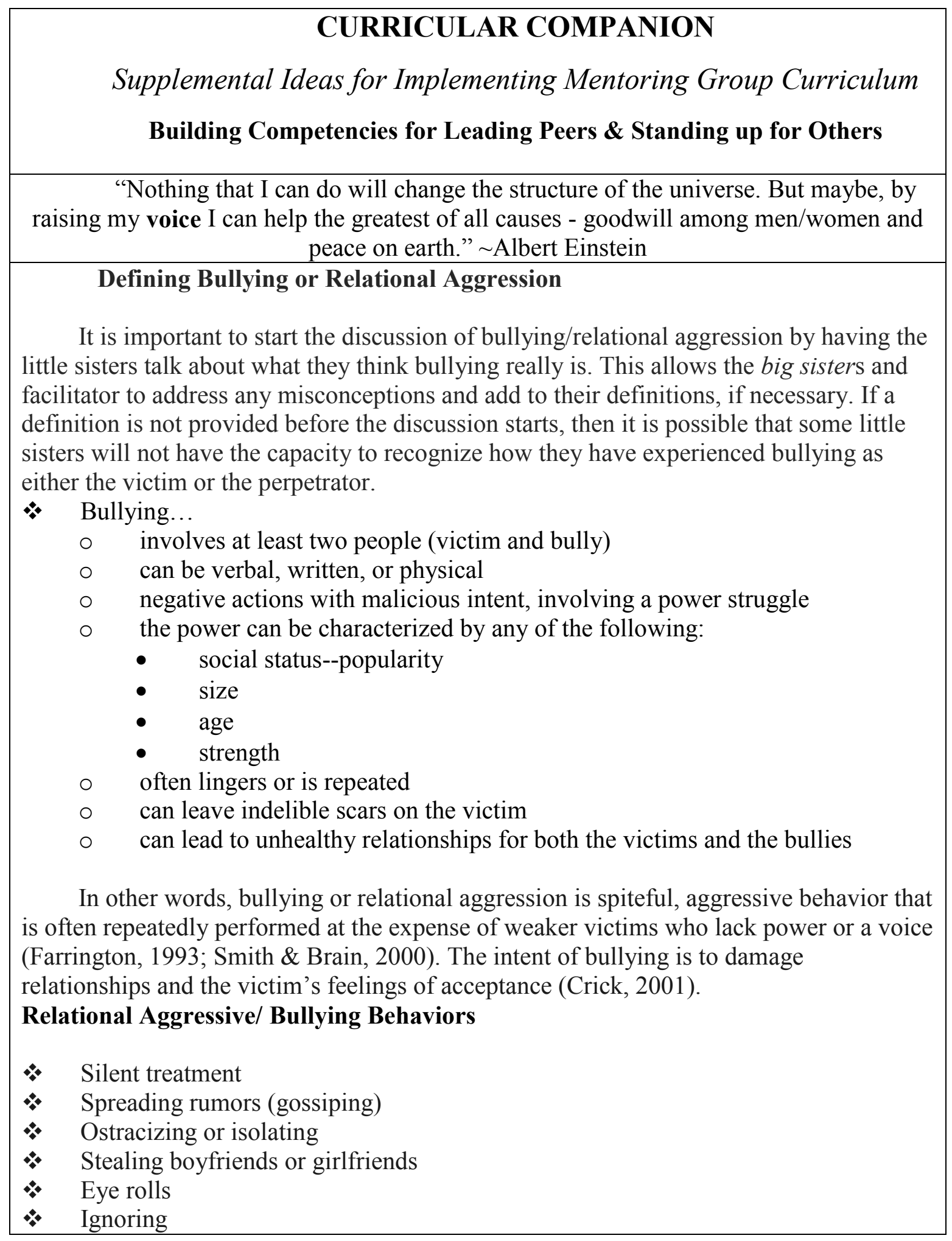




$$
\begin{aligned}
& \text { Ganging up- building alliances } \\
& \text { Trapping someone into saying something about another } \\
& \text { On-line or cyber bullying } \\
& \circ \quad \text { blogs \& online journals } \\
& \circ \quad \text { chat rooms } \\
& \circ \quad \text { posting pictures from cell phone cameras } \\
& \circ \quad \text { editing photos to be unflattering }
\end{aligned}
$$

\section{Roles in a Bullying Scenario}

* According to Wiseman (2002) illustrates the roles of female relational aggressing/bullying by creating hierarchical roles: Queen Bee, Sidekick, Banker, Floater, Torn Bystander, and the Pleaser/Wannabee/Messenger. Each role supports the Queen Bee.

* The Sidekick (second in command) imitates the Queen Bee.

* The Banker collects and holds information (often incriminating) about other girls. This information is viewed as currency in "Girl World." The Banker is devious and tends to be shy or quiet around adults. Strategically, the banker uses the information she has gathered to benefit herself.

* The Floater associates with more than one group of girls. She is confident and well liked by all. If pressed, she is the only one who will stand up to the Queen Bee.

* The Torn Bystander is conflicted about doing the right thing and her allegiance to the clique. The role of a bystander is critically important. The bystander is the audience for the bully. If the bystander intervenes on behalf of the victim, the bully loses.

* The Pleaser/Wannabe/Messenger will do anything to please the Queen Bee and Sidekick. This girl desperately desires acceptance, but does not want to look too desperate for fear of being dropped by the Queen Bee and Sidekick.

\section{Another Perspective about the Roles in Bullying}

* Phillips (2003) ranks powerful (i.e. tough and aggressive) girls into different positions (pecking order). The pecking order is maintained though:

○ physical aggression

$\circ \quad$ physical strength

$\circ$ dominance

$\circ$ intimidation

\section{Consequences of Bullying or Relational Aggression}

* Relational aggression affect three developmental areas for adolescent females:

$\circ \quad$ personal and social development

- academic development and success

- career development.

* The consequences of being bullied or a bully can be severe, especially for the 

victims who have suffered for extended periods of time. Victims of relational aggression or bullying are at risk for adjustment problems later in life.
* Some Consequences for Victims of Bullying
$\circ \quad$ Increased stress
- Eating disorders
○ Psychological disturbances
- Self- destructive behaviors
- Social maladjustment
$\circ \quad$ Deficiencies in physical wellness
o Lower self-esteem
- Higher rates of school absenteeism
- Negative feelings toward the school environment (can result in high levels of asenteeism)
○ Lower grades
○ Decreased self-efficacy related to school achievement and plans for future.
- Depression
○ Unhealthy relationships
○ Victimization Cycle-blaming themselves for the bullying
* Both victims and bullies learn how to interact with others through the bullying exchanges. This can be transferred to significant relationships such as dating relationships and can lead to victims tolerating aggressive behaviors or bullies being aggressive with dating partners. Those who bully are more likely to sexually harass or physically aggressive with their dating partners.

\section{Control What You Can Control}

You cannot control other people; you can only control your own behavior. Decide to be a positive person. Do not let your positive attitude be pulled down by negative people (e.g. gossipmongers, whiners, backstabbers, etc.). Surround yourself with people who are positive influences and make you feel good about yourself. Maintain friendships with people who are supportive and kind. This is ideal and not necessarily realistic for adolescents as they are trying to build their own story of who they are; develop an identity. This is where big sisters can provide some time to reflect on relationships and their impact as well as and some gentle guidance if requested.

\section{Maintaining Composure- Mastering Your Emotions}

Leaders stay calm and think before they react. It is not unusual for adolescents to have shared sentiments of dislike for one another. In fact it is becoming increasingly more common in recent years. The concern becomes not whether adolescents will encounter relational conflict, but rather how they can respond in healthy ways and maintain composure during the inevitable drama. 
It's simple: you either learn to control your emotions or they will control you. Negativity leads to a loss of self-control. Little sisters need training to remain calm and cool in the drama, to remain composed and even-keeled even in the hottest of situations. By doing so, they exhibit that they are in charge of their emotions, not the other way around; leading to a healthier outlook and more success down the road.

Everybody knows individuals who regularly let their anger or other emotions cloud their judgment. In the heat of the moment, these individuals often say things that are emotionally charged, hurtful and even unproductive. These individuals are often not respected nor are they seen as a resource for others to consult when a clear-headed vision is required. The way people respond to conflict speaks volumes about their character and their ability to lead. Leaders remain cool in the face of conflict and control their emotions instead of letting their emotions control them.

\section{Developing Voice}

As previously stated above, bullies lose power if others intervene or deflect the aggressive behavior. Though YWLP, little sisters are building their leadership skills and have an opportunity to be light in the darkness. If properly armed with strategies and confidence, they can deactivate the Queen Bee's ammunition and stick up for others who may not have a voice. Role playing and practicing the strategies in realistic situations can help prepare little sisters to behave like a leader for the inevitable conflicts that arise in middle school.

\section{TIPS: Energizer}

$>\quad$ Emphasize Friendliness: People gravitate toward friendly, happy, people; they are charismatic. Forging a connection is the goal. Eye contact, smiles, handshakes and kind words all facilitate emotional connections. These behaviors can help establish a positive first impression as well as help maintain positive perceptions. These "connection" behaviors are advantageous in every area of life and can certainly help gain respect from adults.

Be Sensitive to Your Group: When deciding whether to do this activity within the group or going for a walk, consider whether your little sister might need to get out and move around. Remember that they have just been through a full day of school where they are sitting still so walking around may be just what they need. Also consider whether the group members can handle the freedom and still be on task. Create more structures (e.g. time limits, create a scavenger hunt, questions to ask, etc.) for the group if you have members who may not be as focused when unsupervised. Lastly, consider whether your group members are energized by competition.

\section{JUSTIFICATION:}


The purpose of this activity is for the little sisters to have practice with the Leadership High Fives that they learned last week. Regardless of which way you decide to practice the techniques, it is important to remember that these are life skills that help people get ahead.

\section{TIPS: Group Check-in}

Hot Topics: This may be an appropriate activity for today, if the topic is related to bullying or teasing. It could get the conversation started and help generate ideas about bullying and teasing. Big sisters could share stories of times that they were a victim, or stepped in to help someone who was being teased. Starting the conversation with teasing may prove to be an easier approach. Most people can relate to being teased or teasing someone in a way that they believe is harmless. One never really knows who a person internalizes the teasing though.

Star Time or High/Lows: Try to spice up this time. Either find interesting ways to recognize people or applaud them (special clap, movement, song, phrase, or say something in a different language). You may want to have people write things on their stars that are related to their goals. Also it is helpful to link the accomplishments on the stars to the Leadership Ladder.

\section{TIPS: Sister Time}

Cultivating the Connections Between the Pairs: Talking about love interests is always a favorite for adolescents! During this time, it is intended that the pairs will discuss the Dating Interview activity that they will be doing with their parents. Big and little pairs can start the topic talking about the characteristics of a healthy relationship or what would a "dream relationship" be for them. There are some more awkward or difficult questions on the interview protocol, so big sisters should use this time to address those and offer suggestions for how to ask these questions in a way that is comfortable for the little sisters.

Goal Setting Group Check-in: Sisters have been creating goals related to: self, relationships, and academic leadership. Big sisters should begin by sharing their own progress with their goals. Honesty is important.

Guide Gently (revisited): Big sisters need to be prepared to provide specific guidance and listen closely without judgment. Use BOOST! Depending on the situation, it may be useful for big sisters to share any struggles (maybe even from middle school) or successes that they have had in school and strategies that have worked for them.

Connect with Teachers (revisited): As a follow up for the conversation, it may be useful for big sisters to connect with little sisters' teachers. This must be done 
with the permission of the little sister and should be approached as if the big sister is joining the "team" supporting the little sisters' academic achievement.

\section{TIPS: Declining the Drama}

Start the conversation small. It might be a good idea for you to talk about teasing first before you talk about bullying. Most people can relate to teasing and have been teased or have teased someone else. Teasing seems harmless and often is, but sometimes unbeknownst to the person doling it out, it may be taken very personally and the impact may leave a scar. By starting small, you are inviting more people into the conversation and it presents the topic in a way that is less judgmental to the people who have actually been a bully before. It is our particular goal to invite the bullies into the conversation, because without participating in the conversation, the activity will not impact their behaviors.

$>\quad$ Use realistic and relevant scenarios. When determining what scenarios you are going to use for the role plays, consider what your little sisters have shared in the past. Using something similar, but NOT exactly the same, could make it more accessible for little sisters. Remember that much of the relational conflict that adolescents experience is related to jealousy, acceptance, insecurities, power, and love interests. Incorporate these ideas in the scenarios.

Read \& monitor your sisters. Be sure to study your sisters and be alert to the non-verbal signs that may represent discomfort or anxiety. If the majority of the group is expressing discomfort, you may want to do an abbreviated version and wait until your group has bonded more. If just one or two sisters seem as though they are not ready to take the risk to be vulnerable with the group and share a bit of themselves, then provide an opportunity for the sister to gracefully exit.

Provide a safety net or scaffolding. Give sisters who are not ready for the activity a way to still participate, but a role that does not involve sharing- e.g. reader of the prompts.

Reflection is key. Taking the time to reflect and discuss after this activity is a key element. (WWLD) What would a leader do in these scenarios? There is not one correct way to respond in any situation, but brainstorming some healthy options of how to respond will better arm the little sisters for the inevitable relationship drama that they will experience.

Provide some strategies for healthy responses to relational drama. Walk, Talk, Tell When you explain these strategies, be sure to use several relevant examples

JUSTIFICATION for Declining the Drama: This activity is meant to reintroduce the Leadership Secret-Leaders keep their cool and respect themselves and 
then to provide some practice time to respond to the drama in healthy ways. Facilitators can also assess and take note of how comfortable the sisters seem to be with managing the relationship drama (at least in a controlled environment).

\section{MEASURING STICK: Assessing Growth}

* Self-reflection

- How did you do this week as a facilitator?

- Did you try the best practices recommend in the FIG?

- Did you help any little sisters shine this week?

- Did any challenge any big sisters in an effort to stretch them?

* Did your little sisters meet established outcomes for this Mentoring Meeting?

* Do the little sisters in your group know the information presented?

- More details about fellow group members

* Coping strategies to remain "cool" in dramatic situations (e.g. bullying)

* Did they demonstrate that they understood the established understandings or principles that are the foundation of the meetings' activities?

- Successful leaders lead by example and use their voices to defend what is right, including victims of bullying and teasing.

* Leaders can influence their peers by keeping their cool and standing up for others.

* Can they apply the facts and principles in meaningful ways? Did they...

- Demonstrate collaborative behaviors in pairs and in groups

- $\quad$ Apply established expectations to own participation in group activitiesparticularly confidentiality

- $\quad$ Participate earnestly and honestly in activities

- Apply healthy strategies in role play situations related to relationship drama

- Demonstrate proficiency with the identified leadership skills for connecting with adults

- $\quad$ Connect the concepts previously discussed

\section{JUSTIFICATION:}

It is important to find some way to assess whether you effectively communicated the facts and principles supporting the Mentoring Meeting's activities. It is equally important to determine (on an individual basis) whether little sisters gained the understandings and knowledge. This can be done through a formal or 
informal conversation, a comment that is made, a behavior displayed, a written "exit card" with questions related to the outcomes (KUDs).

- Mix up how you have the little sisters express what they know, understand and can do. They will get bored when you overuse a strategy.

- It is important that you keep track of little sisters' growth in some waywhether it is done formally or informally. You can share this responsibility with big sisters- perhaps a notebook could be passed around the group, tracking the little sisters' changes. Documenting the growth is important because it sometimes happens so quickly that it is difficult to remember what the little sister used to be like or so slowly and even slightly that changes are noticed. This will provide information to share with parents and for the events at the end of the year.

\section{PRACTICAL EXTENSION: Relating the Activities to Real Life}

* Managing the Adolescent Relationship Drama Like a Leader: Leaders ought to develop their voice so that they can stand up for others and use their influence to help their peers. Once they become more proficient and comfortable, leaders use their skills and power to protect those who may not have their own voices established quite yet.

* Creating a Picture of Healthy Dating: The Dating Interview that the little sisters are going to conduct with their moms, aunts, etc. is one way to get a very important conversation going. Little sisters are often extremely curious about "crushes" and the life of dating. Hearing multiple perspectives about what romantic relationships and dating can be like aids in the development of little sisters' expectations. Having the conversation with their parents and then hearing a variety of points of view will provide a more panoramic picture and hopefully help them create their ideals.

\section{THE BIG PICTURE: Uniting the Concepts within the Curriculum}

- How does the discussion of leading peers, using voice to stand up for others, and remaining calm and composed during relational drama relate to the previous meetings? How about the previous weeks?

- Explicitly creating the connections between the concepts each Mentoring Meetings will deepen sisters' understanding of the concepts and will increase the chances that they will be able to transfer the skills and knowledge to new situations. 
$\circ \quad$ For the visual learners, consider asking the sister to create an illustration that makes connections between some or all of the concepts. Or for the verbal processors, they can participate in a discussion that connects the concepts. 
WEEK FIFTEEN: Leading in Romance

Concepts: $\quad$ Empowerment, Voice, \& Problem Solving

Outcomes:

As a result of this Mentoring Meeting, participants will know...

* More details about fellow group members

* Strategies for leading in romantic relationships

As a result of this Mentoring Meeting, participants will understand that...

* Women and girls have control over their own bodies.

* Women and girls have the power to make healthy decisions about ways to intimately connect with others.

As a result of this Mentoring Meeting, participants will be able to...

* Demonstrate collaborative behaviors in pairs and in groups

* Apply established expectations to own participation in group activitiesparticularly confidentiality

* Participate earnestly and honestly in activities

* Set meaningful and specific goals

* Discuss the relationship between some of the concepts

* Distinguish the difference between behaviors of a leader of a lost person

* Compare and contrast perceptions and realities of dating habits

\section{TO DO LIST: Key Reminders For Week Fifteen Big Sister Meeting}

$\checkmark$ Continue to encourage big sister's who display leadership or participate actively during group.

$\checkmark$ Directly AFTER the Big Sister Meeting, text or email any big sisters who displayed any desired behaviors that promoted engagement. Thanking them individually will encourage them to continue those behaviors.

$\checkmark$ Make copies of the Big Sister Meeting agenda. (optional)

$\checkmark$ Remind big sisters to bring their $7^{\text {th }}$ Grade Curriculum Handbook with them to the Big Sister Meeting.

$\checkmark \quad$ It might be a good idea to go outside (weather permitting) and practice the energizer for this week just to make sure that everyone understands how it works.

$\checkmark$ You might need to communicate throughout the week regarding the School Legacy Project and/or the Sister-to-Sister Project.

SUPPLY LIST: Necessary Supplies for Week Fifteen Big Sister Meeting 
Agenda copied for big sisters (optional)

$\checkmark \quad 7$ th Grade Curriculum Handbook

$\checkmark$ Take a Guess handout

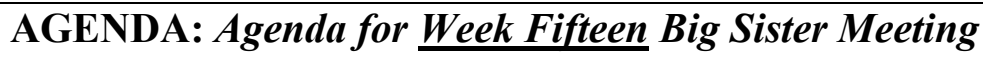

\section{1) Building Big Sister Connections}

a. High/Lows (individual \& pair check-in)

b. Announcements

c. Reports from Group Leadership Roles/Jobs (e.g. photographer, attendance, Sisterto-Sister, etc.)

\section{2) Reflection}

a. In small groups, pairs, or as a whole group reflect on the successes and challenges of the Mentoring Meeting from the prior week.

i. What would you change about last week's Mentoring Meetings?

ii. What did you (as a team) do well?

iii. What interesting thing happened?

\section{3) Strengthening Mentoring Relationships}

a. Discuss in small group, pairs or as a whole group, where everyone is with her little sister. A mentoring relationship has stages (Introduction, Building, Growing, Maturing, Transitioning). Keep in mind that relationships can fluctuate and go backward before they go forward, or even remain static for some time. Have the big sisters put a label on the development of their relationships.

b. How can big sisters support their little sisters as they develop and navigate romantic relationships?

i. How can big sisters model healthy romantic relationships?

ii. What are some necessary boundaries to create between big and little sisters with this topic?

iii. How much information is too much?

iv. How can big sisters discourage "boy crazy" behaviors without hurting their relationship and seeming out of touch/judgmental? 
a. Nuts \& Bolts

i. Problem-solve potential little sisters' responses to the curriculum this week.

1. Who has mentioned that they have "crushes" or romantic interests?

2. Have any little sisters mentioned any inappropriate or unhealthy behaviors associated with a romantic relationship?

a. How will you show sensitivity to those sisters in addressing their needs?

3. The topic of "crushes" can conjure up both positive and negative feelings.

a. Are you prepared to create a space for little sisters along the continuum (those who have never experienced romantic feelings all the way to those who are obsessed with romance \& sex)?

4. How will ensure that your group is a safe and confidential place for all of the members?

ii. How can you check in on the progress of the work related to the School Legacy Project and/or the Sister-to-Sister Project to make sure that it is still moving forward?

\section{b. Take Away Messages}

$i$. Conduct an open discussion about what the following principles mean to the big sisters as individuals.

* Women and girls have control over their own bodies.

* Women and girls have the power to make healthy decisions about ways to intimately connect with others.

5) Recognizing Big Sisters Who Exercised her Voice

a. Have Big Sisters talk about what they have done or observed in the last week that pertains to this week's message. How have they "led in romance" or made healthy decisions based on their wants and needs instead of someone else's.

\section{TO DO LIST: Key Reminders For Week Fifteen Mentoring Meeting}

$\checkmark$ Check in with the office to be sure that they make an after-school announcement.

$\checkmark$ Also check with the School Contact to determine if there are any places that are 
restricted for the energizer.

$\checkmark$ Your room may be locked, so arrive early enough to find a custodian to let you into your room, if necessary.

$\checkmark \quad$ At the beginning of your meeting each week, determine who is in attendance.

Determine which little sisters are on your list, but not in attendance. Send the big sisters sister who is assigned to the missing little sister (or if doable, you can) to the office to call the parents to notify them of the absence.

\section{SUPPLY LIST: Necessary Supplies for Week Fifteen Mentoring Meeting}

$\checkmark$ Nametags

$\checkmark$ Snacks

$\checkmark$ Mascot or item to serve as microphone to indicate who has the floor to speak.

$\checkmark$ Hot Topic box

$\checkmark$ Hot Topic paper slips

$\checkmark$ Writing utensils (pens, or pencils, and markers)

$\checkmark$ Leadership Ladder

$\checkmark$ Signs made for group

$\checkmark$ Star stickies for Star Time

$\checkmark$ Large post-it paper

$\checkmark$ Take a Guess handout

$\checkmark$ Comfortable clothes and sneakers to be outside (weather permitting) during energizer 


\section{CURRICULAR COMPANION}

\section{Supplemental Ideas for Implementing Mentoring Group Curriculum \\ Building Competencies for Leading in Romance \& Developing Healthy Romantic Connections}

\section{Mothers, Daughters \& Sex}

It is natural and developmentally appropriate for adolescent girls to have a heightened interest and curiosity about sex. Some girls have a relationship with their mothers where they can speak openly with their mothers, while others do not have someone to whom they can turn when they have curiosities or questions about sex and sexuality. Mothers and daughters are not always comfortable talking about these topics together for a variety of reasons, but the most obvious is that daughters fear that their mothers will not understand and as a result will judge them. Often this results in girls containing their thoughts and feelings, which is not healthy. The big sisters in YWLP are in the ideal situation to provide a non-judgmental ear.

\section{Safe Space}

Adolescent girls need a safe space to process their sexual feelings and thoughts. By not having that place to express their feelings, it leaves adolescent girls only one choice- to bottle up their thoughts and feeling about sexuality, which sets the stage for them to be unprepared, lacking the knowledge and understanding to take an active role in making decisions regarding sex and sexuality. When adolescent girls are educated and able to sort out what they are thinking and feeling they are better posed to have control; they have power over their own bodies and can make choices for themselves rather than being persuaded into a physical situation for which they are unprotected and ill-equipped.

\section{Wide Range of Experiences}

Adolescent girls develop physically and social emotionally at different rates. The varied rate of development as well as other factors contributes to the broad spectrum of exposure they have with regard to acting upon their sexual thoughts and making decisions regarding sex and sexuality. The curriculum this week may conjure up intense feelings and may make some sisters vulnerable, in new territory. This may be the first time some of the sisters have ever vocalized feelings that they have kept bottled up while other sisters may feel comfortable speaking freely and may have their thoughts fully formulated on the subject. It is important to monitor your group and be sensitive to the wide range of experiences and comfort levels that your big and little sisters may have. Respond accordingly and provide safe spaces for sisters to explore the topic to the degrees that they are comfortable and interested. 


\section{Choices and Control, Being a Leader}

To a large degree society still communicates the expectation that girls will conform to many of the stereotypical "feminine" roles and characteristics that include being: well mannered, compliant, pleasant, agreeable, and sometimes even passive. It is true that there are more messages for girls today about voicing their ideas and opinions and being empowered, but they are often followed by the underlying or hidden messages that are contradictory.

"It just happened" is the phrase Tolman (2005) uses to describe the passive role many girls continue to have today in their sexual experiences. She calls the approach unhealthy and unsafe. In her book Dilemmas of desire: Teenage girls talk about sexuality, she goes on to say that "in a world where 'good,' nice, and normal girls do not have sexual feelings of their own, it is one of the few decent stories that a girl can tell" (Plummer, 1995). When young girls say "it just happened" it is covering up their wants and needs, their role in the situation. She can then obscure that she her active role and responsibility in the situation. It happened to her. 


\section{TIPS: Energizer}

\section{$>\quad$ Enthusiasm is Contagious:}

Some of the little sisters might feel awkward or uncomfortable participating in the energizers. Prepare your big sisters to be fully engaged and willing to be silly. Set the tone that it is the norm to be engaged and to take risks by being silly and having fun. If big sisters are not "into" the activity are not showing enthusiasm, the little sisters are likely to mimic that indifference.

\section{Clear Directions \& Well-Organized Presentation:}

Present the directions and expectations for the energizer in a clear and wellorganized manner. Each one has a few details that must be explained before you begin. Go over the directions at the Big Sister Meeting so that you are clear on how it works beforehand. You may want to have a few big sisters role play and demonstrate how the activity works.

\section{ADAPTATIONS: Energizer}

Discuss which energizer you would like to do at the Big Sister Meeting. You can present both to your group and then let the group decide with little sisters' input, but that will require being prepared to facilitate either energizer. You also can make the decision based on several factors: overall group tone/energy level, group/pair cohesion,

The Screaming Viking-You and your big sisters need to take time to familiarize yourselves with all of the different poses. Practice during the Big Sister Meeting.

- Because of the complexity of and the energy level necessary for this activity versus the Everybody It you can decide which one you will lead based on your group. You know them best!

- As a group, do they seem to pick up on directions easily?

- Will they exert the appropriate amount of enthusiasm to make this activity successful?

\section{JUSTIFICATION:}

The purpose of these activities is for everyone to have fun with one another and bond as pairs and as a group. As the name suggests, these activities are designed to infuse some energy into the group. Also, the fact that they include outside time with a great deal of movement, capitalizes on the adolescents' developmental needs for flexibility and relaxed structure for movement. This activity is intended to loosen people up so they will be more comfortable talking later in the meeting. 
Varied Levels of Interest or Readiness: Do not be surprised if you notice that some sisters have burning issues that they would like to discuss and others do not seem as interested. This is expected as they represent a wide array of developmental and social levels at this age and some may have more exposure to these topics based on older friends and siblings. If this happens, you may consider dividing the group in half based on exposure/readiness or interest about the topic. You can have half of the group do High/Lows \& Star Time and the other half Hot Topics, or you can all participate in the High/Lows \& Star Time and then divide for the Hot Topics discussion. The decision should be made based on your group and the sisters' comfort levels, readiness (experience) and interest.

Hot Topics Box: If you decide to do the Hot Topics this week, it would make sense to have the topics be related to dating or romantic interests. If you do High/Lows and Hot Topics, be sure to do Hot Topics second and set a timer to place boundaries on the conversation.

High/Lows \& Star Time: There is a lot to accomplish during this meeting so you will want to be sure that you keep the sharing moving around the circle without anyone feeling as though they were not heard or rushed along. In the effort to move it along, it is helpful to have sisters share their High/Lows and their weekly "success" at the same time and cheer after each sharing. You also may consider using a timer and passing the mascot around the circle to minimize interruptions.

\section{TIPS: Sister Time}

$>\quad$ Sister Time: Sister Time during this meeting is designed to provide some time for one-on-one discussing in pairs, but it is very structured and has a great deal packed in it. They are listed in order of priority so request that big sisters to address them in order.

Take a Guess: Complete this form in pairs, but encourage big sisters to not dominate. It is most important that little sisters circle the responses that they believe in order to effectively debunk their perceptions of what is going on with the statistics of the reality of what's going on. Instruct big sisters to closely monitor their little sisters' reactions to the questions. If little sisters seem uncomfortable completing this handout, that may be an indication that they are shy or reserved, but it may be an indication of something more serious. Watch closely and in the rare, (but certainly possible chance) that you have a little sister who seems highly disturbed or if it uncovers unpleasant experiences that they then need to discuss. Find a way to gracefully excuse students from completing the form and allow them space and privacy to discuss with their big sister and possible you, the facilitator. 
Leadership Projects: It is common for these projects to fall off the radar since they are not the focus at this point. Encourage pairs to consider how they will move forward. As the pairs are talking, circulate around the room and check in. Ask pairs to share their plans with you. Warn the pairs that you will be doing this so that they are prepared.

$>\quad$ Circle Back on Goals: Encourage pairs to touch base on their goals. It is just as important for big sisters to share their progress and the little sisters. Little sisters need to know that the big sisters are taking it seriously and that they are accountable also. If sisters are making progress and growing in an identified area, this is a time when the two can celebrate together. If sisters are struggling, this is a time when they can share their struggles with a trusted friend and maybe even offer some tips. In order for little sisters to take this activity seriously and to reap the most benefits from it, it is critical that little sisters view this exchange as reciprocal, meaning that both sisters have valid ideas to share and valuable goals that are worth pursuing.

\section{TIPS: What About Dating?}

Defining the Terms: This is an important introduction to the conversation to avoid misunderstandings and to ensure that everyone is on the same page. It is often surprising how quickly the terms change meaning and new terms are invented. Little sisters often enjoy sharing this "knowledge" with the big sisters because it emphasizes how "out of touch" they are and they think that it comical. Be sure to write these terms down on paper in some way-you will need them for reference for later discussions in this meeting and beyond. This discussion can happen in small groups, pairs, or whole group. Read your group and if they seem like they would be higher participation in smaller groups then go that route.

Dating Interview: Encourage big sisters to follow up with their little sisters about how the interview went with their mothers. If big sisters want to share how they would respond (or even how their mother's would respond) too- that might make it even more interesting. Allow the pairs to have some privacy during this time so that they can speak openly. The purpose of this conversation is to continue the discussion of dating, and to set the stage for the more intense discussions to come later in the meeting.

Take a Guess Results: This discussion works best if it is done as a whole group and everyone is able to see the questions. Make the correct answer clear, as it will most likely be very different from what people think. The purpose of this activity is to debunk the misconceptions that many people have about the sexual activity of their peers. The statistics are powerful! 
Be Honest: Honesty is important during this activity. Encourage big sisters to share stories of times when they have been lost and how they learned from the experiences. There is no need to provide significant or private details, the integral piece of this exercise is to provide authentic examples to which the little sisters can relate.

$>\quad$ Emphasize Having Power \& Control: Little sisters respond to the idea of "girl power." Use that to send the message that they have control over their own decisions and actions. This includes when they have romantic interests.

MEASURING STICK: Assessing Growth

How did you do this week as a facilitator?

- What parts or aspects of the meeting were challenging for you?

- What were your strengths as a facilitator this meeting?

- In what ways were you effective in leading your big sisters?

- How are your delegating skills growing?

- How did you uncover little sisters' potential or let them shine?

Did your little sisters meet your established outcomes for this Mentoring Meeting?

Do the little sisters in your group know the information presented?

- More details about fellow group members

- Strategies for leading in romantic relationships

* Did they demonstrate that they understood the established understandings or principles that are the foundation of the meetings' activities?

- Women and girls have control over their own bodies.

- Women and girls have the power to make healthy decisions about ways to intimately connect with others.

* Can they apply the facts and principles in meaningful ways? Did they...

- Demonstrate collaborative behaviors in pairs and in groups

- Apply established expectations to own participation in group activitiesparticularly confidentiality

- Participate earnestly and honestly in activities

- Set meaningful and specific goals

- Discuss the relationship between some of the concepts 
- Distinguish the difference between behaviors of a leader of a lost person

- Compare and contrast perceptions and realities of dating habits

JUSTIFICATION:

It is important for you to reflect on your skills as a facilitator in order to grow. Also, whether your little sisters achieved the goals set out for the meeting is a reflection of your success as a facilitator. Finally, it is critical to determine how your big sisters are doing and where they might need support, encouragement, or even recognition.

\section{PRACTICAL EXTENSION: Relating the Activities to Real Life}

* Leading With Your Body: Follow up with little sisters about how they can maintain control over their bodies and make decisions for themselves. Big sisters should continue this discussion with their little sisters. Discuss the potential obstacles that might stand in the way of doing this.

\section{THE BIG PICTURE: Uniting the Concepts within the Curriculum}

- How does the discussion of having a voice and making healthy decisions about romantic interests relate to having a voice with peers and maintaining composure?

- Explicitly creating the connections between the concepts each Mentoring Meetings will deepen sisters' understanding of the concepts and will increase the chances that they will be able to transfer the skills and knowledge to new situations. 


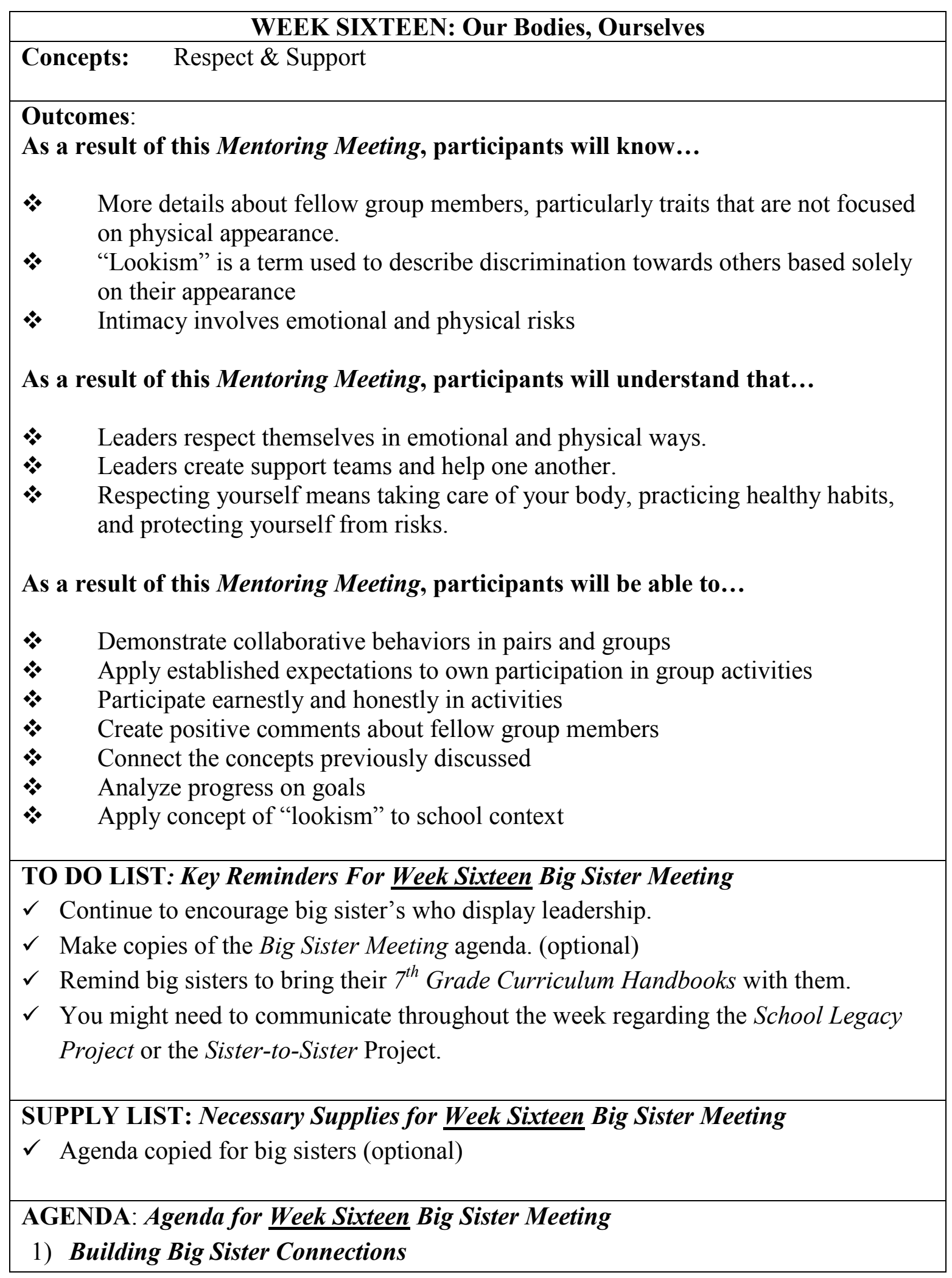


a. High/Lows (individual \& pair check-in)

b. Announcements

c. Reports from Group Leadership Roles/Jobs (e.g. photographer, attendance, Sisterto-Sister, etc.)

\section{2) Reflection}

a. In small groups, pairs, or as a whole group reflect on the successes and challenges of the Mentoring Meeting from the prior week.

$i$.What would you change about last week's Mentoring Meetings?

ii. What did you (as a team) do well?

iii. What interesting thing happened?

$i v$. Who stood out as a leader? (big and little sisters)

\section{3) Strengthening Mentoring Relationships}

a. Continue this discussion, if necessary.

$i$. Discuss in small group, pairs or as a whole group, where everyone is with her little sister. A mentoring relationship has stages (Introduction, Building, Growing, Maturing, Transitioning). Keep in mind that relationships can fluctuate and go backward before they go forward, or even remain static for some time. Have big sisters put a label on the development of their relationships.

$i$. What can big sisters do to support little sisters in the various domains: academics, social \& familial relationships, emotional health?

ii. What are some fun activities that big sisters are doing with the little sisters?

iii. How can big sisters connect more with their little sisters' parents or other important people in little sisters' lives?

\section{4) Mentoring Group Curriculum}

\section{a. Nuts \& Bolts}

i. Consider little sisters' potential responses to the curriculum this week.

1. Who has mentioned that they have body image issues or makes comments to indicate issues?

2. How will you show sensitivity to those students in addressing their needs?

3. The topic of body image can be a very sensitive and sometimes 


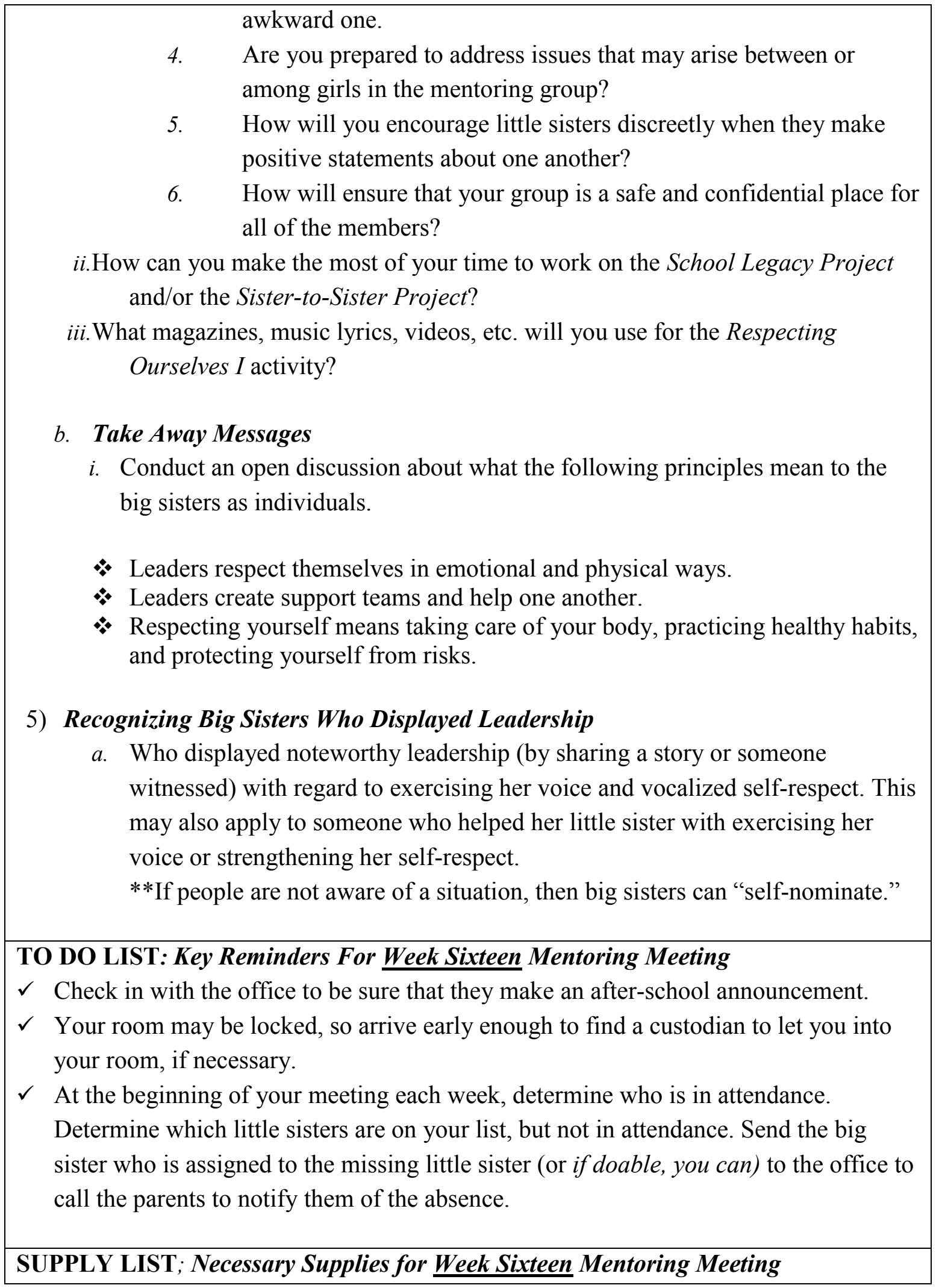




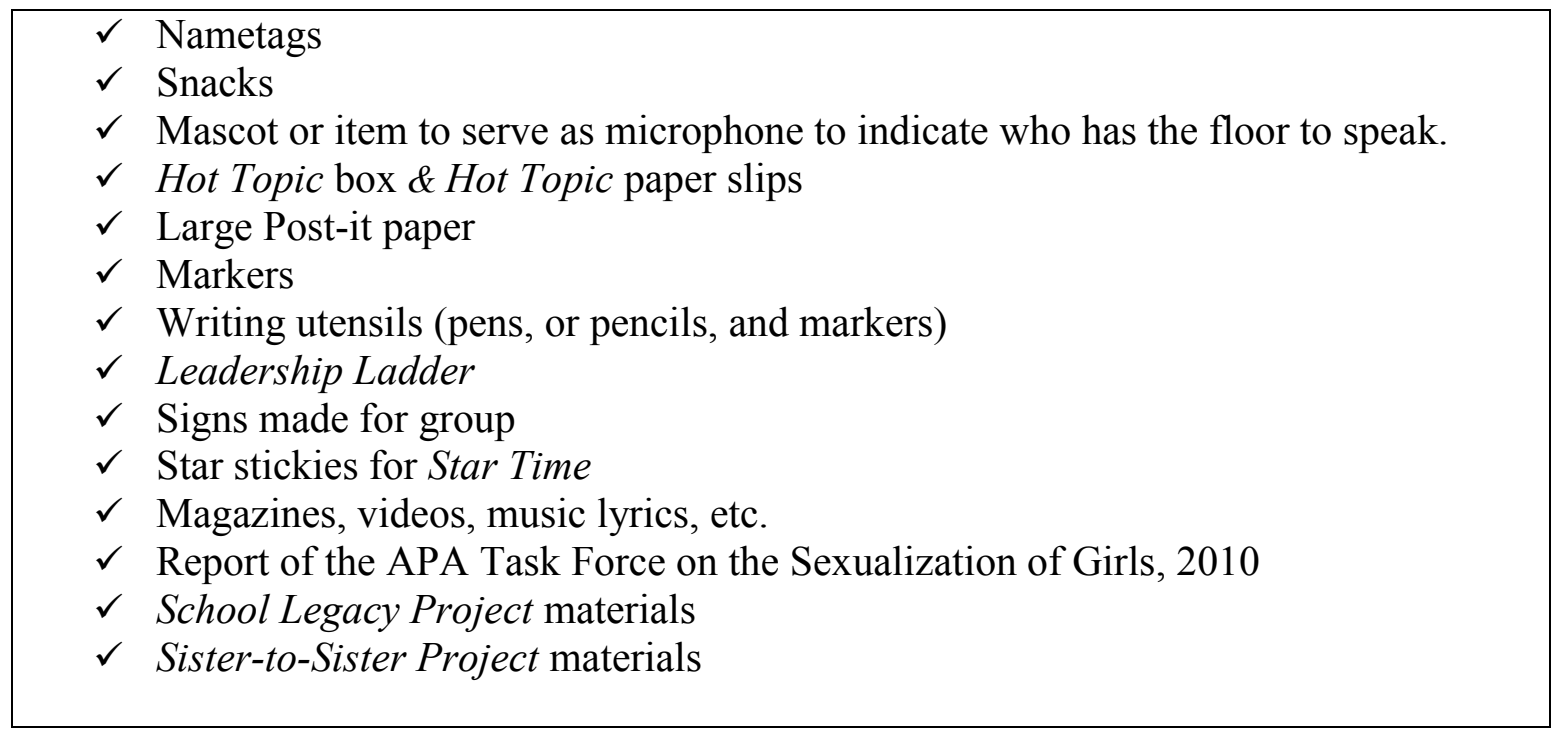




\section{CURRICULAR COMPANION}

\section{Supplemental Ideas for Implementing Mentoring Group Curriculum}

\section{Building Competencies for Respecting Yourself Emotionally and Physically}

\section{"Lookism" and Healthy Body Image}

"Lookism" is the prejudice or discrimination based on a person's physical appearance, particularly based on what society deems to be beautiful characteristics. It is a tough battle to win, but as mentors of adolescent girls it is part of our mission to fight the unhealthy and unrealistic messages that the media sends a million times a day through online sources, magazines, and television, etc. Media images define beauty and what it means to be beautiful and those images fuel women and girls' sense of self. When girls and women do not meet the criteria (which is often since they are unattainable and unrealistic) it can cause feelings of inadequacy. The inadequacy is what drives many girls and women to question their self worth and to work endlessly to try to meet society's criteria of beauty by whatever means necessary.

If adolescent girls are educated about the injustice of "lookism" and are ready to view the world with an awareness of the slanted perspective that worships superficial qualities, they will be armed and hopefully less likely to determine their self-worth by their appearance more likely to recognize the value of intellectual and emotional talents in themselves and others.

\section{Supporting an Anti-'Lookism" Perspective}

It is true that to some extent "lookism" is subconscious, but like any prejudice, once the curtain is pulled back and people are aware of it, they can monitor their own actions and decrease behaviors that are prejudice based on other people's appearance. Everyone can make a small contribution to sending healthier messages about how people should measure worth in people, including themselves such as: through emotional and intellectual gifts and talents rather than physical beauty.

\section{Protecting Yourself Physically and Emotionally}

An important aspect of self-respect is to protect yourself emotionally and physically. This requires being educated so that sisters can make healthy decisions based on information, not on their emotions. Part of the education comes from engaging in discussions in a safe, non-judgmental environment so that questions can be answers and myths debunked. Big sisters can help little sisters understand what it means to be safe and protected regardless of whether little sisters decide to become emotionally intimate with another or not. 


\section{TIPS: Energizer}

$>\quad$ Emphasize Authenticity: In order to provide a comfortable atmosphere where sisters do not feel put on the spot or embarrassed, you might consider allowing just a little bit of time before the activity for the sisters to brainstorm in their pairs. They can bounce ideas off of one another and think of multiple examples of positive traits about each of the sisters instead of thinking under pressure.

Stress Attributes Other than Physical Appearance: This exercise is intended to point out characteristics of sisters other than superficial ones (e.g. how they dress, what they look like, etc.) so that the focus can be on valuing the various aspects of us.

\section{JUSTIFICATION:}

The purpose of this activity is for the little sisters to focus on attributes that are not based on physical appearance. Highlighting characteristics that others view as positive diverts attention toward superficial traits that are less important and sometimes out of a person's control. When sisters receive authentic compliments it will, not only, build their self-confidence, but also the relationship between the sisters. Ask sisters to look at one another with perhaps a different perspective.

\section{TIPS: Group Check-in}

$>\quad$ Hot Topics: If your group chooses to discuss a Hot Topic, be sure to still have some time for Star Time. Little sisters usually have a lot to say with regard to last week and this week's topics. It might be a good idea to provide a safe space for them to process the most recent discussions related to sex and this week with regard to the topic of body image.

$>\quad$ Star Time or High/Lows: If you choose to do this activity this week, be sure to provide some time for little sisters to express what they are thinking as they process last week's discussion. Sister Time can be used for that, but as the facilitator, ask your big sisters to broach the subject in case some little sisters are uncomfortable bringing it up.

\section{TIPS: Sister Time/Homework Help}

Goal Setting Update: Sisters have been creating goals related to: self, relationships, and academic leadership. Big sisters should begin by sharing their own progress with their goals. Honesty is important. If sisters have not made progress toward their goals, encourage them to be honest and consider some of the obstacles. Then brainstorm ways to circumvent the obstacles. Also encourage sisters to amend the goals, if necessary. Sometimes goals sound more realistic on paper, but then in the "real world" it becomes apparent that the goals are out of 
reach. It is important to create goals that can be attained so sisters feel successful.

$>\quad$ Check in \& Follow Up: The topic from the Mentoring Meetings last week was a significant one that often cannot be fully addressed in the time allotted. Big sisters need to check in with the little sisters to see if they have any lingering questions or concerns. The emphasis during this time should be keeping the "nonjudgmental door" open so that little sisters see their big sisters as a source of support. The more little sisters know, the better prepared they will be to make healthy decisions even in the heat of the moment.

\section{TIPS: Leaders Respect Differences and Themselves}

\section{Respecting Ourselves I:}

$>\quad$ Consider dividing the group into smaller groups or having stations. Then sisters will be able to engage in more conversation. The stations could be based on the medium (i.e., magazines, music lyrics, etc.) or based on the questions (i.e., a different question for each station, but the materials could be similar or even the same.).

The sisters might be heated by a new understanding of the injustices that exist regarding girls' and women's portrayals. Taking action and standing up to "lookism" as a group is a great way to feel empowered and use the energy for a productive purpose.

\section{Respecting Ourselves II:}

$>\quad$ Remember that during this activity and whenever you discuss the topic of sex with your little sisters, you are not advocating that they have sex, instead you are advocating that they are educated about the ways to protect themselves and be in control so that they are prepared to make healthy decisions that are right for them.

\section{TIPS: Leadership Projects}

$>\quad$ Before the groups share their progress on the Leadership Project, be sure to emphasize the timeline for the projects and restate the impact these projects potentially have for their Sister Group and school. Have sisters brainstorm what those possible impacts might be and how the Sister Group or school might respond.

\section{MEASURING STICK: Assessing Growth}

* How did you do this week as a facilitator?

- What did you do in the meeting this week that nurture little sisters' potential?

- Were any parts of the meeting were awkward for you? 
- How do you think your energy and image of your own body influenced the meeting?

- Describe your delegating skills? Who can you trust to delegate some of the meeting?

Did your little sisters meet your established outcomes for this Mentoring Meeting?

- Do the little sisters in your group know the information presented?

- More details about fellow group members, particularly traits that are not focused on physical appearance.

- "Lookism" is a term used to describe discrimination towards others based solely on their appearance

- Intimacy involves emotional and physical risks

Did they demonstrate that they understood the established understandings or principles that are the foundation of the meetings' activities?

- Leaders respect themselves in emotional and physical ways.

- Leaders create support teams and help one another.

- Respecting yourself means taking care of your body, practicing healthy habits, and protecting yourself from risks.

* Can they apply the facts and principles in meaningful ways? Did they...

- Demonstrate collaborative behaviors in pairs and in groups

- Apply established expectations to own participation in group activities

- Participate earnestly and honestly in activities

- Create positive comments about fellow group members

- Connect the concepts previously discussed

- Analyze progress on goals

- Apply concept of "lookism" to school context

\section{JUSTIFICATION:}

It is important to find some way to assess whether you effectively communicated the facts and principles supporting the Mentoring Meeting's activities. It is equally important to determine (on an individual basis) whether little sisters gained the understandings and knowledge. This can be done through a formal or informal conversation, a comment that is made, a behavior displayed, a written "exit card" with questions related to the outcomes (KUDs). 
* Focus on a Healthy Body: Healthy people are more attractive. Flip the perspective and avoid focusing on the superficial reasons to change habits (i.e. drinking soda, indulging in sweets, lack of exercise). Instead of big and little sisters looking only at how they look- help them focus on how they feel when they exercise or when they pass up the sweets. Encourage little sisters to keep a food diary and keep track of how certain foods make them feel. Then discuss how to integrate more of the food that results in healthy feelings.

* Developing a Healthy Relationship with Our Bodies: It is critical to lifelong health for girls and women to understand that our bodies may look different at different times of our lives (e.g. during adolescence, our 20's, after childbearing, aging with slower metabolism, etc.). Developing a relationship with your body that goes beyond the superficial appeal and beauty is foreign in our society today. Adolescent girls (our little sisters), in particular, fall victim to society's messages, but big sisters can help reshape young girls' images of their bodies. Big sisters can teach a different and louder message about the value of the female body. Women need to possess a framework that focuses on what their bodies can $d o$ for them and how they can develop and maintain enduring habits of being active. This focus supports a healthy perspective that will help women ride the waves and weather the storms that life presents.

\section{THE BIG PICTURE: Uniting the Concepts within the Curriculum}

- Take time to reflect on this important connection. How does the discussion of body image and self-respect relate to the previous discussion of romantic interests and having a voice? 
WEEK SEVENTEEN: What a Leader!

Concepts: Leadership, Teamwork, \& Reflection

Outcomes:

As a result of this Mentoring Meeting, participants will know...

* More details about fellow group members

As a result of this Mentoring Meeting, participants will understand that...

* Leaders collaborate with others to achieve common goals.

* Successful leaders take time to set attainable yet challenging goals and celebrate when they have reached them.

As a result of this Mentoring Meeting, participants will be able to...

* Collaborate in pairs and groups

* Apply established expectations to own participation in group activitiesparticularly confidentiality

* Participate earnestly and honestly in activities

* Connect the concepts previously discussed

* Reflect on personal and group's growth

\section{TO DO LIST: Key Reminders For Week Seventeen Big Sister Meeting}

$\checkmark$ Remind big sisters to wear watches to the Mentoring Meetings.

$\checkmark \quad$ Make copies of the Big Sister Meeting agenda. (optional)

$\checkmark$ Remind big sisters to bring their 7th Grade Curriculum Handbook with them to the Big Sister Meeting.

$\checkmark$ Ask big sisters to reflect on the success of the group as a whole and as individuals (big and little sisters).

$\checkmark$ You might need to communicate throughout the week to finalize the School Legacy Project and/ or the Sister-to-Sister Project.

$\checkmark$ Decide if you would like member of the $8^{\text {th }}$ Grade Club to come talk to the group about YWLP Tech.

$\checkmark$ Collaborate as a group to make a game plan.

$\checkmark$ Delegate to big sisters to organize and implement plan.

$\checkmark$ Work out details for the Play Day.

$\checkmark$ Encourage all sisters to contribute and voice their ideas about what they would like to do.

$\checkmark$ Plan something that is appealing to most sisters. 


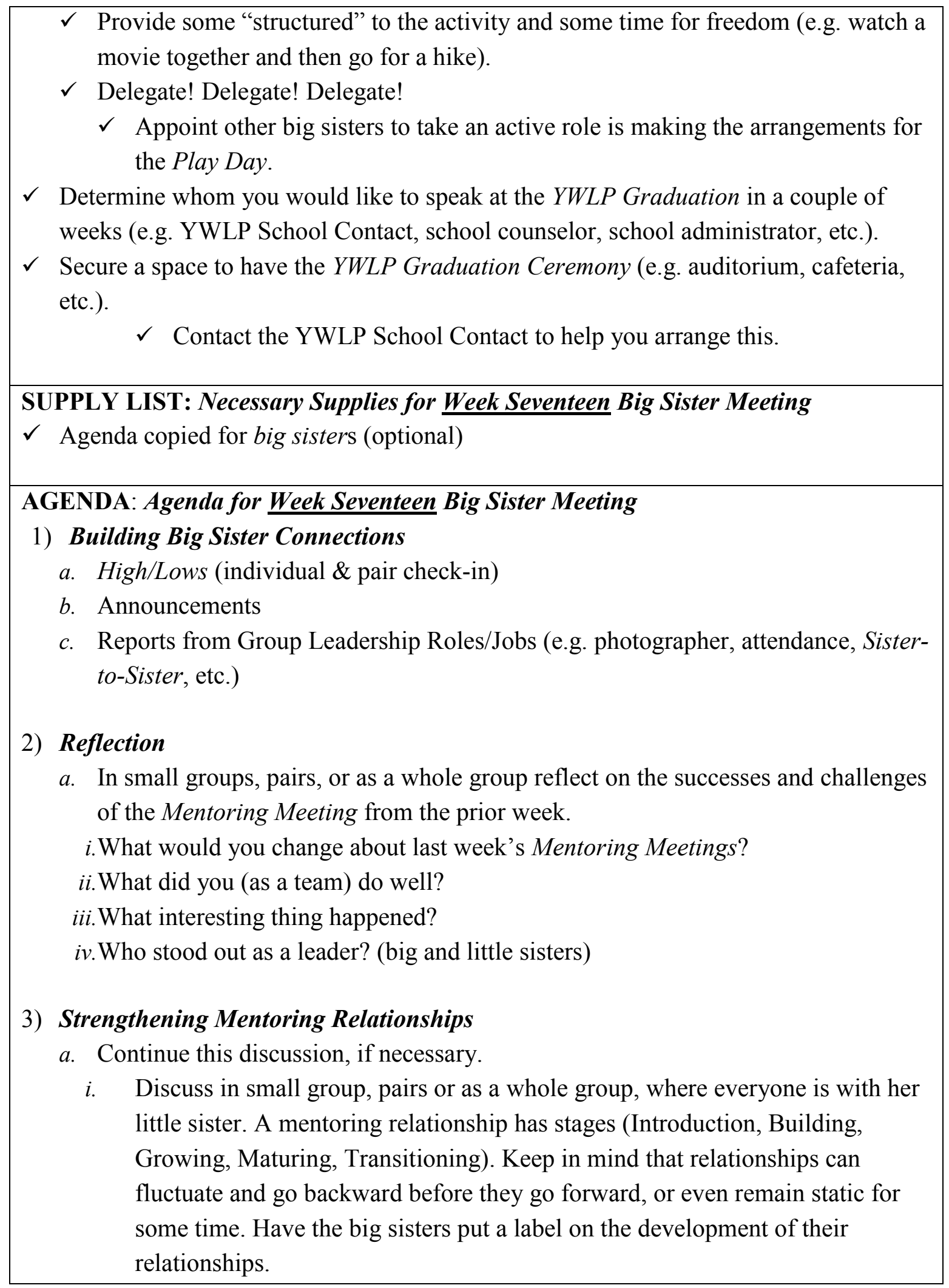


$i v$. What can big sisters do to support little sisters in the various domains: academics, social $\&$ familial relationships, emotional health?

v. What are some fun activities that big sisters are doing with their little sisters?

vi. How can big sisters connect more with their little sisters' parents or other important people in little sisters' lives?

\section{4) Mentoring Group Curriculum}

\section{a. Nuts \& Bolts}

i. Consider little sisters' potential responses to the curriculum this week.

1. Who is going to start disconnecting because the end of the program is approaching and what might that look like?

2. How will you show sensitivity to those students in addressing their needs?

3. The topic of graduation and the end of the program can conjure up negative feelings. How can you address this?

4. How can you make the most of your time to work on the School Legacy Project and/or the Sister-to-Sister Project?

\section{b. Take Away Messages}

$i$. Conduct an open discussion about what the following principles mean to the big sisters as individuals.

Leaders collaborate with others to achieve common goals.

* Successful leaders take time to set attainable yet challenging goals and celebrate when they have reached them.

\section{TO DO LIST: Key Reminders For Week Seventeen Mentoring Meeting}

$\checkmark$ Check in with the office to be sure that they make an after-school announcement.

$\checkmark$ Your room may be locked, so arrive early enough to find a custodian to let you into your room, if necessary.

$\checkmark$ Set the room up so that there is a lot of open space so that sisters can make the star patterns for the energizer.

$\checkmark \quad$ Take attendance. Send the big sister who is assigned to the missing little sister (or if doable, you can) to the office to call the parents to notify them of the absence.

$\checkmark$ Invite sisters from the $8^{\text {th }}$ Grade Club to come share their progress.

$\checkmark$ Call or email School Contact to secure the location for the Graduation Ceremony. 


\section{SUPPLY LIST; Necessary Supplies for Week Seventeen Mentoring Meeting}

$\checkmark$ Nametags

$\checkmark$ Snacks

$\checkmark$ Mascot or item to serve as microphone to indicate who has the floor to speak.

$\checkmark$ Hot Topic box

$\checkmark$ Hot Topic paper slips

$\checkmark$ Writing utensils (pens, or pencils, and markers)

$\checkmark$ Leadership Ladder

$\checkmark$ Signs made for group

$\checkmark$ Camera \& watches (optional)

$\checkmark$ Puzzle piece materials

$\checkmark$ Star stickies for Star Time

$\checkmark$ Leadership Project materials

$\checkmark$ Big sisters need to wear watches or have their phones. 


\section{CURRICULAR COMPANION}

\section{Supplemental Ideas for Implementing Mentoring Group Curriculum}

\section{Building Competencies for Leadership by Setting Goals \& Celebrating Success}

\section{The Importance of Reflection}

Reflection is a valuable tool that can encourage growth. Regardless of the goal, big or small, it is important to take time to consider how far you have come in moving along the continuum toward achieving the goal. During the reflection, you can determine if your approach is working and if it is, what are you doing specifically that is making it work. On the other hand, if you are not making a lot of progress toward your goal, it is helpful to stop along the way to determine the roadblocks and how you can circumvent them. Reflecting on goals is a practice that most successful people do and little sisters will need to help developing what will most likely be a new skill for them. Big sisters can encourage the little sisters by should modeling the reflective behavior, but also by talking out the process for the little sister the first few times.

\section{Growth and Success}

When setting goals, keep your eye on the prize, but don't lose sight of the small goals along the way. If you focus on the uncompleted mound of work that needs to be finished, it can be, not only, daunting, but also it can derail progress. Using a growth mindset that focuses on what you have accomplished instead of what is still ahead to accomplish can keep you motivated and can in the end result in more growth.

Sisters may not all accomplish their goals as they had them set. As the facilitator, encourage sisters to focus on how they have grown as a result of making the goal and how they are better equipped as a leader. The areas in which they have fallen short can be a part of the next goal. 


\section{TIPS: Energizer}

$>\quad$ Encourage Teamwork and Fun: The theme of the Mentoring Meeting should be on having fun together and celebrating the bonds created as well as the personal/team growth with regard to leadership skills.

$>\quad$ Emphasize Reflection on the Leadership Secrets Used: This activity requires communicating effectively to collaborate and work toward a common goal. After the sisters accomplish the goal of creating the star, provide time for them to reflect on why they were successful and what strategies were most effective in problem solving as a team. This time is important because it encourages the sisters to internalize why the employed the approaches they did. Extend the conversation to encourage the sister to reflect on how the strategies (Leadership Secrets) could be successfully transferred to future contexts.

\section{JUSTIFICATION:}

The purpose of this activity is for the sisters to work together and apply the Leadership Secrets they have learned throughout the year in YWLP.

\section{TIPS: Group Check-in}

D Hot Topics: This may be an appropriate activity for today, if the topic is related to bullying or teasing. It could get the conversation started and help generate ideas about bullying and teasing. Big sisters could share stories of times that they were a victim, or stepped in to help someone who was being teased. Starting the conversation with teasing may prove to be an easier approach. Most people can relate to being teased or teasing someone in a way that they believe is harmless. One never really knows who a person internalizes the teasing though.

$>\quad$ Star Time or High/Lows: Try to spice up this time. Either find interesting ways to recognize people or applaud them (special clap, movement, song, phrase, or say something in a different language). You may want to have people write things on their stars that are related to their goals. Also it is helpful to link the accomplishments on the stars to the Leadership Ladder.

\section{TIPS: Sister Time/Homework Help}

Goal Setting Check-in: Sisters have been creating goals related to: self, relationships, and academic leadership. Big sisters should begin by sharing their own progress with their goals. Hopefully, at this point, little sisters have created a habit of goal setting. Encourage big sisters to focus on the growth and achievement over the entire year.

Take Time for Small Celebrations: In order for little sisters to stay motivated, it is important for big sisters to take time to celebrate the small successes that may 
lead to a larger success

\section{TIPS: Leaders Set Goals and Celebrate Success}

The Power of You! This exercise is designed to encourage individual reflection. Big sisters can utilize the competencies share in the previous section. It is important that little sisters feel proud of how they have grown and what they have gained from their YWLP experience.

The Power of Your YWLP Group! This exercise is designed to emphasize group unity and the significance of belonging to a larger community. Your group is most likely diverse. You probably have little sisters from different backgrounds with varied interests. The little sisters in the group are probably not all friends outside of YWLP. For some reason, somehow, you made your group unite this year. They came together in some ways and were stronger as a result. Focus on that. Focus on how your group, though it was diverse, needed that diversity of ideas and personalities. The diversity is what made the group stronger and more successful. Teach your sisters that this is a model for life and the importance of being a member of a larger community and contributing toward the success of that community. In order to accomplish our goals, we often need help from others so it is our responsibility to offer help to others as they are trying to accomplish their goals.

\section{MEASURING STICK: Assessing Growth}

* $\quad$ Self-reflection

- How did you do this week as a facilitator?

- What did you do this week to foster little sisters' potential?

- $\quad$ Did any big sisters exhibit exceptional leadership?

* Did your little sisters meet your established outcomes for this Mentoring Meeting?

* Do the little sisters in your group know the information presented?

- $\quad$ More details about fellow group members

* Did they demonstrate that they understood the established understandings or principles that are the foundation of the meetings' activities?

- Leaders collaborate with others to achieve common goals. 


\begin{tabular}{|c|c|}
\hline$*$ & $\begin{array}{l}\text { - Successful leaders take time to set attainable yet challenging goals and } \\
\text { celebrate when they have reached them. } \\
\text { Can they apply the facts and principles in meaningful ways? Did they... } \\
\text { - Collaborate in pairs and groups } \\
\text { - Apply established expectations to own participation in group activities- } \\
\text { - } \text { particularly confidentiality } \\
\text { - Connect the concepts previously discussed } \\
\text { - } \text { Reflect on personal and group's growth }\end{array}$ \\
\hline & $\begin{array}{l}\text { FICATION: } \\
\text { It is important to find some way to assess whether you effectively communicated } \\
\text { the facts and principles supporting the Mentoring Meeting's activities. It is } \\
\text { equally important to determine (on an individual basis) whether little sisters } \\
\text { gained the understandings and knowledge. This can be done through a formal or } \\
\text { informal conversation, a comment that is made, a behavior displayed, a written } \\
\text { "exit card" with questions related to the outcomes (KUDs). }\end{array}$ \\
\hline PR & $\begin{array}{l}\text { TICAL EXTENSION: Relating the Activities to Real Life } \\
\text { Continuing on the Path of Success: The success that each sister accomplished } \\
\text { this year, whether big or small was a step toward being a better leader. As the } \\
\text { facilitator of the group, you need to encourage your sisters to continue down that } \\
\text { path while there is momentum. Encourage sisters to use some of the strategies } \\
\text { learned this year in YWLP. You may want to suggest that little sisters who have } \\
\text { connected might support each other in the future with their goals. }\end{array}$ \\
\hline $\begin{array}{l}0 \\
0 \\
0\end{array}$ & $\begin{array}{l}\text { BIG PICTURE: Uniting the Concepts within the Curriculum } \\
\text { What concepts do the little sisters remember? } \\
\text { How are they connected? } \\
\text { For the visual learners, consider asking the sisters to create an illustration that } \\
\text { makes connections between some or all of the concepts. Or for the verbal } \\
\text { processors, they can participate in a discussion that connects the concepts. }\end{array}$ \\
\hline
\end{tabular}




\section{WEEK EIGHTEEN: Play Day}

\section{Concepts: Connection}

\section{Outcomes:}

As a result of this Mentoring Meeting, participants will know...

* More details about fellow group members

As a result of this Mentoring Meeting, participants will understand that...

* Connection between people can be cultivated through activities that both people find interesting and engaging.

\section{As a result of this Mentoring Meeting, participants will be able to...}

* Demonstrate collaborative behaviors in pairs and in groups

* Participate earnestly and honestly in activities

* Connect with fellow participants in a casual setting

\section{TO DO LIST: Key Reminders For Week Eighteen Big Sister Meeting}

(This will need to be communicated via email or phone call if the big sister meeting is cancelled for that week.)

$\checkmark$ Continue to encourage big sister's who display leadership or participate actively during group.

$\checkmark$ Determine whom you would like to speak at the Graduation Ceremony in a couple of weeks (e.g. YWLP School Contact, school counselor, school administrator, etc.).

$\checkmark$ Secure a space to have the Graduation (e.g. auditorium, cafeteria, etc.).

$\checkmark$ Contact the YWLP School Contact to help you arrange this.

$\checkmark$ Work out details for the Play Day.

$\checkmark$ Encourage all sisters to contribute and voice their ideas of what they would like to do.

$\checkmark$ Plan something that is appealing to most sisters.

$\checkmark$ Provide some structure to the activity and some free time (e.g. watch a movie together and then go for a hike).

$\checkmark$ Delegate! Delegate! Delegate!

$\checkmark$ Appoint other big sisters to take an active role is making the arrangements for the Play Day.

\section{SUPPLY LIST: Necessary Supplies for Week Eighteen Big Sister Meeting}

$\checkmark$ Agenda copied for big sisters (optional) 
AGENDA: Agenda for Week Eighteen Big Sister Meeting

1) Building Big Sister Connections

a. High/Lows (individual \& pair check-in)

b. Announcements

c. Reports from Group Leadership Roles/Jobs (e.g. photographer, attendance, Sisterto-Sister, etc.)

\section{2) Reflection}

a. In small groups, pairs, or as a whole group reflect on the successes and challenges of last week's Mentoring Meeting.

$i$.What would you change about last week's Mentoring Meeting?

ii. What did you (as a team) do well?

iii. What interesting thing happened?

$i v$. Who stood out as a leader? (big and little sisters)

\section{3) Strengthening Mentoring Relationships with a Play Day}

a. Plan an activity that allows sisters to bond with one another. Choose something that places sisters in a collaborative role or encourage healthy competition without emphasizing it. In other words, if there is competition, do not pit sisters against one another in a highly competitive situation.

4) Play Day

a. Nuts \& Bolts

i. How will you use the time (if necessary) to work on the Leadership Projects or Graduation presentations?

1. Invitations should be sent and can perhaps be hand delivered during this day.

2. Transportation details need to be determined and big sisters can use the time when they see their little sisters' parents to talk about transportation.

ii. Problem-solve potential little sisters' responses to the Play Day.

1. Who do you think might create an excuse to avoid attending?

2. What can you and the big sisters do to motivate little sisters to attend?

3. What can you and the big sisters do to help little sisters (e.g. provide rides, call parents, etc.)?

4. How will you make little sisters feel included if they are unable to attend?

5. How will you show sensitivity to those sisters who might not be allowed to attend due to something unavoidable such as lack of parental 
permission, money restrictions, food allergies, or physical restrictions?

6. How will you show sensitivity to sisters who might have difficulty participating in the Play Day due to physical limitations?

\section{TO DO LIST: Key Reminders For Week Eighteen Mentoring Play Day}

$\checkmark$ Call parents to communicate details about the Play Day...

- Location

- Times

- Transportation

- Details about the activity

- Get permission, if necessary (e.g. seeing a PG-13 movie)

- If eating, consider food allergies

$\checkmark$ Secure location and details. Plan an activity that requires little money and would be interesting to most of the sisters. 


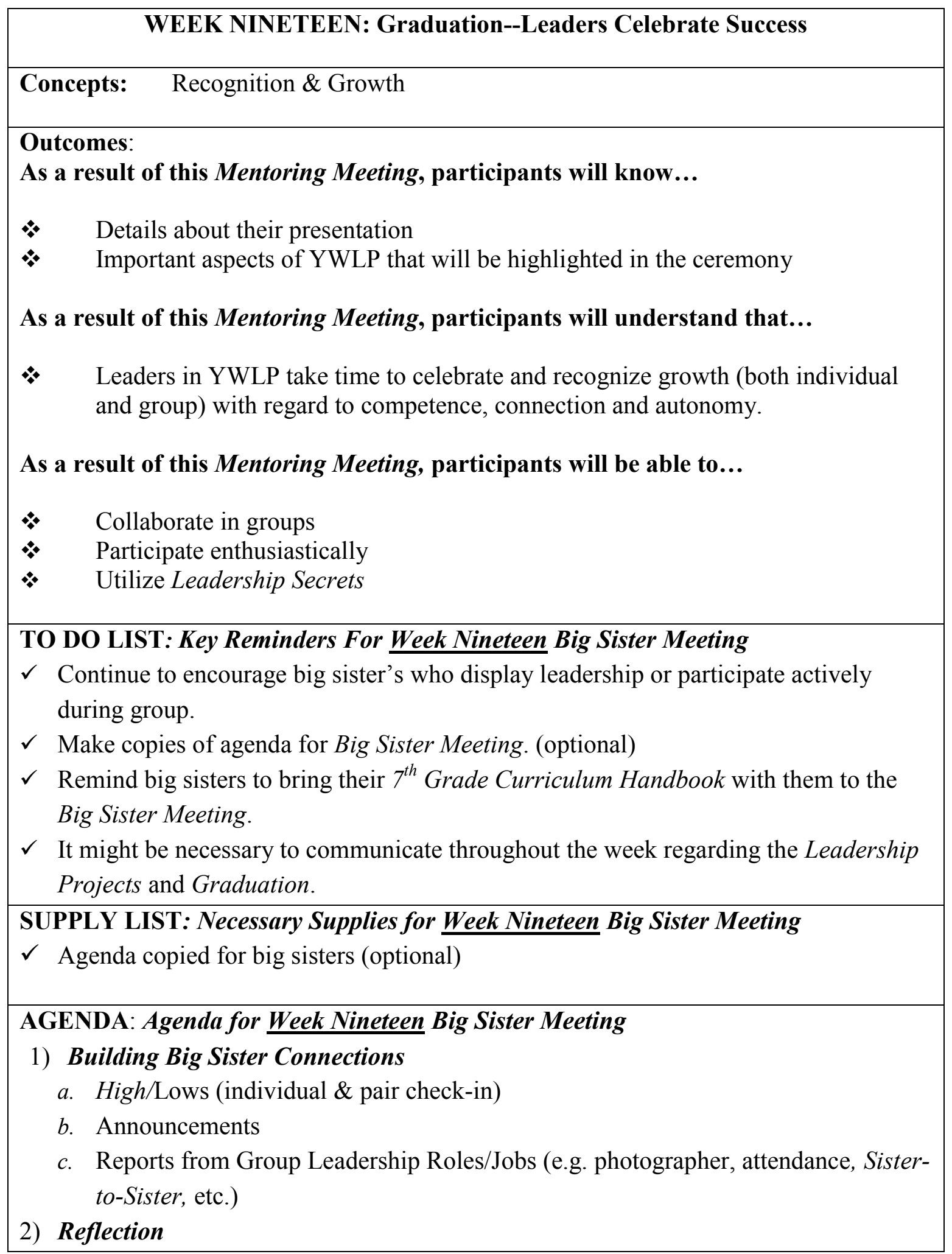


i. In small groups, pairs, or as a whole group reflect on the successes of the group and the growth of the little sisters throughout the year.

\section{3) Saying Good Bye}

a. Discuss ways to disconnect from the official mentoring role. This notion will be addressed in class, but discuss how it applies to your specific group. Hypothesize how particular little sisters might respond.

\section{4) Graduation}

\section{a. Nuts \& Bolts}

i. Problem-solve potential little sisters' responses to the Graduation Ceremony, conclusion of group, and departure of big/little pairs.

1. Who has demonstrated behaviors of anxiety toward the end of the program year?

2. How will you show sensitivity to those students in addressing their needs?

3. How will ensure that your sisters feel valued and "celebrated?"

4. What will you do for little sisters who might not have a family member present at the Graduation Ceremony?

\section{b. Take Away Messages}

$i$. Conduct an open discussion about what the following principles mean to the big sisters as individuals.

- Leaders in YWLP take time to celebrate and recognize growth (both individual and group) with regard to competence, connection and autonomy.

\section{TO DO LIST: Key Reminders For Week Nineteen Graduation}

$\checkmark$ Check in with the office to be sure that they make an after-school announcement.

$\checkmark$ Double and triple check with big sisters that the invitations have all been sent. It might be necessary for you or your big sisters to make phone calls to parents and other invited guests.

$\checkmark$ Determine whom you would like to speak at the Graduation (e.g. YWLP School Contact, school counselor, school administrator, etc.).

$\checkmark$ Secure a space to have the Graduation (e.g. auditorium, cafeteria, etc.).

- Contact the YWLP School Contact to help you arrange this.

Set up and test audio equipment before the Graduation Ceremony begins. 
At the beginning of your meeting each week, determine who is in attendance.

Determine which little sisters are on your list, but not in attendance. Send the big sister who is assigned to the missing little sister (or if doable, you can) to the office to call the parents to notify them of the absence.

\section{SUPPLY LIST; Necessary Supplies for Week Nineteen Graduation}

$\checkmark$ Nametags

$\checkmark$ Snacks

$\checkmark$ Graduation Certificates- Check that the names are all spelled correctly

$\checkmark$ Necessary presentation materials (e.g. laptop, LCD projector, etc.)

$\checkmark$ Podium (if the speaker would like one)

$\checkmark$ Information about Summer Club and $8^{\text {th }}$ Grade Club

$\checkmark$ Decorations (FYI: Do not forget tape if you are using streamers.)

\section{TIPS: Graduation Ceremony Preparation}

$>\quad$ Provide a "Heads Up": Communicate the logical sequence of the day's events so that the big and little sisters are aware of, not only, the point of hosting a graduation, but also what is going to take place and your expectations for them. Once sisters are aware of the day's events and the purpose, they will be better equipped to participate in the way that you expect, allowing them to flourish.

Recognize Individual \& Group Growth: Emphasize that the Graduation Ceremony is a time to celebrate how each sister has grown, but also how the group has grown collectively. It is also a time for sisters to share what they have learned in a meaningful setting with significant people.

Make the Space Look Inviting \& Festive: Take advantage of the resources and space available. Use decorations provided from YWLP and delegate the decorating to a couple of pairs.

IMPORTANT NOTE: All sisters will help clean up afterward!

\section{JUSTIFICATION:}

The purpose of the Graduation Ceremony is for the little sisters to feel proud of how they have developed their leadership qualities and skills through their participation in YWLP this year. The facilitator should use this time to explain the purpose of Graduation Ceremony and provide a brief overview of how the day will unfold.

\section{TIPS: Presentation Practice}

$>\quad$ Practice, Practice, Practice: Many sisters will be anxious to perform so keep in 
mind that the more comfortable people feel with their roles within the presentation, the more comfortable they will be performing at the $Y W L P$ Graduation Ceremony. Utilize people's strengths and delegate when possible. The more you trust others to take on larger leadership roles, that more you, as the facilitator, are encouraging growth.

\section{TIPS: YWLP Graduation Program}

Welcome: The facilitator(s) will most likely choose to welcome the guest, but certainly if others express interest, find a way to incorporate them. Communicate in an enthusiastic and inviting manner. Express the significance of the little sisters' involvement, as well as the appreciation of the support from parents. Stress that would be impossible to operate without the support from the school and particularly the YWLP School Contact.

$>\quad$ Highlights: You can share this information in a variety of ways. Remember to structure this aspect of the ceremony in a way that maximizes engagement while sharing the fun the group has had together. For example, this can be shared through slideshow of pictures while sisters narrate or sisters could share their favorite experiences, etc.

$>\quad$ Project Presentations: This is the perfect time to delegate to pairs. Be prepared to jump in and assist, if necessary. Try your best to really just Facilitate and resist the urge to take over. Allowing sisters to take the lead promotes growth with regard to their leadership skills.

Invited School Speaker: Often speakers will ask for some guidance about what topics to address. Ask him/her to accentuate the benefits of leadership and to comment of the growth they have seen in the little sisters if that is possible (if not on an individual basis than collectively).

$>\quad$ Graduation Ceremony: This can be awkward if sisters are not sure of where to stand or go. Practice how this is going to happen before the ceremony.

Conclusion: Thank everyone for coming! Again stress the important role the parents have in their daughter's growth with YWLP. Invite everyone to continue the celebration with food.

\section{MEASURING STICK: Assessing Growth}

How did you do this week as a facilitator of the YWLP Graduation Ceremony?

* Did any big and little sisters show efforts to stretch themselves?

* Did the group function collaboratively? 
* Did sisters exhibit behaviors to indicate that they felt honored and recognized as individuals and as a group?

\section{JUSTIFICATION:}

Take time to assess and reflect on the success of the Graduation Ceremony. Just as it was important for you to model the value of recognizing and reflecting on the growth and success of your little sisters, you should take time to do the same for yourself and your big sisters. The questions above are a reflection of your function as a leader of the group. 